\title{
Investigation of Nano-ceria Catalyst Infiltration of Solid Oxide Fuel Cell (SOFC) Electrodes Using Bio-Inspired Catechol Surfactants
}

\author{
Ozcan Ozmen \\ ozozmen@mix.wvu.edu
}

Follow this and additional works at: https://researchrepository.wvu.edu/etd

Part of the Materials Science and Engineering Commons, and the Nanoscience and Nanotechnology Commons

\section{Recommended Citation}

Ozmen, Ozcan, "Investigation of Nano-ceria Catalyst Infiltration of Solid Oxide Fuel Cell (SOFC) Electrodes Using Bio-Inspired Catechol Surfactants" (2019). Graduate Theses, Dissertations, and Problem Reports. 7378.

https://researchrepository.wvu.edu/etd/7378

This Dissertation is protected by copyright and/or related rights. It has been brought to you by the The Research Repository @ WVU with permission from the rights-holder(s). You are free to use this Dissertation in any way that is permitted by the copyright and related rights legislation that applies to your use. For other uses you must obtain permission from the rights-holder(s) directly, unless additional rights are indicated by a Creative Commons license in the record and/ or on the work itself. This Dissertation has been accepted for inclusion in WVU Graduate Theses, Dissertations, and Problem Reports collection by an authorized administrator of The Research Repository @ WVU.

For more information, please contact researchrepository@mail.wvu.edu. 


\title{
Investigation of Nano-ceria Catalyst Infiltration of Solid Oxide Fuel Cell (SOFC) Electrodes Using Bio-Inspired Catechol Surfactants
}

\author{
Ozcan Ozmen
}

\author{
Dissertation submitted \\ to the Statler College of Engineering and Mineral Resources \\ At West Virginia University \\ in partial fulfillment of the requirements for the degree of \\ Doctor of Philosophy in \\ Materials Science and Engineering
}

Edward M. Sabolsky, Ph.D., Chair

Xingbo Liu, Ph.D.

Bruce S. Kang, Ph.D.

John W. Zondlo, Ph.D.

Shiwoo Lee, Ph.D.

Department of Mechanical and Aerospace Engineering

Morgantown, West Virginia

2019

Keywords: Solid oxide fuel cell, infiltration, catechol, deposition Copyright 2019 Ozcan Ozmen 


\section{ABSTRACT \\ Investigation of Nano-ceria Catalyst Infiltration of Solid Oxide Fuel Cell \\ (SOFC) Electrodes Using Bio-Inspired Catechol Surfactants}

\section{Ozcan Ozmen}

Development of solid oxide fuel cell (SOFC) electrodes with nano-structured grains can show enhanced power density with high catalytic activity owing to the higher surface area to volume ratio of the particles. However, the addition of nano-particles during the conventional electrode manufacturing process causes inevitable structural changes due to the coarsening of nano-particles at sintering temperatures. Wet impregnation/ infiltration methods are a practical and well-utilized method to form nanoparticles within the porous electrode microstructure of solid oxide fuel cells (SOFC) which requires relatively low calcination temperatures. Critical factors that impact the reduction of the electrode polarization using the nano-catalyst impregnation strategy include catalyst loading, decoration type, and volumetric distribution homogeneity through the porous electrode microstructure. These can mostly be tuned by performing repetitive infiltration cycles followed by a co-firing step after each cycle for calcination. This labor and timeintensive method continues until the desired nano-catalyst loading is achieved. The factors that may degrade the performance as inter-particle interactions, pore-clogging, and/or inhomogeneous deposition result in gas diffusion related to rapid cell voltage degradation issues.

The objective of this work is to investigate organic electrode modifiers to enhance nanocatalyst infiltration efficiency and uniformity within a commercial nickel oxide (NiO)/ yttria stabilized zirconia (YSZ) anode support and lanthanum strontium manganite (LSM)/YSZ cathode systems. The aim is to reduce the process to minimal processing steps while increasing both the performance and stability of the SOFC by decorating the nano-catalyst deposition. In this study, nano- $\mathrm{CeO}_{2}$, ceria, was used as a redox catalyst system and efficiently inserted throughout both porous SOFCs electrodes simultaneously by using a bio-inspired surfactant-assisted infiltration protocol. The process includes the initial modification of the electrode pore walls with a catecholbased surfactant film, i.e., poly-dopamine (pDA), poly epinephrine (pNE) or other alternative surfactants from the catechol family. The nano-ceria layer is then deposited uniformly over the bio-template surfactant layer during a single submersion of the SOFC into a cerium salt solution. Voltage-current-power curves and impedance spectroscopy were used to characterize the electrochemical performance of the impregnated anode-supported SOFC button cells. The endgoal of the work was to develop an infiltration protocol that performs boosted initial power density (performance) with high-stability by mitigating the nano-catalyst coarsening. The infiltrated cells displayed up to $35 \%$ reduction in polarization over the baseline cell with high electrochemical stability during 300 hours of testing at $750^{\circ} \mathrm{C}$.

The catechol surfactant deposition kinetics and the degree of polymerization of the surfactants on planar substrates were investigated. The adhered catechol thickness was fitted to 
exponentially decreasing function of time. The growth of the fired ceria particles over the pNE coated substrates showed that the growth of ceria particles can be both by forming new nuclei or growing over the existing nuclei. 


\section{DISCLAIMER}

This work was funded by the Department of Energy, National Energy Technology Laboratory, an agency of the United States Government, through a support contract with Leidos Research Support Team (LRST). Neither the United States Government nor any agency thereof, nor any of their employees, nor LRTS, nor any of their employees, makes any warranty, expressed or implied, or assumes any legal liability or responsibility for the accuracy, completeness, or usefulness of any information, apparatus, product, or process disclosed, or represents that its use would not infringe privately owned rights. Reference herein to any specific commercial product, process, or service by trade name, trademark, manufacturer, or otherwise, does not necessarily constitute or imply its endorsement, recommendation, or favoring by the United States Government or any agency thereof. The views and opinions of authors expressed herein do not necessarily state or reflect those of the United States Government or any agency thereof 


\section{Table of Contents}

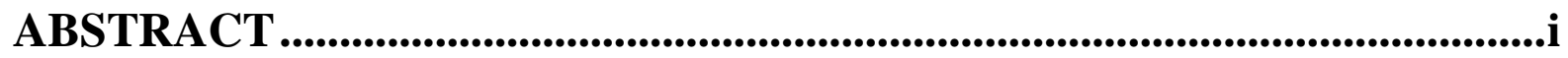

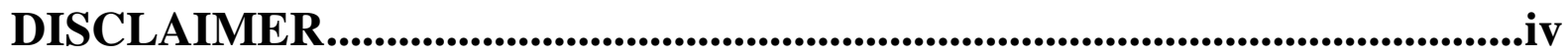

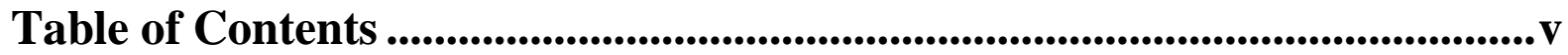

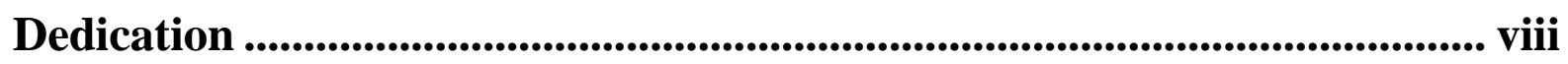

Acknowledgments ......................................................................................................................ix

List of Figures............................................................................................................................... $\mathrm{x}$

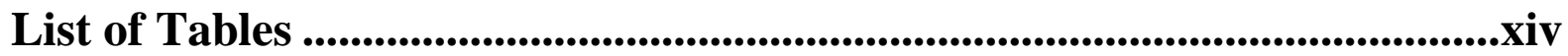

Chapter 1 : Introduction and the Statement of Problem 1

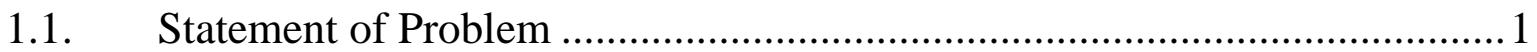

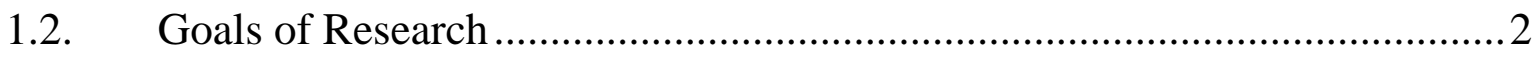

Chapter 2 : Literature Review $\quad 4$

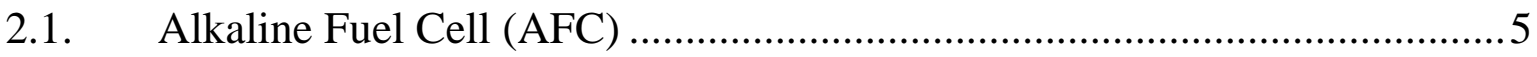

2.2. Proton Exchange Membrane Fuel Cell (PEMFC) ........................................6

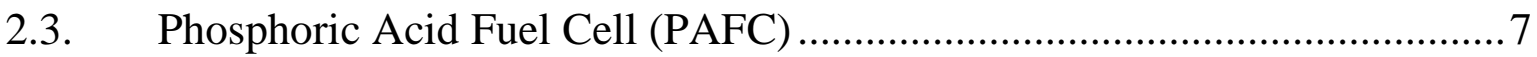

2.4. Molten Carbonate Fuel Cell (MCFC) ………….......................................

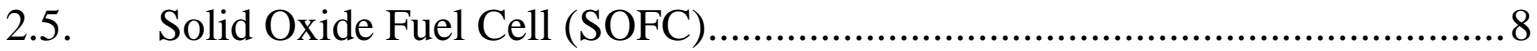

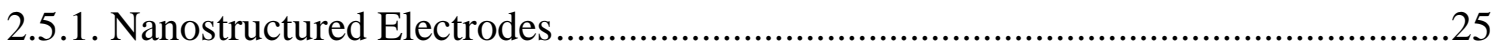

2.5.1.1. Microstructure Engineering by Nanomaterial Infiltration.........................25

2.5.2. Selected Strategies of Infiltration on SOFC Anode Electrode ………...................29

2.5.2.1. Electrochemical Performance Enhancement by Catalyst Infiltration.........29

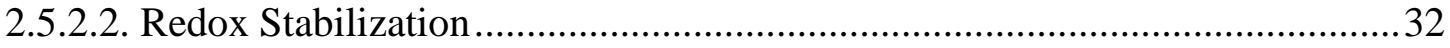

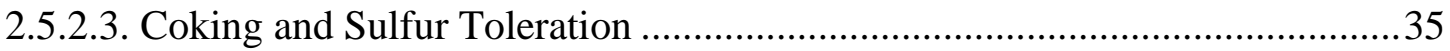

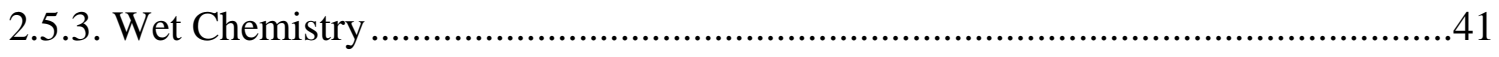

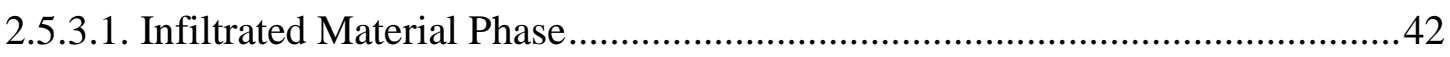

2.5.3.2. Surfactants and Dispersants .........................................................................46 


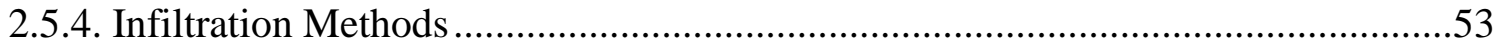

2.5.4.1. Dripping Method /Tape-cast Infiltration ...................................................55

2.5.4.2. Dip Coating ....................................................................................58

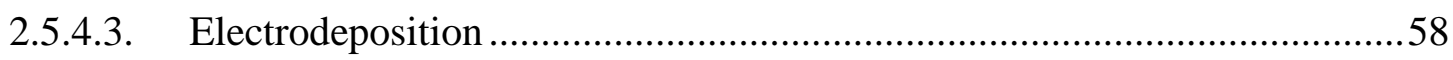

2.5.4.4. Spin Coating .................................................................................61

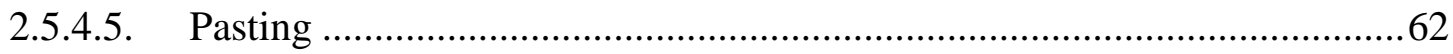

2.5.5. Selected Topic 1: Microstructure Altering Acid Leaching Treatments Prior to

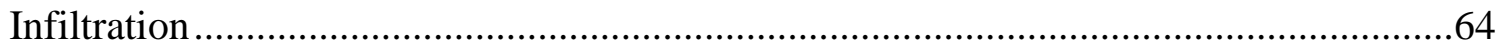

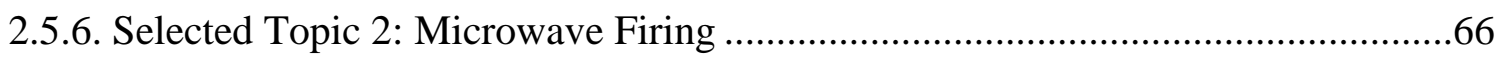

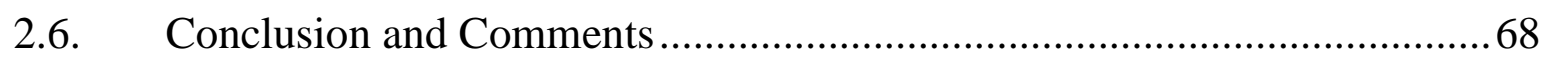

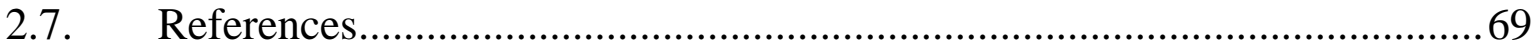

Chapter 3 : pDA Bio-Surfactant Assisted Nano-Catalyst Infiltration of SolidOxide Fuel Cell (SOFC) Electrodes $\quad \mathbf{8 0}$

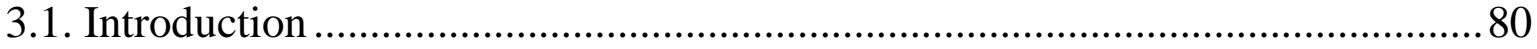

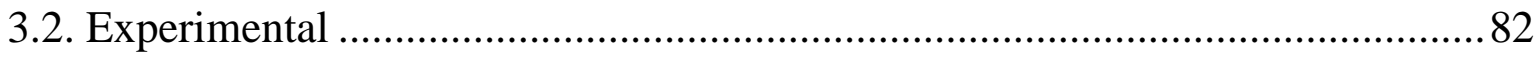

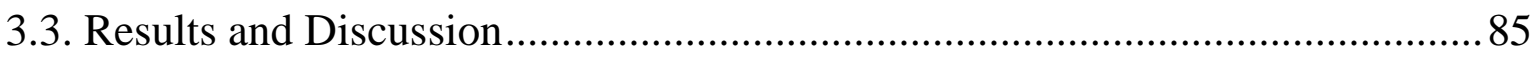

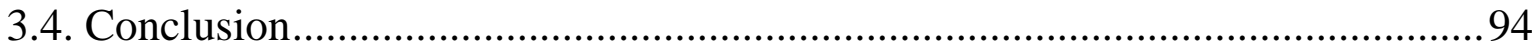

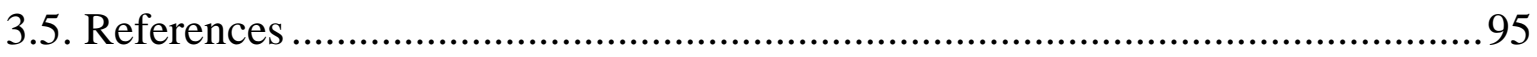

Chapter 4 : pNE Bio-Surfactant Assisted Nano-Catalyst Infiltration of SolidOxide Fuel Cell (SOFC) Electrodes $\quad 98$

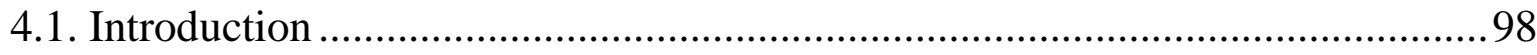

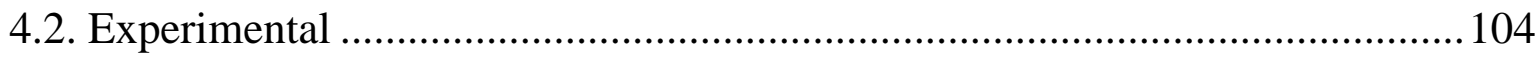

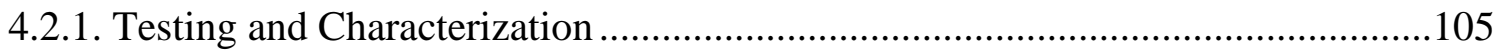

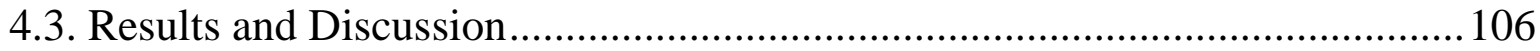

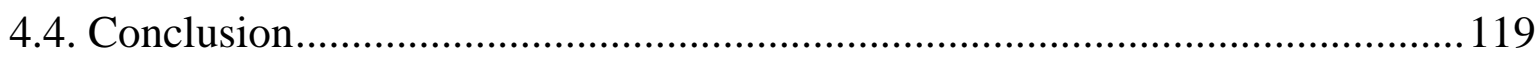

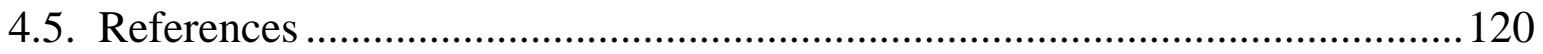

Chapter 5 : Kinetics of Growth Study of Catechol Surfactant and Ceria Nano $\begin{array}{ll}\text { particles onto the Planar Substrates } & 124\end{array}$

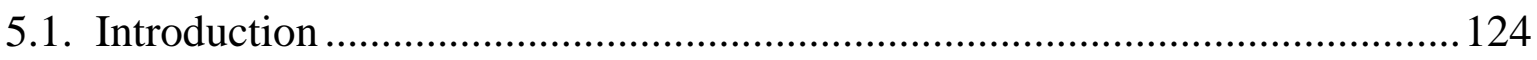

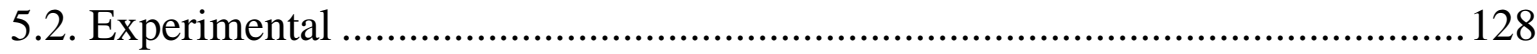

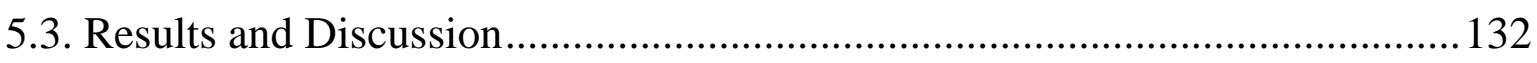

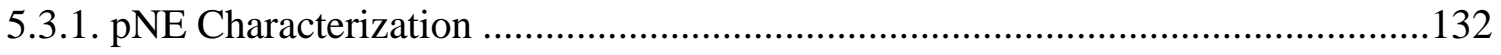


5.3.2. Wet-deposited Ion Characterization

5.3.3. Deposited Cerium Oxide Characterization.

5.4. Conclusion. 153

5.5. References 154

Chapter 6 : Investigation of Alternative Catecholamine Surfactant Assisted Nano-Ceria Infiltration Anode of Electrolyte-Supported Solid Oxide Fuel Cells (SOFCs)

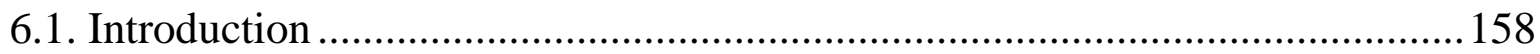

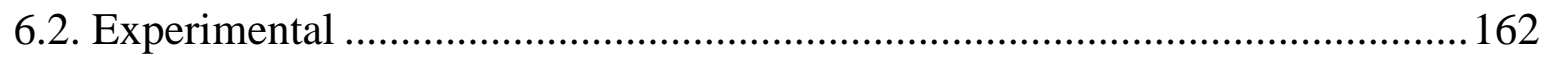

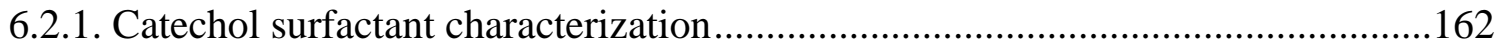

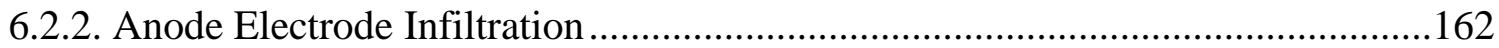

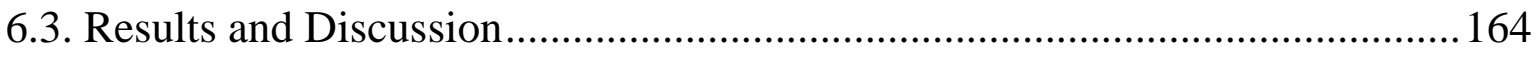

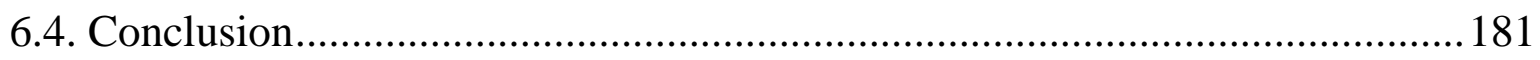

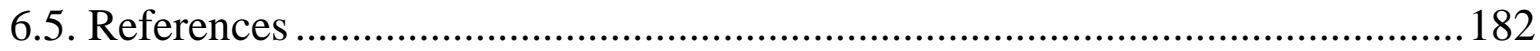

$\begin{array}{ll}\text { Chapter } 7 \text { : Conclusion } & 184\end{array}$

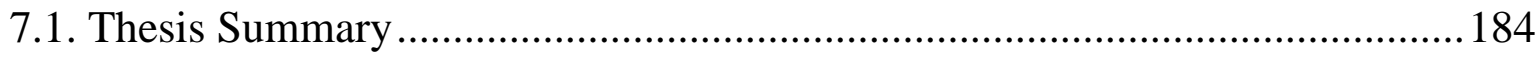

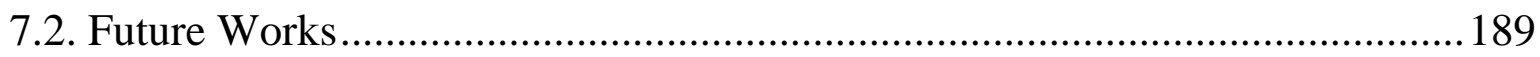




\section{Dedication}

I dedicate this dissertation to my beloved parents, who have been the source of my strength. Your words made me stronger, better, and more fulfilled than I could have ever imagined...

to my mentors, friends, both near and far, my sister and brother who shared their words of advice and encouragement to finish this journey and touched my heart...

to my little nephew, Uras Celik whom we have never met in person yet due to my hectic Ph.D. workload. If you read these lines one day, just so you know that many memories will have been treasured; I promise...

"Science is the most reliable guide for civilization, for life, for success in the world." Mustafa Kemal Ataturk 


\section{Acknowledgments}

This thesis becomes a reality after countless pages of reading, hours of discussion, and endless times of failure/success sequences.

First and foremost, I would like to express my sincere gratitude and appreciation to my research adviser. Professor Edward M. Sabolsky expertly guided and supported me in making this thesis possible. His enthusiasm for materials science always engaged with my work and pushed me forward. Special thanks to my committee members, Dr. Bruce Kang, Dr. Xinbo Liu, and Dr. John. W. Zondlo, for accepting to be a part of my thesis committee. I am highly indebted to Dr. Shiwoo Lee for showing his dedication to leverage my scientific acumen. Your mentorship constantly kept me engaged with my work.

I would especially like to acknowledge the help and support of the Sabolsky Energy Materials Lab. Special thanks to Katarzyna Sabolsky for hours of valuable discussions. Working with this team has been irreplaceable. I wish to bridge our friendship for longer years. Many thanks to the WVU Shared Research Facilities managers Dr. Marcela Redigolo, Dr. Qiang Wang, and Mr. Harley Hart for their expertise and valuable advice in materials characterization tools and senior research scientist Dr. Yoosef Pichard at National Energy Technology Laboratories (NETL) for his valuable collaboration in TEM studies.

This project would not be completed without financial support from NETL. I would like to special thanks to Dr. Thomas Kalapos, Dr. Harry Abernathy, Dr. Gregory Hackett, and the entire NETL Fuel Cell Team. Your mentorship, friendship has been a great experience that I will always remember. I feel lucky to have worked with you all! 


\section{List of Figures}

Figure 2.1. A schematic representation of the different fuel cell types [2]................................ 5

Figure 2.2. Concept diagram of SOFC based on oxygen-ion conductors using $\mathrm{H}_{2}$ as fuel [6].... 9 Figure 2.3. SOFC stack designs: (a) Seal-less tubular design, (b) Segmented-Cell-in-Series design (c) Monolithic design (d) Flat-plate design [8] ........................................................... 11

Figure 2.4. SOFC's based on the support component (a) electrolyte (b) anode (c) cathode (d) metal (interconnect) supported SOFC designs [11]............................................................ 12

Figure 2.5. Reaction pathways of oxygen reduction (a) and (b) for electronically conductive systems mixed with electrolyte material (YSZ), (c) for MIEC systems. Modified from [11]. .... 14

Figure 2.6. Reaction pathways of hydrogen dissociation and $\mathrm{H}_{2} \mathrm{O}$ formation [12] .................... 16

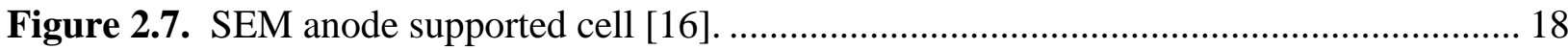

Figure 2.8. Ideal and actual fuel cell voltage/current characteristic with responsible polarization

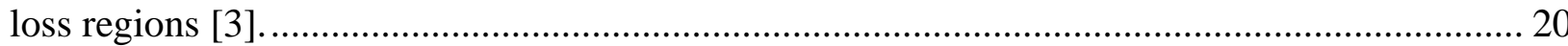

Figure 2.9. Possible impurity poisoning mechanisms of SOFC anodes [24] .......................... 22

Figure 2.10. Determination of carbon formation region (a) C-H-O ternary phase diagram [25, 27] (b) Coking of a Ni/YSZ anode as found in TEM [25, 26] (c) Ni/YSZ anode surface after test (200 h) in $\mathrm{H}_{2}$ by mixing $3 \% \mathrm{C}_{3} \mathrm{H}_{8}$ and $3 \mathrm{ppm} \mathrm{H}_{2} \mathrm{~S}$ [24] (d) FESEM image of deposited carbon on the $\mathrm{Ni} / \mathrm{YSZ}$ anode surface after $\mathrm{H}_{2}-3 \% \mathrm{C}_{3} \mathrm{H}_{8}-3 \mathrm{ppm} \mathrm{H}_{2} \mathrm{~S}$ for $200 \mathrm{~h}$ [24]............................... 24

Figure 2.11. Published anode infiltration studies in recent years [29-152] ............................... 28

Figure 2.12. Backbone structures of infiltrated anodes in recently published studies [29-152].. 28

Figure 2.13. Infiltrated material compositions in recently published studies [29-152] .............. 29

Figure 2.14. Scheme of the infiltrated nano-structured electrodes on pre-sintered porous

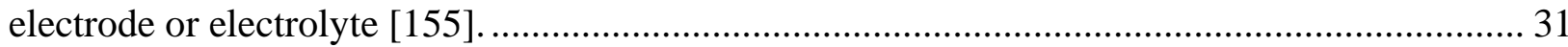

Figure 2.15. Impedance spectra for $\mathrm{H}_{2}$ oxidation on pure $\mathrm{Ni}$ and $\mathrm{Ni}$ anode with 0.52 and $1.7 \mathrm{mg}$ cm-2 GDC infiltration at (a) $900{ }^{\circ} \mathrm{C}$, (b) $800{ }^{\circ} \mathrm{C}$, and (c) $700^{\circ} \mathrm{C}$ [53] .................................. 32

Figure 2.16. (a) Schematic representation of the changes occurring the conventional Ni-YSZ cermet prepared by high temperature co-sintering and the scanning electron microscopy image showing the actual microstructure of such a cermet after redox cycling (b) Schematic representation of the change occurring Ni-YSZ structure obtained by polymeric precursor infiltration, scanning electron microscopy images showing the general microstructure of such a cermet (upper) and the energy dispersive X-ray spectroscopy mapping showing the distribution of Ni phase [38].

Figure 2.17. Changes in the electrical conductivity of the samples YSZ (1150)-35 Ni, YSZ (1150)-20YSZ(1000)-35Ni and YSZ(1150)-30YSZ(1000)-35Ni upon redox cycling at $800^{\circ} \mathrm{C}$ [40].

Figure 2.18. SEM images of (a) blank Ni/YSZ anode and Ag infiltrated (b) Cell A: 0.89 wt. \%,

(c) Cell B: 1.59 wt. \%, (d) Cell C: 2.48 wt. \% [96] .

Figure 2.19. Long-term stability of the cells with different Ag contents in dry $\mathrm{CH} 4$ at $1023 \mathrm{~K}$. Ag loadings of the infiltrated cells are Cell A: 0.89 wt. \%, Cell B:1.59 wt. \%, Cell C: 2.48 w. t\% [96].

Figure 2.20. Time dependence of methane conversion and $\mathrm{CO}$ selectivity under $\mathrm{CH}_{4}: \mathrm{O}_{2}=2.2: 1$ conditions for the $\mathrm{LiLaNi}-\mathrm{Al}_{2} \mathrm{O}_{3}$ catalyst [94]. 
Figure 2.21. $\mathrm{O}_{2}$-TPO profiles of $\mathrm{LiLaNi}-\mathrm{Al}_{2} \mathrm{O}_{3}, \mathrm{LaNi}-\mathrm{Al}_{2} \mathrm{O}_{3}, \mathrm{LiNi}-\mathrm{Al}_{2} \mathrm{O}_{3}, \mathrm{LaCaNi}-\mathrm{Al} 2 \mathrm{O} 3$, $\mathrm{CaNiAl}_{2} \mathrm{O}_{3}$ and $\mathrm{Ni}-\mathrm{Al}_{2} \mathrm{O}_{3}$ catalysts after operation under $\mathrm{CH}_{4}: \mathrm{O}_{2}=11.5: 1$ conditions for $100 \mathrm{~h}$ [94],

Figure 2.22. Wetting angles of different $\mathrm{SSC}(\mathrm{Sm} 0.5 \mathrm{Sr} 0.5 \mathrm{CoO} 3-\mathrm{x})$ precursor solutions on LSCF, LSM, YSZ and GDC substrates (note: mixture 1 had a water-to-ethanol volume ratio of 1:0.3 and mixture 2 has a water-to-ethanol volume ratio of 1:0.6) [167]. 42

Figure 2.23. SEM images of (a) GDC starting powder and (b) GDC-impregnated Ni-YSZ electrode after fired at $800^{\circ} \mathrm{C}$ for $2 \mathrm{~h}$. [63].

Figure 2.24. Scanning electron microscope pictures of (a) surface and (b) fractured cross-section of pure $\mathrm{Ni}$ anode, $(\mathbf{c})$ surface and (d) fractured cross-section of $2.7 \mathrm{mg} / \mathrm{cm}^{2} \mathrm{Y}_{2} \mathrm{O}_{3}$-stabilized $\mathrm{ZrO}_{2}$-impregnated $\mathrm{Ni}$ anode, (e) surface and (f) fractured cross-section of $1.7 \mathrm{mg} / \mathrm{cm}^{2} \mathrm{Gd}$-doped $\mathrm{CeO}_{2}$-impregnated $\mathrm{Ni}$ anode [54].

Figure 2.25. XRD patterns of the decomposition products from LSM precursor (a) without and (b) with Triton-X 100, sintered at $800^{\circ} \mathrm{C}$ for $1 \mathrm{~h}$ [28].

Figure 2.26. SEM images of porous YSZ structures infiltrated with (a) Ni once with Triton-X100 surfactant and (b) Ni five times with proprietary (Triton X-45) surfactant [174] ............... 48 Figure 2.27. XRD scans for powders produced by firing various $\mathrm{Sm}\left(\mathrm{NO}_{3}\right)-\mathrm{Sr}\left(\mathrm{NO}_{3}\right)_{2}-\mathrm{Co}\left(\mathrm{NO}_{3}\right)_{2}$. $\mathrm{PND}=$ Pure nitride derived, $\mathrm{TXD}=$ Triton $\mathrm{X}-100$ derived, $\mathrm{CAD}=\mathrm{Citric}$ acid derived [175]....... 48 Figure 2.28. X-ray diffraction patterns of the pure YSB powders and the YSB after the infiltration with LSM. Both the XRD patterns of LSM nitrate precursor with and without the addition of glycine are showed [55].

Figure 2.29. Cross-sectional micrographs of (a) YSB backbone, (b) LSM-YSB composite [55].

Figure 2.30. SEM micrographs of $\mathrm{Cu}-\mathrm{CeO} 2 / \mathrm{YSZ}$ composite anode without (a) and with (b)

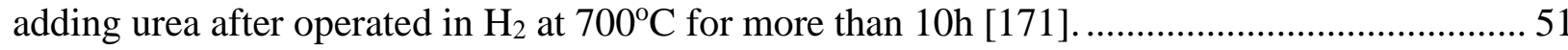
Figure 2.31. I-V-P characteristic curves of $\mathrm{Cu}-\mathrm{CeO} 2 / \mathrm{YSZ}$ composite anode impregnated with or without adding urea when operated in $\mathrm{H}_{2}$ at $700^{\circ} \mathrm{C}$ [171].

Figure 2.32. XRD patterns of nanoscale SSC from (a) nitrate precursor and (b) urea plus nitrate heated at $800^{\circ} \mathrm{C}$ for $2 \mathrm{~h}$. (P) Peaks corresponding to perovskite phase [28]. 52

Figure 2.33. SEM images of an LSM-YSZ cathode with dispersed SSC nanoparticles after heating at $700^{\circ} \mathrm{C}[28]$.

Figure 2.34. Infiltration methods applied for anode electrode in recently published studies [29-

152]. 55

Figure 2.35. Infiltration of a porous scaffold. A metal nitrate is infiltrated into the scaffold. This is heated to decompose the nitrate to the oxide The operation is then repeated several times [179]. 56

Figure 2.36. SEM graphs of p-YSZ/d-YSZ: (a) p-YSZ surface and (b) cross-section for pYSZ/d-YSZ [83]. 57

Figure 2.37. Schematic representation of vacuum assisted dip coating infiltration method. .... 58 Figure 2.38. Ohmic resistance measurements at $1173 \mathrm{~K}$ in humidified $\mathrm{H} 2$ as a function of time for (○) Co-Cu-ceria-YSZ ( 5 vol\% electrodeposited Co, 13 vol\% Cu); $(\diamond) \mathrm{Cu}$-ceria-YSZ (18\%vol $\mathrm{Cu}) ;(\Delta) \mathrm{Co}-\mathrm{Cu}$-ceria YSZ (co-impregnation of $5 \mathrm{vol} \% \mathrm{Co}$ and $13 \mathrm{vol} \% \mathrm{Cu}$ ); ( $\square$ ) Co-ceria-YSZ (18 vol\% Co); (x) Co-ceria-YSZ (30 vol\% Co) [32]. 
Figure 2.39. SEM images of a porous YSZ matrix (a) before and (b) after incorporation of 10 vol \% ceria and 20 vol \% Ni or (c) 30 vol \% Co [56].

Figure 2.40. (a) The fracture surface where the EDS mapping data was collected (b) EDS map showing the Ni distribution in the Ni-YSZ cermet (Ni signals are in dark gray) [40]. 62

Figure 2.41. Cross-sectional SEM images of the catalyst-catalyst anode interface after the operation on methane fuel [94].

Figure 2.42. Time dependence of the peak power density and open circuit voltage (a) and voltage and power density under constant polarization current density of $500 \mathrm{~mA} \mathrm{~cm}{ }^{-2}(\mathbf{b})$, of the fuel cell with the $\mathrm{LiLaNi}-\mathrm{Al}_{2} \mathrm{O}_{3}$ catalyst layer, paste operating on pure methane fuel [94]........ 64 Figure 2.43. The cross-sectional SEM of the $\mathrm{Cu}-\mathrm{CeO} 2-\mathrm{YSZ} / \mathrm{Ni}-\mathrm{ScSZ} / \mathrm{PCM}$ single cell (a) the interface between the $\mathrm{Cu}-\mathrm{CeO} 2-\mathrm{YSZ}$ supported anode and the $\mathrm{Ni}-\mathrm{ScSZ}$ anode functional layer (b), the porous YSZ matrix after acid leaching treatment (c) and the $\mathrm{Cu}-\mathrm{CeO} 2-\mathrm{YSZ}$ anode matrix after impregnation (d) [99].

Figure 2.44. Cross-sectional SEM images of $\mathrm{Cu}_{\mathrm{M}} / \mathrm{Ni} / \mathrm{YSZ}$ cell: (a) anode-electrolyte interface, (b) enlarged image taken from region P. [52].....

Figure 3.1. (a) A mussel sticks to the rocks by the polymerized dopamine [14]. (b) DOPA is synthesized at the mussel legs in various molarities (mfp) [15] (c) the molecular structure of DOPA and dopamine. 81

Figure 3.2. TGA of dopamine hydrochloride and poly dopamine (pDA). 86

Figure 3.3. I-V-P curve of baseline and pDA treated anode supported cell tested with $300 \mathrm{sccm}$ air and $300 \mathrm{sccm} \mathrm{H}_{2}\left(3 \%\right.$ humidified) at $750^{\circ} \mathrm{C}$.

Figure 3.4. Contact angle drift of droplets of pDA and cerium nitrate DI water solutions as a function of ethanol substitute.

Figure 3.5. Droplet images of (a) pDA and (b) cerium nitrate of $100 \mathrm{vol} \%$ DI water solution and (c) pDA and (d) cerium nitrate of 1:1 vol \% water-ethanol mixture on to the $\mathrm{NiO} / \mathrm{YSZ}$ pellets.

Figure 3.6. Cross section SEM images of in-situ DC pDA dip coated cell, which were taken from the anode (A) middle layer, (B) active layer, and cathode (C) middle layer, (D) active layer of the anode-supported cell after testing at $750^{\circ} \mathrm{C}$ for 300 hours.

Figure 3.7. I-V-P curves of baseline and impregnated SOFCs using the in-situ and ex-situ polymerized pDA surfactant before nano-ceria impregnation.

Figure 3.8. (a) Nyquist and (b) Bode plots of the baseline and bio-coating assisted dip-coat infiltrated cells under $0.4 \mathrm{~A}\left(0.325 \mathrm{~A} / \mathrm{cm}^{2}\right)$ at $750{ }^{\circ} \mathrm{C}$

Figure 4.1 Schematic representation of (a) untreated surface (b) pDA coated surface, (c), (d), and (e) progressive incubation of metal ion chelation with pDA layers.

Figure 4.2 AFM images, $1.5 \mu \mathrm{m}$ line scans and line scan RMS values of (a-c) untreated and polished, and ceria coating without (d-f) and with pNE treatment (g-i) of NiO, YSZ and LSM surfaces.

Figure 4.3 (a) Current density vs. Electrode Overpotential at $300 \mathrm{~h}$ (b) Percentage decrease in over potential vs. infiltrated $\mathrm{CeO}_{2}$ amount at $300 \mathrm{~h}, 0.325 \mathrm{~A} / \mathrm{cm}^{2}$....

Figure 4.4 Infiltrated catalyst amount vs. polarization resistance

Figure 4.5 EIS bode plot of the cells in (a) $48 \mathrm{~h}$ (b) $150 \mathrm{~h}$ and (c) $300 \mathrm{~h}$ operation at $750{ }^{\circ} \mathrm{C}$ under $0.325 \mathrm{~A} / \mathrm{cm}^{2}$. 
Figure 4.6 Anode active region SEM images of (a) IC-1, (b) IC-2, (c) IC-3 and (d) IC-4, for 300 $\mathrm{h}$ of testing at $750^{\circ} \mathrm{C}$ and $0.325 \mathrm{~A} / \mathrm{cm}^{2}$

Figure 4.7 Cathode active region SEM images of (a) IC-1, (b) IC-2, (c) IC-3 and (d) IC-4, after $300 \mathrm{~h}$ of testing at $750^{\circ} \mathrm{C}$ and $0.325 \mathrm{~A} / \mathrm{cm}^{2}$.

Figure 5.1 (a) A representative AFM image of pNE coated YSZ surface inscribed by fine needle tip (b) A line scan profile along the needle mark and the pNE coating that shows the method of pNE layer thickness measurement. $R_{v}$ denotes the maximum valley depth and the $R_{q}(R M S)$ denotes root mean square parameters.

Figure 5.2 Schematic of SU-8 patterning and pNE+ceria decoration on YSZ single crystals. . 131 Figure 5.3 Representative images of (a) clear nor-epinephrine (b) polymerized pNE solution.

Figure 5.4 UV-Vis spectroscopy of diluted (a) $0.5 \mathrm{mg} / \mathrm{ml}$, (b) $1 \mathrm{mg} / \mathrm{ml}$, (c) $2 \mathrm{mg} / \mathrm{ml} \mathrm{pNE}$ and (d) $\Delta$ absorption values $[350 \mathrm{~nm}-550 \mathrm{~nm}]$ of pNE solutions as a function of time.

Figure 5.5 pNE film thickness and relative degree of polymerization contour plot as a function of immersion time.

Figure 5.6 XPS survey spectra (a), (b); C1s core level spectra before (c),(d) and after (e),(f) Ar+ sputtering; and O1s core level spectra $(\mathbf{g}),(\mathbf{h})$ of untreated and pNE coated YSZ single crystal respectively. 138

Figure 5.7 (a) XPS survey spectra of cerium nitrate immersed YSZ and pNE coated YSZ single crystal; (b) C1s, (c) Ce 3d, and (d) O1s core level spectra of cerium (III) nitrate solution immersed pNE coated YSZ single crystal.

Figure 5.8. Post-sputtered $(0.5 \mathrm{kV}, 6 \mathrm{~s})$ XPS Ce $3 \mathrm{~d}$ core level spectra of a) chelated cerium complex and used cerium (III) nitrate hexahydrate crystals, in normalized intensity b) freshly opened cerium nitrate (III) hexahydrate crystals. Both are supplied from the same vendor (Alfa Aesar) and in \%99.5 purity. c) XPS Ce-3d and O-1s core level spectra of $\mathrm{CeO}_{2}$ (red) and $\mathrm{Ce}_{2} \mathrm{O}_{3}$ films as a reference [50]

Figure 5.9 Post sputtered XPS (a) Pd 3d core level spectra (b) O1s core level spectra of Pd (II) nitrate solution immersed pNE coated YSZ single crystal.

Figure 5.10 Schematics of (a) Ce-complex formation and (b) reduced $\mathrm{Pd}$ particle formation inside the pNE layer. AFM images of (c) deposited Ce-complex + pNE framework and (d) deposited Pd particles + PNE framework.

Figure 5.11 (a) Optical micrograph and (b) AFM image and the (c) AFM line scans of SU-8 2 patterns on YSZ single crystals. The pattern design is $\sim 20 \mu \mathrm{m}$ wide, $1.5 \mu \mathrm{m}$ height and $25 \mu \mathrm{m}$ gap on each photoresist stripe. (d) A representative final AFM image of ceria formation on clean area after the pattering and coating protocols.

Figure 5.12 The AFM images of $1 \mathrm{mg} / \mathrm{ml} \mathrm{pNE}$ coated YSZ single crystals for (a) $6 \mathrm{~h}$, (b) $12 \mathrm{~h}$, and (c) $24 \mathrm{~h}$. All the AFM scans are in $25 \times 25 \mu \mathrm{m}$ mapping area. 148

Figure 5.13 Deposited ceria particle histogram plots of (a) 6 h, (b) $12 \mathrm{~h}$, and (c) $24 \mathrm{~h}$ cerium nitrate dip-coated samples over the $1 \mathrm{mg} / \mathrm{ml} \mathrm{pNE}$ coated patterned YSZ single crystals for 6 hours. (d) Particle number and projected total particle area (\%) comparison of the ceria particles on the un-patterned areas. The mapping area for all the samples is $10 \times 10 \mu \mathrm{m}$. 150

Figure 5.14 The AFM images $0.4 \mathrm{M}$ cerium nitrate immersed (24 h) samples over various $1 \mathrm{mg} / \mathrm{ml} \mathrm{pNE}$ immersion times: (a) $6 \mathrm{~h}$ immersed (b) $12 \mathrm{~h}$ immersed, and (c) $24 \mathrm{~h}$ immersed to 
pNE. (d)The highlighted area of pNE $24 \mathrm{~h}$ (c). Mapping area for (a-c) are $35 \times 35 \mu \mathrm{m}$ and for is $10 \times 10 \mu \mathrm{m}$. (e) The line scan height profile in the direction of arrow in (d) ........................ 152

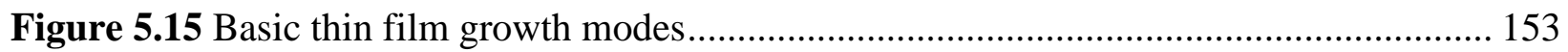

Figure 6.1 Molecular structures of selected monomers in catechol family............................... 161 Figure 6.2 UV-Vis spectra of $1 \mathrm{mg} / \mathrm{ml}$ (a) $\mathrm{pNE}$, (b) pGA, (c) pDHC, (d) pCA polymerized for 1 , 6 and $12 \mathrm{~h}$. 166

Figure 6.3 AFM images of $1 \mathrm{mg} / \mathrm{ml}$ (a) pNE (b) pGA, (c) pDHC and (d) pCA polymerized for $12 \mathrm{~h}$. Mapping area is $50 \times 50 \mu \mathrm{m}^{2}$, line scan length is $40 \mu \mathrm{m}$. 168

Figure 6.4 (a) Nyquist (b) Ohmic resistance (c) Polarization resistance and (d) Bode plots of baseline and only cerium nitrate and $\mathrm{pNE}, \mathrm{pCA}, \mathrm{pDHC}$, pGA assisted cerium nitrate infiltrated cells operated at $750^{\circ} \mathrm{C}$ for $75 \mathrm{~h}$.

Figure 6.5 Time-dependent electrode overpotential change plot of baseline, only cerium nitrate, and pNE, pCA, pDHC, pGA assisted cerium nitrate infiltrated cells operated at $750^{\circ} \mathrm{C}$ for $75 \mathrm{~h}$.

Figure 6.6 Time dependent electrode overpotential change plot of baseline, pCA and pCA 2 assisted infiltered cells operated at $750^{\circ} \mathrm{C}$ for $75 \mathrm{~h}$.

Figure 6.7 Bode plot of baseline, pCA and pCA -2 assisted infiltered cells operated at $750^{\circ} \mathrm{C}$ for $75 \mathrm{~h}$

Figure 6.8 HAADF and EDS mapping of (a) Baseline (b) pCA as. inf. cell, (c) pCA 2 as. inf. cell. 179

Figure 6.9 (a) HAADF mode and (b) EDS mode images of the cerium film phase over the nickel backbone at the active area of pCA 2 . inf. cell. 180 Figure 6.9 Cross-section of Ce L-alpha shell signal comparison of baseline, pCA and pCA 2 as. inf. cells 181

\section{List of Tables}

Table 1. Backbone and nanoparticles functions in each electrode class. Adapted from [28]....... 26 


\section{Chapter 1 : Introduction and the Statement of Problem}

\subsection{Statement of Problem}

The wet nano-catalyst infiltration (or impregnation) of porous Solid Oxide Fuel Cell (SOFC) electrodes is a recognized, cost-effective process to enhance electrochemical performance. The known impregnation methods include pipetting aqueous salt solutions onto the SOFC electrodes, which are then followed by multiple co-firing steps for calcination. These series of processes are replicated until the desired catalyst loading level achieved. The studies in the literature usually demonstrate initial enhanced electrocatalytic activity, boosted performance due to extending the triple phase boundary (TPB) length. However, apart from being a time-consuming and labor-intensive method, these infiltrated cells may suffer from long-term stability issues. One reason for the unstable nature of the nanoparticles is the multiple infiltration cycles and co-firing step between these cycles. The multiple infiltration cycles of diluted metal salt solutions may control the deposition amount between the steps; however, infiltration over the already formed nano-catalyst particles (from the previous step) may cause inhomogeneous deposition throughout the inner electrode surface. Besides, during the precursor drying stage inside the electrode, the solution is subjected to 3-D segregation where the dried gel is located at the edges and/or in the near-surface region. Lower co-firing temperatures help to form nano-particles. In contrast, poorly decorated highly and connected nano-particle networks lead to the reduction of overall surface energy by agglomeration and particle growth (Oswald Ripening) at an operating temperature which is higher than the co-firing temperatures. Agglomerated nano-particles lead to catalytic deactivation and gas-starvation issues due to pore-clogging. 
By utilizing an innovative method, three-dimensional segregation during the drying process can be avoided by precipitating the metal ions and attaching them to the inner electrode surface. With a homogenous and controlled nano-catalyst decoration throughout the electrode inner surface, coarsening related drawbacks can be minimized. Hence the process will result in a lower electrode overpotential, enhanced power density, and enhanced long-term stability with a simplified and cost-effective infiltration protocol.

\subsection{Goals of Research}

The end-goals of this research are to develop impregnation/infiltration protocol(s) that can enhance the nano-catalyst decoration for highly stable infiltrated fuel cells using bioinspired surfactants. The objectives of this research are:

- Adapting and tuning the catechol-based surfactant protocol to the three-dimensional networks of SOFC electrodes.

- Better understanding the effect of the catalyst network on the initial and the long-term stability of the fuel cells. This includes selecting process parameters and methods to adjust the microstructures and properties.

- Investigating the parameters to control the film thickness of the catechol film adhered to planar substrates.

- Investigating the chelating mechanism of the cerium precursor on to the catechol coated planar substrates. Monitoring the effect of nano-catalyst microstructure and decoration as a function of various conditions.

- Observing the change in surface morphology of cerium oxide formation of the fired samples as a function of $\mathrm{pNE}$ and cerium nitrate immersion times. 
- Investigating alternative surfactants with similar chemical structure and comparing the infiltrated fuel cell properties and microstructure. 


\section{Chapter 2 : Literature Review}

Over the past decades, there has been an increased demand for energy along with exceptionally efficient and environmentally friendly sources of electricity. Traditional fossil fuel conversion to energy is known to be an inefficient and polluting process. Fuel cells are one promising system to substitute for the direct combustion of fossil fuels in that sense. Fuel cells are known to convert chemicals (in the gas, liquid, or solid phase) directly to electricity with very little thermal or electrical loss. Fuel cell systems can also be practical where there is no access to the public grid or as a replacement of uninterruptible power supplies (UPS) for power generation [1, $2]$.

Fuel cells convert the various chemical forms to electricity through an electrochemical reaction. The most basic fuel cell reaction is based on the oxidation of hydrogen to form water. Eq.1 shows the net electrochemical reaction in a fuel cell system [1].

$$
2 \mathrm{H}_{2}(\mathrm{~g})+\mathrm{O}_{2}(\mathrm{~g}) \rightarrow 2 \mathrm{H}_{2} \mathrm{O}+(\text { electrical power }+ \text { heat })
$$

Fuel cells vary according to their efficiency, operating temperature, and electrochemical reaction, but mainly they are classified based on the electrolyte and fuel type. Figure 2.1 shows a brief introduction of the anode feed, cathode feed, exhaust chemistry, electrolyte material, operating temperature, and electrochemical reaction for each of the main fuel cell types: alkaline fuel cell (AFC), phosphoric acid fuel cell (PAFC), molten carbonate fuel cell (MCFC) proton exchange membrane fuel cell (PEMFC) and solid oxide fuel cell (SOFC) [2] . 


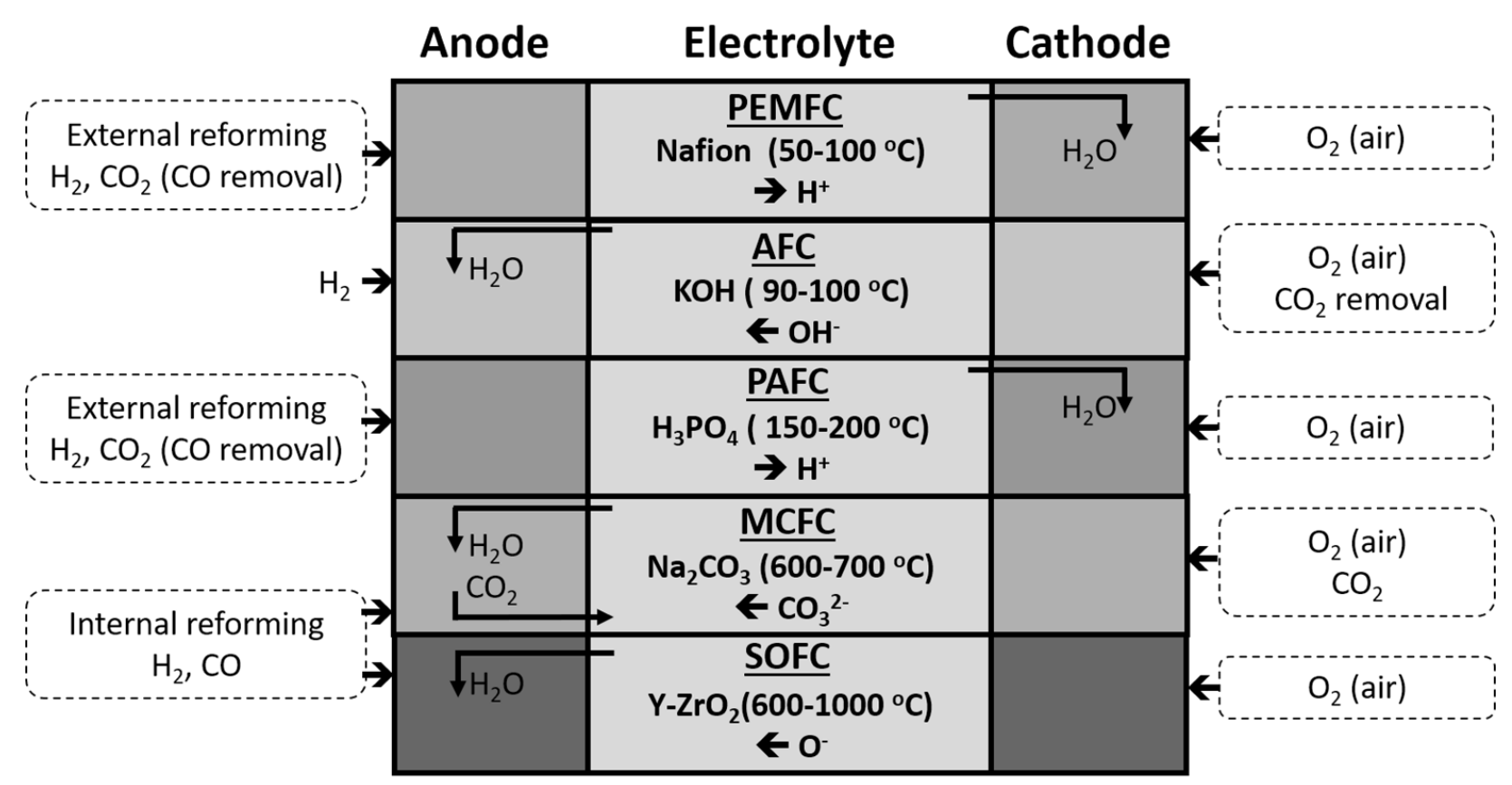

Figure 2.1. A schematic representation of the different fuel cell types [2].

\subsection{Alkaline Fuel Cell (AFC)}

One type of low-temperature fuel cell is called the alkaline fuel cell (AFC) which was one of the modern fuel cells developed in the 1960s to provide onboard electric power for the Apollo space vehicle[3]. The electrolyte, potassium hydroxide $(\mathrm{KOH})$-water solution, allows for the migration of hydroxyl ions $\left(\mathrm{OH}^{-}\right)$from the cathode to the anode side. The migrating $\mathrm{OH}^{-}$groups react with hydrogen gas to form $\mathrm{H}_{2} \mathrm{O}$ and $2 \mathrm{e}^{-}$. The AFC's operate below $100{ }^{\circ} \mathrm{C}$ with a low cost. The electrical efficiency of AFC is around $60 \%$ (>80\% combined heat and power-CHP-). Mostly, nickel is used as the catalyst for the cathode and anode electrodes[4]. Despite the relatively low catalyst cost, they are incredibly intolerant to carbon dioxide. The presence of $\mathrm{CO}_{2}$ in the air shortens the lifetime of AFCs through the conversion of potassium hydroxide $(\mathrm{KOH})$ to potassium carbonate $\left(\mathrm{K}_{2} \mathrm{CO}_{3}\right)$, which affects the conductivity, and hence, the overall cell performance. In that sense, purified air or oxygen must be used to increase the operational life of AFCs. All in all, the 
need of $\mathrm{CO}_{2}$-free hydrogen and air increases the cost and storage issues that affect the practicality of AFCs.

\subsection{Proton Exchange Membrane Fuel Cell (PEMFC)}

PEMCs are low-temperature fuel cells that usually operate between $60-100^{\circ} \mathrm{C}$. They were first invented by GE in the 1960s to be used by the U.S. Navy [1]. The fluorinated sulfonic acid polymer or a similar polymer is used as the hydrogen (or proton) electrolyte, but these electrolytes block the flow of electron and reactant transport. The electrochemical reaction occurs at the cathode electrode, where oxygen gas meets the hydrogen ions, and electrons pass through the external circuit and generate electricity. PEMFC systems can be stationary and compact, and they typically require low maintenance. Thus, the adaptation of PEMFC through road vehicles is a very promising application area [4]. Since a non-corrosive solid electrolyte is used, it is safe to handle. They are semi-tolerant to $\mathrm{CO}_{2}$, and atmospheric air can also be purged [1]. However, they are intolerant to hydrogen impurities such as more than $50 \mathrm{ppm} \mathrm{CO}$ and sulfur. In the case of hydrocarbon fuel usage, extensive fuel processing systems must be used. A working temperature above $100^{\circ} \mathrm{C}$ vaporizes the water within the cell architecture causing dehydration of the membrane, which leads to a reduction in the proton conductivity of the membrane. In a cost perspective, platinum is used as the catalyst, and the solid polymer membrane is relatively expensive, as well. The electrical efficiency of PEMFC is between 40-50\%, and the output power can be as high as $250 \mathrm{~kW}$. The main application area is for light electric vehicles and portable electronic equipment. 


\subsection{Phosphoric Acid Fuel Cell (PAFC)}

Phosphoric acid fuel cells (PAFC) use liquid phosphoric acid $\left(\mathrm{H}_{3} \mathrm{PO}_{4}\right)$ within a silicon carbide matrix as the electrolyte and carbon paper electrodes. PAFCs can only operate at the range of $150-220^{\circ} \mathrm{C}$ since the charge carrier $\left(\mathrm{H}^{+}\right)$conduction is very low at lower temperatures. Water forms at the cathode electrode with the presence of a platinum catalyst[4]. PAFCs can tolerate up to $30 \% \mathrm{CO}_{2}$; therefore, these fuel cells may use air directly from the atmosphere as for PEMFCs. While working at a medium temperature, they can use the waste heat for co-generation. The electrolyte has lower volatility and long-term stability. However, carbon monoxide (CO) generation from steam reforming poisons the cell. Also, the liquid electrolyte is corrosive at average temperatures, so safety and handling problems arise. The entry of water to the system can dilute the electrolyte acid concentration, which may cause performance degradation [1]. PAFCs are an expensive system to manufacture due to the need for finely dispersed platinum catalyst coating the electrode. The development of PAFC had slowed down after peak research of PEFC over the decades that were thought to have a better cost potential.

\subsection{Molten Carbonate Fuel Cell (MCFC)}

The first working MCFC was built in the 1960s by the US Navy. Molten carbonate fuel cells are based on the use of an electrolyte composed of a mixture of lithium and potassium carbonate. This fuel cell architecture runs with circulating carbonate ions $\left(\mathrm{CO}_{3}{ }^{2-}\right)$ from the cathode to the anode[1]. The molten carbonate fuel cell requires high-temperature to function. Typically, the working temperature is around $650^{\circ} \mathrm{C}$. They require carbon dioxide and oxygen as the oxidant. In the MCFC, the reaction at the anode electrode occurs between hydrogen fuel and the carbonate ion, which react to form carbon dioxide, water, and electrons. 
MFCs are currently used for natural gas and coal-based power plants in the electrical utility, industrial military, and marine applications. MCFCs may be directly fueled with hydrogen and carbon monoxide, natural gas, and propane[4]. At the high operating temperatures, the MCFC anode and cathode are $\mathrm{Ni}$ and nickel oxide, respectively, and are adequate to promote the reaction. A benefit for MCFCs is that there is no requirement for an expensive noble catalyst which gives the cost effectiveness of the system. Also, MCFCs are capable of internal reforming which provides a high-level capability for fuel flexibility. MCFC stacks also show a tolerance to sulfur which is typically present in many fossil fuel sources. The main challenge for MCFCs is that they include a very corrosive mobile electrolyte that may potentially result in handling and safety issues. Also, $\mathrm{CO}_{2}$ flow is required at the cathode side, which is usually recycled from anode exhaust to form a carbonate ion [3].

\subsection{Solid Oxide Fuel Cell (SOFC)}

The gradual increase of energy demand of the world pursues efficient, economic, and environmentally-friendly electric generators. Solid oxide fuel cells (SOFCs) are one promising system that arises among other fuel cell technologies in many respects. SOFC systems operate at high temperatures up to 600 to $1000^{\circ} \mathrm{C}$ due to technical requirements [5]. Hence high operating temperature produces a byproduct of heat for co-generation. The efficiency of an SOFC system can reach up $70 \%$ with additional heat recovery [6]. First SOFC, operating at $1000^{\circ} \mathrm{C}$, was built by Baur and Preis [6]. The components that were used are $\mathrm{Fe}$ or $\mathrm{C}$ as an anode, 10 wt. \% $\mathrm{MgO}-$ $\mathrm{ZrO}_{2}$ or 15 wt. $\% \mathrm{Y}_{2} \mathrm{O}_{3}-\mathrm{ZrO}_{2}$ as electrolyte and $\mathrm{Fe}_{3} \mathrm{O}_{4}$ as a cathode. After decades of development, a wide range of electrodes and electrolyte compositions have been utilized to decrease the overall 
resistance, operating temperature, catalytic activity, and stability. Recently, the main requirements and design are reviewed by Keegan C. Wincevicz et al., and A. Boudghene Stambouli et al. [5, 6]. An SOFC consists of two electrodes, an anode and a cathode sandwich that are manufactured as a porous network to allow gas diffusion through a few micron thick active area. The electrolyte, the middle component, is required to be a dense, oxygen ion-conductive ceramic layer. As structural components, interconnects are used to complete the circuit through the anode to the cathode, and a sealant is used to provide hermetic tightness between the manifold and the electrode surface. Figure 2.2 illustrates the general mechanism of the SOFC based on the simplest fuel system. Fed hydrogen oxidizes with the oxygen ions in the anode electrode, which generates free electrons and water vapor (or other oxidized by-products, such as $\mathrm{CO} / \mathrm{CO}_{2}$ for hydrocarbon fuels).

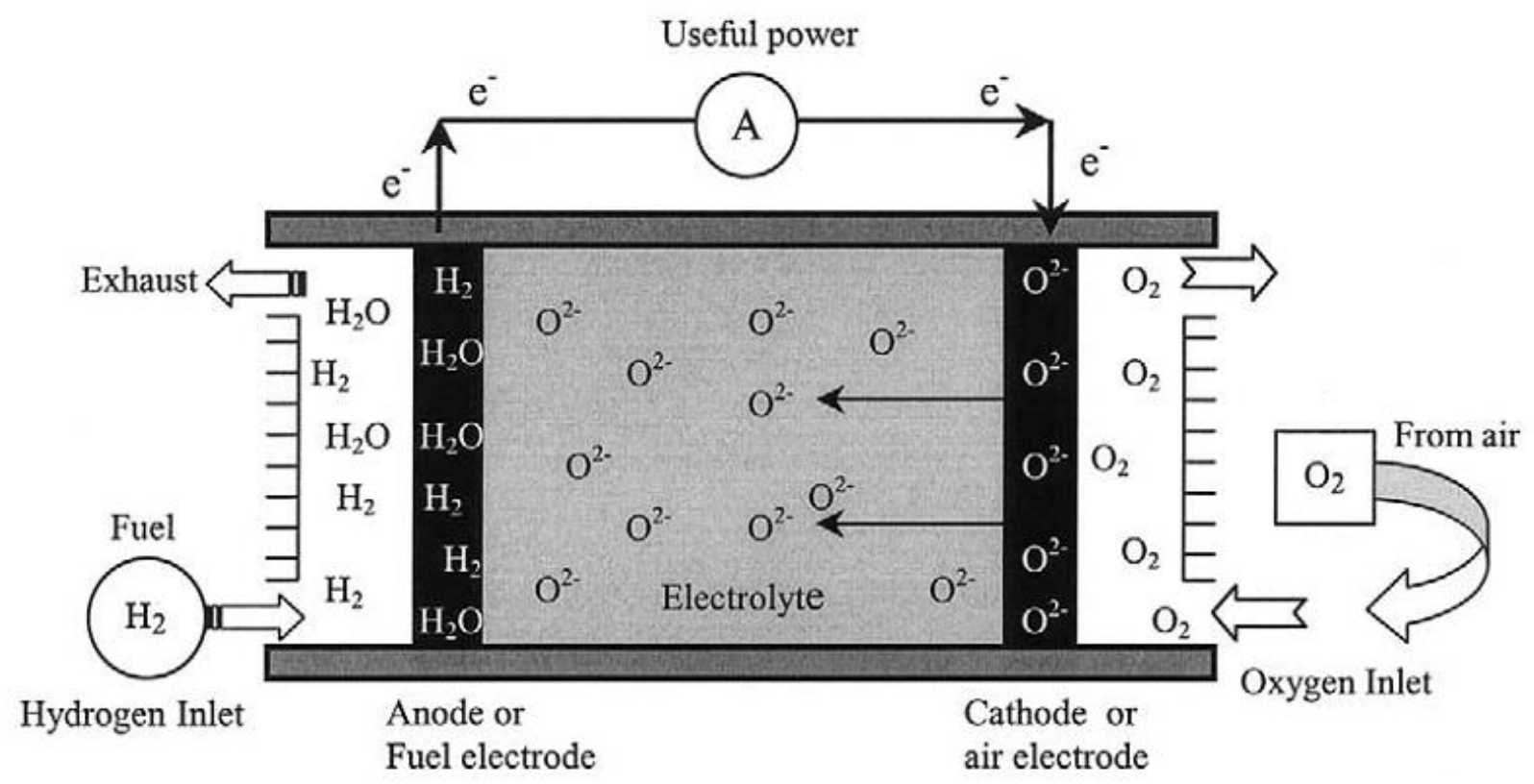

Figure 2.2. Concept diagram of SOFC based on oxygen-ion conductors using $\mathrm{H}_{2}$ as fuel [6]. 
The fuel cell performance is limited by three factors: 1) transportation of charge related to ohmic losses, 2) gas starvation/transport of ions related mass transport losses and 3) catalytic deactivation of the electrodes. Ohmic and mass-transport limitations have been overcome by engineering the fuel cell designs and geometry. To minimize the ohmic and polarization resistance, the current path in the components must be as short as possible. So, the cell components must be manufactured as thin layers. Moreover, to reduce the mass transportation losses, the design must provide good, homogeneous access for the reacting gasses [7]. Solid oxide fuel cell stacks are categorized based on their shapes: the seal-less tubular design, segmented-cell-in-series design, the monolithic design, and the flat-plate design as schematically shown in Figure 2.3.b. [8]. Tubular design (Figure 2.3.a) was first proposed by Westinghouse in the 1950s, and the first sealless design was launched in 1980 [9]. The main feature of the sealless tubular design is the stack does not need a sealing component under gas flow. Moreover, each cell is built over one thick ceramic support which gives a uniform thermal expansion coefficient that prevents thermal cyclic cracking. However, due to the form factor and thickness of the support, the current travels a longer path. This long current path in the electrodes results in high cell resistance and losses. The support tube also causes the rate limiting step of gas diffusion through the tube which affects the performance. Manufacturing techniques such as electrochemical vapor deposition (EVD), slurry coating or plasma spraying processes increase the cost of tubular SOFC [10]. The segmented-cellin-series design is a modified tubular design which was proposed in the 1960s. Short-cylinder cells are joined together with interconnecting materials. The interconnect also acts as a sealant between the anode and the cathode. Like the seal-less tubular SOFC, the segmented-cell-in-series design improves mechanical durability. The system offers improved stack efficiency. However, above five cells in series, it is reported that the power output diminishes in airflow series. Planar SOFC 
designs (Figure 2.3. c, d) were also utilized well over time. Feasible designs such as monolithic SOFCs offer great potential and advantages due to the high active surface area. It was demonstrated only in the laboratory scale due to the difficulty of fabrication at the commercial scale [9]. The most utilized stack design among the current architectures is the flat plate SOFC design. Flat plate design consists of thick planar plates usually rectangular or circular (button type). This design shows higher power densities relative to the tubular designs. Planar SOFC's are usually fabricated by tape casting, screen printing or tape calendaring. Those simple fabrication routes increase the feasibility and cost-effectiveness of the stack. Also, thin manufacturing minimizes the ohmic and electrical resistance of the system.
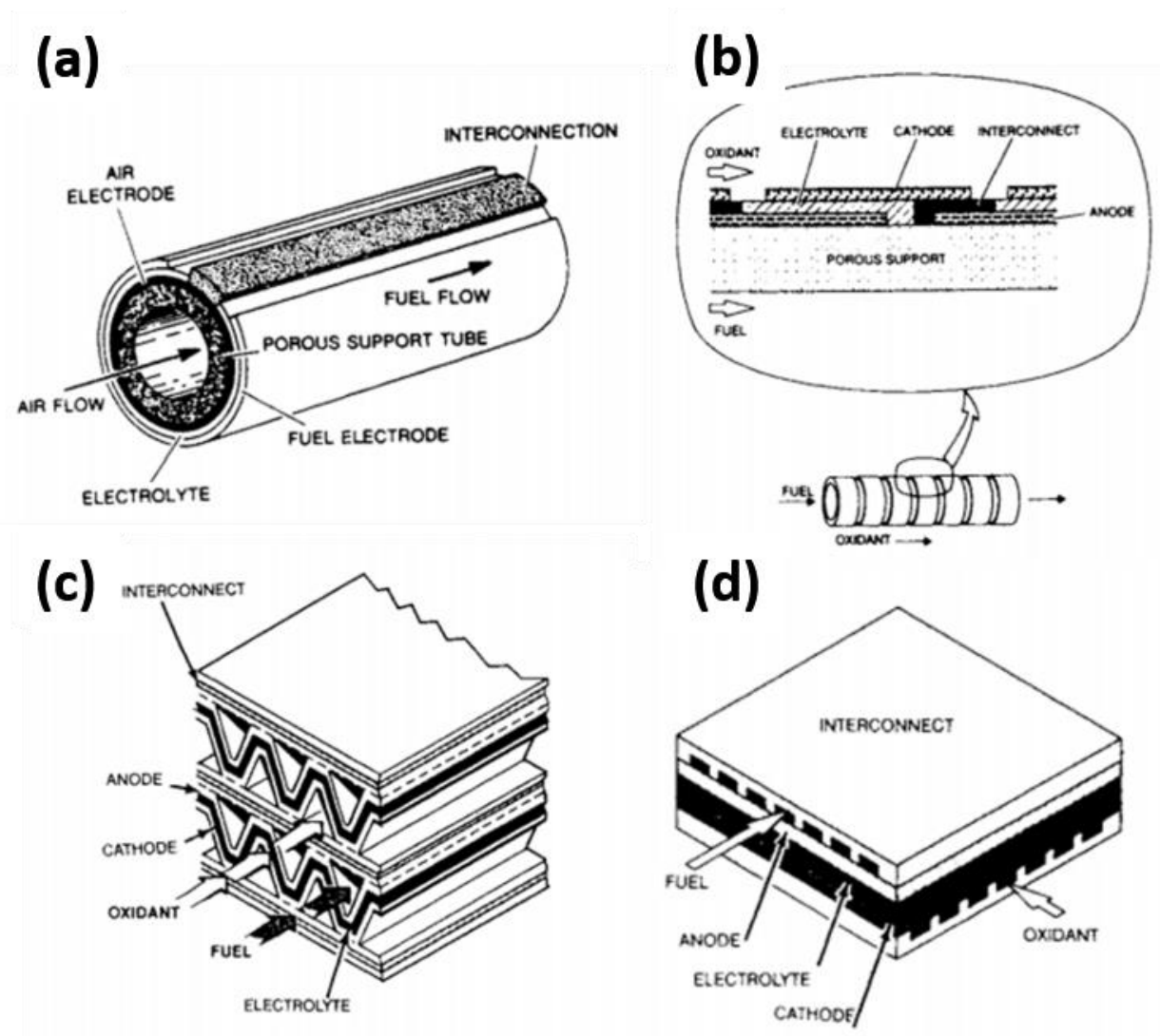

Figure 2.3. SOFC stack designs: (a) Seal-less tubular design, (b) Segmented-Cell-inSeries design (c) Monolithic design (d) Flat-plate design [8]. 
Another categorization is based on the thickest functional component, which adequately supports the cell. Figure 2.4 illustrates different SOFC designs based on the support component [11]. Usually, the support component of the cell is manufactured in a few hundred microns to provide mechanical rigidity. Moreover, in tubular SOFC designs, a thick ceramic isolator houses the fuel cell components. By giving the advantage of inertness and low thermal expansion coefficient, it is preferred for ceramic-based fuel cells. Owing to very small electrical loss, interconnect metal plates also are preferred as the supporting component. Both electrodes and electrolyte can be deposited or printed as very thin layers onto the interconnect metal in metalsupported SOFCs.

(a)

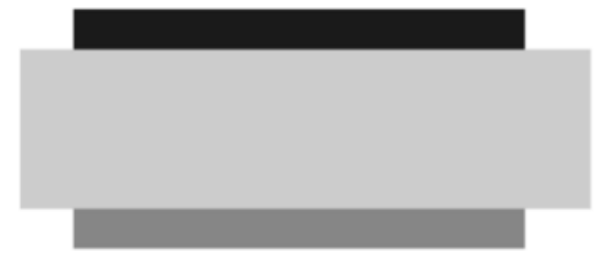

(c)

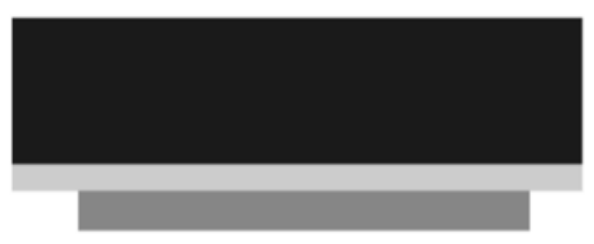

(b)

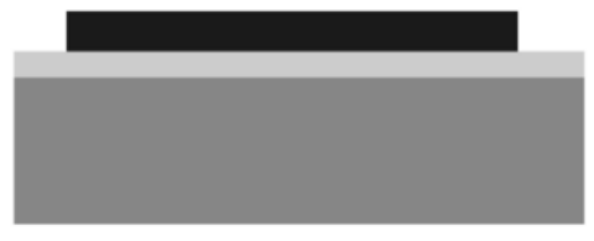

(d)

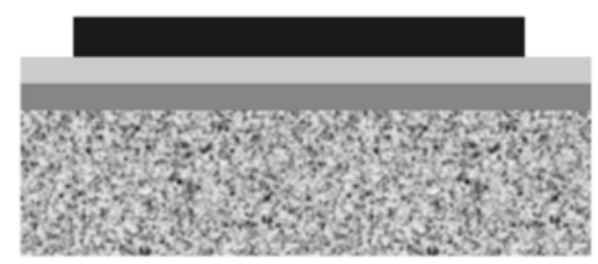

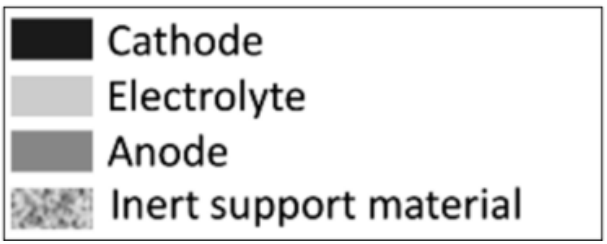

Figure 2.4. SOFC's based on the support component (a) electrolyte (b) anode (c) cathode (d) metal (interconnect) supported SOFC designs [11].

The third factor that affects the fuel cell performance, the catalytic deactivation overtime at elevated temperature, can be overcome by materials selection. Generally, the cathode electrode 
is referred to as the air or oxygen electrode where oxygen in the air reacts with the electrons and becomes oxygen ions. The reduction reaction of oxygen is given in Eq. 2.2.

$$
1 / 2 \mathrm{O}_{2 \text { (gas/air) }}+2 \mathrm{e}^{-} \rightarrow \mathrm{O}^{2-}
$$

The main material selection requirements for cathode materials are high electrical conductivity and ionic conductivity, good catalytic activity for oxygen reduction and high stability in an oxidizing environment at working temperatures. The cathode electrode materials are generally perovskite or related structures. Among the many candidates have been studied by the researchers, the lanthanum-based cathode $\left(\mathrm{LSM}=\mathrm{La}_{x} \mathrm{Sr}_{(1-\mathrm{-x})} \mathrm{MnO}_{3}\right)$ is the most popular material for high-temperature SOFC's owing to the good stability with yttria stabilized zirconia (YSZ $=\mathrm{Y}_{\mathrm{x}} \mathrm{Zr}_{(1-}$ ${ }_{\text {x) }} \mathrm{O}_{2}$ ) electrolyte [5]. For low-temperature cells, $\quad \mathrm{LSF}=\mathrm{La}_{\mathrm{x}} \mathrm{Sr}_{(1-\mathrm{x})} \mathrm{FeO}_{3}(\mathrm{x} \sim 0.8), \mathrm{LSCF}=\mathrm{La}_{(1-}$ $\left.{ }_{\mathrm{x}}\right) \mathrm{Sr}_{\mathrm{x}} \mathrm{Fe}_{\mathrm{y}} \mathrm{Co}_{(1-\mathrm{y})} \mathrm{O}_{3}(\mathrm{x} \sim 0.4, \mathrm{y} \sim 0.2)$ and strontium based $\left(\mathrm{SSC}=\mathrm{Sm}_{\mathrm{x}} \operatorname{Sr}_{(1-\mathrm{x})} \mathrm{CoO}_{3}(\mathrm{x} \sim 0.5)\right)$ perovskite cathodes are substituted due to the low conductivity of LSM cathode. Depending on the electrical/ionic properties, the electrochemical phase boundary may vary. For instance, LSM is a poor ionic conducting cathode material and is often compensated by mixing with an ionic conducting phase, such as yttria-stabilized zirconia (YSZ). Here, the electrochemical reaction takes place at the triple-phase boundary (termed as TPB or 3PB), which is the point of contact of the electronic conductor, oxygen ion conductor, and oxygen gas (Figure 2.5.a and b). For the mixed ionic-electronic conducting (MIEC) systems, such as LSCF, the double-phase boundary (DPB, or 2PB) dominates at the point of contact to the MIEC and air [12] as shown in Figure 2.5.c. Cathodes are usually manufactured thin and porous to increase the diffusion and the phase boundary points, 
(a)

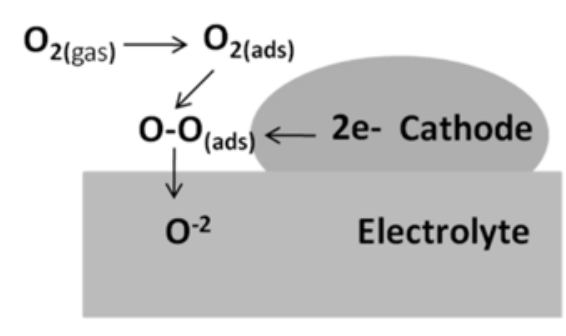

(b)

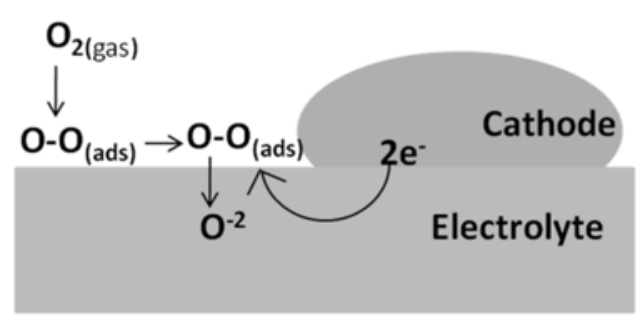

(c)

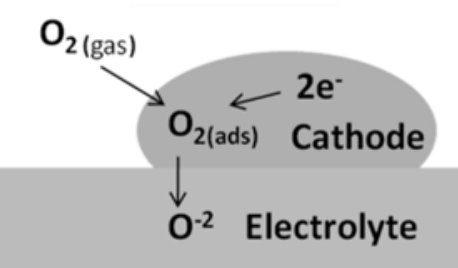

Figure 2.5. Reaction pathways of oxygen reduction (a) and (b) for electronically conductive systems mixed with electrolyte material (YSZ), (c) for MIEC systems. Modified from [11].

The electrolyte, the middle layer, is made up of a dense metal oxide (ceramic) containing a population of oxygen vacancies that allow for only $\mathrm{O}^{-2}$ charge carriers to pass from the cathode to anode electrode due to the concentration gradient. So, as a rule of thumb, an electrolyte material must be electronically insulating (high ohmic resistance) but ionically conductive, chemically stable in both oxidizing and reducing atmospheres and gas-tight hence free of porosity. Yttria stabilized zirconia (YSZ) and pure or gadolinium doped ceria (GDC) are the most popular electrolyte materials owing to their excellent properties. Defect chemistry of these compounds can be written in Kröger-Vink notation. As shown in Eq. 2.3 and Eq. 2.4, doping with a lower valent cation is compensated by oxygen vacancies due to the charge neutrality principle [13].

Moreover, cerium oxide has a unique oxygen ion conductivity and oxygen storage capacity by dual oxidation states of $\mathrm{Ce}^{+3}$ and $\mathrm{Ce}^{+4}$. It is reported that this switching mechanism is driven by downsizing the ceria crystallite size. Moreover, the oxygen partial pressure also promotes this 
mechanism. As a result, oxygen vacancies are created in the lattice, represented by Eq. 2.5 [14]. It should be noted that electrolyte ionic conductivity primarily determines the operating temperature of the whole SOFC.

$$
\begin{aligned}
& \mathrm{Y}_{2} \mathrm{O}_{3}\left(\mathrm{ZrO}_{2}\right) \rightarrow 2 \mathrm{Y}^{\prime} \mathrm{Zr}+\mathrm{V}^{*}{ }_{\mathrm{O}}+3 \mathrm{O}^{\mathrm{x}}{ }_{\mathrm{o}} \\
& \mathrm{Gd}_{2} \mathrm{O}_{3}\left(\mathrm{CeO}_{2}\right) \rightarrow 2 \mathrm{Gd}^{\prime}{ }_{\mathrm{Ce}}+\mathrm{V}^{*}{ }_{\mathrm{O}}+3 \mathrm{O}^{\mathrm{x}}{ }_{\mathrm{o}} \\
& 2 \mathrm{Ce}_{\mathrm{Ce}}+\mathrm{O}_{\mathrm{o}} \rightarrow 1 / 2 \mathrm{O}_{2}+\mathrm{V}^{*}{ }_{\mathrm{O}}+2 \mathrm{Ce}_{\mathrm{Ce}}^{\prime}
\end{aligned}
$$

The second electrode, the anode, is referred to as the fuel electrode where the hydrogen gas or hydrocarbon fuel is fed. Mostly anodes are made as of a ceramic-metal composite, called cermet to meet the physical and chemical criteria. Major design requirements for the anode is that it must be electrically and ionically conductive for electron and ion flow and highly electrocatalytic active to break hydrogen and/or carbon bonds in the fuel. When hydrogen is fed, the oxidation reaction of hydrogen at the anode side is given in Eq. 2.6. Carbon monoxide (CO) and hydrocarbons $\left(\mathrm{CH}_{4}\right)$ can also be purged to the anode electrode for electron or hydrogen generation. At elevated temperature, it is applicable to oxidize $\mathrm{CO}$ to $\mathrm{CO}_{2}$ and complete the circuit (Eq. 2.7), or with the water gas shift reaction, hydrogen can be generated (Eq. 2.8). Since direct oxidation of $\mathrm{CH}_{4}$ is not being performed yet, steam forming reactions (Eq. 2.8 and Eq. 2.9) allow hydrogen generation to be achieved [15].

$$
\begin{aligned}
& \mathrm{H}_{2}+\mathrm{O}^{2-} \rightarrow \mathrm{H}_{2} \mathrm{O}+2 \mathrm{e}^{-} \\
& \mathrm{CO}+\mathrm{O}^{2-} \rightarrow \mathrm{CO}_{2}+2 \mathrm{e}^{-} \\
& \mathrm{CO}+\mathrm{H}_{2} \mathrm{O} \rightarrow \mathrm{CO}_{2}+\mathrm{H}_{2} \\
& \mathrm{CH}_{4}+\mathrm{H}_{2} \mathrm{O} \rightarrow \mathrm{CO}+3 \mathrm{H}_{2}
\end{aligned}
$$

At the anode site, electrochemical reactions are also driven by $2 \mathrm{~PB}$, for MIEC, and 3PB, for the composite matrix. Although the mechanism of $\mathrm{H}_{2}$ oxidation and $\mathrm{H}_{2} \mathrm{O}$ reduction is 
controversial, adsorption/desorption, surface diffusion, and charge-transfer reactions take place at these sites [12]. For the Ni/YSZ anode system, the schematics of the proposed mechanisms are illustrated in Figure 2.6. Adsorption and dissociation of $\mathrm{H}_{2}$ into $\mathrm{H}^{+}$ions on the Ni surface resulting in water formation on the surfaces and through bulk Ni and YSZ is shown in Figure 2.6.a. In Figure 2.6.b, the migration of $\mathrm{O}^{2-}$ or $\mathrm{OH}^{-}$from the $\mathrm{YSZ}$ to the $\mathrm{Ni}$ along the surface, which results in water formation on the $\mathrm{Ni}$, is visualized. The third proposed mechanism is shown in Figure 2.6.c, where the water formation takes place at the surface of YSZ and the electron transport, occurs at the surface of YSZ and through the Ni. For MIEC electrocatalysts, the reaction is extended to the entire ceramic/gas interface ( $2 \mathrm{~PB})$ with the surface reaction being rate-determining.

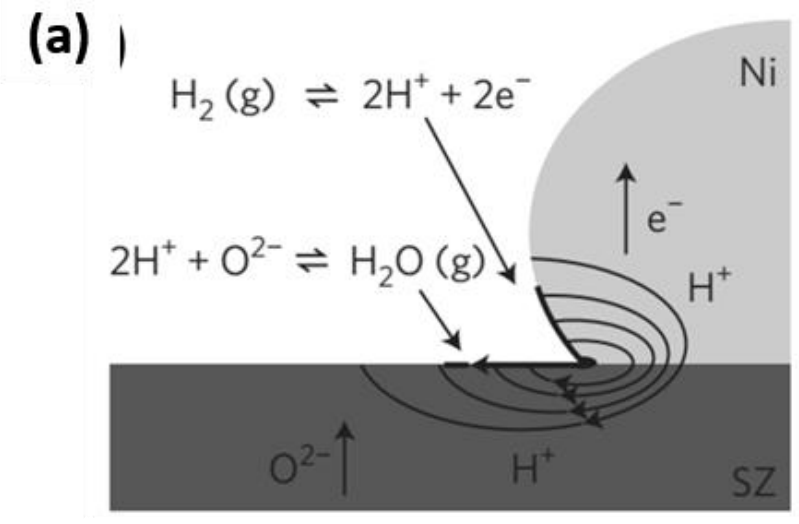

(b)

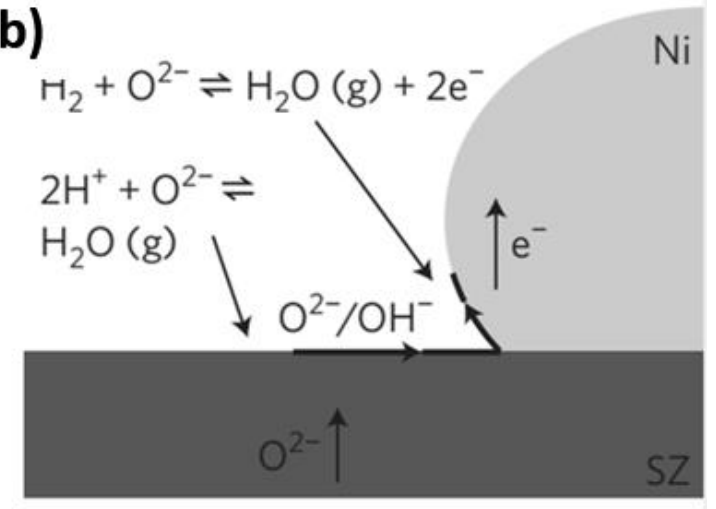

(c)

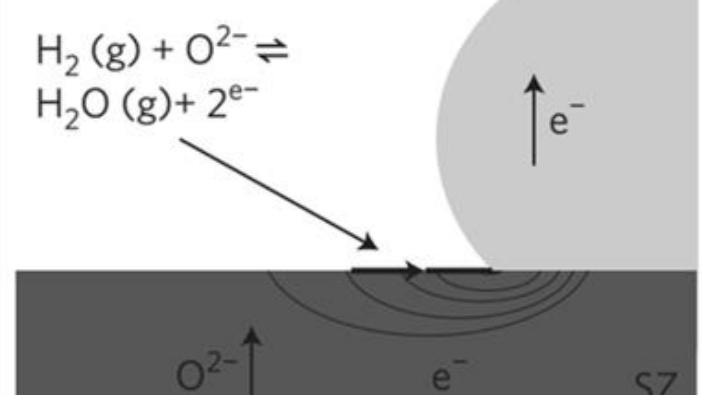

Figure 2.6. Reaction pathways of hydrogen dissociation and $\mathrm{H}_{2} \mathrm{O}$ formation [12]. 
Nickel is the most common and cost-effective electrocatalyst that reduces the hydrogen to protons. It also provides excellent electrical conductivity at the SOFC working temperature [11]. To improve the ionic conductivity of the electrode and extend the triple-phase boundary, the YSZ phase is usually mixed into the anode composition proportionally. This also helps to match the thermal expansion coefficient to the YSZ electrolyte. One drawback of Ni/YSZ cermet composite structure is the close melting temperature of nickel $\left(1455^{\circ} \mathrm{C}\right)$ relative to the anode fabrication temperature $\left(\sim 1400^{\circ} \mathrm{C}\right)$. In that sense, nickel oxide is more preferred for processing of the anode owing to it a high melting temperature $\left(1955^{\circ} \mathrm{C}\right)$. Both phases contribute to the Ni/YSZ anode during the operation due to the reduction process of $\mathrm{NiO}$ to $\mathrm{Ni}$ metal under the $\mathrm{H}_{2}$ environment. The anode structure is designed to have $20-40 \%$ porosity to facilitate gas transport. Figure 2.7displays the scanning electron microscope (SEM) image of an anode-supported cell composed of porous Ni/YSZ anode, YSZ electrolyte, and porous LSM/YSZ cathode. Despite the benefits of the nickel-based anodes, this cell architecture encounters a series of problems, including a mismatch of thermal expansion coefficients to certain electrolytes and hydrocarbon fuels/impurities poisoning. In that sense, replacing nickel with a more resistant copper reduces the carbon formation to bring fuel flexibility. Lanthanum-based perovskite anodes, $\mathrm{La}_{1-\mathrm{x}} \mathrm{Sr}_{\mathrm{x}} \mathrm{CrO}_{3}$, $\mathrm{La}_{1-\mathrm{x}} \mathrm{Sr}_{\mathrm{x}} \mathrm{Cr}_{1-\mathrm{y}} \mathrm{M}_{\mathrm{y}} \mathrm{O}_{3}(\mathrm{M}=\mathrm{Mn}, \mathrm{Fe}, \mathrm{Co}, \mathrm{Ni}), \mathrm{La}_{0.3} \mathrm{Sr}_{0.7} \mathrm{TiO}_{3}$-LST- are also alternatively used compositions for stability benefits [5]. 


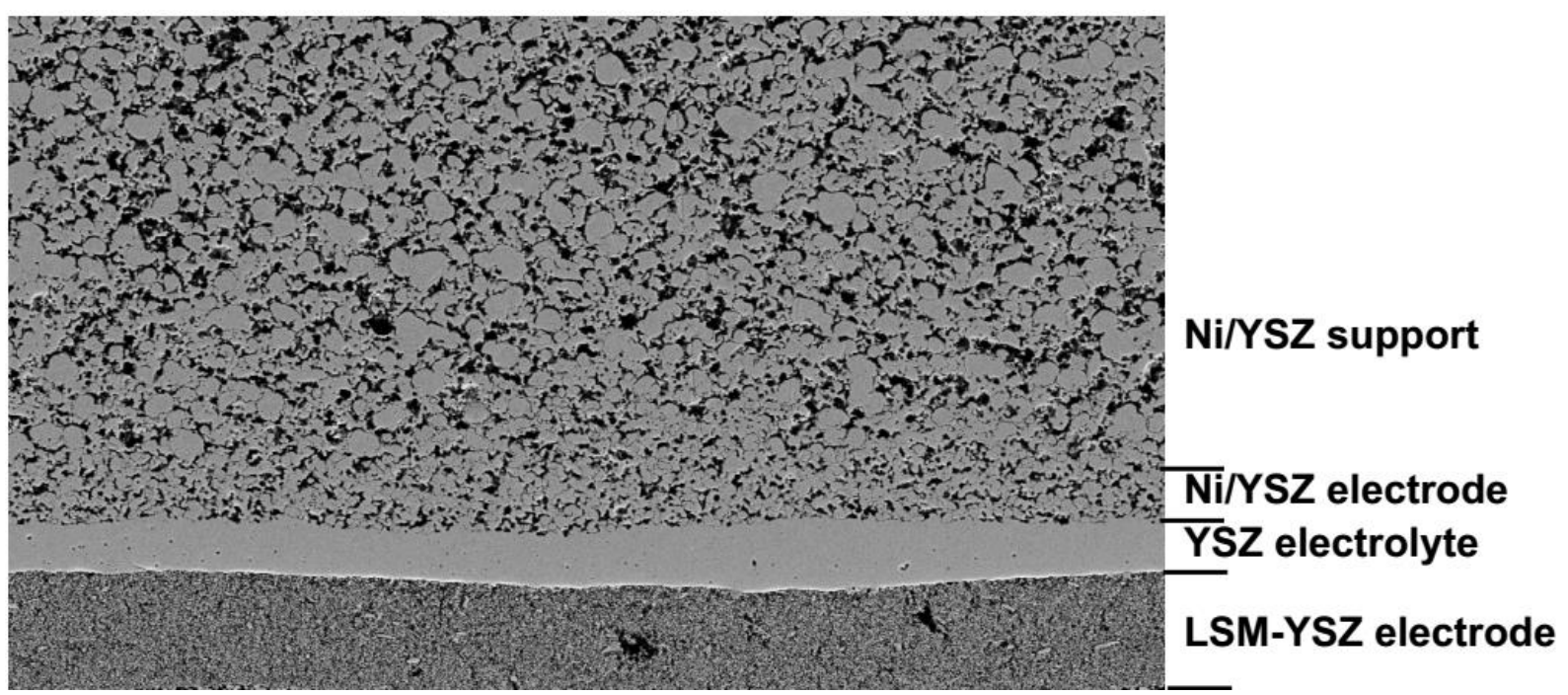

Figure 2.7. SEM anode supported cell [16].

Solid oxide fuel cells generate the electricity by direct conversion of fuel energy to electrical energy unlike conventional chemical energy to thermal energy to mechanical energy path [17]. The electrons generated at the anode electrode travel through the external circuit through the cathode electrode, and the power generation is based on the electrochemical oxidation of the fuel. As depicted above, the overall reaction is two separate reactions at the anode and cathode electrodes. If it is assumed that the hydrogen is fed to the anode as fuel and the air is fed to the cathode as oxidant, reduction and oxidation reactions conclude that the driving force of the electromotive force, emf, is given by the Nernst equation (Eq. 2.10). The equation denotes oxygen concentration gradient between the electrodes where $\mathrm{R}$ is the gas constant, $\mathrm{T}$ the temperature, $\mathrm{F}$ the Faraday constant, $\mathrm{P}_{\mathrm{O}_{2}}$ the partial pressure of at the anode, $\mathrm{A}$, and cathode, $\mathrm{C}$, electrode. Although several reactions and concentration gradients such as $\mathrm{CO}, \mathrm{CH}_{4}$, can be plugged into the Nernst equation, the ideal voltage $\left(\mathrm{E}_{\mathrm{o}}\right)$ from a single SOFC fed with $\mathrm{H}_{2}$ under open-circuit voltage is typically around 1.1 V DC. However, the useful voltage output (V) under load conditions is affected by various losses. The voltage drop depends on the current density (current per active 
electrode area, $\mathrm{A} / \mathrm{cm}^{2}$ ), temperature, gas flow rate, partial pressure and cell material [17]. The ratio of cell voltage under load to the open circuit, equilibrium voltage is called the voltage efficiency and the voltage difference is called polarization or over-voltage denoted as $\eta$. Polarization cannot be entirely excluded but can be minimized by tuning the internal and external properties/parameters of the system. Previous studies have separated total polarization of the cell into four sub-polarizations: charge/activation polarization, $\eta_{A}$, diffusion polarization, $\eta_{D}$, ohmic polarization, $\eta_{\Omega}$, and reaction polarization, $\eta_{\mathrm{R}}$, (Eq. 2.11) that would allow a complementary analysis of each polarization type.

$$
\begin{aligned}
& \mathrm{E}_{\mathrm{r}}=\frac{R T}{4 F} \ln \frac{P_{O_{2(c)}}}{P_{O_{2(a)}}} \\
& \eta=\eta_{\mathrm{A}}+\eta_{\mathrm{R}}+\eta_{\Omega}+\eta_{\mathrm{D}}
\end{aligned}
$$

Activation related polarization, $\eta_{\mathrm{A}}$, is basically the energy barrier threshold that the reactants must overcome. These losses depend on the catalytic nature and the microstructure of the electrode and reactant activity [3]. In detail, adsorption, desorption, and electron transfer capability of the electrodes drive the activation polarization. Thus, extending the triple-phase boundary and the electrocatalytic activity of the anode determines the charge transfer process [18] Reactant polarization, $\eta_{\mathrm{R}}$, has the least significant role in the total polarization. It is driven by the supplied cell reactants and removal of products. Reactant polarization is usually small at operating temperatures. Ohmic polarization, $\eta_{\Omega}$, is caused by the electronic resistance through electrodes and ionic resistance through the electrolyte. SOFC materials selection and stack current collection components directly affect the ohmic polarization. For anodes, the internal resistance is determined by the electronic resistivity of the material and the thickness of anode. Diffusion polarization, $\eta_{D}$, is also referred as mass-transport related polarization [17]. Apart from the reactant (fuel and oxidant) activity, electrode porosity dominates diffusion polarization. As mentioned previously, 
electrodes are manufactured porous to avoid gas starvation issues which directly affect the electrode performance. It has been reported that more than $30 \%$ percolated porosity is required to facilitate the transport of reactant and product gasses for Ni-YSZ system [18]. Figure 2.8 shows the typical current-voltage (IV) curve of a fuel cell and regions are labeled with the driven polarization type. According to the kinetics factors addressed as structure or material properties above, mitigation of voltage degradation under the current, in other words, achieving high power density, can still be attained by modifying the addressed structure or material property.

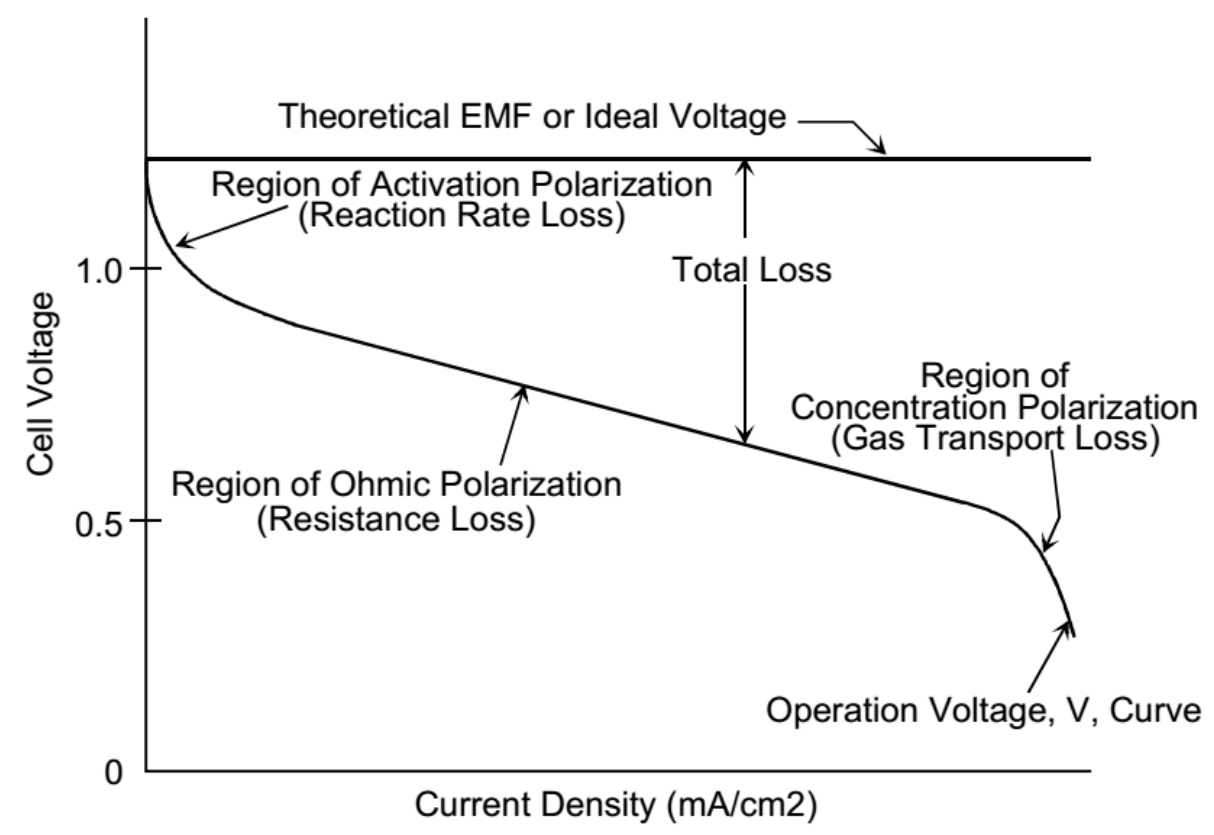

Figure 2.8. Ideal and actual fuel cell voltage/current characteristic with responsible polarization loss regions [3].

Conventional Ni/YSZ anodes provide a satisfactory catalytic activity for hydrogen oxidation and steam reforming of methane gas for syngas production. While Ni/YSZ anodes have such benefits in many aspects, the nickel has some major drawbacks that gradually affect the cell 
SOFC performance. Although $\mathrm{Ni}$ is stable in a hydrogen environment, it catalyzes the formation of carbonaceous deposits that foul the anode under hydrocarbon exposure [19]. Moreover, sulfur impurities as low as $1 \mathrm{ppm}$ in the fuel causes $\mathrm{Ni}$ deactivation by poisoning [20]. Long term and redox stability of conventional Ni/YSZ fuel electrodes are disturbed by the sintering, grain growth, and agglomeration of nickel phase [21, 22]. High-Temperature sintering that is needed to achieve good bonding and contact between the $\mathrm{NiO} / \mathrm{YSZ}$ phase causes initial grain growth for both $\mathrm{NiO}$ and YSZ phases. During the reduction stage of $\mathrm{SOFC}, \mathrm{NiO}$ in the ceramic electrode reduces to $\mathrm{Ni}$, resulting in $\sim 26 \%$ volume reduction with finer particle sizes. It has been studied that the poor wettability between Ni metal and YSZ phase accelerates agglomeration and grain growth of $\mathrm{Ni}$ phase which reduces the TPB area at the electrode/electrolyte interface [23].

As depicted above, one advantage of SOFCs is the fuel selection flexibility, so hydrogen or various hydrocarbons can be considered. Naturally, these fuels contain minor impurities at the ppm level. Considering the high current passing through the current collectors, high operational pressure, and the use of inexpensive, hence high impurity materials, contamination of those constituents can be fatal to electrode structure and performance [24]. The phenomenon called poisoning seriously affects cell life and stability in a few hours. Both catalytic hydrogen dissociation and TPB activity are seriously disturbed by poisoning. Shown in Figure 2.9 are possible degradation types resulting from specific contaminants on the conventional Ni/YSZ anode structure. In summary, at low concentrations of sulfur, adsorption type poisoning is driven and $\mathrm{NiS}$ forms on the nickel surface and TPB, which blocks the $\mathrm{O}^{-2}$ pathway (Figure 2.9.a). Chlorine impurity bonds with nickel and forms gaseous $\mathrm{NiCl}_{2}(\mathrm{~g})$. This type of reaction is called sublimation type poisoning and causes Ni loss out the structure (Figure 2.9.b). In deposition type poisoning, siloxane triggered $\mathrm{SiO}_{2}(\mathrm{~s})$, and fuel triggered carbon and sulfur deposits could be observed. Again, 
these deposits grow at the TPB region and block the ionic pathway (Figure 2.9.c). Specifically, carbon deposition is called coking in the literature. At higher sulfur concentrations, $\mathrm{Ni}_{3} \mathrm{~S}_{2}$ solid phase forms at the $\mathrm{Ni}$ surface below $600^{\circ} \mathrm{C}$. This type of poisoning is called reaction type poisoning (Figure 2.9.d). This secondary phase reaction also decreases the melting point of Ni to only above $800^{\circ} \mathrm{C}$ by making a eutectic point. (Figure 2.9.f). With the presence of boron, grain growth of nickel is observed which adversely affects long term durability and electronic conductivity (Figure 2.9.e)

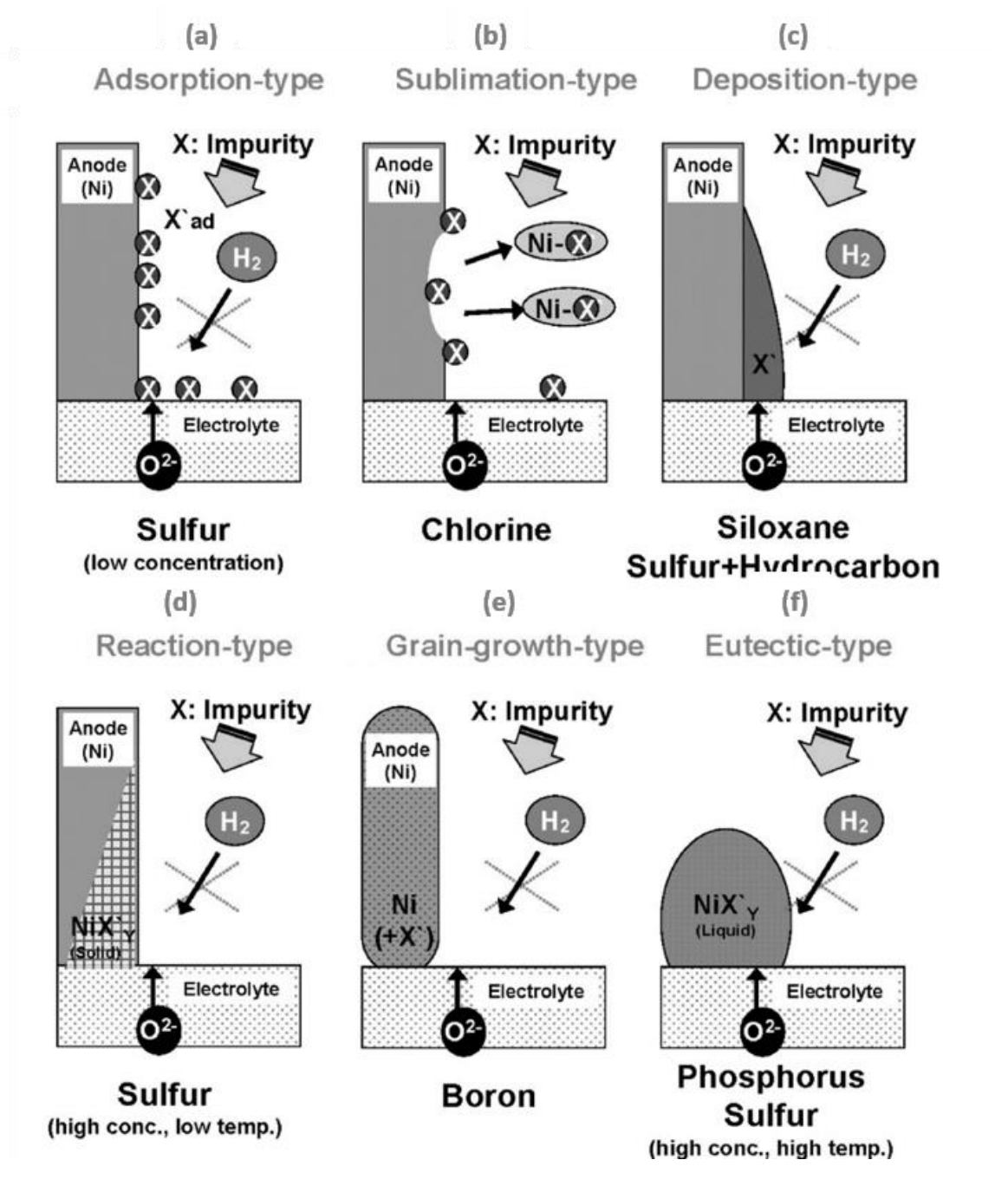

Figure 2.9. Possible impurity poisoning mechanisms of SOFC anodes [24]. 
Among these types of poisoning, sulfur and carbon poisoning are the most studied types. Studies are divided into two areas. One side is finding alternative anode materials such as perovskite ceramic compositions, that are resistant to sulfur poisoning and coking. The other side of research interest is to mitigate and control the poisoning of existing anode compositions by adding a protective second phase into the system. Mainly, $\mathrm{H}_{2} \mathrm{~S}$ gas reacts with nickel and forms a second phase, $\mathrm{NiS}$, which deteriorates the migration of $\mathrm{O}^{2-}$ ions towards to the TPB. The damaging mechanism of sulfur over Ni/YSZ anode can either be by physical adsorption, sulfidation or chemisorption. These mechanisms result in different types of degradation depending on the $\mathrm{H}_{2} \mathrm{~S}$ concentration and fuel type. In addition, $\mathrm{Ni}_{3} \mathrm{~S}_{2}$, another impurity phase, the formation cannot be recovered and damages the cell [25]. The formation of the sulfide phase is given below in Eq. 2.12-2.14.

$$
\begin{aligned}
& \mathrm{H}_{2} \mathrm{~S}(\mathrm{~g}) \Leftrightarrow \mathrm{HS}_{\mathrm{ads}}+\mathrm{H}_{(\mathrm{g} / \mathrm{ads})} \Leftrightarrow \mathrm{S}_{\mathrm{ads}}+\mathrm{H}_{2 \text { (g/ads })} \\
& 3 \mathrm{Ni}+\mathrm{xH}_{2} \mathrm{~S} \Leftrightarrow \mathrm{xH}_{2}+\mathrm{Ni}_{3} \mathrm{~S}_{\mathrm{x}} \\
& \mathrm{Ni}+\mathrm{H}_{2} \mathrm{~S} \Leftrightarrow \mathrm{H}_{2}+\mathrm{NiS}
\end{aligned}
$$

Coking, or carbon poisoning, also opened various research areas including new anode compositions or modification of microstructures of existing anode systems. Carbon deposition on the Ni/YSZ system results from different reactions and temperature ranges. The type of carbon also ranges by gas type and temperature (Figure 2.10.a). It has been found that carbon deposit formation occurs when atomic carbon, $\mathrm{C}_{\alpha}$, is excessively produced and saturated by a metal catalyst. Hence unbonded adsorbed $\mathrm{C}_{\alpha}$ forms a polymeric form of carbon, $\mathrm{C}_{\beta}$ due to lack of oxygen. Likewise, whisker/fiber carbon, $\mathrm{C}_{\mathrm{v}}$, and graphitic carbon, $\mathrm{C}_{\mathrm{C}}$, forms in the anode metal structure (Figure 2.10.c). All the carbon deposits cause rapid degradation in the fuel cell. It was reported that $\mathrm{C}_{\mathrm{C}}$ and $\mathrm{C}_{\beta}$ form a barrier film over the metal catalyst surface and deactivates the metal 
backbone function (Figure 2.10.b) $[25,26]$. Besides, $\mathrm{C}_{V}$ causes a breakdown in catalysis (Figure 2.10.d). These poisoning mechanisms can cause a rapid voltage decrease. To achieve long term stability from SOFC's with coke free anode electrodes, microstructural and materials reconsiderations should be taken.
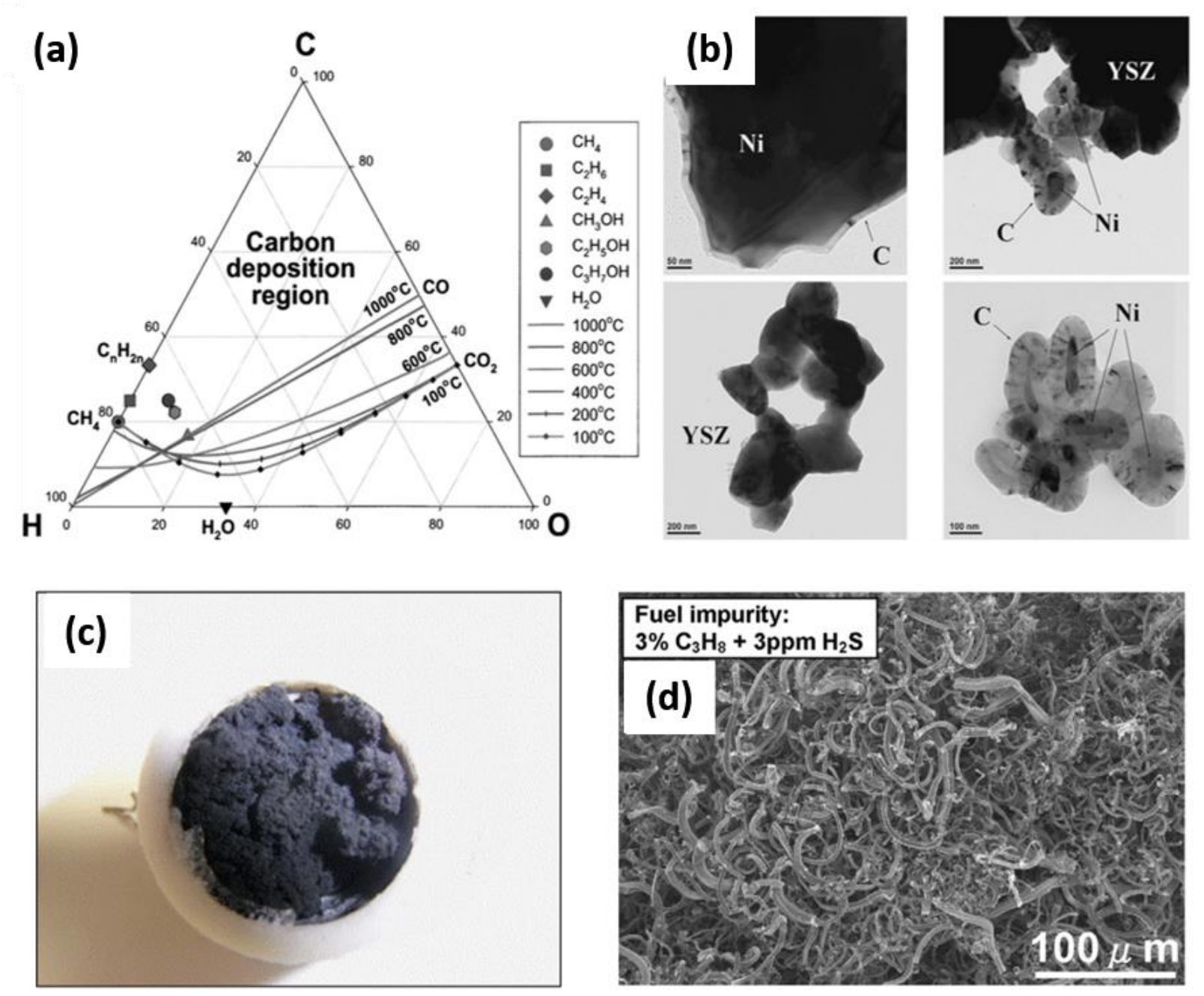

Figure 2.10. Determination of carbon formation region (a) C-H-O ternary phase diagram [25, 27] (b) Coking of a Ni/YSZ anode as found in TEM [25, 26] (c) Ni/YSZ anode surface after test (200 h) in $\mathrm{H}_{2}$ by mixing $3 \% \mathrm{C}_{3} \mathrm{H}_{8}$ and 3 ppm $\mathrm{H}_{2} \mathrm{~S}$ [24] (d) FESEM image of deposited carbon on the Ni/YSZ anode surface after $\mathrm{H}_{2}-3 \% \mathrm{C}_{3} \mathrm{H}_{8}-3$ ppm $\mathrm{H}_{2} \mathrm{~S}$ for $200 \mathrm{~h}$ [24]. 


\subsubsection{Nanostructured Electrodes}

In SOFC's, the interest of nanoscale materials usage has been progressively increasing. Owing to the high surface area, TPB/DPB can be extended, ionic and electronic conductivity can be improved, and surface vacancy concentration of the catalysts can be enhanced. On the whole, interfacial electrochemical activities can be promoted. However, constructing the entire electrode(s) causes potential inevitable structural instabilities due to the grain growth mechanism promoted by SOFC operating temperature ranges [21]. Thus, both nano and micron-sized particles should be incorporated for electrodes. A conventional micron-sized backbone structure is used to keep the stability while nano-structured particles enhance overall fuel cell performance. Usually, the conventional sintering temperature of anode constituents is around $1300-1400{ }^{\circ} \mathrm{C}$, and after this high-temperature sintering step obtaining micron-sized particles is inevitable.

In contrast, the decomposition temperatures of metal nitrates are between 500 to $850^{\circ} \mathrm{C}$, which are much lower than the electrode sintering temperature and very close to the SOFC operation temperature. Thus, nanoparticles can be formed by introducing metal nitrate solution to a sintered electrode backbone structure.

One way to introduce nanomaterials within the electrode microstructure is called infiltration or impregnation method. The following subsections of this chapter aim to give an introduction to the infiltration method and materials for evaluating a functional SOFC anode that consists of nanoparticles.

\subsubsection{Microstructure Engineering by Nanomaterial Infiltration}

There are two main functions for depositing nanoparticles within as-sintered electrodes i) to add catalytic role ii) to enhance conduction pathways critically related to triple phase boundary 
(TPB) length where ionically conductive (i.e., YSZ) and/or electrically conductive (i.e., Ni) constituents are in contact with the anode electrode.

There are few strategies to construct an anode depending on the backbone structure, in the literature, Table 1 summarizes the possible scenarios for existing anode backbone before infiltration. Depending on the anode backbone function, the optimum amount of nanoparticle material, as infiltrated material, can be engineered and introduced into the structure.

Table 1. Backbone and nanoparticles functions in each electrode class. Adapted from [28].

\begin{tabular}{|c|c|c|}
\hline Porous electrode class & Backbone function & Nanoparticle function \\
\hline $\begin{array}{l}\text { Single component electrode } \\
\text { composition }\end{array}$ & $\begin{array}{l}\text { i) Oxygen ion conduction } \\
\text { (YSZ, GDC) } \\
\text { ii) Electron ion conduction } \\
(\mathrm{Ni}-\mathrm{Cu})\end{array}$ & $\begin{array}{l}\text { i) Global electron supply, } \\
\text { electrocatalyst }(\mathrm{Ni}, \mathrm{Cu}, \mathrm{Co}) \\
\text { ii)Local oxygen ion } \\
\text { conductivity (YSZ, doped } \\
\mathrm{CeO}_{2}\end{array}$ \\
\hline $\begin{array}{l}\text { MIEC } \\
\text { (Mixed Ionic Electronic } \\
\text { Conductor) }\end{array}$ & $\begin{array}{l}\text { Oxygen ion and electron } \\
\text { conduction, electrocatalyst } \\
\left(\mathrm{LCrM}, \mathrm{SrTiO}_{3}\right)\end{array}$ & $\begin{array}{l}\text { Secondary ionic or electronic } \\
\text { pathway, electrocatalyst } \\
\left(\text { doped } \mathrm{CeO}_{2} \text { ) }\right.\end{array}$ \\
\hline Composite / Cermet & $\begin{array}{l}\text { Global oxygen ion and } \\
\text { electron conductivity, } \\
\text { electrocatalyst (Ni-YSZ, Cu- } \\
\text { YSZ }\end{array}$ & $\begin{array}{l}\text { Local oxygen and electron } \\
\text { conductivity, electrocatalyst } \\
\left(\mathrm{Ni}, \mathrm{Cu}, \mathrm{Co} \text {, doped } \mathrm{CeO}_{2}, \mathrm{Pd} \text {, }\right. \\
\mathrm{Ru}, \mathrm{Pt})\end{array}$ \\
\hline
\end{tabular}


In the literature, anode SOFC infiltration/impregnation study has had progressive attention over recent years, pioneered by Gorte et al. [29-32]. Due to the ease of infiltration application and the methodological needs, there is increasing interest as evidenced by published papers in this area over the years, as shown in Figure 2.11. Among the reviewed studies, it has been observed that the advancement of conventional $\mathrm{YSZ}$ and $\mathrm{Ni} / \mathrm{NiO}$ backbone structures have been mostly studied (Figure 2.12). Alternatively, promising new perovskite MIEC compositions have also been chosen to facilitate desired properties such as electronic, ionic conductivity or electrocatalytic activity. Finally, Figure 2.13 assesses the literature in the infiltrated phase perspective. Initially, precious metal infiltrations were experimented starting from the early stages. However, it should be noted that $\mathrm{Ni}$ is the most chosen electrically conductive/catalyst phase. By experiencing the limitations/problems of micron-sized Ni particles in the anode electrode, studies have aimed to overcome those issues by downsizing the particle diameter with a homogeneous dispersion within the backbone structure. Moreover, there has been considerable attention of modified ceria, $\mathrm{CeO}_{2}$, based nano-catalysts infiltration. Gadolinium, Gd, strontium, Sr, zirconium, Zr, molybdenum, Mo have been used as modifiers for ceria to enhance the catalytic activity, ionic conductivity and mitigate the grain growth of the backbone. Also, few studies on tungsten-based, $\mathrm{NaWO}_{3}, \mathrm{KWO}_{3}$, and titanate based, $\mathrm{LaSrTiO}_{3}$, perovskite systems have also been infiltrated to various backbone structures. 


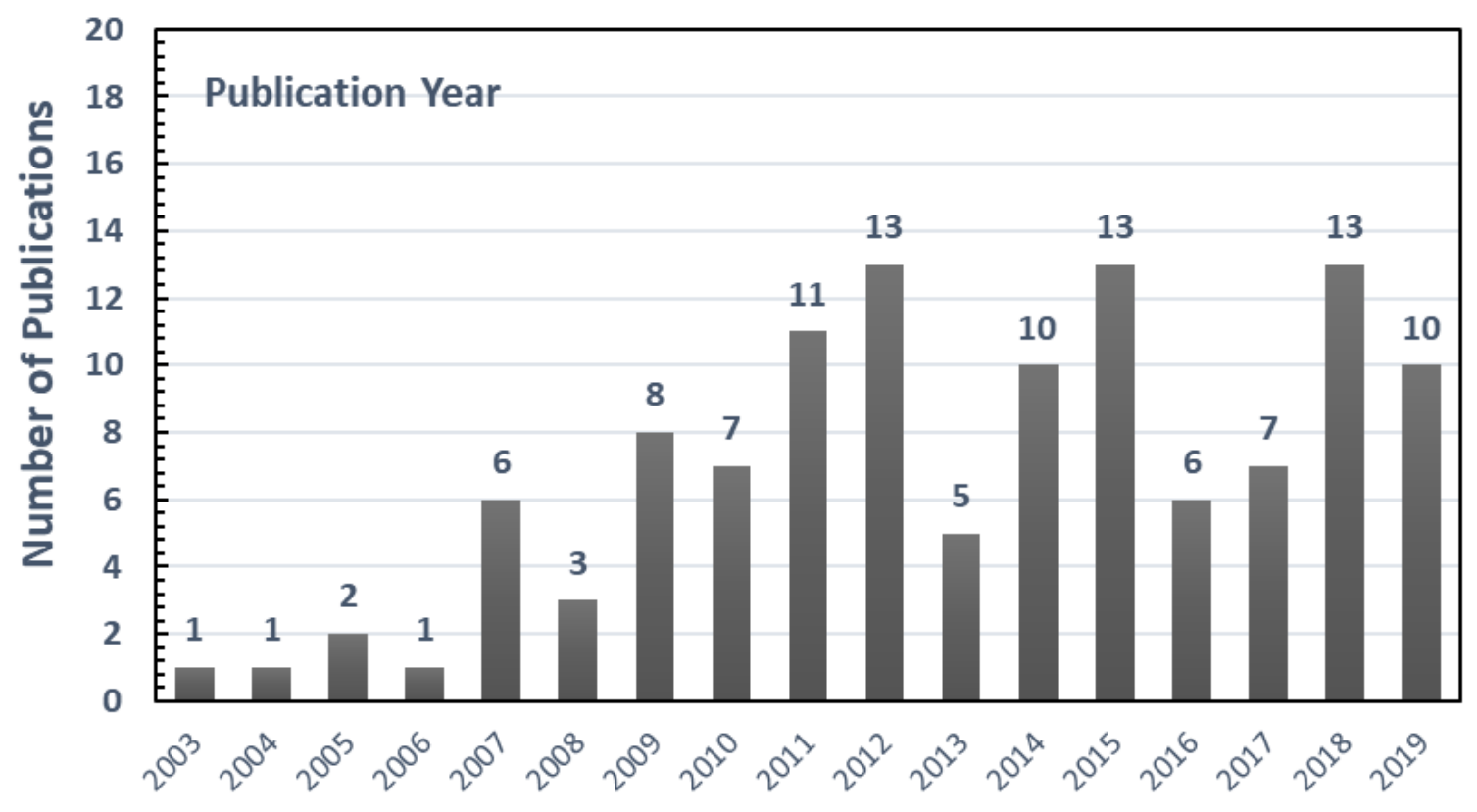

Figure 2.11. Published anode infiltration studies in recent years [29-152]

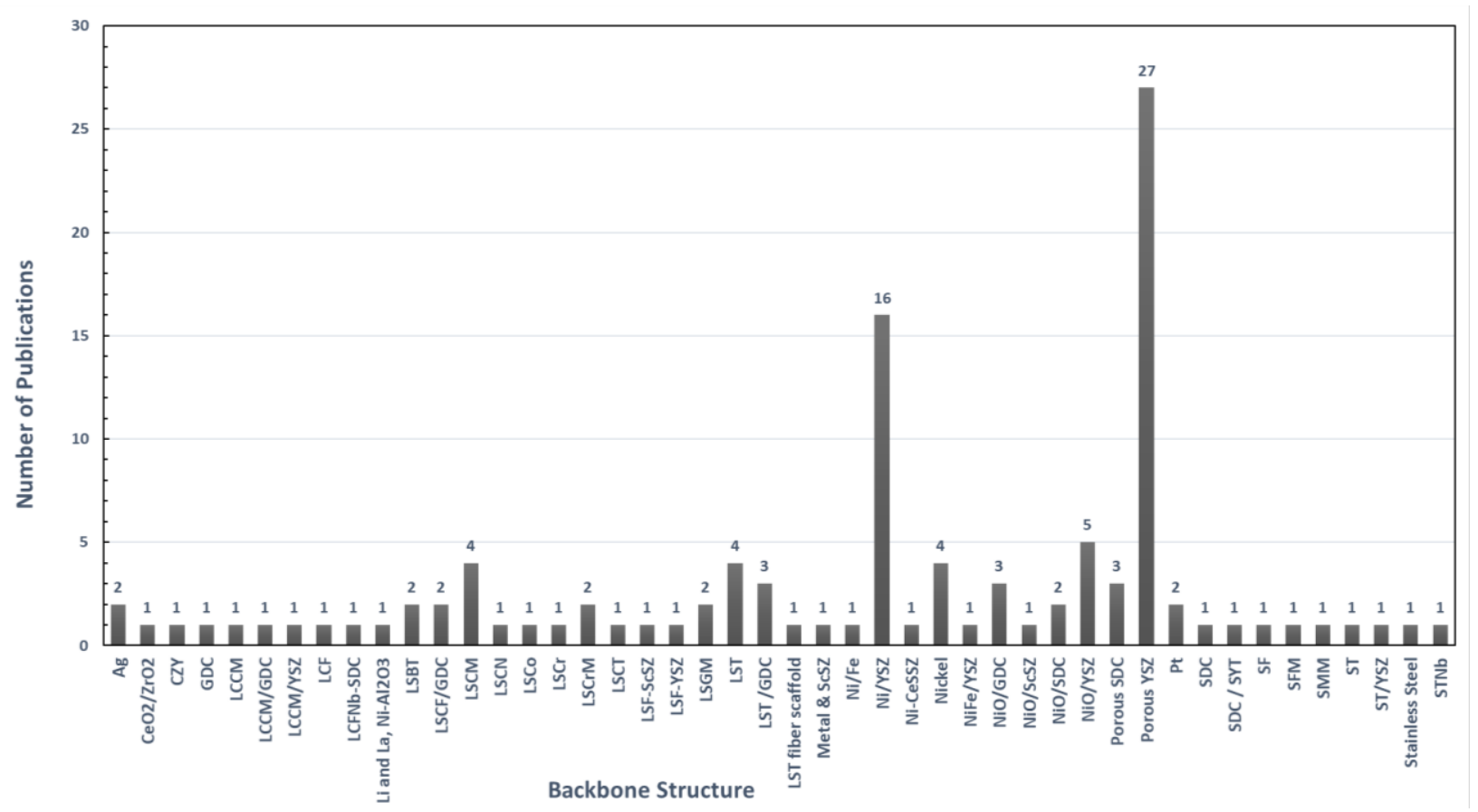

Figure 2.12. Backbone structures of infiltrated anodes in recently published studies [29152]. 


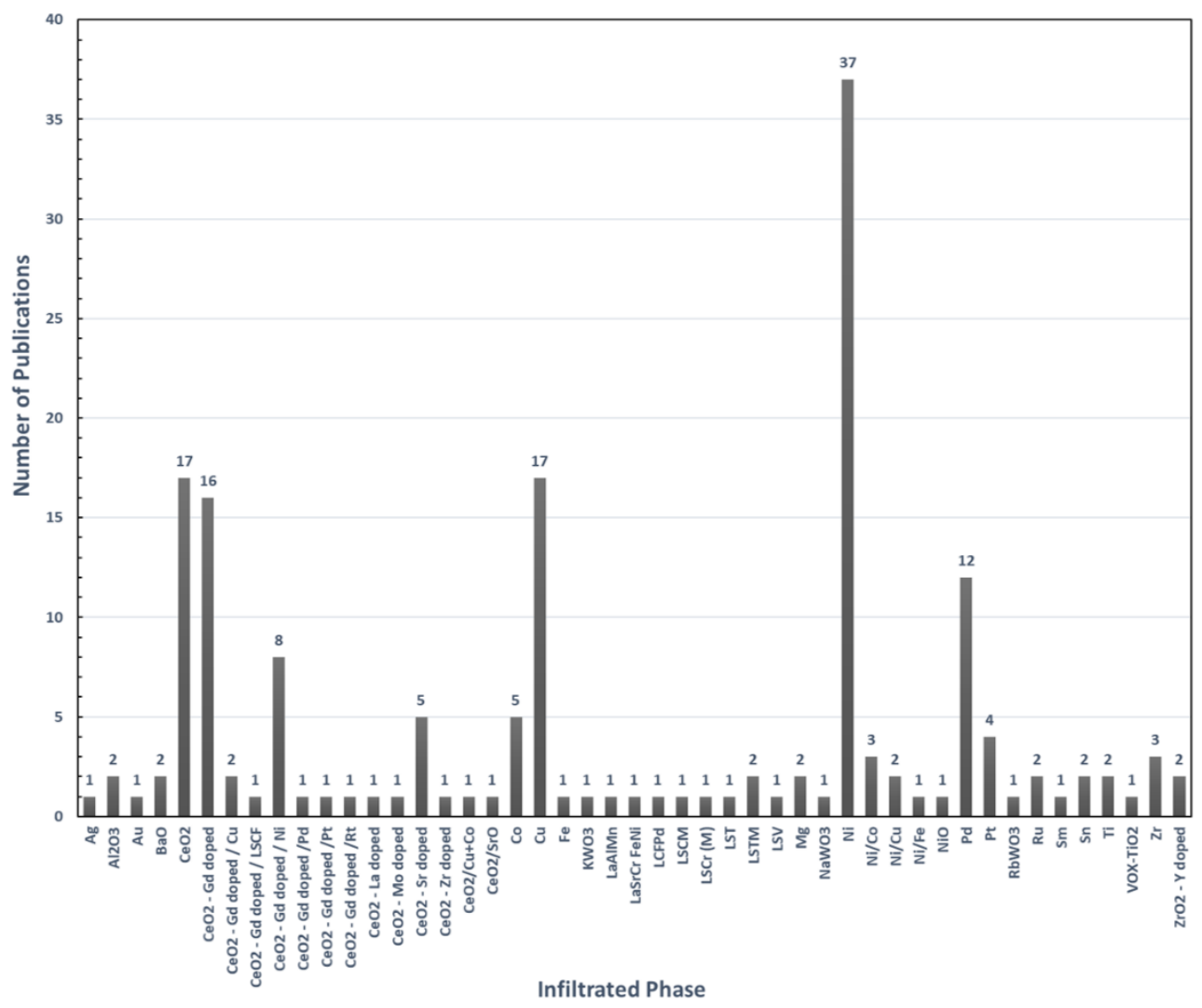

Figure 2.13. Infiltrated material compositions in recently published studies [29-152].

\subsubsection{Selected Strategies of Infiltration on SOFC Anode Electrode}

\subsubsection{Electrochemical Performance Enhancement by Catalyst Infiltration}

The conductive nickel phase at the anode electrode has been known to have catalytic, fueldissociation character. However, this property strongly depends on the particle size and the dispersion of the phase in the structure. Gorte et al. have noted that noble metals such as Pd, Pt, $\mathrm{Au}$, and $\mathrm{Ru}$ also improved catalytic activity $[30,35,36,47,48,51,59,60,63,71,93,106,112$, $117,132,136,139,153,154]$. Due to the cost restrictions, the use of these precious materials can only be viable by liquid infiltration. Figure 2.14 illustrates the ideal case of isolated nanoparticle island deposition on the porous backbone structure that creates new TPB [155]. By tuning the infiltration step or the concentration of the precursor, particles can either be deposited discretely 
or in a connected network. Another catalytic material doped ceria (XDC, X=Metal), attracted attention due to its flexibility of use either in the anode or cathode or even the electrolyte material $[30,32,37,42,44,45,51,53,58,59,61,63,64,69,72,76,77,80,83,87,91,96,99,100,102$, 103, 105, 107, 109, 113, 121, 122, 130, 134, 140, 147] . For example, gadolinium-doped ceria (GDC) acts as an ionic conductor, and also by switching the valence character of ceria from +4 to +3 repeatedly, nanoparticles can achieve hydrogen storage capability. The study by S. P. Jiang has been one of the trend-changing research for increasing the performance of conventional anodes by using the cost-effective catalyst GDC [53]. Highly concentrated $\mathrm{Gd}\left(\mathrm{NO}_{3}\right)_{3}$ and $\mathrm{Ce}\left(\mathrm{NO}_{3}\right)_{3} \cdot 6 \mathrm{H}_{2} \mathrm{O}$ metal nitrates were dissolved in water, and the solution is dripped over the nickel anode surface. As a result, the particle size of infiltrated GDC particles was around 100-200 nm in the nickel anode backbone. Figure 2.15 shows the impedance curves of the cells during the operation at different temperatures [53]. It can be seen that GDC infiltration reduced impedance arcs expressively for each temperature. For instance, at $700^{\circ} \mathrm{C}$, electrode resistance, $\mathrm{R}_{\mathrm{E}}$, decreased from $10.7 \mathrm{ohm} \cdot \mathrm{cm}^{2}$ to $4.9 \mathrm{ohm} \cdot \mathrm{cm}^{2}$ by one step infiltration $\left(0.52 \mathrm{mg} / \mathrm{cm}^{2}\right)$ whereas double-step infiltration $\left(1.7 \mathrm{mg} / \mathrm{cm}^{2}\right)$ decreased the $\mathrm{R}_{\mathrm{E}}$ even further to $1.5 \mathrm{ohm} \cdot \mathrm{cm}^{2}$. It should be noted that the starting points of the arcs are also shifted towards to left which was mainly due to the promotion of ionic conductivity by the GDC phase. 


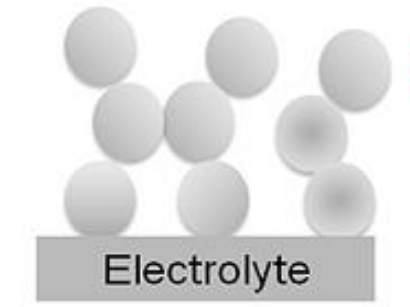

Rigid electrode/electrolyte scaffold/skeleton structure

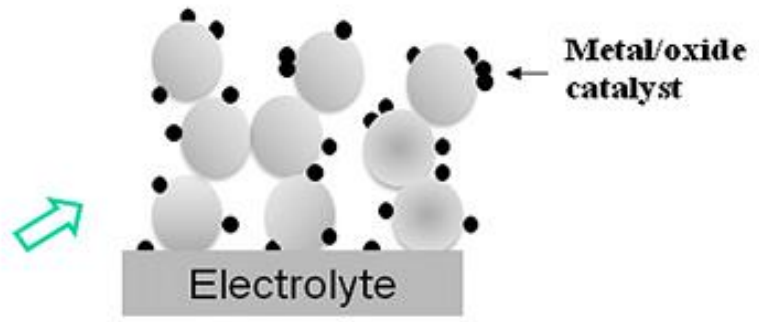

Discretenanoparticles

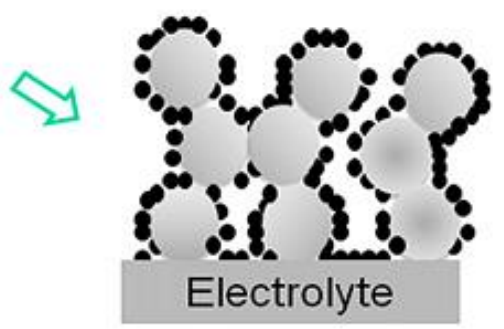

Continuousnanoparticles

Figure 2.14. Scheme of the infiltrated nano-structured electrodes on pre-sintered porous electrode or electrolyte [155]. 

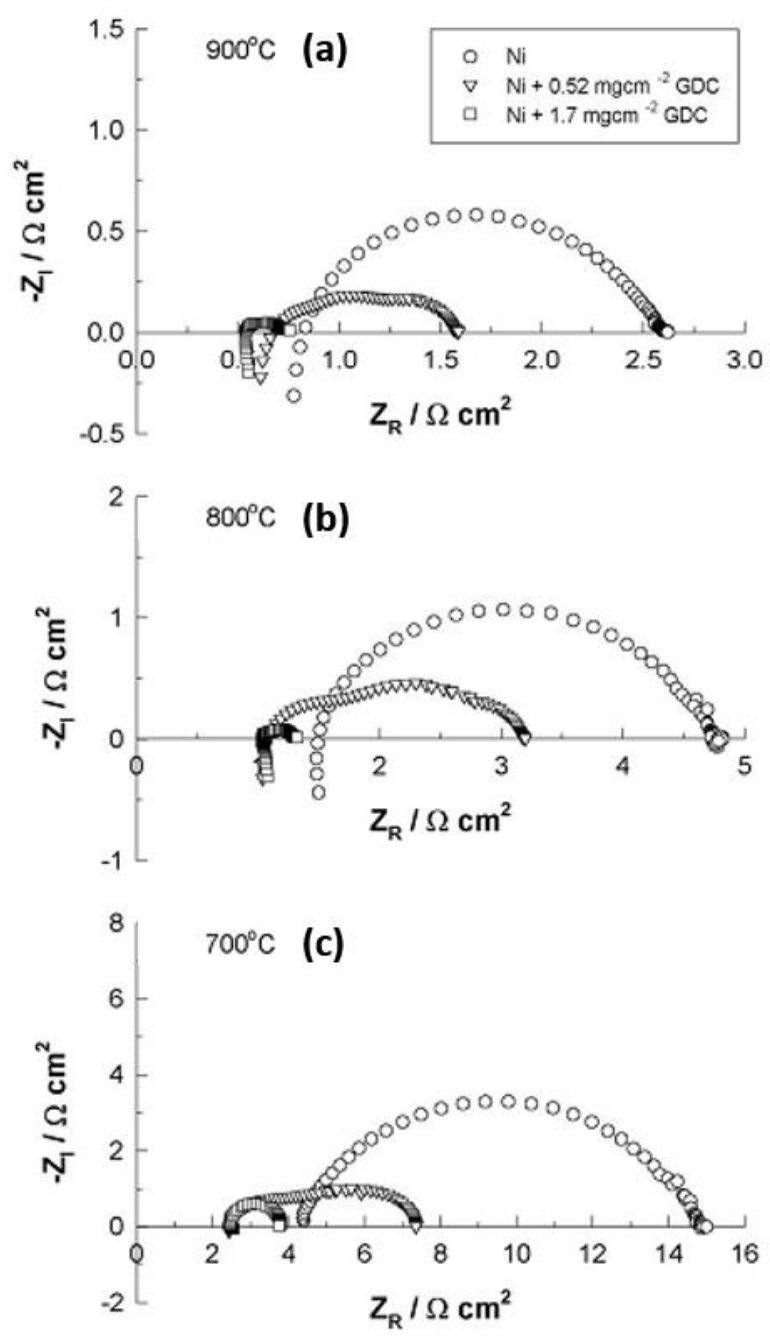

Figure 2.15. Impedance spectra for $\mathrm{H}_{2}$ oxidation on pure $\mathrm{Ni}$ and $\mathrm{Ni}$ anode with 0.52 and $1.7 \mathrm{mg} \mathrm{cm}-2 \mathrm{GDC}$ infiltration at (a) $900{ }^{\circ} \mathrm{C}$, (b) $800^{\circ} \mathrm{C}$, and (c) $700^{\circ} \mathrm{C}[53]$.

\subsubsection{Redox Stabilization}

Solid oxide fuel cells are designed to operate continuously as long as the gas is fed. In case of intentional or mistaken interruptions in the fuel flow, the anode undergoes several oxidationreduction cycles, which are called redox reactions. During these reactions, anode materials must withstand and stay stable in these reactions. However, for Ni-based anodes, significant volume changes can be observed due to the phase change between $\mathrm{Ni}$ to $\mathrm{NiO}$. The oxidation of $\mathrm{Ni}$ to $\mathrm{NiO}$ causes a volume expansion of $69.2 \%$, and during the reduction, the volume shrinks to $40.9 \%$ 
[156]. Due to the brittle nature of the ceramic materials, these stresses cause micro-cracks in the network which disturb the oxygen ion collection and also cause cell failure when it is not compensated by the porosity of the electrode as seen Figure 2.16. There have been some precautions held to hinder this mechanism, such as improving the strength of the material for higher redox tolerance $[44,50,92,110,115,141,157]$, but one approach to overcome massive volumetric change is to infiltrate Ni precursor to the YSZ network. After low-temperature firing, nano nickel/nickel oxide particles can be formed onto the YSZ phase. This weak nickel phase does not cause stress during the redox cycles, and hence long term stability can be achieved [38]. The SEM image of such engineered cermet composites shows a continuous but thin coating over YSZ surface which EDX spectroscopy mapping identified as a homogenous distribution of the Ni phase within the cermet (Figure 2.16.b). 
(a)

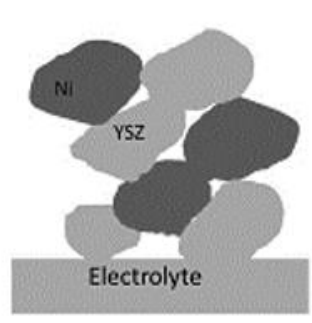

Initial State (Ni-YSZ)

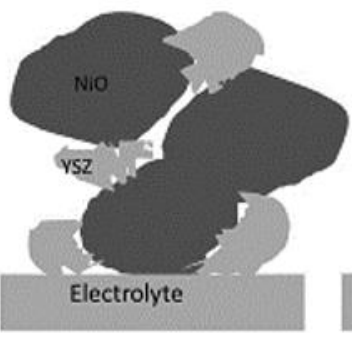

Oxidized state (NiO-YSZ)

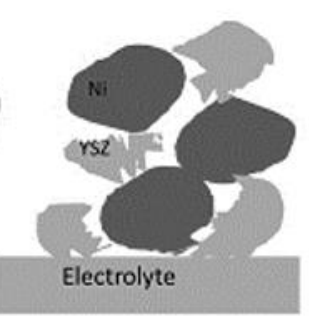

Re-reduced state (Ni-YSZ)

(b)

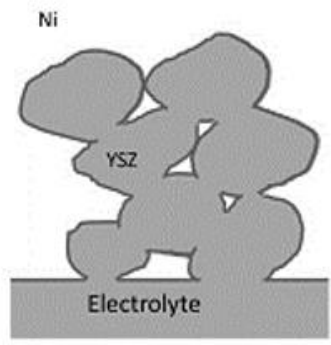

Initial State (Ni-YSZ)

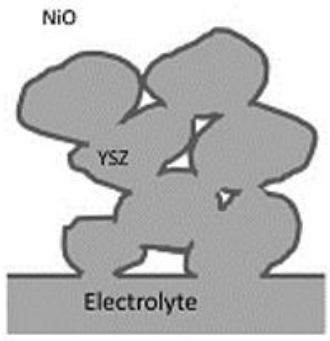

Oxidized state (NiO-YSZ)

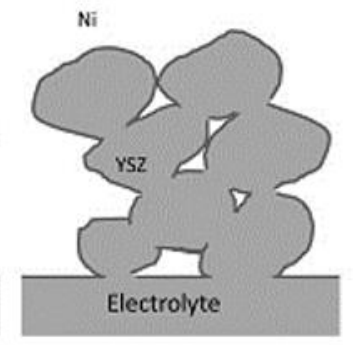

Re-reduced state (Ni-YSZ)
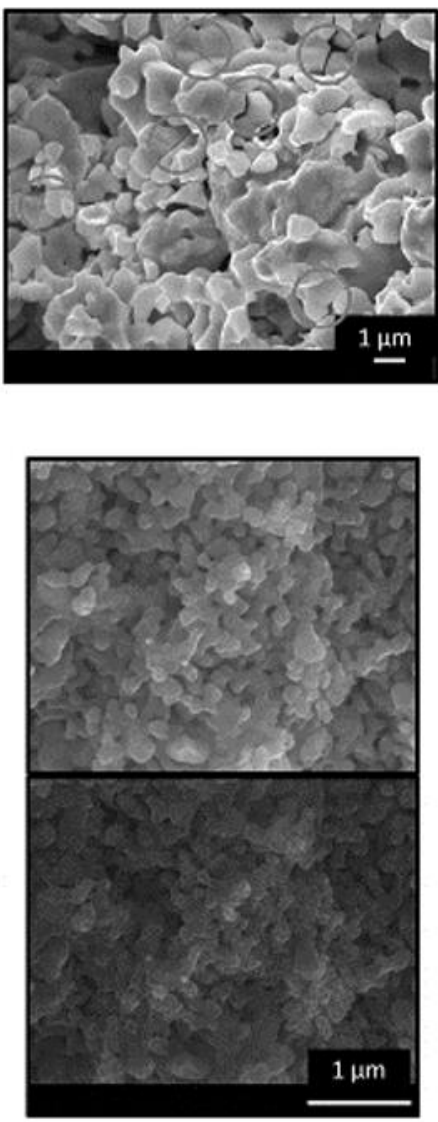

Figure 2.16. (a) Schematic representation of the changes occurring the conventional NiYSZ cermet prepared by high temperature co-sintering and the scanning electron microscopy image showing the actual microstructure of such a cermet after redox cycling (b) Schematic representation of the change occurring Ni-YSZ structure obtained by polymeric precursor infiltration, scanning electron microscopy images showing the general microstructure of such a cermet (upper) and the energy dispersive X-ray spectroscopy mapping showing the distribution of Ni phase [38].

Furthermore, sintering related cracks at the contact area of the porous YSZ backbone can deviate to micron-sized cracks on a dense electrolyte and hence resulted in a reduction in the conductivity. By infiltrating YSZ precursor to YSZ backbone, those weak contact areas can be covered by nano-YSZ particulates which reinforces the structure after heat treatment and redox 
reactions. As tabulated in Figure 2.17, YSZ and nickel infiltrated cells on a porous YSZ backbone (white and blue data points) had a stable conductivity value as a function of redox cycles which supported the mechanism mentioned above. However, only the nickel infiltrated cell (35 vol \%) showed continuous degradation. The studies [38-40] showed that constructing the whole anode by infiltration was an effective method to obtain redox stability.

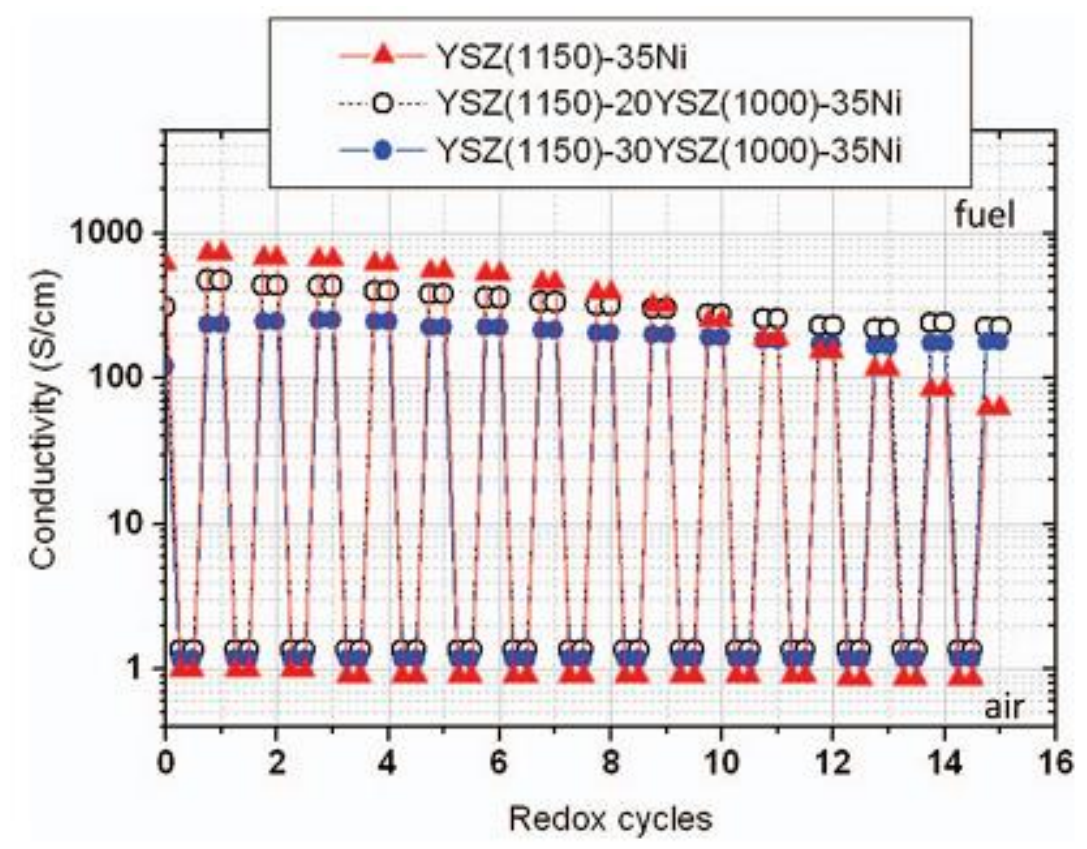

Figure 2.17. Changes in the electrical conductivity of the samples YSZ (1150)-35 Ni, YSZ (1150)-20YSZ(1000)-35Ni and YSZ(1150)-30YSZ(1000)-35Ni upon redox cycling at $800^{\circ} \mathrm{C}[40]$.

\subsubsection{Coking and Sulfur Toleration}

As mentioned previously, utilization of hydrocarbon fuel such as natural and shale gas is a promising area in SOFC's. However, these fuels have a degree of undesired contaminants such as $\mathrm{H}_{2} \mathrm{~S}$ and carbon deposits which restrict their use in SOFC technology due to their detrimental nature. 
To suppress carbon deposition, there are four possible strategies in the SOFC system. The first two are passing the fuel through an external reforming unit before the anode feed and/or purging a high steam-to-fuel ratio ( $>2$ for methane) to bond all the adsorbed carbon with excess oxygen [96]. The third strategy is constructing a non-coking anode system mainly perovskite ceramic or $\mathrm{Cu} / \mathrm{Ceria}$ based anodes. However, those systems have inferior catalytic or electronic properties $[5,10,158,159]$. The infiltration of coke-resistant materials to conventional Ni/YSZ cermet is the fourth possible strategy. It has been known that some precious metals ( $\mathrm{Au}, \mathrm{Sn}, \mathrm{Ru}$, $\mathrm{Rh}, \mathrm{Pd}, \mathrm{W}, \mathrm{Pt}$,) transition metals (Cu, Sn, Sm, ), alkaline earth metal (Ba) $[32,35,42,46,47,66$, $71,73,84,94-96,98-100,105,116,148,160-166]$ can be infiltrated for this purpose.

The first infiltration studies were carried out for direct utilization of hydrocarbons by infiltrating precious metals by Gorte et al. $[29,153]$ almost two decades ago. By the introduction of a small amount of precious metal (1\% Pd) into the ceria-YSZ cell, anodes can dissociate $\mathrm{CH}_{4}$ at $923 \mathrm{~K}$ with increased power density.

A study by Wu et al. infiltrated Ag on Ni/YSZ system as a coke-resisting material [96]. Among other proven coke-resistant precious metals, silver is one of the cost-effective and low resistivity candidates of intermediate temperature, IT-SOFCs. Ag infiltration was performed by the dripping method applied to the Ni/YSZ surface. Three different Ag loadings were chosen by tuning the precursor concentration. Figure 2.18 showed that high silver loading influences the initial particle and the dispersion of the Ag particles as well. The microstructure of the highest Ag loaded sample (Cell C) had around $5 \mu \mathrm{m}$ flakes with nearly full coverage of surface while other samples (Cell A and B) showed smaller particle size and discrete dispersion. Stability tests revealed that the baseline cell failed within 5 hours under $\mathrm{CH}_{4}$ and all the infiltrated cells displayed better stability than the baseline cell (Figure 2.19). The results indicate that silver infiltration 
improved carbon tolerance. Among the infiltrated cells, cell B ran steadily, meaning that critical particle size, solid loading and surface coverage played a role to passivate carbon formation. The detailed study exposed that infiltration of even small amounts of catalytic material (less than $2 \mathrm{wt}$. $\%$ ) assisted to dissociate $\mathrm{CH}_{4}$ fuel but suppressed coking of the whole anode by also promoting carbon separation into small islands [96].
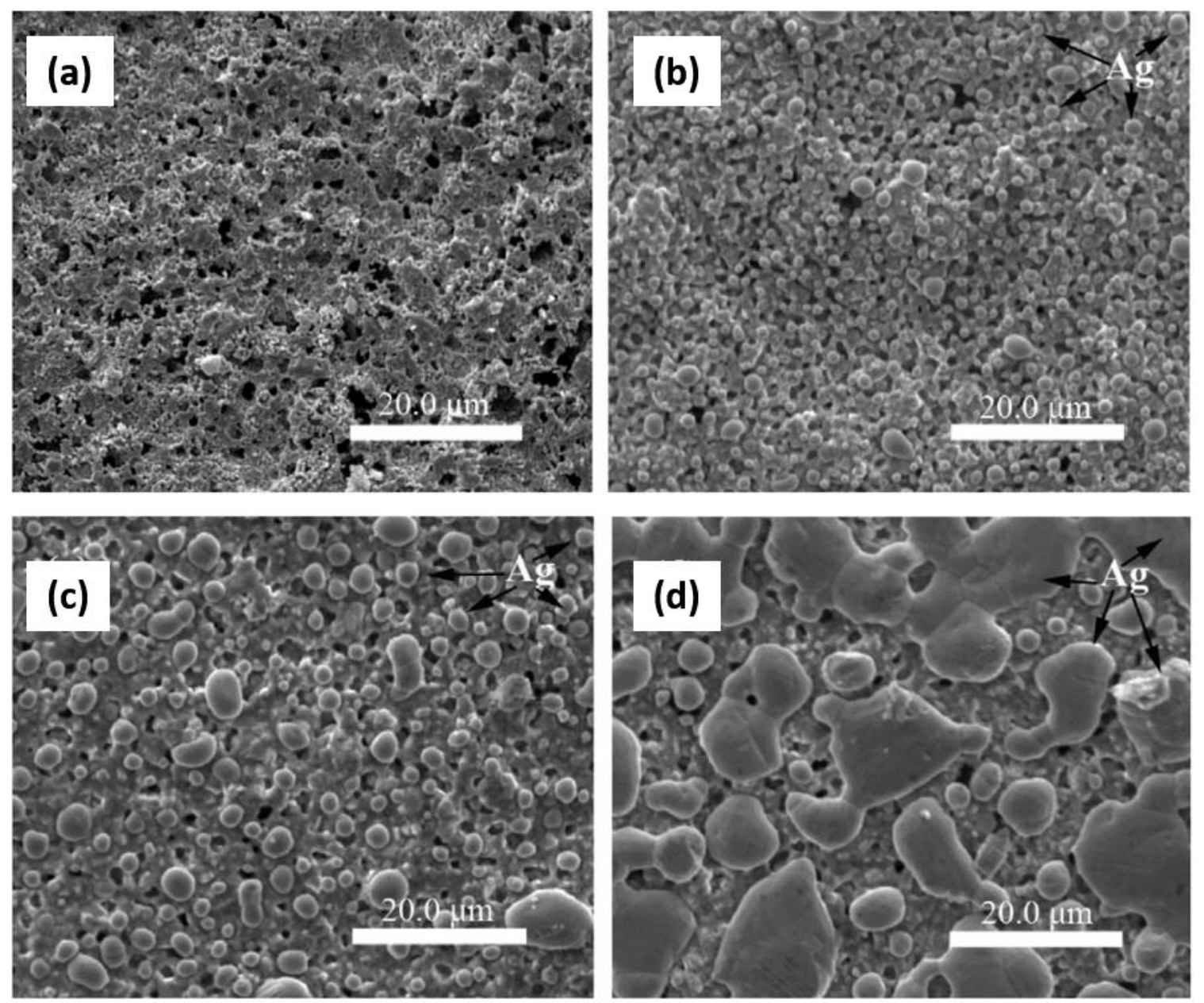

Figure 2.18. SEM images of (a) blank Ni/YSZ anode and Ag infiltrated (b) Cell A: 0.89 wt. \%, (c) Cell B: 1.59 wt. \%, (d) Cell C: 2.48 wt. \% [96] 


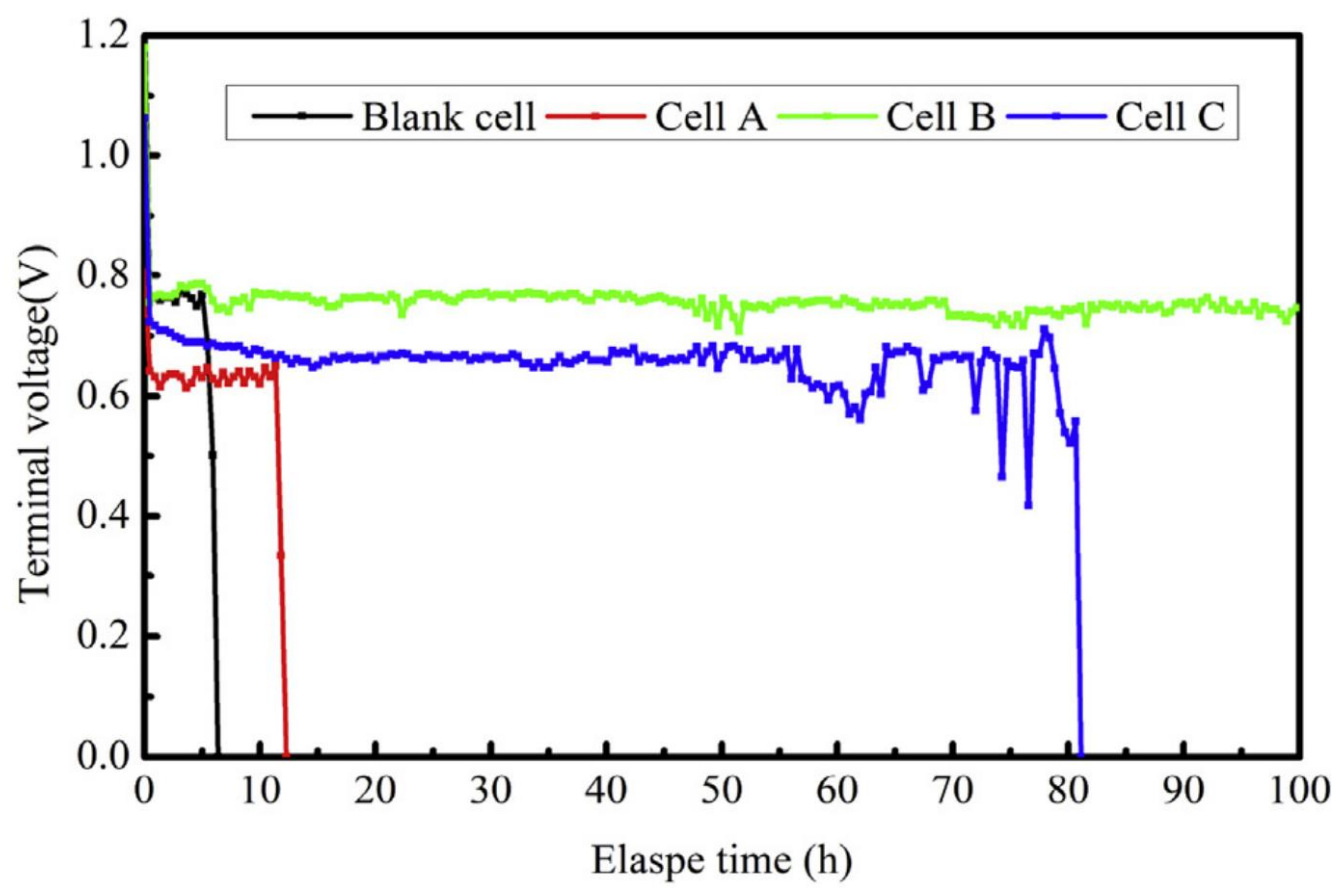

Figure 2.19. Long-term stability of the cells with different $\mathrm{Ag}$ contents in dry $\mathrm{CH} 4$ at 1023 K. Ag loadings of the infiltrated cells are Cell A: 0.89 wt. \%, Cell B:1.59 wt. \%, Cell C: 2.48 w. t $\%[96]$.

In the literature, investigators are looking for alternatives to precious metals that have high coking tolerance and catalytic nature together. Despite the bad known coking behavior of $\mathrm{Ni}$, Wang et al. studied modified nickel as an infiltrated phase for a highly coking-resistant catalytic species [94]. Ni- $\mathrm{Al}_{2} \mathrm{O}_{3}$ has a combination of good catalytic activity with high coking tolerance. Moreover, $\mathrm{Ni}-\mathrm{Al}_{2} \mathrm{O}_{3}$ also has better mechanical performance owing to the $\mathrm{Al}_{2} \mathrm{O}_{3}$ phase. Researchers aimed to promote this catalyst system by modifying with $\mathrm{Li}, \mathrm{La}$, and $\mathrm{Ca}$. Their studies on $\mathrm{CH}_{4}$ conversion and $\mathrm{CO}$ selectivity of $\mathrm{Li}-\mathrm{La}$ modified $\mathrm{Ni}-\mathrm{Al}_{2} \mathrm{O}_{3}$ monitored that methane conversion was very stable within 300 hours and reached $95 \%$. CO selectivity was $100 \%$ during that period showing an excellent performance with methane fuel (Figure 2.20). 


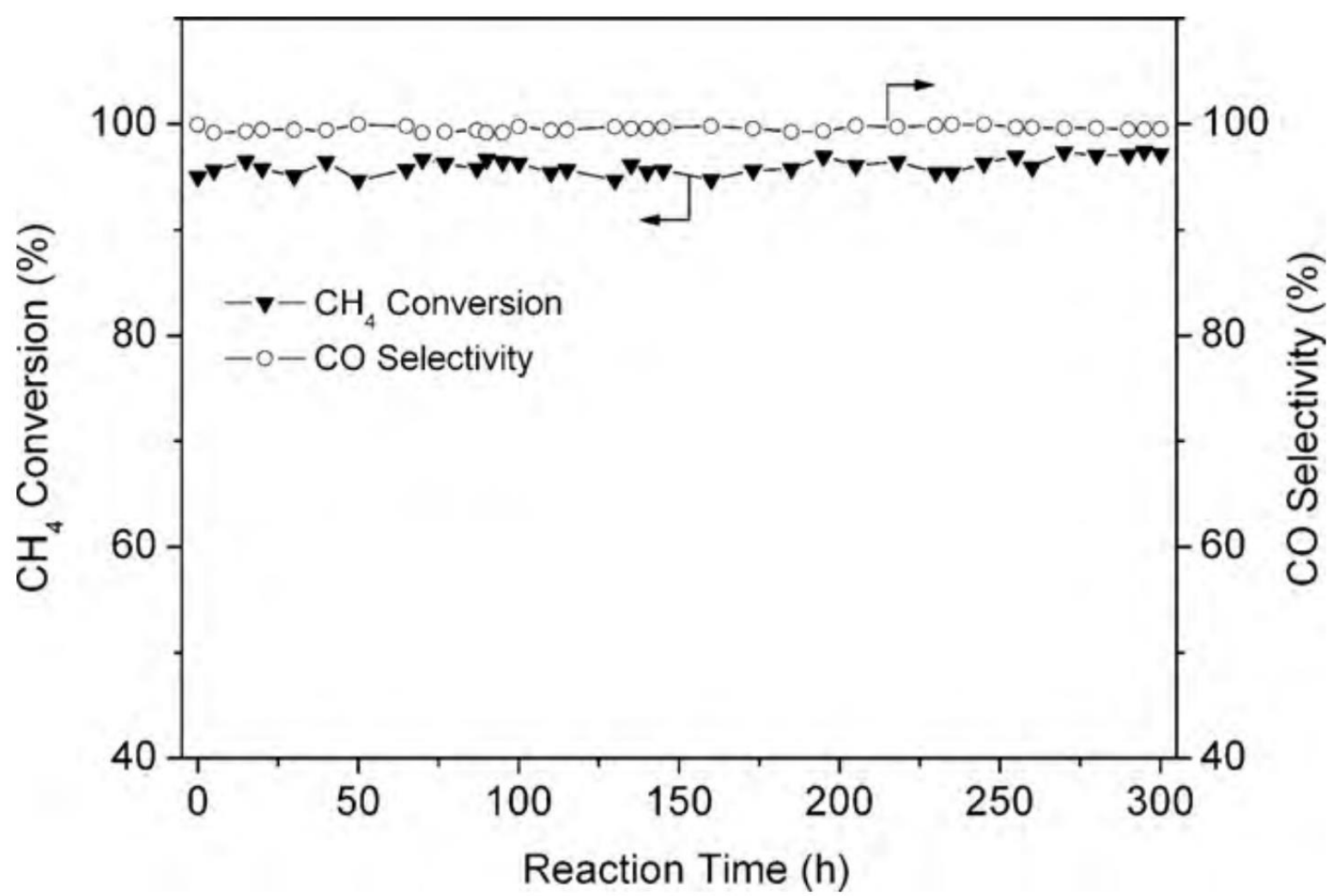

Figure 2.20. Time dependence of methane conversion and $\mathrm{CO}$ selectivity under $\mathrm{CH}_{4}: \mathrm{O}_{2}=$ 2.2:1 conditions for the $\mathrm{LiLaNi}-\mathrm{Al}_{2} \mathrm{O}_{3}$ catalyst [94].

To measure the coke tolerance of the modified catalyst systems. Temperature Programmed Oxidation (TPO) analysis was performed with purged $\mathrm{CH}_{4}$. As shown in Figure 2.21, the $\mathrm{CO}_{2}$ peak area reduced when using alkali metal modification and rare earth metal oxides. Moreover, peak temperatures were also shifted to lower temperatures. As noted, $\mathrm{CaO}$-promoted $\mathrm{Ni}-\mathrm{Al}_{2} \mathrm{O}_{3}$ catalyst showed the best coking resistance.

This study showed the latest trend in catalyst engineering of SOFCs. Starting from the precious metals, small amounts of nano-catalysts also displayed high coking tolerance and stability. 


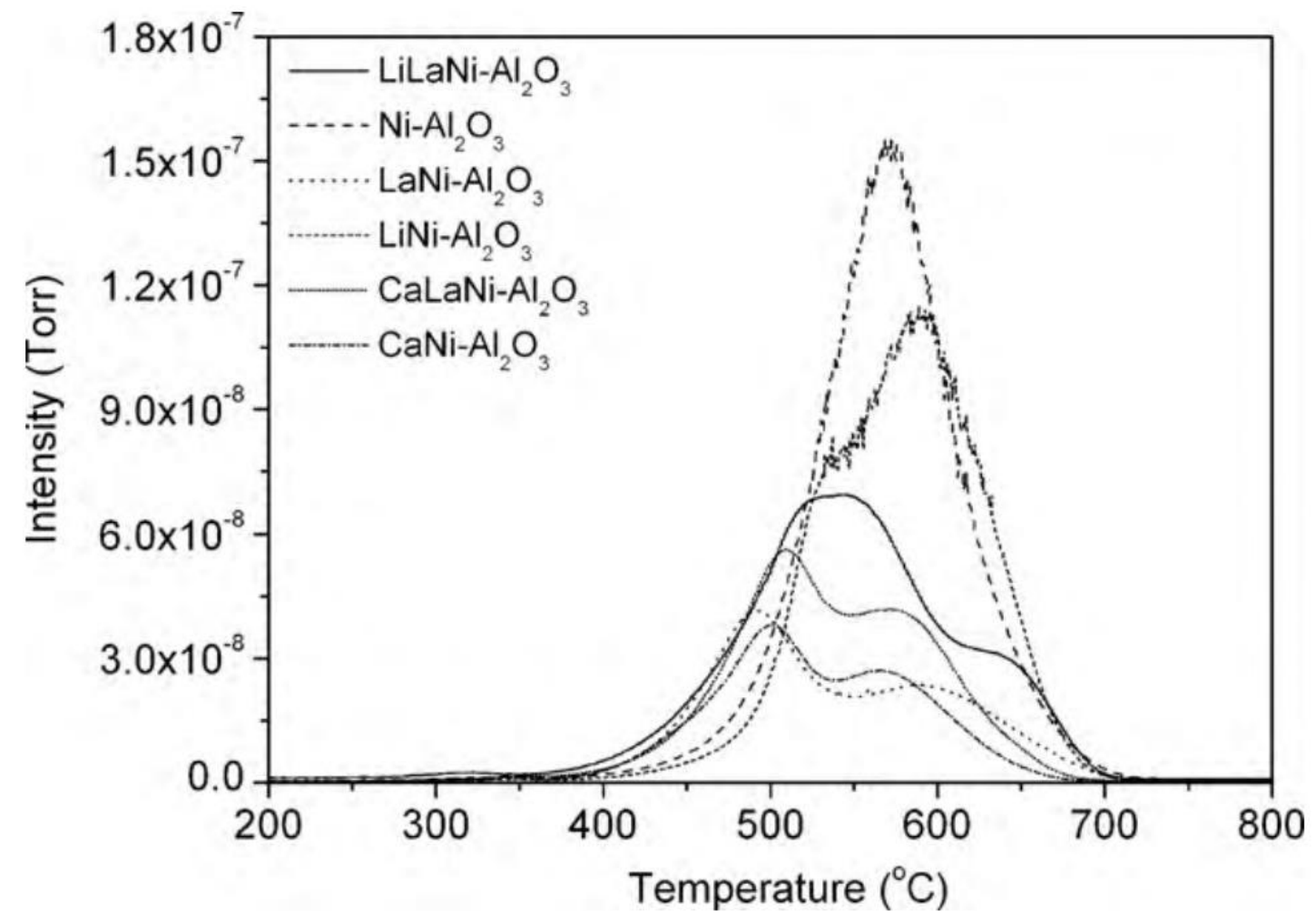

Figure 2.21. $\mathrm{O}_{2}$-TPO profiles of $\mathrm{LiLaNi}-\mathrm{Al}_{2} \mathrm{O}_{3}, \mathrm{LaNi}^{-} \mathrm{Al}_{2} \mathrm{O}_{3}, \mathrm{LiNi}-\mathrm{Al}_{2} \mathrm{O}_{3}, \mathrm{LaCaNi}-\mathrm{Al} 2 \mathrm{O} 3$, $\mathrm{CaNiAl}_{2} \mathrm{O}_{3}$ and $\mathrm{Ni}-\mathrm{Al}_{2} \mathrm{O}_{3}$ catalysts after operation under $\mathrm{CH}_{4}: \mathrm{O}_{2}=11.5: 1$ conditions for $100 \mathrm{~h}[94]$,

Experiments showed that traditional Ni/YSZ cermet anodes also could not tolerate hydrogen sulfide impurity. Studies showed that a few ppm of $\mathrm{H}_{2} \mathrm{~S}$ retards the system with a sharp decrease of voltage during initial hours and an increase in polarization resistance $[34,46,103,106$, $154]$.

Hence, studies have aimed to substitute nickel with an alternative material without sacrificing conductivity and catalytic properties. Researchers are using the same precious metals $(\mathrm{Pd}, \mathrm{Au}, \mathrm{Pt}, \mathrm{Ru})$ and transition metal-based systems $(\mathrm{Cu}, \mathrm{Co})$ to suppress sulfur poisoning. Alternatively, owing to the high surface area and activity of the nanoparticles, catalytic particle, 
or sulfur tolerant particle decoration via infiltration can be a promising method to modify the electrodes [154].

\subsubsection{Wet Chemistry}

Modifying the wet chemistry of the precursor solution is vital to enhance the penetration ability and hence the yield of material deposition per step. Apart from some external engineering solutions such as vacuum or pressure assistance, the surface tension of the precursor system plays an important role in the wettability of the electrode backbone. It is common knowledge that alcohol-based solvents have lower surface tension than water and hence a better wettability on solids. In that sense, non-aqueous precursor systems are more preferred [38-40, 45, 46, 57, 88, 92, 97, 167]. Meilin Liu and his coworker's controlled the wetting property of SSC $\left(\mathrm{Sm}_{0.6} \mathrm{Sr}_{0.4} \mathrm{CoO}_{3}\right.$ $\delta)$ precursor by tuning the solvent mixture $[73,167]$. As a solvent additive, ethanol was added into the aqueous SCC solution with different ratios to modify the liquid surface tension on the LSCF cathode backbone. In Figure 2.22, the wetting angles of a precursor droplet of different water-toethanol volume ratios were shown on different substrates as a quantitative measure of wettability. It was observed that higher ethanol content in the precursor promoted lower contact angles regardless of the substrate material. Although using $100 \%$ ethanol as a solvent may limit the solubility hence adversely affect solution/suspension stability and drying kinetics after infiltration, optimum ratios of water-alcohol mixtures would potentially decrease the number of infiltration steps with homogenous infiltrated particles. 


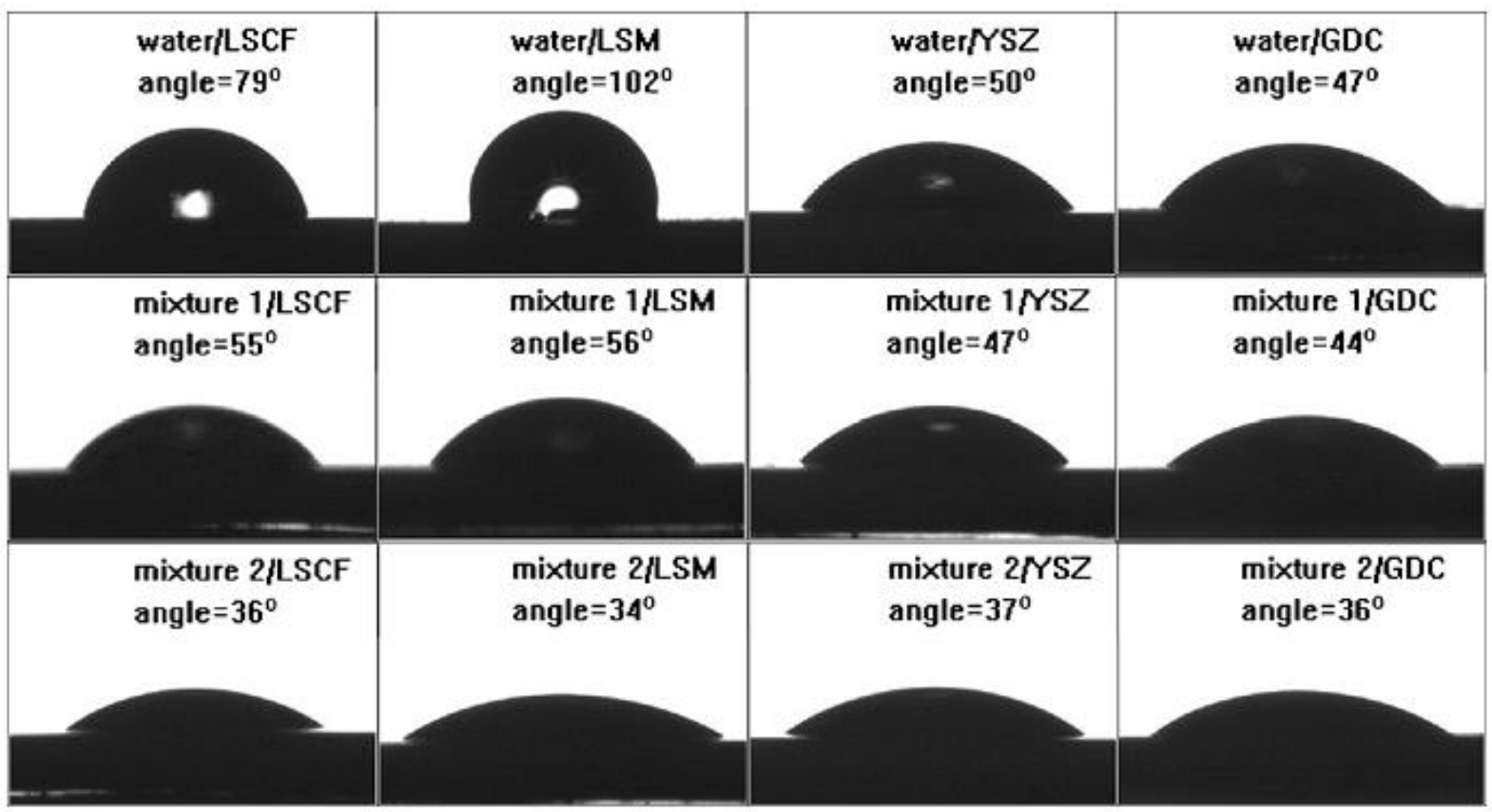

Figure 2.22. Wetting angles of different $\mathrm{SSC}(\mathrm{Sm} 0.5 \mathrm{Sr} 0.5 \mathrm{CoO} 3-\mathrm{x})$ precursor solutions on

LSCF, LSM, YSZ and GDC substrates (note: mixture 1 had a water-to-ethanol volume ratio of 1:0.3 and mixture 2 has a water-to-ethanol volume ratio of 1:0.6) [167].

\subsubsection{Infiltrated Material Phase}

Infiltration of a metal precursor solution is the most popular strategy in the literature. The precursor solution comprises dissolved metal salts (chlorides, sulfides, and mostly nitrides) into water or alcohol. After the precursor is infiltrated to the electrode, the solution dries and precipitates out the dissolved metal salt. Then in the final calcination step, the infiltrated cell is fired to $400-1000{ }^{\circ} \mathrm{C}$ to form nano infiltrated particles.

Due to the solubility limit of metal salts, molarity is usually kept low. As a result, infiltration protocol is generally carried by repetitive steps. To decrease the number of infiltrations steps, molten salts infiltration can also be done [168]. The molten-salt infiltration can be possible owing to low melting point metal nitrates. However, even near melting point, the precursors have 
such a high viscosity that capillary action does not help the self-infiltration process by itself. Vacuum assistance can be utilized to provide better penetration.

One of the most straightforward approaches is dispersing pre-synthesized nanoparticles in a solvent and then infiltrating the dispersed suspension on top of the electrode $[46,54,63,64,80]$. High solid loading of the infiltrated phase is one benefit of this methodology, which allows fewer repetitive infiltration steps to achieve the desired deposition amount. Here, the initial particle size plays a vital role since the dispersion of high surface area particles is difficult to stabilize whereas low surface area particles - relatively larger particles - are challenging to infiltrate through the porous electrode efficiently. Moreover, pore-clogging and gas starvation issues may be other potential complications.

P.K. Lohsoontorn et al. infiltrated GDC catalyst into Ni-YSZ electrode [63]. In their experiment, GDC solid loading was kept at $20 \mathrm{wt} \%$ with a solvent of butanol-mixed xylene. Figure 2.23.a shows the GDC starting powder from the infiltration solution, and it is concluded that the particles are submicron-sized but highly agglomerated (Figure 2.23.b). Moreover, it was noted that the infiltration of GDC particles was not homogenous on the Ni/YSZ substrate. 

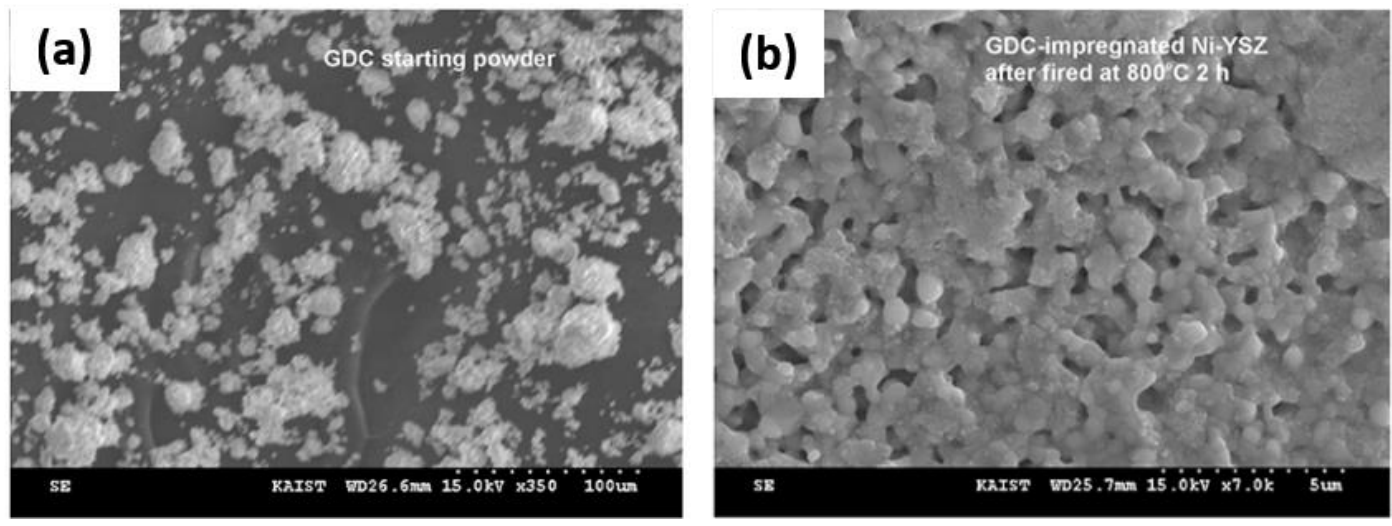

Figure 2.23. SEM images of (a) GDC starting powder and (b) GDC-impregnated Ni-YSZ electrode after fired at $800^{\circ} \mathrm{C}$ for $2 \mathrm{~h}$. [63].

S. P. Jiang et al. performed a comparison of infiltration materials [54]. NiO screen printed YSZ substrate was used as an anode and then reduced under $\mathrm{H}_{2}$. The final porosity of the $\mathrm{Ni}$ anode was calculated as 30 vol\%. YSZ and GDC were selected as the ionically conductive infiltrated phases. Nano-YSZ suspension and $3 \mathrm{M}$ GDC $\left(\mathrm{Gd}_{0.2} \mathrm{Ce}_{0.8}\left(\mathrm{NO}_{3}\right)_{\mathrm{x}}\right.$ nitrate solution were used. The suspension or solution was deposited on the anode top surface, and the impregnated cells were fired at $850^{\circ} \mathrm{C}$ for $1 \mathrm{~h}$ to decomposition. The study showed that YSZ oxide infiltration loading was $2.7 \mathrm{mg} / \mathrm{cm}^{2}(17 \mathrm{vol} \%)$ after one infiltration treatment and $4.0 \mathrm{mg} / \mathrm{cm}^{2}(21 \mathrm{vol} \%)$ after repeated infiltration cycles. In case of GDC nitrate infiltration, $0.52 \mathrm{mg} / \mathrm{cm}^{2}(3.5 \mathrm{vol} \%)$ was achieved after one infiltration, and repeated infiltration treatments increased the loading up to $1.7 \mathrm{mg} / \mathrm{cm}^{2}(8.5$ vol\%). The solid loading yield difference between YSZ suspension infiltration and GDC solution clearly states the efficiency of these two starting routes. Due to the higher concentration of suspension, it was possible to deposit a higher amount of YSZ particles than GDC solution infiltration. Figure 2.24 shows the SEM images of the surface and fractured cross-sections of pure $\mathrm{Ni}$, YSZ, and GDC infiltrated Ni anodes. As seen in Figure 2.24.c and d, a thin YSZ oxide film layer was observed on the Ni backbone. On the other hand, GDC nitrate solution infiltration was 
different from YSZ suspension infiltration, as seen in Figure 2.24.e and f. It was observed that GDC coverage was not homogenous over the nickel particles.
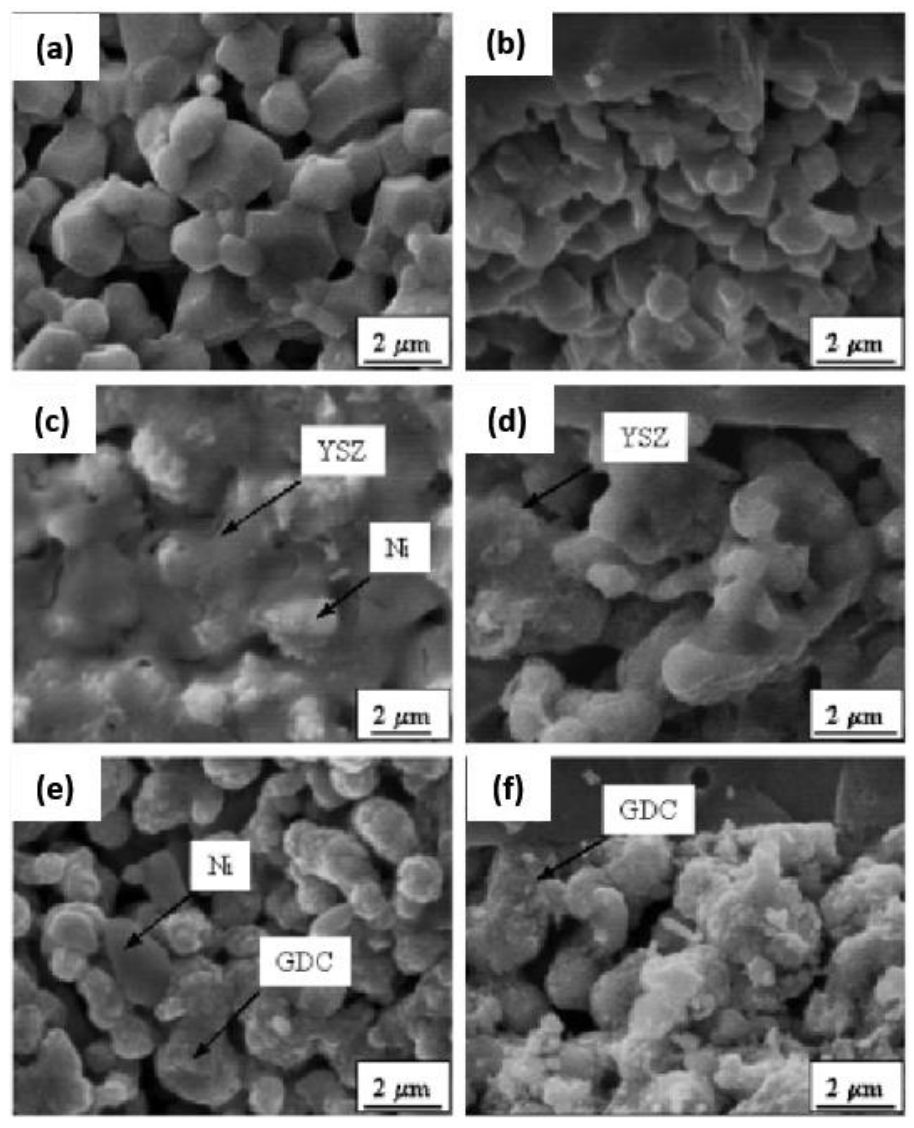

Figure 2.24. Scanning electron microscope pictures of (a) surface and (b) fractured crosssection of pure $\mathrm{Ni}$ anode, $(\mathbf{c})$ surface and (d) fractured cross-section of $2.7 \mathrm{mg} / \mathrm{cm}^{2} \mathrm{Y}_{2} \mathrm{O}_{3}$ stabilized $\mathrm{ZrO}_{2}$-impregnated $\mathrm{Ni}$ anode, (e) surface and (f) fractured cross-section of 1.7 $\mathrm{mg} / \mathrm{cm}^{2} \mathrm{Gd}$-doped $\mathrm{CeO}_{2}$-impregnated $\mathrm{Ni}$ anode [54].

Finally, the precursor drying parameters have a significant influence on the particle localization. Dissolved metal nitrate or particles localized unevenly and drifted through due to the phenomenon called 3-D segregation, in which ions can precipitate onto the previously calcined catalyst surface $[31,78,80,169-172]$. The study by Zhu et al. showed that drying method of the 
infiltrated cell facilitated the morphology of the gel in flower-like which facilitated the infiltration process [108].

Progressively increasing the catalyst loading with repetitive steps can improve electronic conductivity, but it requires tedious infiltration/drying/ calcination steps and could potentially reduce the original porosity of the porous scaffold, causing gas transport limitations [28] and hence increasing the polarization resistance [45]. There have been only limited efforts devoted to developing a protocol for one or two infiltration steps with high nitrate concentration in the presence of dispersant or surfactant $[38,74,78,156,173]$.

\subsubsection{Surfactants and Dispersants}

To control the dispersion and wetting of porous structures with salt solutions, various additives have been used to facilitate infiltrated nanoparticle distribution and phase complexation that prevents individual single oxide phase impurity formation prematurely.

Triton X-100 $\left(\mathrm{C}_{14} \mathrm{H}_{22} \mathrm{O}\left(\mathrm{C}_{2} \mathrm{H}_{4} \mathrm{O}\right)_{\mathrm{n}}\right.$, Union Carbide Chemicals and Plastics Co., Inc) is a commercial surfactant that is used as a surfactant additive for precursor solutions. One proven function of Triton- $\mathrm{X}$ is to obtain phase stability as a complexing agent. Figure 2.25 displays that direct decomposing of LSM, metal nitrate precursors only yield to a pure perovskite phase with the use of Triton X surfactant [28]. The study by Tucker et al. demonstrated the effect of the use of Triton-X on particle size and distribution [174]. Shown in Figure 2.26, are fine infiltrated Ni particles on to the YSZ backbone. It was stated that with the use of Triton-X-100, individual particles are in the range of 40-100 nm (Figure 2.26.a). The precursor solution filled only 3 vol $\%$ of the total pore volume per step, so the protocol was repeated 12 times to build up a connected network of Ni catalyst. It is reported that, by substituting a lower chain length Triton-X surfactant (Triton-X-45), smaller micelle formation was achieved that yielded the reduction of Ni particles down to $10-50 \mathrm{~nm}$ [21]. Only 5 infiltration steps were needed to attain a well-connected network 
(Figure 2.26.b) [174]. Although the LSM precursor is basically a cathode material, similar behavior of Triton can potentially be seen for anode compositions [80].

On the other hand, one case study of Nicholas and Barnett showed that Triton X-100 in SSC $\left(\mathrm{Sm}_{0.5} \mathrm{Sr}_{0.5} \mathrm{CoO}_{3-\mathrm{x}}\right)$ nitrate solution did not produce an SSC phase but adding citric acid $\left(\mathrm{C}_{6} \mathrm{H}_{8} \mathrm{O}_{7}\right)$ as an ion-complexation agent, resulted in pure SSC phase as shown in Figure 2.27. [175]. Pure nitrate derived (PND) and Triton X-100 derived samples contained sub-constituent oxides, $\mathrm{Co}_{3} \mathrm{O}_{4}, \mathrm{SmCoO}_{3}$ and $\mathrm{SrCoO}_{3}[175]$. Furthermore, the presence of additives had little effect on the morphology or the performance of the infiltrated SSD-GDC composite cathodes.

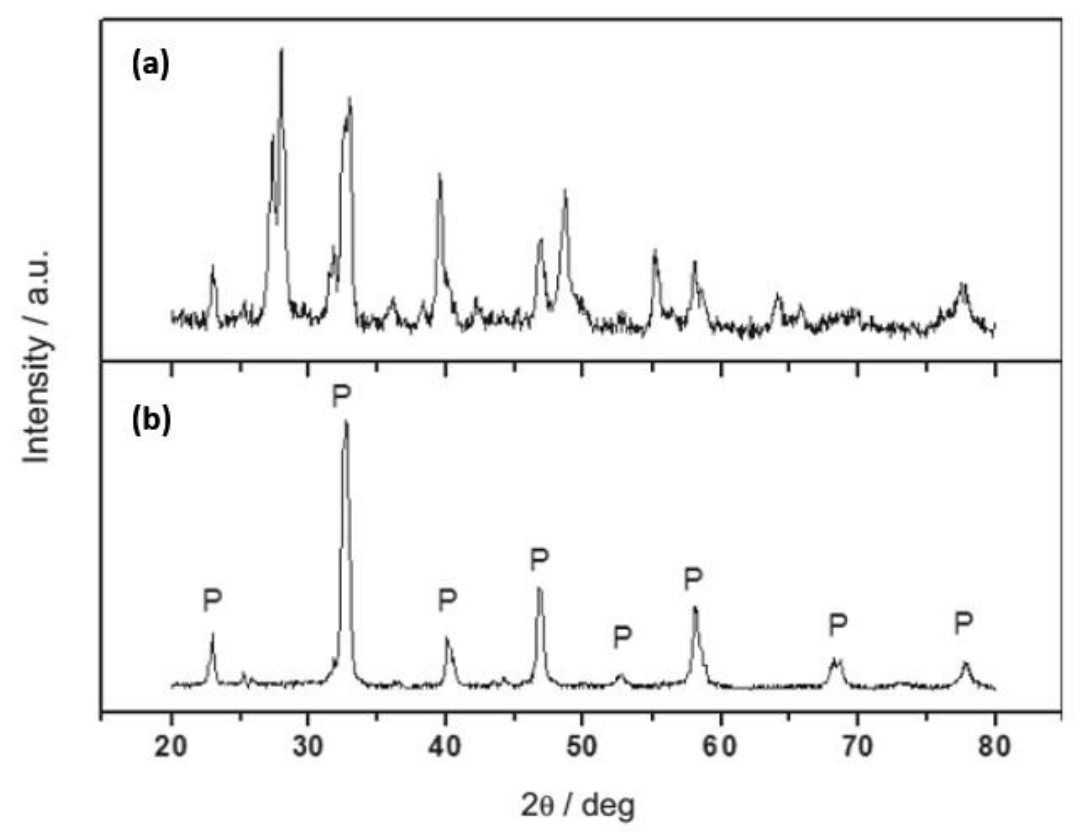

Figure 2.25. XRD patterns of the decomposition products from LSM precursor (a) without and (b) with Triton-X 100, sintered at $800^{\circ} \mathrm{C}$ for $1 \mathrm{~h}[28]$. 

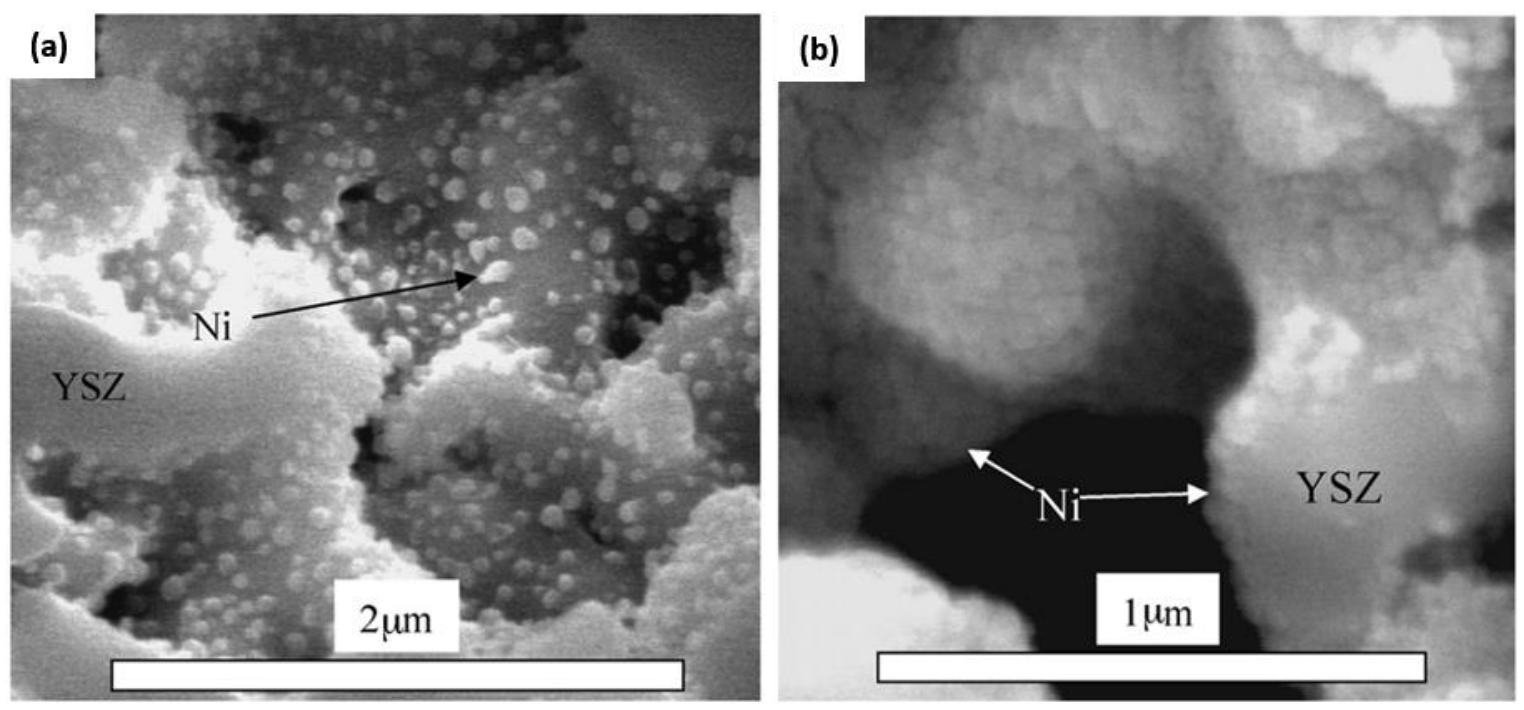

Figure 2.26. SEM images of porous YSZ structures infiltrated with (a) Ni once with Triton-X-100 surfactant and (b) Ni five times with proprietary (Triton X-45) surfactant [174]

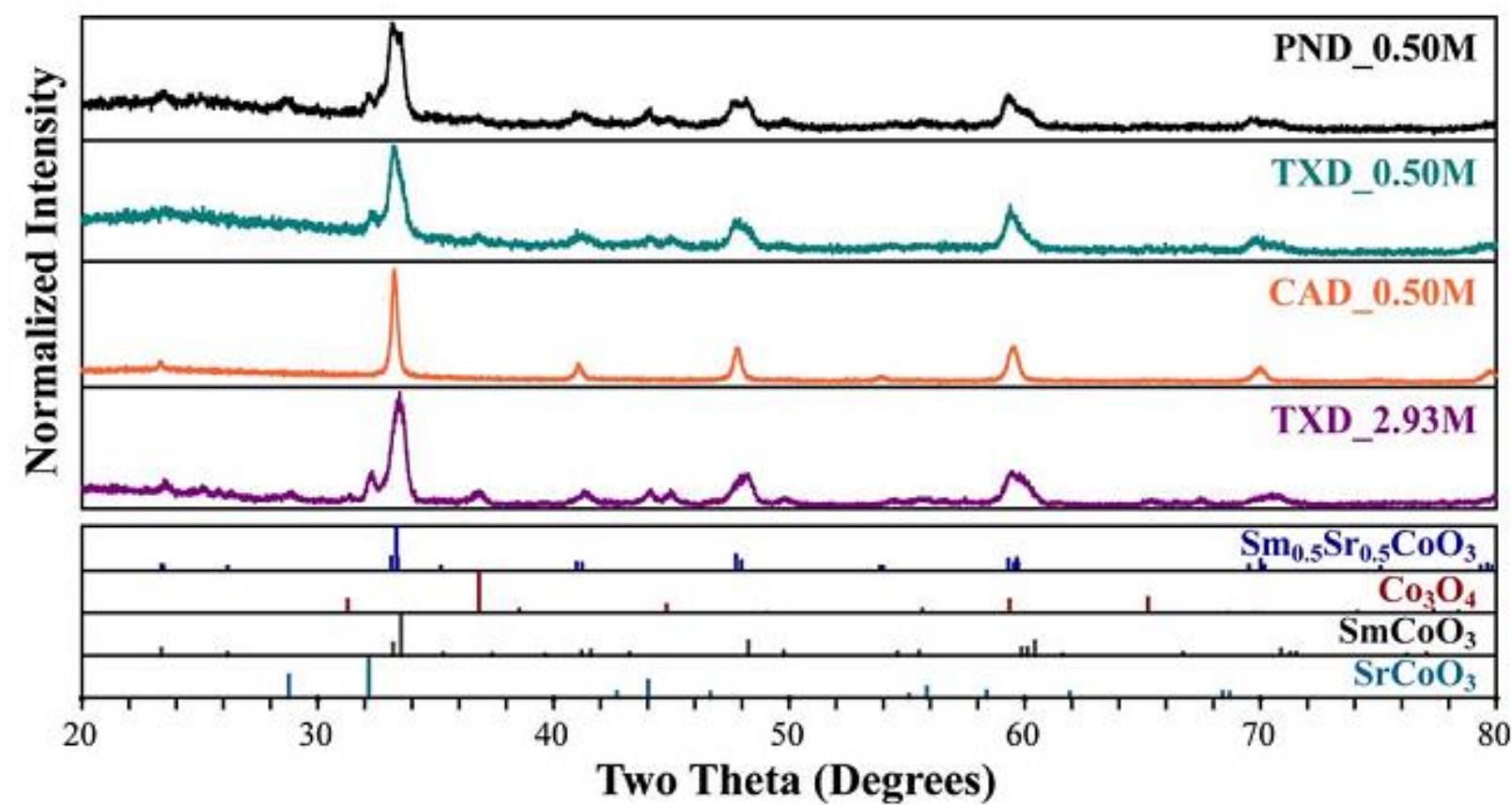

Figure 2.27. XRD scans for powders produced by firing various $\mathrm{Sm}\left(\mathrm{NO}_{3}\right)-\mathrm{Sr}\left(\mathrm{NO}_{3}\right)_{2}$ $\mathrm{Co}\left(\mathrm{NO}_{3}\right)_{2} . \mathrm{PND}=$ Pure nitride derived, $\mathrm{TXD}=$ Triton $\mathrm{X}-100$ derived, $\mathrm{CAD}=\mathrm{C}$ itric acid derived [175]. 
The addition of glycine has also shown to be effective in promoting the uniform distribution of infiltrated yttria-stabilized bismuth (YSB) nanoparticles with reduced infiltration steps. The studies by $\mathrm{Z}$. Jiang et al., on infiltrating LSM particles on a YSB $\left(\mathrm{Y}_{0.5} \mathrm{Bi}_{1.5} \mathrm{O}_{3}\right)$ backbone which were aimed of getting lower polarization resistance, Rp, than conventional LSM/YSZ system, included glycine to the metal nitrate/water solution as a complexing agent (glycine to nitrate molar ratio of 0.5$)[55,176]$. After dripping the solution to the top of the porous YSB layer for only one step, the cell was heated to $800^{\circ} \mathrm{C}$ for $1 \mathrm{~h}$ to form LSM nanoparticles. Phase characterization in Figure 2.28. Indicated that the presence of glycine yields single-phase LSM particle. Moreover, glycine also acted as a surfactant for the coverage of LSM particles on YSB backbone as seen in Figure 2.29.b. The authors noted that the two-step infiltration was enough to get a big upshift on the conductivity and downshift on polarization resistance of the cathode at elevated temperatures.

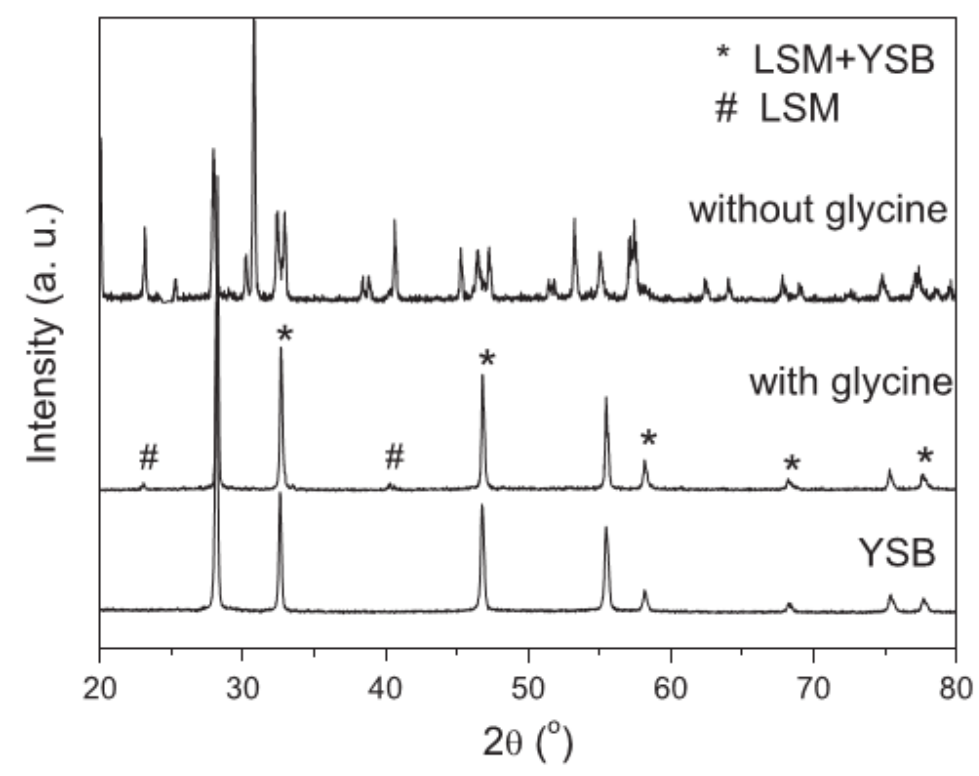

Figure 2.28. X-ray diffraction patterns of the pure YSB powders and the YSB after the infiltration with LSM. Both the XRD patterns of LSM nitrate precursors with and without the addition of glycine are showed [55]. 


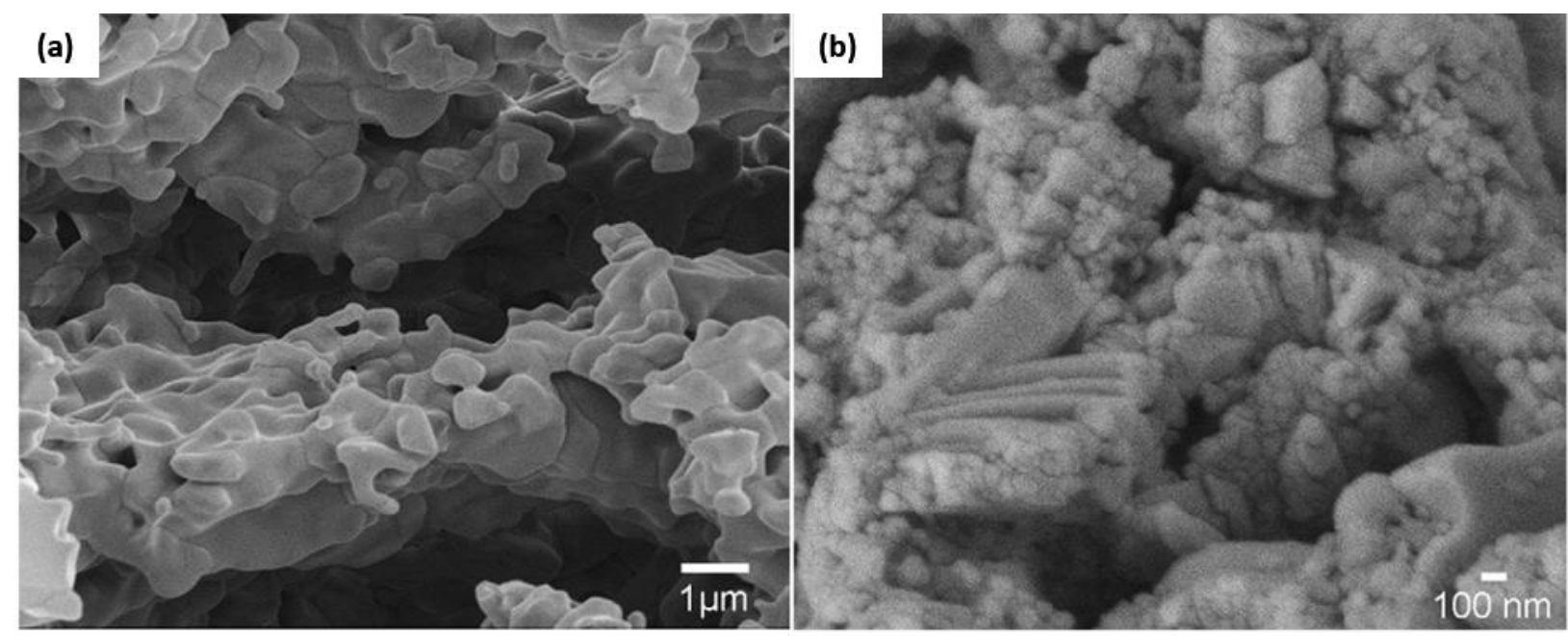

Figure 2.29. Cross-sectional micrographs of (a) YSB backbone, (b) LSM-YSB composite [55].

Using of glycine in anode infiltration. L. Fan et al. added glycine with the molar ratio of metal cations-to-glycine $2: 1$, as a complexing agent in the $\mathrm{GDC}, \mathrm{Ce}\left(\mathrm{NO}_{3}\right)_{3} \cdot 6 \mathrm{H}_{2} \mathrm{O}$ and $\mathrm{Gd}\left(\mathrm{NO}_{3}\right)_{3} \cdot \mathrm{H}_{2} \mathrm{O}$ in a mole ratio of $\left.0.2: 0.8\right)$ solution of ethyl alcohol and deionized water (50-50 vol\%) to LST $\left(\mathrm{La}_{0.2} \mathrm{Sr}_{0.8} \mathrm{TiO}_{3}\right)$ nanofiber scaffolds [44].

Urea $\left(\mathrm{CO}\left(\mathrm{NH}_{2}\right)_{2}\right)$ is another organic chemical that has been used to minimize the nonuniform deposition and impurity phases $[28,31]$. The dissolution of urea in water gives $\mathrm{OH}^{-}$ions to be consumed by the metal cation $\left(\mathrm{M}^{+}\right)$in the solution. Hence, the metal cation is induced to precipitate by forming metal hydroxide $\mathrm{M}(\mathrm{OH})_{(\mathrm{s})}$ before the drying step. Li et al. showed that the effect of adding urea is to enhance the distribution on the electronic connectivity of nanoparticle phases in the infiltrated $\mathrm{Cu}$ and $\mathrm{CeO}_{2}$ composite anodes on porous YSZ scaffold. As shown in Figure 2.30, the addition of urea assisted the formation of a layer of finer particles homogeneously [171]. As a fact of enhanced TBP length, the power density of the urea added infiltration was $37 \%$ higher than the infiltration without urea (Figure 2.31). 


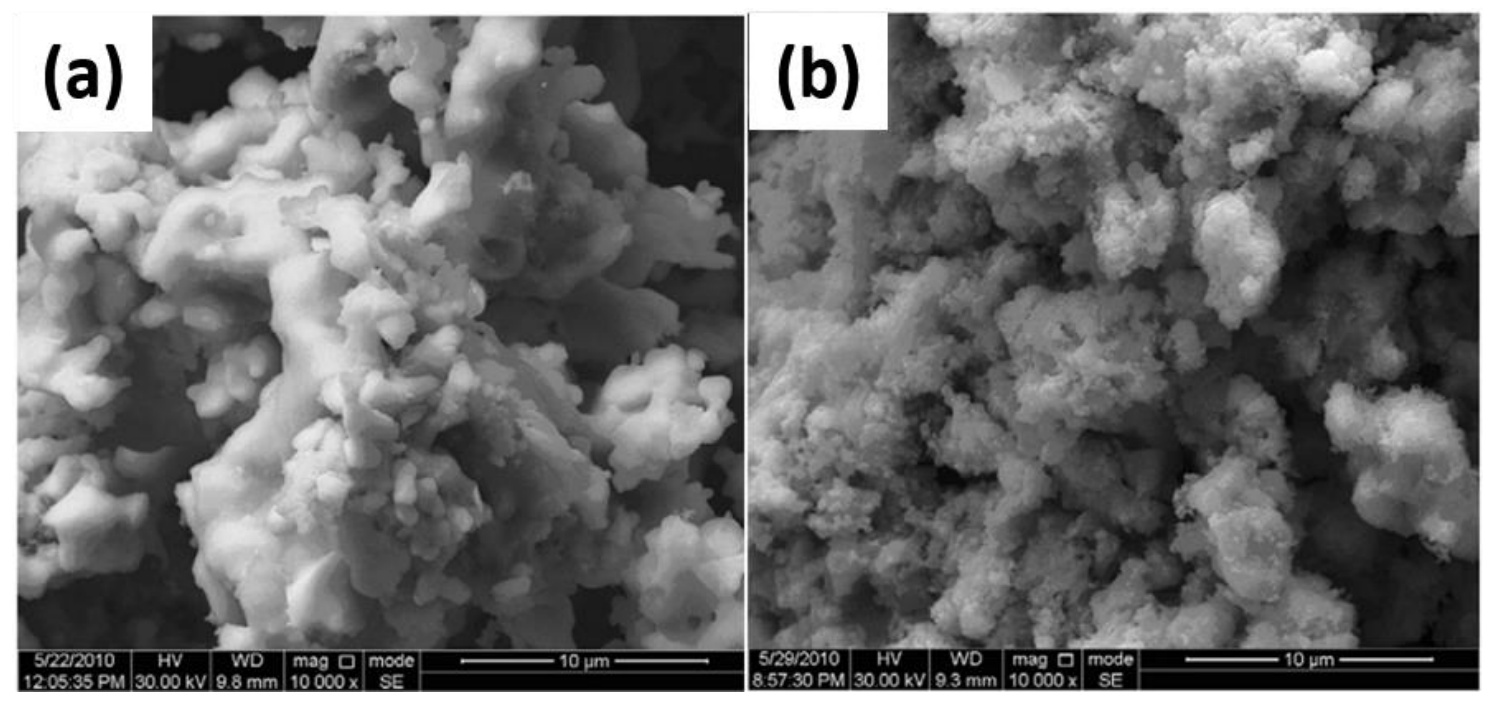

Figure 2.30. SEM micrographs of $\mathrm{Cu}-\mathrm{CeO} 2 / \mathrm{YSZ}$ composite anode without (a) and with (b) adding urea after operated in $\mathrm{H}_{2}$ at $700^{\circ} \mathrm{C}$ for more than $10 \mathrm{~h}[171]$.

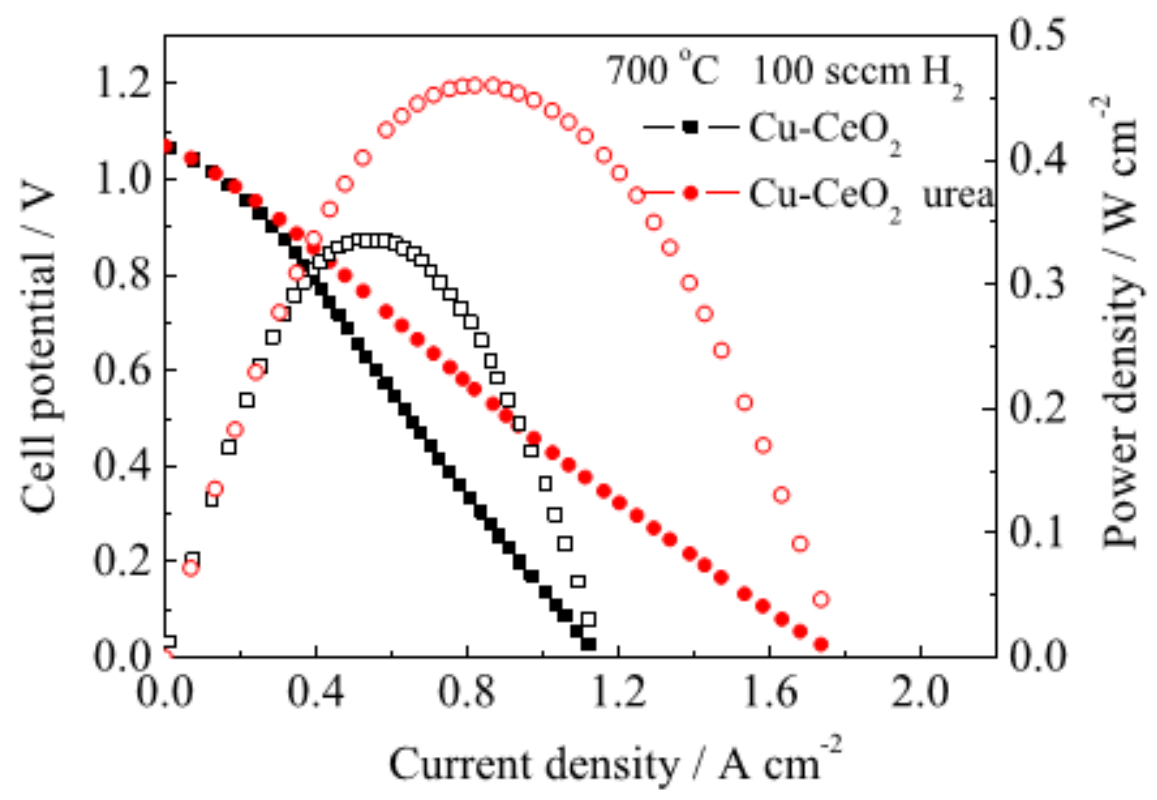

Figure 2.31. $\mathrm{I}-\mathrm{V}-\mathrm{P}$ characteristic curves of $\mathrm{Cu}-\mathrm{CeO} 2 / \mathrm{YSZ}$ composite anode impregnated with or without adding urea when operated in $\mathrm{H}_{2}$ at $700^{\circ} \mathrm{C}$ [171].

Besides the single-phase infiltration, the formation of complex nano-catalyst phases such as $(\mathrm{La}, \mathrm{Sr})(\mathrm{Cr}, \mathrm{Fe}) / \mathrm{Ni}[110]$ and $\mathrm{SSC}\left(\mathrm{Sm}_{0.6} \mathrm{Sr}_{0.4} \mathrm{CoO}_{3-\delta}\right)$ can also be achieved by urea precipitation 
[28]. Figure 2.32 illustrates that the addition of urea attains the SSC perovskite phase while calcination of only nitrate mixture resulted in multiple secondary phases in the catalyst system. Moreover, it was found that urea can also promote preferential deposition on composite substrates. As shown Figure 2.33, reaction infiltrated SSC particles with urea tend to deposit on LSM particles instead of YSZ particles.

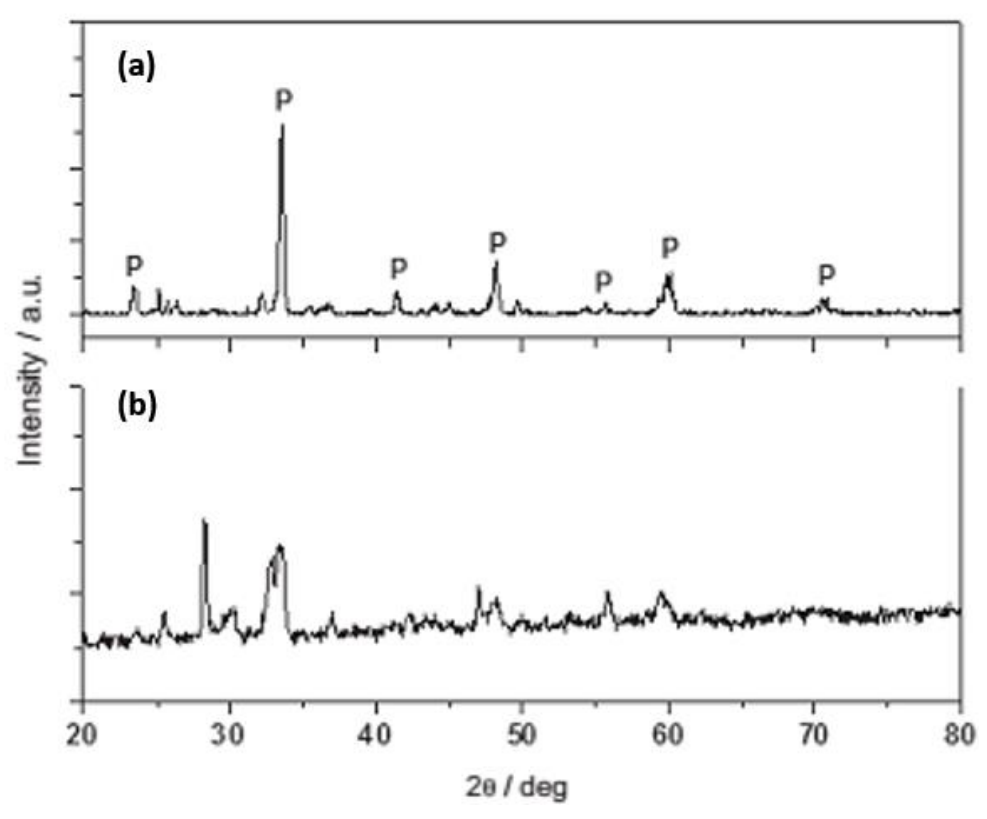

Figure 2.32. XRD patterns of nanoscale SSC from (a) nitrate precursor and (b) urea plus nitrate heated at $800^{\circ} \mathrm{C}$ for $2 \mathrm{~h}$. (P) Peaks corresponding to perovskite phase [28]. 


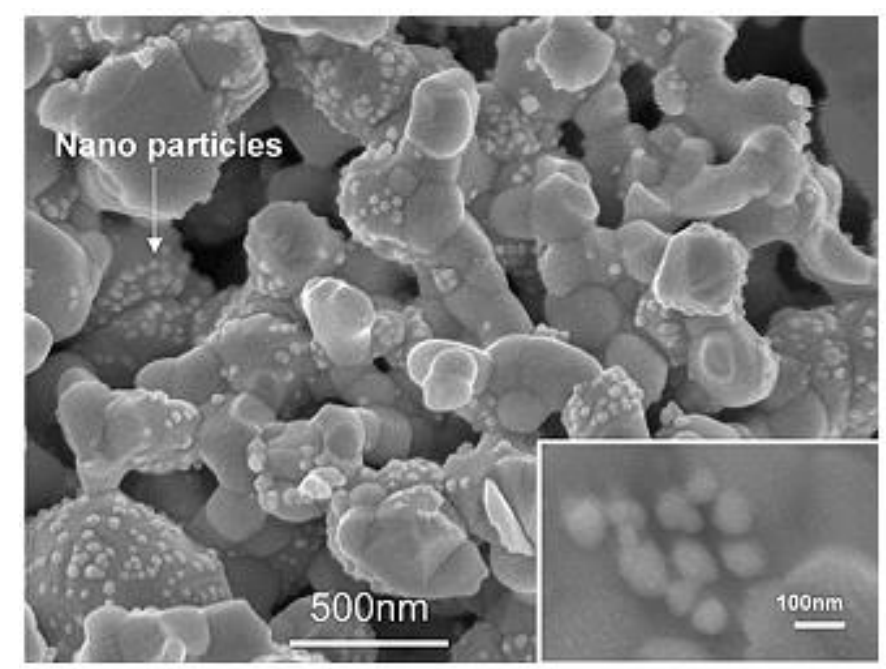

Figure 2.33. SEM images of an LSM-YSZ cathode with dispersed SSC nanoparticles after heating at $700^{\circ} \mathrm{C}[28]$.

Also, A. Buyukaksoy et al. added ethylene glycol to an aqueous $\mathrm{Ni}\left(\mathrm{NO}_{3}\right)$ solution as a polymerization agent before heating the resultant solution to $100^{\circ} \mathrm{C}$ until the water was removed and $\mathrm{Ni}$ ions were incorporated into polymer complex [38-40]. Moreover, 2-butoxyethanol was added with a 1:2 ratio of the polymeric precursor to promote the wettability of the polymer complex. Finally, in the study of particulate GDC infiltration on Ni/YSZ by P. K-Lohsoontorn et al., butvar binder and polyvinyl pyrrolidone (PVP) as a plasticizer are added to the suspension of a butanol-xylene mixture [63].

In conclusion, the main efforts of including these additives listed above are to achieve single complex phases, with isolated particulate decoration and less repetitive steps. In addition, the infiltration method has a direct influence on the final microstructure.

\subsubsection{Infiltration Methods}

In the first infiltration studies, researchers were seeking an easy and effective way to improve the SOFC performance without altering the process of reliable existing electrodes but by adding nano-catalyst in the structure. A technique called the dripping method has been the most 
performed protocol to meet those necessities. Today, the infiltration process has received much attention and can be performed by various technologies as shown in the literature in Figure 2.34. One of the main initial goals of infiltration studies is achieving maximum dispersion/decoration within the electrode without having undesired agglomeration and performance loss over time. The second goal is to be able to monitor or predict the catalyst deposition amount by tuning just a few parameters, such as solution concentration. Although, the dripping method is the most utilized technique, there are some innovative alternative methods applied to lower the steps required to deposit material and enhance the homogeneity, such as atomic layer deposition $[112,120,132$, 136, 149], inkjet printing [134, 143, 144, 147, 177, 178], etc. 


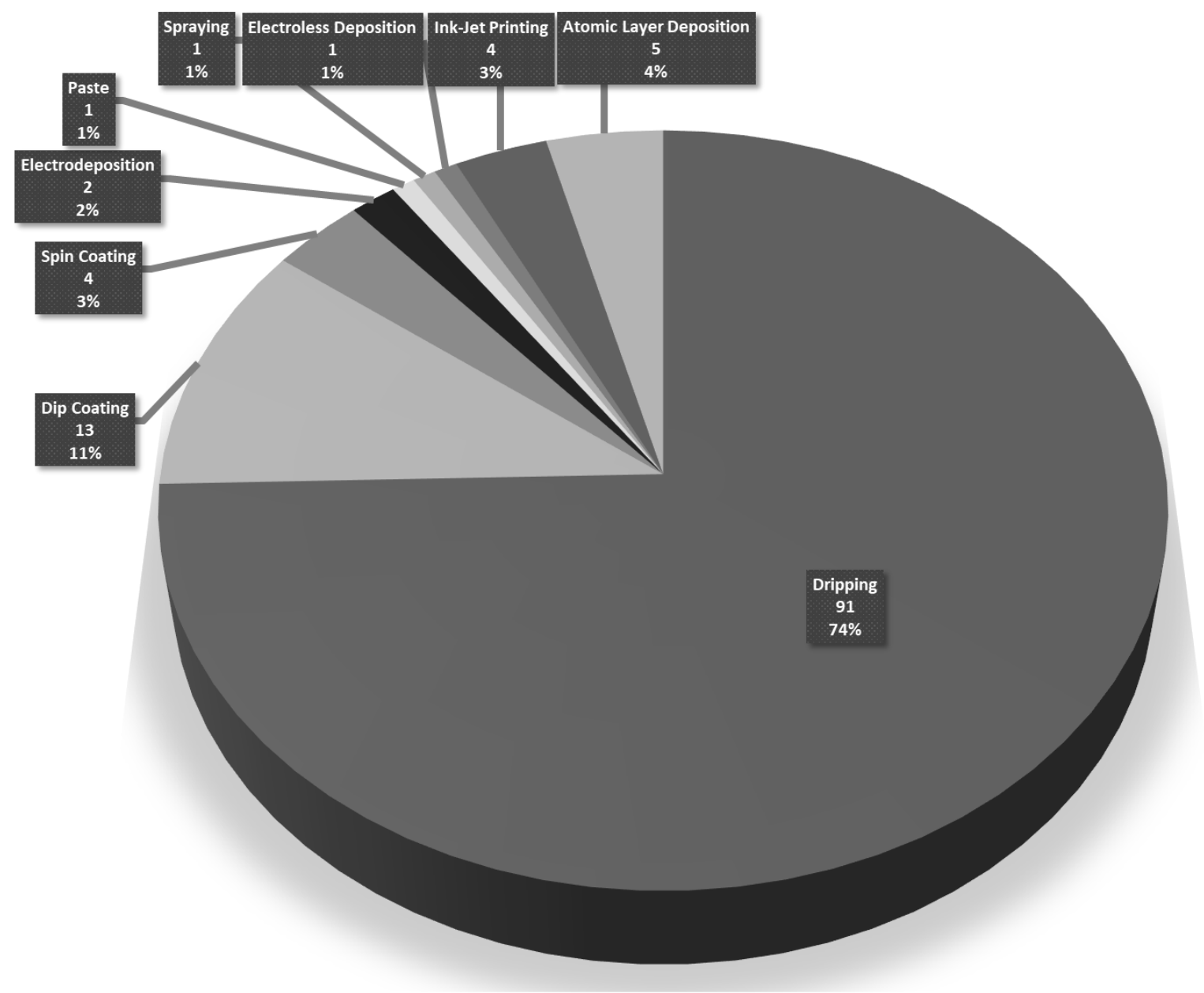

Figure 2.34. Infiltration methods applied for anode electrode in recently published studies [29-152].

\subsubsection{Dripping Method /Tape-cast Infiltration}

As seen in Figure 2.35, the infiltration protocol is mostly performed by a technique called the dripping method. In this method, precursor solution(s) or suspension(s) were dripped over the top of the anode electrode by a simple pipette. The overall process is schematically illustrated in Figure 2.35. A porous backbone structure is infused by the catalyst precursor owing to capillary action. The dripping process requires many infiltration repetitions of low-concentration metal salt 
solutions to achieve sufficient solid loading to form a percolated network. To enhance the infiltration efficacy of this process, vacuum assistance can also be used. One drawback of the dripping method is the operator cannot control the process to achieve desired deposition yield and homogeneity. There is no linear correlation of deposition yield between the infiltration steps and the performance enhancement.

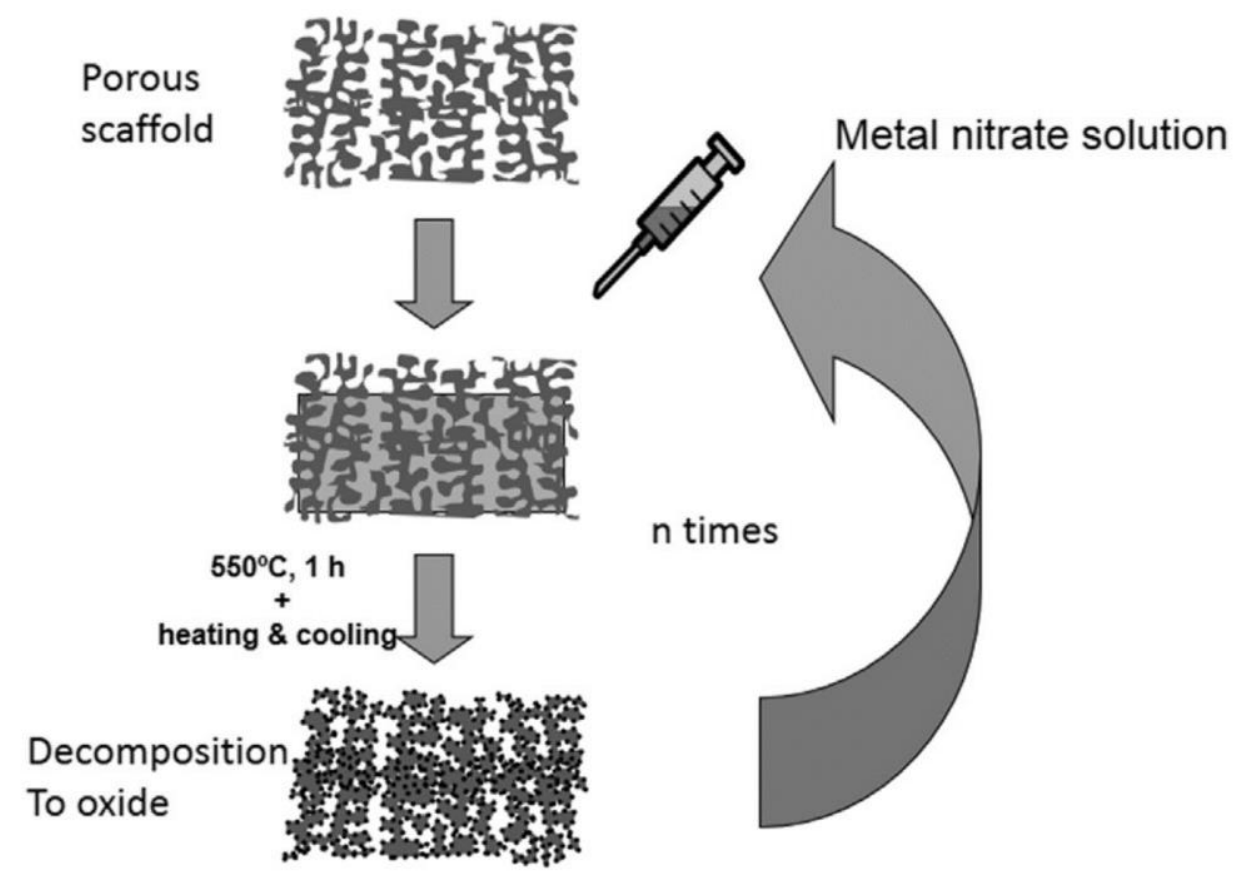

Figure 2.35. Infiltration of a porous scaffold. A metal nitrate is infiltrated into the scaffold. This is heated to decompose the nitrate to the oxide The operation is then repeated several times [179].

Similar to the dripping method, Qiao et al. introduced a method called tape-casting infiltration (TCI) to control the ionically conductive electrode backbone porosity by supporting the structure with a dense electrolyte layer. In this method, thin and dense YSZ tape $-30 \mu \mathrm{m}$ thick without pore former- was laminated with YSZ tapes containing starch pore formers $-800 \mu \mathrm{m}$ thick. After firing of that sandwich structure, a resulting YSZ network with 60-65\% porosity was 
infiltrated with nickel and ceria nitrate precursors by the dripping method under vacuum several times to get the desired infiltrated particle loading [83]. Figure 2.36 shows the porous YSZ network which will be infiltrated on the later step and dense region which will act as the electrolyte.
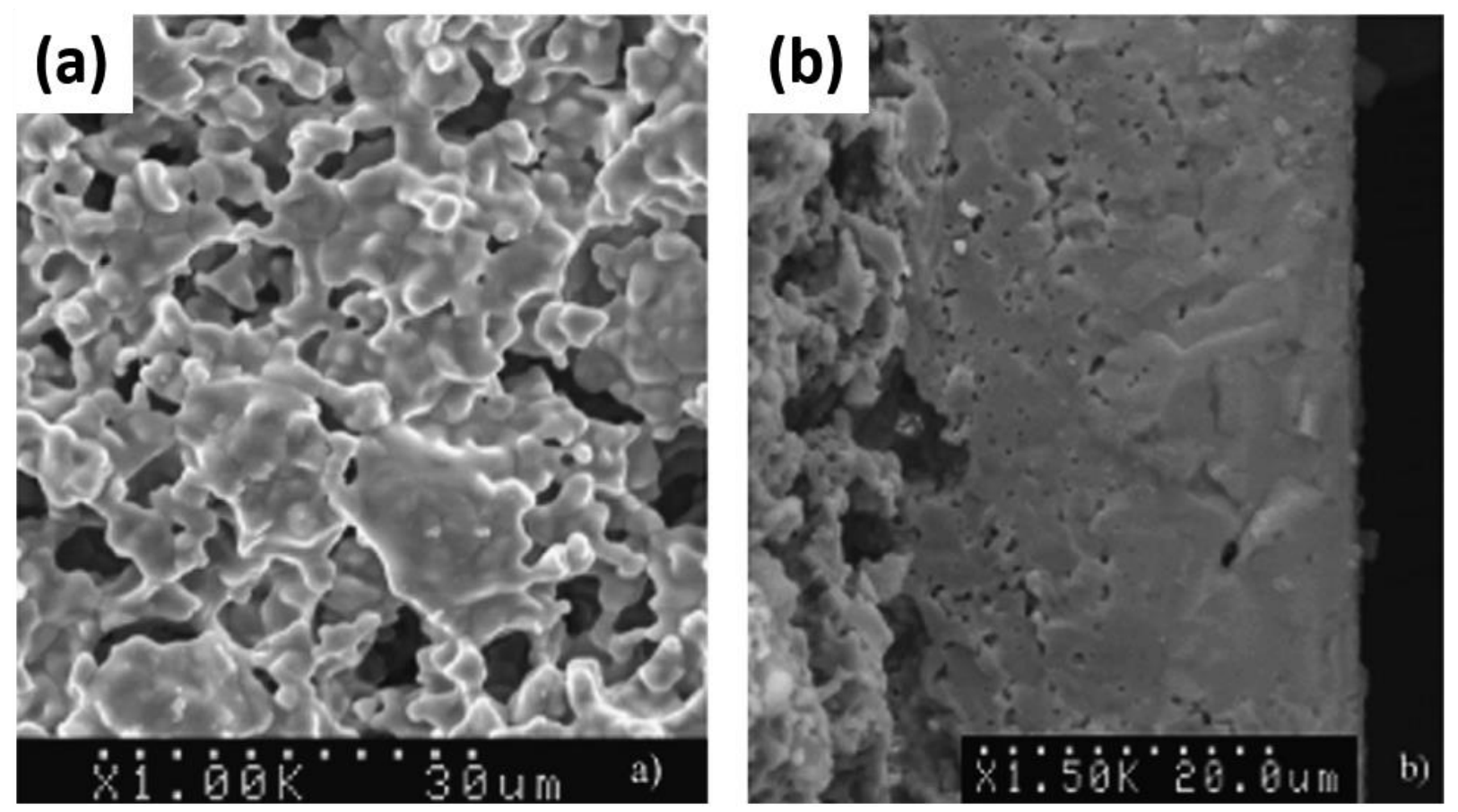

Figure 2.36. SEM graphs of p-YSZ/d-YSZ: (a) p-YSZ surface and (b) cross-section for pYSZ/d-YSZ [83].

Although it is an easy application method and requires almost no equipment, the dripping method has some disadvantages. With the necessity of repetitive infiltration cycle and multiple firing steps, the dripping method is a labor-intensive process. In addition, the amount of infiltrated nano-particle is inconsistent between the cycles because of the operator handling and microstructure/porosity variance. Precursor film formation during the drying step gives inhomogeneous and localized nanoparticle precipitation, which makes the overall method irreproducible. In that sense, researchers have been studying other alternative and controlled deposition techniques for the infiltration of SOFC electrodes. 


\subsubsection{Dip Coating}

Dip coating is a well-known method for the coating of planar substrates. Also, it has been used to modify or infiltrate 3-D scaffolds such as SOFC electrodes [52, 58, 60, 61, 74, 78, 80, 84, $96,99,103,105,113,125]$. A schematic representation of the dip-coating method is shown in Figure 2.37. Dip coating has few advantages over the dripping method. First, the dip-coating method is claimed to facilitate a uniform precursor coverage starting from the surface regions. Secondly, in comparison to the dripping method, dip coating is usually composed of a singular infiltration and firing step which needs less operator control and time.

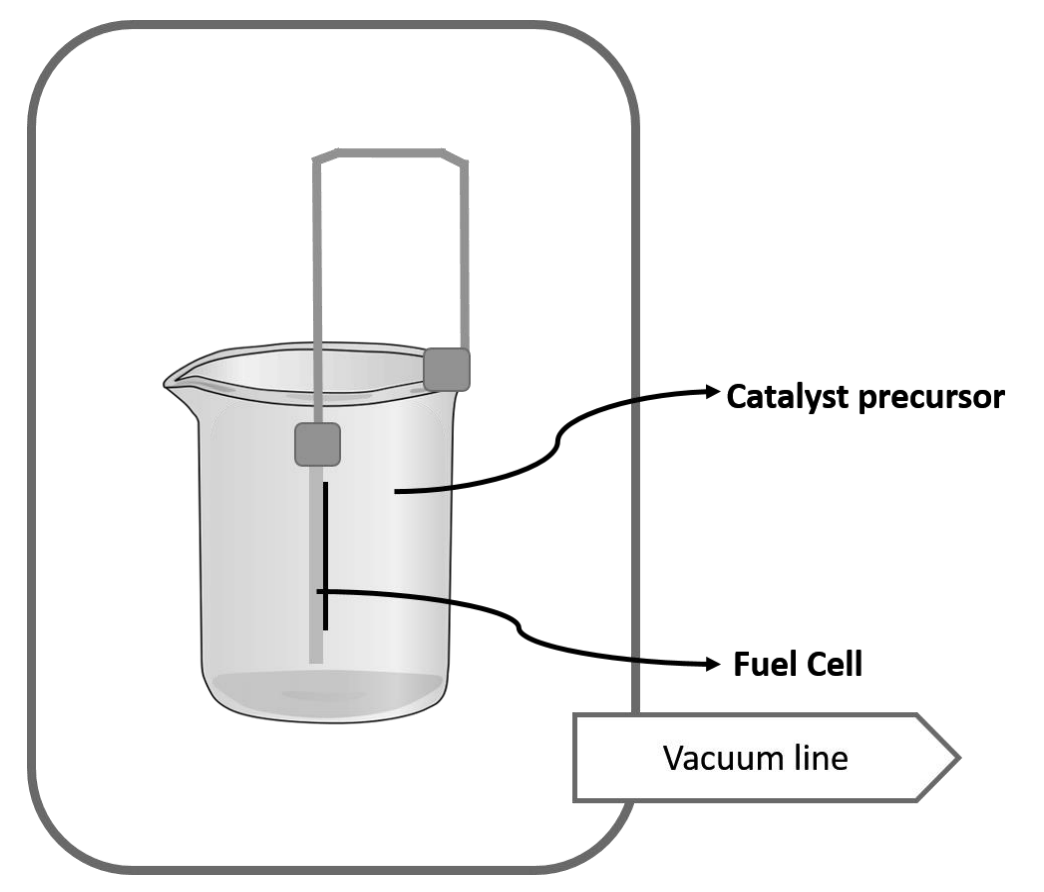

Figure 2.37. Schematic representation of vacuum assisted dip coating infiltration method.

\subsubsection{Electrodeposition}

Due to the limitations of the dripping method mentioned above, the electrodeposition method first was demonstrated by Gorte et al $[32,56]$. By electrodeposition, higher amounts of metal particles can potentially be deposited into the porous conductive network. To achieve 
homogenous deposition within the cell, solution concentration, conductivity, and applied voltage are critical parameters.

To achieve a conductive network of the electrode, Gorte et al. demonstrated two different approaches and experimental parameters. One way was to utilize a cermet (ceramic-metal) structure of the anode [32]. A $\mathrm{Cu}$ salt was infiltrated into a YSZ wafer along with ceria nanoparticles, by repetitive steps, was fired at $723 \mathrm{~K}$ in air and then reduced in humidified (3\% $\left.\mathrm{H}_{2} \mathrm{O}\right) \mathrm{H}_{2}$ at the same temperature. Hence, electrically conductive (13 vol\% Cu) anode electrode was achieved. Next, the cell was immersed in Co precursor solution with $\mathrm{H}_{3} \mathrm{BO}_{3}$ and $\mathrm{HCl}$ and $\mathrm{Co}$ was deposited on to the $\mathrm{Cu}$ in the anode under the galvanostatic condition in one step without any need of firing. Figure 2.38 showed the ohmic resistance of cells prepared with different protocols as a function of time. It can be seen that the cell with electrodeposited Co showed the lowest ohmic resistance among other cells including, the co-impregnated Co cell. Moreover, thermal stability was also achieved by Co electroplating which demonstrated the efficacy of electroplating. 


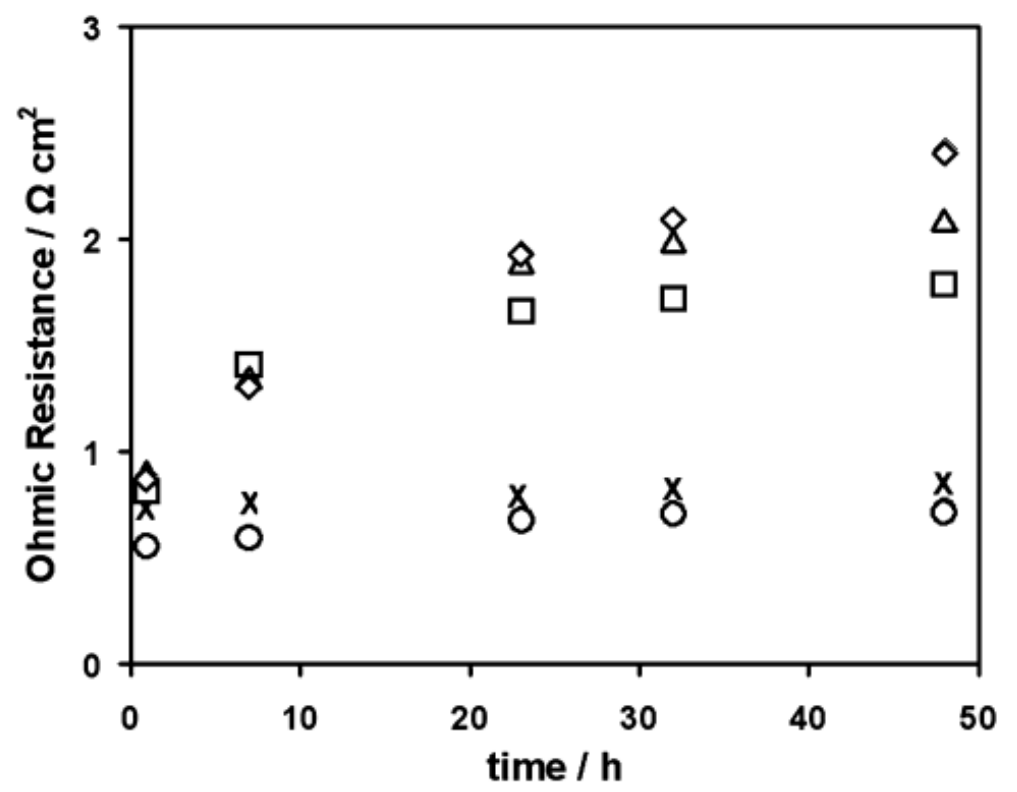

Figure 2.38. Ohmic resistance measurements at $1173 \mathrm{~K}$ in humidified $\mathrm{H} 2$ as a function of time for (०) Co-Cu-ceria-YSZ ( 5 vol\% electrodeposited Co, 13 vol\% Cu); ( $)$ Cu-ceriaYSZ (18\%vol Cu); $(\Delta)$ Co-Cu-ceria YSZ (co-impregnation of 5 vol\% Co and $13 \mathrm{vol} \% \mathrm{Cu}$ ); () Co-ceria-YSZ (18 vol\% Co); (x) Co-ceria-YSZ (30 vol\% Co) [32].

The second way that Gorte et al. demonstrated was treating the porous YSZ by carbon coating [56]. A conductive carbon layer (11 vol \%) was achieved by purging n-butane at $1123 \mathrm{~K}$ $\left(850^{\circ} \mathrm{C}\right)$ for $10 \mathrm{~min}$. An electroplating step was performed with the same protocol an above with Co and Ni chloride aqueous solutions. SEM images after the decarbonization step showed that highly deposited $\mathrm{Ni}(20 \mathrm{vol} \%)$ and $\mathrm{Co}(30 \mathrm{vol} \%)$ composites with ceria had a uniform interface within the anode electrode (Figure 2.39) [56]. 


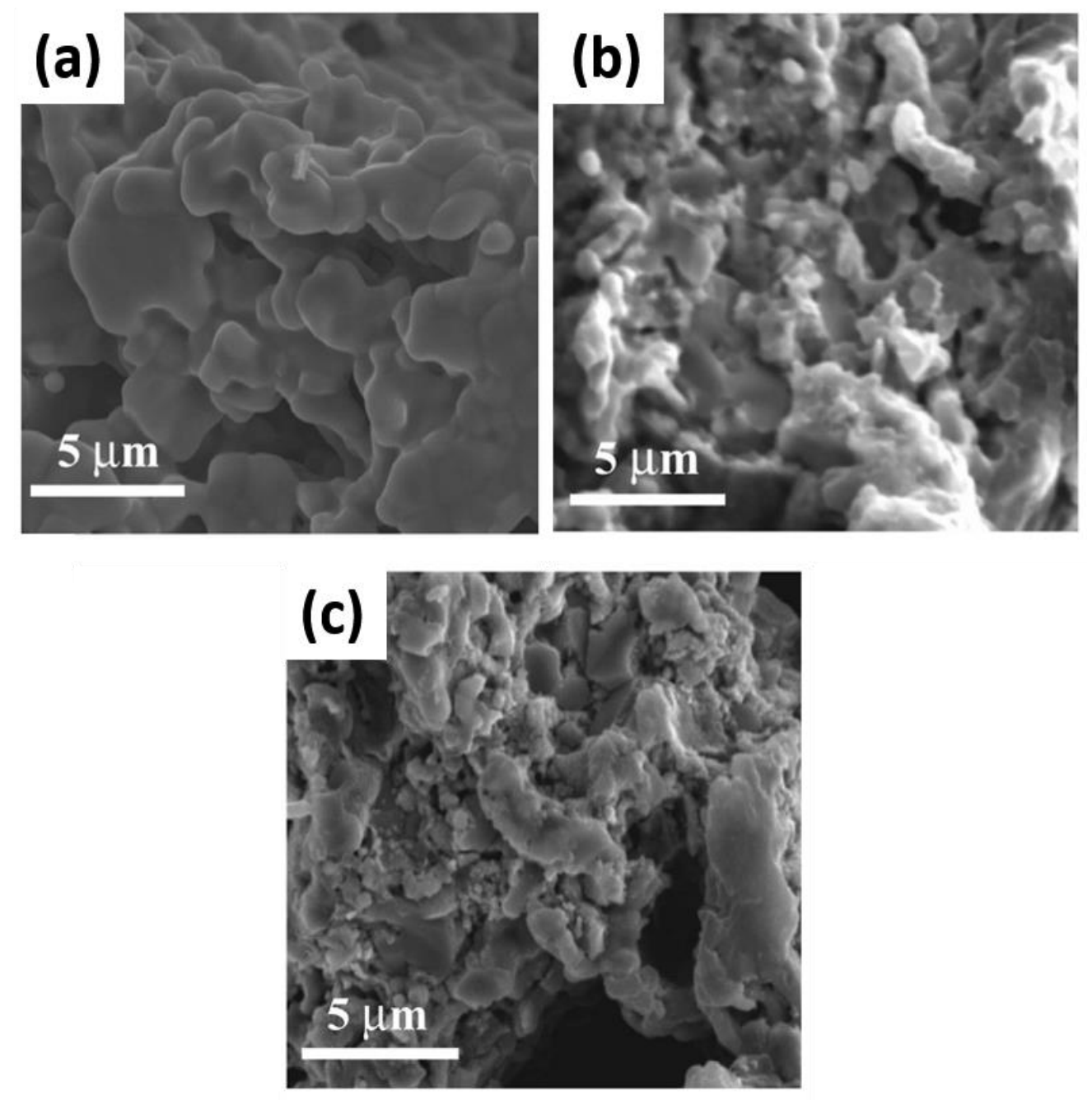

Figure 2.39. SEM images of a porous YSZ matrix (a) before and (b) after incorporation of $10 \mathrm{vol} \%$ ceria and $20 \mathrm{vol} \% \mathrm{Ni}$ or (c) 30 vol \% Co [56].

\subsubsection{Spin Coating}

Spin coating method provides lateral uniformity and good control of the infiltrated component amounts. In the literature, the method is applied for metal-supported and porous electrolyte substrates. Buyukaksoy et al. utilized spin coating for infiltration on their studies for both anode and cathode [38-40, 180]. First, a porous YSZ backbone layer was formed by spin coating of a YSZ powder suspension on the YSZ electrolyte at $3000 \mathrm{rpm}$. After firing at $1150^{\circ} \mathrm{C}$, 
the porosity of the spin-coated YSZ porous backbone was around 50\% after. It was required to repeat spin coating around 10-30 times to achieve the desired thickness. Then a polymeric nickel precursor was infiltrated to the porous backbone again with the spin coating technique. The cell was finally heated to $400^{\circ} \mathrm{C}$ for the decomposition of the polymeric precursor. To get the percolation of nickel oxide particles, it was necessary to repeat the process up to 35 times. The ratio of $\mathrm{NiO} / \mathrm{YSZ}$ was around $40 \%$. Figure 2.40 displays the structure of a porous YSZ backbone and the nickel oxide particles [40].

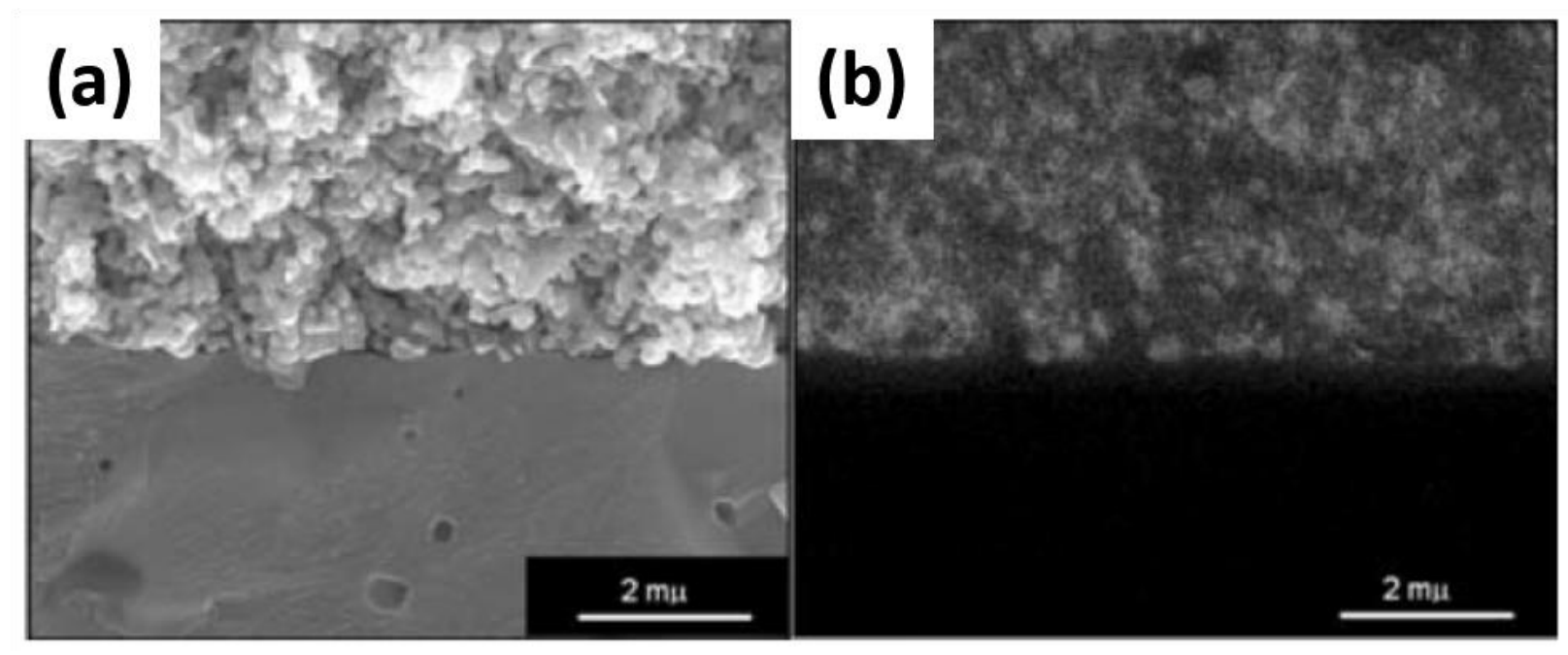

Figure 2.40. (a) The fracture surface where the EDS mapping data was collected (b) EDS map showing the Ni distribution in the Ni-YSZ cermet (Ni signals are in dark gray) [40].

\subsubsection{Pasting}

In this study, lanthanum promoted $\mathrm{Ni}-\mathrm{Al}_{2} \mathrm{O}_{3}$ catalysts were prepared by the glycine method [94]. Stoichiometric amounts of nickel nitrate, lanthanum nitrate, lithium nitrate, and aluminum were dissolved in DI water with the addition glycine at a molar ratio of glycine to total metallic cations of two. The gel precursor was obtained by heating the solution on a hot plate. The gel precursor was transferred to an oven at $240^{\circ} \mathrm{C}$. The obtained powder was calcined at $850^{\circ} \mathrm{C}$ for 5 hours as the last step. Then a slurry of the catalyst powder was painted onto the top surface of 
$\mathrm{Ni}-\mathrm{ScSZ}$ anode layer within a single step and sintered at $850^{\circ} \mathrm{C}$ in air for 1 hour. Figure 2.41 depicts the SEM image of the anode after running the fuel cell on methane for 10 hours. The pasted catalyst layer still adhered to the Ni-ScSZ layer without delamination and carbon deposition.

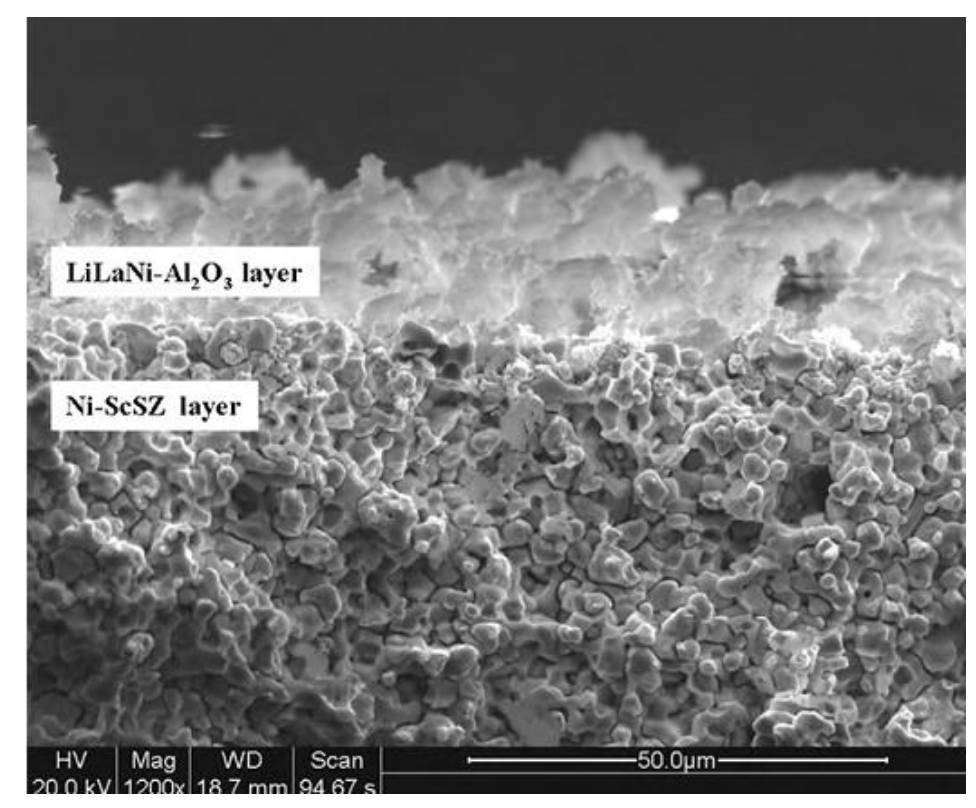

Figure 2.41. Cross-sectional SEM images of the catalyst-catalyst anode interface after the operation on methane fuel [94].

Figure 2.42.a shows the stability of the catalyst-pasted cell for the open circuit voltage (OCV) under methane fuel. During 150 minutes of operation, OCV was around $\sim 1.17 \mathrm{~V}$ and the peak power density (PPD) altered from $437 \mathrm{~mW} / \mathrm{cm}^{2}$ to $421 \mathrm{~mW} / \mathrm{cm}^{2}$, with a reduction of $3.7 \%$. With the application of $500 \mathrm{~mA} \mathrm{~cm}{ }^{-2}$ current density, the voltage decreased to $0.685 \mathrm{~V}$ with a decrease of $1.3 \%$ after testing under the same conditions (Figure 2.42.b). The study showed that pasting $\mathrm{LiLaNi}-\mathrm{Al}_{2} \mathrm{O}_{3}$ catalyst had high coking resistance as a promising application, although there was no diffusion study along the anode composition or coarsening study of catalysts. 

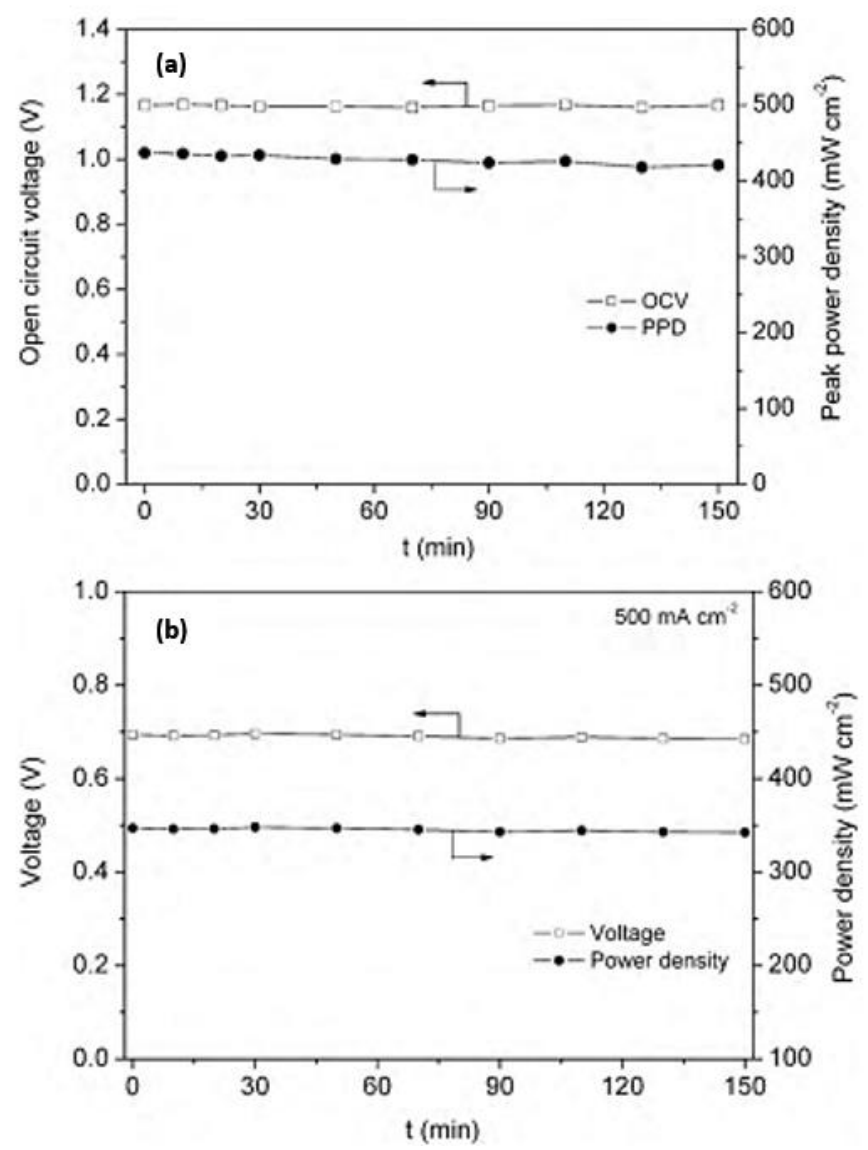

Figure 2.42. Time dependence of the peak power density and open circuit voltage (a) and voltage and power density under constant polarization current density of $500 \mathrm{~mA} \mathrm{~cm}{ }^{-2}(\mathbf{b})$, of the fuel cell with the $\mathrm{LiLaNi}-\mathrm{Al}_{2} \mathrm{O}_{3}$ catalyst layer, paste operating on pure methane fuel [94].

\subsubsection{Selected Topic 1: Microstructure Altering Acid Leaching Treatments Prior to Infiltration}

The study by Ye et al. mentioned the limitation of catalyst loading by the porosity of the anode matrix. However, having a critical porosity level is a requirement in order to meet mechanical strength and geometrical stability [99]. In that sense, an acid leaching process of nickel in the traditional $\mathrm{Ni} / \mathrm{YSZ}$ anode is utilized by taking the advantage of insoluble character of $\mathrm{ZrO}_{2}$ in 
acidic medium. Thus, it was aimed to have a YSZ frame with a properly interconnected porosity without the influence of other properties in the nonexistence of nickel structure. Leaching was performed by immersing $\mathrm{NiO} / \mathrm{YSZ}$ - current collection layer -, NiO/ScSZ - active layer - anode with ScSZ electrolyte structure to $2.2 \mathrm{M} \mathrm{HNO}_{3}$ at $80^{\circ} \mathrm{C}$ for about 2 hours to entirely remove nickel. It was mentioned that a relatively dense active layer was not affected by the acid leaching process. Infiltration of $\mathrm{CeO}_{2}$ and $\mathrm{CuO}_{2}$ catalysts were then infiltrated simultaneously by a dripping method on highly porous acid leached microstructure. Figure 2.43.b-c shows the difference between microstructures before and after acid leaching. After leaching, the measured average pore size was $5 \mu \mathrm{m}$. EDX results of spectrum 1 and spectrum 2 of Figure 2.43.c (not shown) detected that spectrum 1 was mainly composed of infiltrated particles and zirconia, while spectrum 2 was nickel and zirconia. This indicated the efficacy of acid leaching and infiltration protocol. Though, researchers perform this route in small batches of cells, nickel leaching is not a cost-effective route to create porosity. 

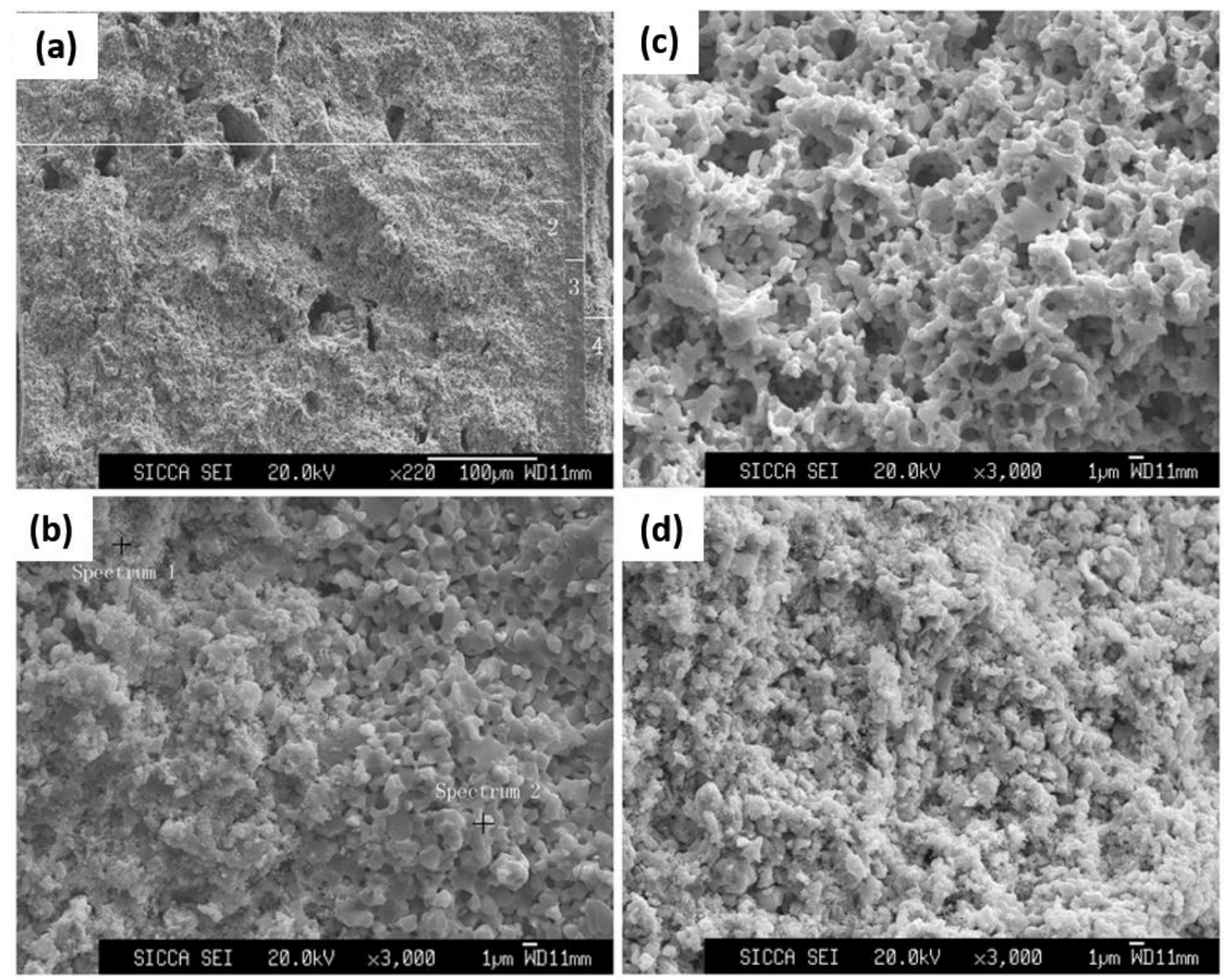

Figure 2.43. The cross-sectional SEM of the $\mathrm{Cu}-\mathrm{CeO} 2-\mathrm{YSZ} / \mathrm{Ni}-\mathrm{ScSZ} / \mathrm{PCM}$ single cell (a) the interface between the $\mathrm{Cu}-\mathrm{CeO} 2-\mathrm{YSZ}$ supported anode and the Ni-ScSZ anode functional layer (b), the porous YSZ matrix after acid leaching treatment (c) and the $\mathrm{Cu}-\mathrm{CeO} 2-\mathrm{YSZ}$ anode matrix after impregnation (d) [99].

\subsubsection{Selected Topic 2: Microwave Firing}

After each infiltration step, cells are usually fired conventionally in air atmosphere between $450-1000^{\circ} \mathrm{C}$. Transition-metal precursors (mostly metal salts) are calcined to form oxide nanoparticles. To form metallic nanoparticles, such as nickel [85] or silver [96], the calcination 
must be carried under reducing atmosphere, which is not a practical and cost-effective technique. Islam and Hill [52] demonstrated microwave irradiation as an alternative to conventional firing to shorten the time needed for subsequent calcination steps in impregnation cycle(s). In their research, the $\mathrm{Ni} / \mathrm{YSZ}$ anode of an electrolyte supported cell is dipped to a beaker of $\mathrm{Cu}$ precursor solution, then the beaker was placed in a household microwave oven $(2.45 \mathrm{~Hz}, 700 \mathrm{~W})$ for 15 seconds. The measured temperature of the solution during irradiation was $365 \mathrm{~K}\left(92^{\circ} \mathrm{C}\right)$. After washing and drying steps, the amount of $\mathrm{Cu}$ was $6 \mathrm{wt} \%$ with respect to $\mathrm{Ni}$ of the anode structure. In Figure 2.44, infiltrated nano particles less than $100 \mathrm{~nm}$ size can be seen clearly although some regions were not covered by $\mathrm{Cu}$ nanoparticles completely. Owing the time needed for calcination, the microwave irradiation method has shown a clear advantage over conventional firing methods both for achieving a fast calcination route and obtaining the desired metal phase. However, reproducibility of the protocol and potential cracking due to local temperature gradients between metal (nickel), metal oxide (YSZ) particles in anode cermet should be assessed in detail.
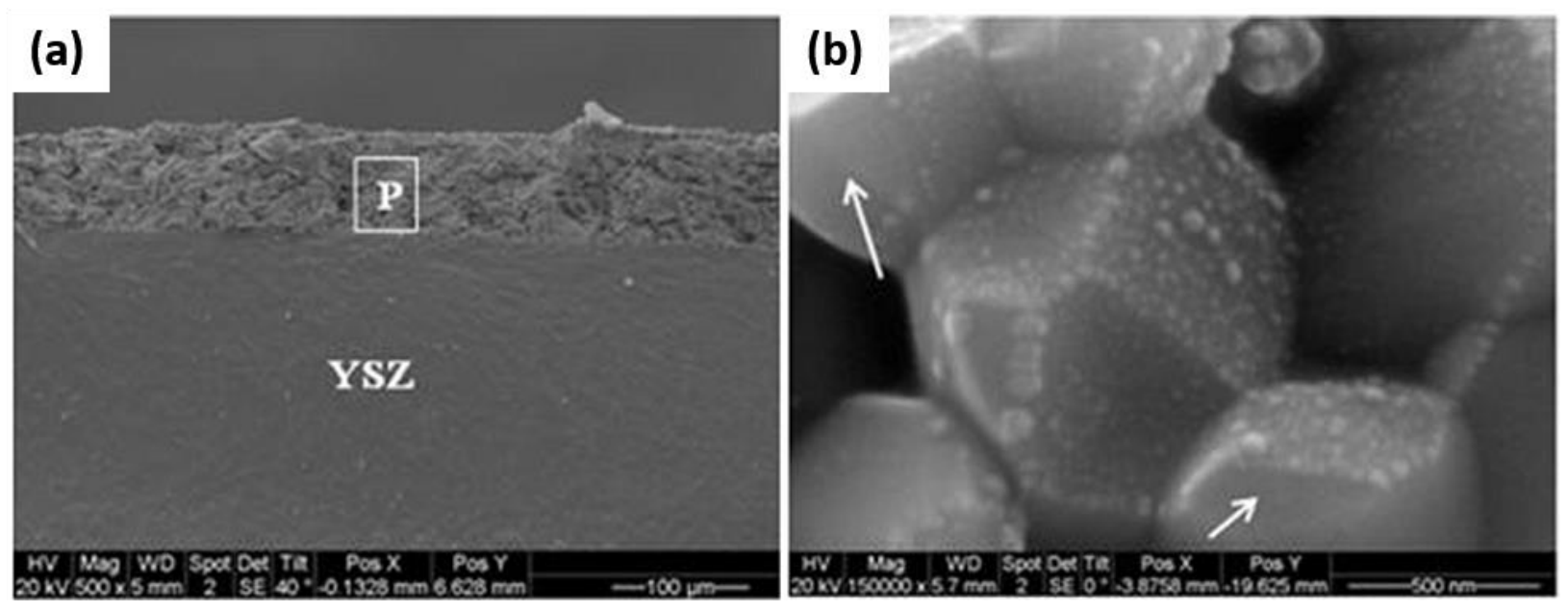

Figure 2.44. Cross-sectional $\mathrm{SEM}$ images of $\mathrm{Cu}_{\mathrm{M}} / \mathrm{Ni} / \mathrm{YSZ}$ cell: (a) anode-electrolyte interface, (b) enlarged image taken from region P. [52] 


\subsection{Conclusion and Comments}

In this review, infiltration methods and materials were systematically assessed. According to this review, the wet infiltration/impregnation method of various nanoparticles/catalysts was shown to be a promising technique to activate or modify the porous anode and cathode electrodes. The major outcome for infiltration is decreasing the polarization resistance of the electrode as a result of increasing triple phase boundary (TPB) density owing to high surface area nano-particles. Performance improvement can be achieved by infiltrating precious metal ( $\mathrm{Pd}, \mathrm{Ru}, \mathrm{Pt}, \mathrm{Au}, \mathrm{Ag})$, transition metal $(\mathrm{Ni}, \mathrm{Cu}, \mathrm{Co})$, or mixed-oxide conducting systems (ceria). The studies clearly showed that high oxygen ion conductivity and/or catalytic activity could be incorporated into electrode structures by wet impregnation/infiltration methods.

On the processing side, wet infiltration has some technical difficulties. Conventional infiltration methods mostly require repetitive steps, including multiple firing cycles, which make the whole process very labor-intensive. On each step, the liquid precursor dries previously calcined nano particles instead of the backbone which causes uncontrolled agglomeration. This potentially

reduces the efficacy of the infiltration by promoting grain growth during each firing step and potential clogging risks. To avoid these issues, a single infiltration protocol with an isolated decoration of anchored nanoparticles to the pore walls could be an optimum strategy. However, due to the solubility limits of the precursor, low precursor concentrations are usually preferred for the dripping method.

Unlike successful applications for the cathode, the wet infiltration of a SOFC Ni-based anodes is typicially found to be more difficult, since the most common SOFCs possess an anodesupported architecture. This means that the anode electrode is the thickest portion and the 
relatively denser electrode of the fuel cell. This challenging electrode structure is the key difficulty placement of catalyst to the active area.

Another aspect is that most previous research showed an increased improvement in electrochemical performance, usually reflected in an increase in power density or decrease in polarization resistance, within a relatively short operation time. Typically the performance enhancement is only shown for the first few hours of current loading. These works showed the effect of incorporated nano-particles shown sintering and coarsening in the initial few hours of operation which negates any perceived performance enhancements. For a realistic evaluation, long-term fuel cell operation ( $>500 \mathrm{~h}$ ) should be completed and characterized by these nanoinfiltration studies. In that sense, possible coarsening mitigation mechanisms must be taken into account. Furthermore, infiltration experiments should be carried on off-the-shelf commercial cells for a real case reference comparison and any potential scale-up options.

\subsection{References}

1. Andújar, J.M. and F. Segura, Fuel cells: History and updating. A walk along two centuries. Renewable and Sustainable Energy Reviews, 2009. 13(9): p. 2309-2322.

2. $\quad$ Steele, B.C. and A. Heinzel, Materials for fuel-cell technologies. Nature, 2001. 414(6861): p. 345-52.

3. EG\&G Technical Services, I., Fuel Cell Handbook. 7 ed. 2004: U.S. Department of Energy, Office of Fossil Energy. 427.

4. Mekhilef, S., R. Saidur, and A. Safari, Comparative study of different fuel cell technologies. Renewable and Sustainable Energy Reviews, 2012. 16(1): p. 981-989.

5. Wincewicz, K. and J. Cooper, Taxonomies of SOFC material and manufacturing alternatives. Journal of Power Sources, 2005. 140(2): p. 280-296.

6. Stambouli, A.B. and E. Traversa, Solid oxide fuel cells (SOFCs): a review of an environmentally clean and efficient source of energy. Renewable and Sustainable Energy Reviews, 2002. 6(5): p. 433-455.

7. Nguyen Quang Minh, T.T., Stack design and fabrication, in Science and Technology of Ceramic Fuel Cells. 1995, Elsevier. p. 233-306.

8. Nguyen Quang Minh, T.T., Introduction, in Science and Technology of Ceramic Fuel Cells. 1995, Elsevier. p. 1-14.

9. Yamamoto, O., Solid oxide fuel cells- fundamental aspects and prospects. Electrochimica Acta, 2000. 45: p. 2423-2435. 
10. Zhe Cheng, J.-H.W.a.M.L., Anodes, in Solid Oxide Fuel Cells: Materials Properties and Performance, R.H. Jeffrey Fergus, Xianguo Li, David P. Wilkinson, Jiujun Zhang, Editor. 2009, CRC Press. p. 73-129.

11. Irshad, M., et al., A Brief Description of High Temperature Solid Oxide Fuel Cell's Operation, Materials, Design, Fabrication Technologies and Performance. Applied Sciences, 2016. 6(3): p. 75.

12. Irvine, J.T.S., et al., Evolution of the electrochemical interface in high-temperature fuel cells and electrolysers. Nature Energy, 2016. 1(1): p. 15014.

13. Nguyen Quang Minh, T.T., Electrolyte, in Science and Technology of Ceramic Fuel Cells. 1995. p. 69-116.

14. Aadhavan, R. and K.S. Babu, Role of oxygen vacancy tuning in EBPVD deposited LaxCe1-xO2- ffilms in high temperature oxidation protection. RSC Adv., 2015. 5(102): p. $83538-83545$.

15. Pederson, L.R., P. Singh, and X.D. Zhou, Application of vacuum deposition methods to solid oxide fuel cells. Vacuum, 2006. 80(10): p. 1066-1083.

16. Mogensen, M., Introduction to fuel cells: Fundamentals of electrochemical inetics, thermodynamics and solid state chemistry for the experienced (I), in LargeSOFC Summer School 2010. 2010, Technical University of Denmark: Riso National Laboratory.

17. Nguyen Quang Minh, T.T., Principles of operation - Thermodynamic principle, in Science and Technology of Ceramic Fuel Cells. 1995, Elsevier. p. 15-40.

18. Zhu, W.Z. and S.C. Deevi, A review on the status of anode materials for solid oxide fuel cells. Materials Science and Engineering: A, 2003. 362(1-2): p. 228-239.

19. Gorte, R.J. and J.M. Vohs, Nanostructured anodes for solid oxide fuel cells. Current Opinion in Colloid \& Interface Science, 2009. 14(4): p. 236-244.

20. Kurokawa, H., et al., Ceria Nanocoating for Sulfur Tolerant Ni-Based Anodes of Solid Oxide Fuel Cells. Electrochemical and Solid-State Letters, 2007. 10(9): p. B135.

21. Sholklapper, T.Z., et al., Nanostructured Solid Oxide Fuel Cell Electrodes. Nano Letters, 2007. 7(7): p. 2136-2141.

22. Jiang, S.P., A review of wet impregnation-An alternative method for the fabrication of high performance and nano-structured electrodes of solid oxide fuel cells. Materials Science and Engineering: A, 2006. 418(1-2): p. 199-210.

23. Jiang, S.P., Y.Y. Duan, and J.G. Love, Fabrication of High-Performance $\mathrm{Ni} / \mathrm{Y}_{2} \mathrm{O}_{3}-\mathrm{ZrO}_{2}$ Cermet Anodes of Solid Oxide Fuel Cells by Ion Impregnation. Journal of The Electrochemical Society, 2002. 149(9): p. A1175.

24. Sasaki, K., et al., Chemical durability of Solid Oxide Fuel Cells: Influence of impurities on long-term performance. Journal of Power Sources, 2011. 196(22): p. 9130-9140.

25. Khan, M.S., et al., Fundamental mechanisms involved in the degradation of nickel-yttria stabilized zirconia (Ni-YSZ) anode during solid oxide fuel cells operation: A review. Ceramics International, 2016. 42(1): p. 35-48.

26. Chen, T., et al., Evaluation of carbon deposition behavior on the nickel/yttrium-stabilized zirconia anode-supported fuel cell fueled with simulated syngas. Journal of Power Sources, 2011. 196(5): p. 2461-2468.

27. Sasaki, K. and Y. Teraoka Equilibria in Fuel Cell Gases: I. Equilibrium Compositions and Reforming Conditions. Journal of The Electrochemical Society, 2003. 150(7): p. A878A884. 
28. Sholklapper, T.Z., et al., Synthesis of Dispersed and Contiguous Nanoparticles in Solid Oxide Fuel Cell Electrodes. Fuel Cells, 2008. 8(5): p. 303-312.

29. McIntosh, S., J.M. Vohs, and R.J. Gorte, Effect of Precious-Metal Dopants on SOFC Anodes for Direct Utilization of Hydrocarbons. Electrochemical and Solid-State Letters, 2003. 6(11): p. A240.

30. Wang, W., J.M. Vohs, and R.J. Gorte, Hydrogen Production Via CH4 and CO Assisted Steam Electrolysis. Topics in Catalysis, 2007. 46(3-4): p. 380-385.

31. Jung, S., et al., Influence of composition and $C u$ impregnation method on the performance of $\mathrm{Cu} / \mathrm{CeO} 2 / Y S Z$ SOFC anodes. Journal of Power Sources, 2006. 154(1): p. 42-50.

32. Gross, M.D., J.M. Vohs, and R.J. Gorte, A study of thermal stability and methane tolerance of Cu-based SOFC anodes with electrodeposited Co. Electrochimica Acta, 2007. 52(5): p. 1951-1957.

33. Adijanto, L., et al., SOFC anodes based on infiltration of tungsten bronzes. International Journal of Hydrogen Energy, 2011. 36(24): p. 15722-15730.

34. Afshar, M.R., et al., Impregnation of $\mathrm{La}_{0.4} \mathrm{Ce}_{0.6} \mathrm{O}_{1.8}-\mathrm{La}_{0.4} \mathrm{Sr}_{0.6} \mathrm{TiO}_{3}$ as solid oxide fuel cell anode in $\mathrm{H}_{2} \mathrm{~S}$-containing fuels. Journal of Power Sources, 2015. 274: p. 211-218.

35. Babaei, A., et al., Pd-promoted $(\mathrm{La}, \mathrm{Ca})(\mathrm{Cr}, \mathrm{Mn}) \mathrm{O}_{3} / \mathrm{GDC}$ anode for hydrogen and methane oxidation reactions of solid oxide fuel cells. Solid State Ionics, 2010. 181(25-26): p. 12211228.

36. Bi, Z.H. and J.H. Zhu, Effect of Current Collecting Materials on the Performance of the Double-Perovskite $\mathrm{Sr}_{2} \mathrm{MgMoO}_{6-\delta}$ Anode. Journal of The Electrochemical Society, 2011. 158(6): p. B605.

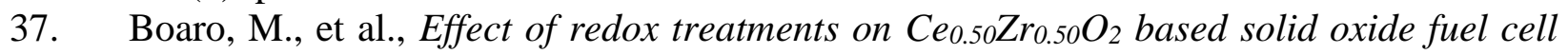
anodes. Journal of Power Sources, 2014. 270: p. 79-91.

38. Buyukaksoy, A., V. Petrovsky, and F. Dogan, Optimization of Redox Stable Ni-YSZ Anodes for SOFCs by Two-Step Infiltration. Journal of the Electrochemical Society, 2012. 159(12): p. F841-F848.

39. Buyukaksoy, A., V. Petrovsky, and F. Dogan, Redox Stable Solid Oxide Fuel Cells with Ni-YSZ Cermet Anodes Prepared by Polymeric Precursor Infiltration. Journal of The Electrochemical Society, 2012. 159(2): p. B232.

40. Buyukaksoy, A., V. Petrovsky, and F. Dogan, Stability and Performance of Solid Oxide Fuel Cells with Nanocomposite Electrodes. Journal of The Electrochemical Society, 2012. 159(6): p. B666.

41. Chen, Y., et al., Performance enhancement of Ni-YSZ electrode by impregnation of $\mathrm{Mo}_{0.1} \mathrm{Ce}_{0.9} \mathrm{O}_{2+\delta}$. Journal of Power Sources, 2012. 204: p. 40-45.

42. Cimenti, M. and J.M. Hill, Direct utilization of ethanol on ceria-based anodes for solid oxide fuel cells. Asia-Pacific Journal of Chemical Engineering, 2009. 4(1): p. 45-54.

43. Di Bartolomeo, E., et al., Ni and Ni-Co $\mathrm{La}_{0.8} \mathrm{Sr}_{0.2} \mathrm{Ga}_{0.8} \mathrm{Mg}_{0.2} \mathrm{O}_{3-\delta}$ infiltrated cells in $\mathrm{H}_{2}$ and $\mathrm{CH}_{4} / \mathrm{CO}_{2}$ mixture. Applied Catalysis B: Environmental, 2016. 191: p. 1-7.

44. Fan, L., et al., Performance of $\mathrm{Gd}_{0.2} \mathrm{Ce}_{0.8} \mathrm{O}_{1.9}$ infiltrated $\mathrm{La}_{0.2} \mathrm{Sr}_{0.8} \mathrm{TiO}_{3}$ nanofiber scaffolds as anodes for solid oxide fuel cells: Redox stability and effects of electrolytes. Journal of Power Sources, 2015. 294: p. 452-459.

45. Fernández-González, R., et al., Decreasing the polarisation resistance of a Ni-YSZ solid oxide fuel cell anode by infiltration of a ceria-based solution. International Journal of Hydrogen Energy, 2016. 
46. Garcia, A., et al., Highly cost-effective and sulfur/coking resistant $\mathrm{VO}_{x^{-}}$grafted $\mathrm{TiO}_{2}$ nanoparticles as an efficient anode catalyst for direct conversion of dry sour methane in solid oxide fuel cells. Journal of Materials Chemistry A, 2015. 3(47): p. 23973-23980.

47. Gaudillère, C., et al., Screening of ceria-based catalysts for internal methane reforming in low temperature SOFC. Catalysis Today, 2010. 157(1-4): p. 263-269.

48. Gavrielatos, I., V. Drakopoulos, and S. Neophytides, Carbon tolerant Ni-Au SOFC electrodes operating under internal steam reforming conditions. Journal of Catalysis, 2008. 259(1): p. 75-84.

49. Haberko, K., et al., Structural and electrical properties of Ni-YSZ cermet materials. Journal of Power Sources, 2010. 195(17): p. 5527-5533.

50. Hua, B., et al., Improved microstructure and performance of Ni-based anode for intermediate temperature solid oxide fuel cells. Journal of Power Sources, 2014. 247: p. 170-177.

51. Hussain, A.M., et al., Efficient ceramic anodes infiltrated with binary and ternary electrocatalysts for SOFCs operating at low temperatures. Journal of Power Sources, 2012. 216: p. 308-313.

52. Islam, S. and J.M. Hill, Preparation of $\mathrm{Cu}-\mathrm{Ni} / \mathrm{YSZ}$ solid oxide fuel cell anodes using microwave irradiation. Journal of Power Sources, 2011. 196(11): p. 5091-5094.

53. Jiang, S.P., et al., Performance of GDC-Impregnated Ni Anodes of SOFCs. Electrochemical and Solid-State Letters, 2004. 7(9): p. A282.

54. Jiang, S.P., et al., Fabrication and Performance of Impregnated Ni Anodes of Solid Oxide Fuel Cells. Journal of the American Ceramic Society, 2005. 88(7): p. 1779-1785.

55. Jiang, Z., et al., $\mathrm{La}_{0.85} \mathrm{Sr}_{0.15} \mathrm{MnO}_{3-\delta}$ Infiltrated $\mathrm{Y}_{0.5} \mathrm{Bi}_{1.5} \mathrm{O}_{3}$ Cathodes for IntermediateTemperature Solid Oxide Fuel Cells. Electrochemical and Solid-State Letters, 2009. 12(6): p. B91.

56. Jung, S.W., J.M. Vohs, and R.J. Gorte, Preparation of SOFC Anodes by Electrodeposition. Journal of The Electrochemical Society, 2007. 154(12): p. B1270.

57. Karczewski, J., et al., Solid oxide fuel cells with Ni-infiltrated perovskite anode. Solid State Ionics, 2012. 221: p. 11-14.

58. Kiebach, R., et al., Infiltration of SOFC Stacks: Evaluation of the Electrochemical Performance Enhancement and the Underlying Changes in the Microstructure. Fuel Cells, 2016. 16(1): p. 80-88.

59. Kim, G., et al., SOFC Anodes Based on LST-YSZ Composites and on $\mathrm{Y}_{0.04} \mathrm{Ce}_{0.48} \mathrm{Zr}_{0.48} \mathrm{O}_{2}$. Journal of The Electrochemical Society, 2008. 155(4): p. B360.

60. Kim, H.S., et al., $\mathrm{Pd}$ catalyzed $\mathrm{Sr}_{0.92} \mathrm{Y}_{0.08} \mathrm{TiO}_{3-\delta} / \mathrm{Sm}_{0.2} \mathrm{Ce}_{0.8} \mathrm{O}_{2-\delta}$ anodes in solid oxide fuel cells. Ceramics International, 2014. 40(6): p. 8237-8244.

61. Kim, H.S., et al., $\mathrm{Sr}_{0.92} \mathrm{Y}_{0.08} \mathrm{TiO}_{3-\delta} / \mathrm{Sm}_{0.2} \mathrm{Ce}_{0.8} \mathrm{O}_{2-\delta}$ anode for solid oxide fuel cells running on methane. International Journal of Hydrogen Energy, 2012. 37(21): p. 16130-16139.

62. Kim, J.H., et al., Investigation of Microstructural and Electrochemical Properties of Impregnated (La,Sr)(Ti,Mn) $\mathrm{O}_{3 \pm \delta}$ as a Potential Anode Material in High-Temperature Solid Oxide Fuel Cells. Chemistry of Materials, 2011. 23(17): p. 3841-3847.

63. Kim-Lohsoontorn, P., et al., Gadolinium doped ceria-impregnated nickel-yttria stabilised zirconia cathode for solid oxide electrolysis cell. International Journal of Hydrogen Energy, 2011. 36(16): p. 9420-9427.

64. Klemens $\varnothing$, T., et al., High performance metal-supported solid oxide fuel cells with Gddoped ceria barrier layers. Journal of Power Sources, 2011. 196(22): p. 9459-9466. 
65. Klemens $\varnothing$, T., et al., Stability of Ni-yttria stabilized zirconia anodes based on Niimpregnation. Journal of Power Sources, 2010. 195(21): p. 7295-7301.

66. Laosiripojana, N. and S. Assabumrungrat, Methane steam reforming over $\mathrm{Ni} / \mathrm{Ce}-\mathrm{ZrO} \mathrm{O}_{2}$ catalyst: Influences of $\mathrm{Ce}-\mathrm{ZrO}_{2}$ support on reactivity, resistance toward carbon formation, and intrinsic reaction kinetics. Applied Catalysis A: General, 2005. 290(1-2): p. 200-211.

67. Li, Y., et al., Cobalt-impregnated $\mathrm{La}_{0.75} \mathrm{Sr}_{0.25} \mathrm{Cr}_{0.5} \mathrm{Mn}_{0.5} \mathrm{O}_{3-\delta}$ anodes for solid oxide fuel cells. International Journal of Hydrogen Energy, 2014. 39(15): p. 7980-7987.

68. Liu, X., et al., Impregnated nickel anodes for reduced-temperature solid oxide fuel cells based on thin electrolytes of doped LaGaO3. Journal of Power Sources, 2013. 222: p. 9296.

69. Liu, Z., et al., Effect of impregnation phases on the performance of Ni-based anodes for low temperature solid oxide fuel cells. Journal of Power Sources, 2011. 196(20): p. 85618567.

70. Lo Faro, M., et al., Electrochemical behaviour of propane-fed solid oxide fuel cells based on low Ni content anode catalysts. Electrochimica Acta, 2009. 54(22): p. 5280-5285.

71. Lu, X. and J. Zhu, $\mathrm{Cu}(\mathrm{Pd})$-impregnated $\mathrm{La}_{0.75} \mathrm{Sr}_{0.25} \mathrm{Cr}_{0.5} \mathrm{Mn}_{0.5} \mathrm{O}_{3-\delta}$ anodes for direct utilization of methane in SOFC. Solid State Ionics, 2007. 178(25-26): p. 1467-1475.

72. Lund, A., et al., The effect of loading and particle size on the oxygen reaction in CGO impregnated Pt electrodes. Journal of Solid State Electrochemistry, 2011. 16(3): p. 11611168.

73. McIntyre, M.D., et al., Comparing in Situ Carbon Tolerances of Sn-Infiltrated and BaOInfiltrated Ni-YSZ Cermet Anodes in Solid Oxide Fuel Cells Exposed to Methane. The Journal of Physical Chemistry C, 2015. 119(14): p. 7637-7647.

74. Meng, X., et al., Highly stable microtubular solid oxide fuel cells based on integrated electrolytelanode hollow fibers. Journal of Power Sources, 2015. 275: p. 362-369.

75. Oh, T.-S., et al., Infiltrated lanthanum strontium chromite anodes for solid oxide fuel cells: Structural and catalytic aspects. Journal of Power Sources, 2014. 262: p. 207-212.

76. Osinkin, D.A., et al., High-performance anode-supported solid oxide fuel cell with impregnated electrodes. Journal of Power Sources, 2015. 288: p. 20-25.

77. Osinkin, D.A., N.M. Bogdanovich, and A.L. Gavrilyuk, Rate determining steps of fuel oxidation over $\mathrm{CeO}_{2}$ impregnated $\mathrm{Ni}$-YSZ in $\mathrm{H}_{2}+\mathrm{H}_{2} \mathrm{O}+\mathrm{CO}+\mathrm{CO}_{2}$ ambient. Electrochimica Acta, 2016. 199: p. 108-115.

78. Ozmen, O., et al., Bio-inspired surfactant assisted nano-catalyst impregnation of SolidOxide Fuel Cell (SOFC) electrodes. Materials Letters, 2016. 164: p. 524-527.

79. Presto, S., et al., Electrochemical performance of Ni-based anodes for solid oxide fuel cells. Journal of Applied Electrochemistry, 2009. 39(11): p. 2257-2264.

80. Presto, S. and M. Viviani, Infiltration of Metal Substrates with Nanostructured $\mathrm{CeO}_{2}$ by a Room-Temperature Wet Process. Journal of Nanoscience and Nanotechnology, 2015. 15(5): p. 3562-3567.

81. Puengjinda, P., et al., Optimization of anode material composed of $\mathrm{Y}$-doped $\mathrm{SrTiO}_{3}$ and metal and/or oxide additives for solid oxide fuel cells. Journal of Power Sources, 2012. 204: p. 67-73.

82. Puengjinda, P., et al., Stability of solid oxide fuel cell anodes based on YST-SDC composite with Ni catalyst. Journal of Power Sources, 2012. 216: p. 409-416.

83. Qiao, J., et al., $\mathrm{Ni} / \mathrm{YSZ}$ and $\mathrm{Ni}-\mathrm{CeO}_{2} / \mathrm{YSZ}$ anodes prepared by impregnation for solid oxide fuel cells. Journal of Power Sources, 2007. 169(2): p. 253-258. 
84. Qiao, J., et al., Performance of mix-impregnated $\mathrm{CeO}_{2}-\mathrm{Ni} / Y S Z$ Anodes for Direct Oxidation of Methane in Solid Oxide Fuel Cells. Fuel Cells, 2009. 9(5): p. 729-739.

85. Salehi, Z. and S. Salehi, $\mathrm{La}_{0.8} \mathrm{Sr}_{0.2} \mathrm{Ga}_{0.8} \mathrm{Mg}_{0.2} \mathrm{O}_{3-\delta}$ infiltrated with $\mathrm{Ni}$-Cu for direct methane solid oxide fuel cell application. Iranian Journal of Hydrogen \& Fuel Cell, 2015. 2(3): p. 139-149.

86. Sandoval, M.V., et al., Barium-modified NiO-YSZ/NiO-GDC cermet as new anode material for solid oxide fuel cells (SOFC). Solid State Ionics, 2014. 261: p. 36-44.

87. Savaniu, C.D. and J.T.S. Irvine, La-doped $\mathrm{SrTiO}_{3}$ as anode material for IT-SOFC. Solid State Ionics, 2011. 192(1): p. 491-493.

88. Shen, J., et al., Impregnated $\mathrm{LaCo}_{0.3} \mathrm{Fe}_{0.67} \mathrm{Pd}_{0.03} \mathrm{O}_{3-\delta}$ as a promising electrocatalyst for "symmetrical" intermediate-temperature solid oxide fuel cells. Journal of Power Sources, 2016. 306: p. 92-99.

89. Solís, C., et al., Catalytic surface promotion of highly active $\mathrm{La}_{0.85} \mathrm{Sr}_{0.15} \mathrm{Cr}_{0.8} \mathrm{~N}_{i 0.2} \mathrm{O}_{3-\delta}$ anodes for La $a_{5.6} W_{11.4-\delta}$ based proton conducting fuel cells. Applied Catalysis B: Environmental, 2014. 147: p. 203-207.

90. Tamm, K., et al., Solid oxide fuel cell anodes prepared by infiltration of strontium doped lanthanum vanadate into doped ceria electrolyte. Electrochimica Acta, 2013. 106: p. 398405.

91. Timurkutluk, B., et al., Anode-supported solid oxide fuel cells with ion conductor infiltration. International Journal of Energy Research, 2011. 35(12): p. 1048-1055.

92. Tiwari, P. and S. Basu, Ni infiltrated YSZ anode stabilization by inducing strong metal support interaction between nickel and titania in solid oxide fuel cell under accelerated testing. International Journal of Hydrogen Energy, 2013. 38(22): p. 9494-9499.

93. Torknik, F.S., et al., Microstructural refinement of $\mathrm{Ni} / \mathrm{Ce} 0 .{ }_{8} \mathrm{Gd}_{0.2} \mathrm{O}_{2-\delta}$ anodes for lowtemperature solid oxide fuel cell by wet infiltration loading of $\mathrm{PdCl}_{2}$. Ceramics International, 2014. 40(8): p. 12299-12312.

94. Wang, W., R. Ran, and Z. Shao, Lithium and lanthanum promoted $\mathrm{Ni}-\mathrm{Al}_{2} \mathrm{O}_{3}$ as an active and highly coking resistant catalyst layer for solid-oxide fuel cells operating on methane. Journal of Power Sources, 2011. 196(1): p. 90-97.

95. Wang, W., et al., A NiFeCu alloy anode catalyst for direct-methane solid oxide fuel cells. Journal of Power Sources, 2014. 258: p. 134-141.

96. $\mathrm{Wu}, \mathrm{X}$., et al., Preparation and electrochemical performance of silver impregnated Ni-YSZ anode for solid oxide fuel cell in dry methane. International Journal of Hydrogen Energy, 2015. 40(46): p. 16484-16493.

97. Xiao, G., et al., Ni modified ceramic anodes for solid oxide fuel cells. Journal of Power Sources, 2012. 201: p. 43-48.

98. Ye, X.-F., et al., Preparation and performance of a $\mathrm{Cu}-\mathrm{CeO}_{2}-\mathrm{ScSZ}$ composite anode for SOFCs running on ethanol fuel. Journal of Power Sources, 2007. 164(1): p. 203-209.

99. Ye, X.-F., et al., Improvement of $\mathrm{Cu}-\mathrm{CeO}_{2}$ anodes for SOFCs running on ethanol fuels. Solid State Ionics, 2009. 180(2-3): p. 276-281.

100. Ye, X.-F., et al., Research of carbon deposition formation and judgment in $\mathrm{Cu}-\mathrm{CeO}-\mathrm{ScSZ}$ anodes for direct ethanol solid oxide fuel cells. International Journal of Hydrogen Energy, 2012. 37(1): p. 505-510.

101. Yoo, K.B. and G.M. Choi, LST-GDC composite anode on LaGaO3-based solid oxide fuel cell. Solid State Ionics, 2011. 192(1): p. 515-518. 
102. Yue, X., A. Arenillas, and J.T.S. Irvine, Application of infiltrated LSCM-GDC oxide anode in direct carbon/coal fuel cells. Faraday Discuss., 2016.

103. Yun, J.W., et al., Ceria Coatings Effect on $\mathrm{H}_{2} \mathrm{~S}$ Poisoning of Ni/YSZ Anodes for Solid Oxide Fuel Cells. Journal of The Electrochemical Society, 2010. 157(12): p. B1825.

104. Zhang, C., et al., Improving single-chamber performance of an anode-supported SOFC by impregnating anode with active nickel catalyst. International Journal of Hydrogen Energy, 2010. 35(15): p. 8171-8176.

105. Zhang, L.-s., et al., Samaria-doped Ceria Modified Ni/YSZ Anode for Direct Methane Fuel in Tubular Solid Oxide Fuel Cells by Impregnation Method. Chinese Journal of Chemical Physics, 2009. 22(4): p. 429-434.

106. Zheng, L.L., et al., Effect of Pd-impregnation on performance, sulfur poisoning and tolerance of $\mathrm{Ni} / \mathrm{GDC}$ anode of solid oxide fuel cells. International Journal of Hydrogen Energy, 2012. 37(13): p. 10299-10310.

107. Zhou, Y., et al., Long-term stability of metal-supported solid oxide fuel cells employing infiltrated electrodes. Journal of Power Sources, 2015. 295: p. 67-73.

108. Zhu, X., et al., A rapid preparation of acicular Ni impregnated anode with enhanced conductivity and operational stability. Journal of Power Sources, 2014. 256: p. 424-429.

109. Zhu, X., et al., Enhanced performance of solid oxide fuel cells with $\mathrm{Ni} / \mathrm{CeO}_{2}$ modified $\mathrm{La}_{0.75} \mathrm{Sr}_{0.25} \mathrm{Cr}_{0.5 \mathrm{Mn}} \mathrm{M}_{0.5} \mathrm{O}_{3-\delta}$ anodes. Journal of Power Sources, 2009. 190(2): p. 326-330.

110. Zhu, X., et al., Fabrication and evaluation of a $\mathrm{Ni} / \mathrm{La}_{0.75} \mathrm{Sr}_{0.25} \mathrm{Cr}_{0.5} \mathrm{Fe}_{0.5} \mathrm{O}_{3-\delta}$ coimpregnated yttria-stabilized zirconia anode for single-chamber solid oxide fuel cells. International Journal of Hydrogen Energy, 2010. 35(13): p. 6897-6904.

111. Zhu, X., et al., Performance of the Single-Chamber Solid Oxide Fuel Cell with a $\mathrm{La}_{0.75} \mathrm{Sr}_{0.25} \mathrm{Cr}_{0.5} \mathrm{Mn}_{0.5} \mathrm{O}_{3-\delta}$-Based Perovskite Anode. Journal of The Electrochemical Society, 2010. 157(5): p. B691.

112. Chang, I., et al., Ultrathin YSZ Coating on Pt Cathode for High Thermal Stability and Enhanced Oxygen Reduction Reaction Activity. Advanced Energy Materials, 2015. 5(10): p. 1402251.

113. Choi, H.-J., et al., Enhanced electrochemical performance of metal-supported solid oxide fuel cells via an inner coating of $\mathrm{Gd}_{0.1} \mathrm{Ce}_{0.9} \mathrm{O}_{2-\delta}$ nanosol in the porous $\mathrm{NiFe}$-metal support. Journal of Power Sources, 2018. 406: p. 81-87.

114. Chrzan, A., et al., $\mathrm{La}_{0.6} \mathrm{Sr}_{0.4} \mathrm{Co}_{0.2} \mathrm{Fe}_{0.8} \mathrm{O}_{3-\delta}$ oxygen electrodes for solid oxide cells prepared by polymer precursor and nitrates solution infiltration into gadolinium doped ceria backbone. Journal of the European Ceramic Society, 2017. 37(11): p. 3559-3564.

115. Costa, R., et al., Performances and Limitations of Metal Supported Cells with Strontium Titanate based Fuel Electrode. Fuel Cells, 2018. 18(3): p. 251-259.

116. Drasbæk, D.B., et al., Testing Novel Nickel and Cobalt Infiltrated STN Anodes for Carbon Tolerance using In Situ Raman Spectroscopy and Electrochemical Impedance Spectroscopy. Fuel Cells, 2019.

117. Futamura, S., et al., SOFC anodes impregnated with noble metal catalyst nanoparticles for high fuel utilization. International Journal of Hydrogen Energy, 2019. 44(16): p. 85028518.

118. Gao, Z., et al., Tape Casting of High-Performance Low-Temperature Solid Oxide Cells with Thin $\mathrm{La}_{0.8 \mathrm{Sr}} \mathrm{.}_{2.2} \mathrm{Ga}_{0.8} \mathrm{Mg}_{0.2} \mathrm{O}_{3-\delta}$ Electrolytes and Impregnated Nano Anodes. ACS Appl Mater Interfaces, 2017. 9(8): p. 7115-7124. 
119. Gasper, P., et al., Effect of anodic current density on the spreading of infiltrated nickel nanoparticles in nickel-yttria stabilized zirconia cermet anodes. Journal of Power Sources, 2019. 410-411: p. 196-203.

120. Gong, Y., et al., Stabilizing nanostructured solid oxide fuel cell cathode with atomic layer deposition. Nano Lett, 2013. 13(9): p. 4340-5.

121. Hays, T., et al., Improved Sulfur Tolerance of SOFCs through Surface Modification of Anodes. ACS Applied Energy Materials, 2018. 1(4): p. 1559-1566.

122. Hussain, A.M., et al., Highly Performing Chromate-Based Ceramic Anodes $\left(\mathrm{Y}_{0.7} \mathrm{Ca}_{0.3} \mathrm{Cr}_{1-}\right.$ ${ }_{x} \mathrm{Cu}_{x} \mathrm{O}_{3-\delta}$ ) for Low-Temperature Solid Oxide Fuel Cells. ACS Appl Mater Interfaces, 2018. 10(42): p. 36075-36081.

123. Jeon, O.S., et al., Effects of dispersed copper nanoparticles on Ni-ceria based dry methanol fuelled low temperature solid oxide fuel cells. RSC Advances, 2019. 9(11): p. 6320-6327.

124. Jeong, H.Y., et al., Effect of Fe infiltration to Ni/YSZ solid-oxide-cell fuel electrode on steam/CO $\mathrm{C}_{2}$ co-electrolysis. International Journal of Energy Research, 2019. 43(9): p. 49494958.

125. Kang, J., et al., Application of electroless plating process for multiscale Ni$\mathrm{La}_{0.8} \mathrm{Sr}_{0.2} \mathrm{Ga}_{0.8} \mathrm{Mg}_{0.2} \mathrm{O}_{3-\sigma} \mathrm{SOFC}$ anode fabrication. International Journal of Hydrogen Energy, 2018. 43(12): p. 6400-6405.

126. Karimaghaloo, A., et al., Nanoscale Surface and Interface Engineering of Solid Oxide Fuel Cells by Atomic Layer Deposition. International Journal of Precision Engineering and Manufacturing-Green Technology, 2019. 6(3): p. 611-628.

127. Kim, S., et al., Tailoring Ni-based catalyst by alloying with transition metals $(M=N i$, Co, $\mathrm{Cu}$, and $\mathrm{Fe}$ ) for direct hydrocarbon utilization of energy conversion devices. Electrochimica Acta, 2017. 225: p. 399-406.

128. Kong, X., et al., Surface tuned $\mathrm{La}_{0.9} \mathrm{Ca}_{0.1} \mathrm{Fe}_{0.9} \mathrm{Nb}_{0.1} \mathrm{O}_{3-\delta}$ based anode for direct methane solid oxide fuel cells by infiltration method. Electrochimica Acta, 2017. 234: p. 71-81.

129. Lee, K., et al., Evaluation of metal-supported solid oxide fuel cells (MS-SOFCs) fabricated at low temperature $\left(\sim 1,000{ }^{\circ} \mathrm{C}\right)$ using wet chemical coating processes and a catalyst wet impregnation method. International Journal of Hydrogen Energy, 2018. 43(7): p. 37863796.

130. Lee, M.-J., et al., Fabrication and electrochemical performance of nickel- and gadoliniumdoped ceria-infiltrated $\mathrm{La}_{0.2} \mathrm{Sr}_{0.8} \mathrm{TiO}_{3}$ anodes for solid oxide fuel cells. Journal of Power Sources, 2018. 374: p. 181-187.

131. Li, W., et al., On the limiting factor of impregnation methods for developing $\mathrm{Cu} / \mathrm{CeO}_{2}$ anodes for solid oxide fuel cells. Journal of Solid State Electrochemistry, 2018. 22(6): p. $1735-1743$.

132. Li, Y.K., et al., Nanoporous silver cathodes surface-treated by atomic layer deposition of $\mathrm{Y:ZrO}$ for high-performance low-temperature solid oxide fuel cells. Journal of Power Sources, 2015. 295: p. 175-181.

133. Lu, Y., et al., Improving intermediate temperature performance of Ni-YSZ cermet anodes for solid oxide fuel cells by liquid infiltration of nickel nanoparticles. Journal of Power Sources, 2018. 396: p. 257-264.

134. Mitchell-Williams, T.B., et al., Infiltration of commercially available, anode supported SOFC's via inkjet printing. Materials for Renewable and Sustainable Energy, 2017. 6(2). 
135. Muzaffar, N., et al., Fabrication and Electrochemical Performance of Zn-Doped $\mathrm{La}_{0.2} \mathrm{Sr}_{0.25} \mathrm{Ca}_{0.45} \mathrm{TiO}_{3}$ Infiltrated with Nickel-CGO, Iron, and Cobalt as an Alternative Anode Material for Solid Oxide Fuel Cells. Catalysts, 2019. 9(3): p. 269.

136. Neoh, K.C., et al., Nanoporous silver cathode surface treated by atomic layer deposition of $\mathrm{CeO}_{(x)}$ for low-temperature solid oxide fuel cells. Nanotechnology, 2016. 27(18): p. 185403.

137. $\mathrm{Ni}, \mathrm{C}$, , et al., Microstructure dependence of performance degradation for intermediate temperature solid oxide fuel cells based on the metallic catalyst infiltrated La-and Cadoped $\mathrm{SrTiO}_{3}$ anode support. Journal of Materials Chemistry A, 2018. 6(13): p. 5398-5406.

138. $\mathrm{Ni}, \mathrm{C}$., et al., Effect of anode calcination on the performance and redox stability of lowtemperature solid oxide fuel cells prepared via impregnation. International Journal of Hydrogen Energy, 2017. 42(52): p. 30760-30768.

139. Niu, B., et al., Pd-impregnated $\mathrm{Sr}_{1.9} \mathrm{VMoO}_{6}$-double perovskite as an efficient and stable anode for solid-oxide fuel cells operating on sulfur-containing syngas. Electrochimica Acta, 2018. 274: p. 91-102.

140. Sarno, C., et al., Lanthanum chromite based composite anodes for dry reforming of methane. International Journal of Hydrogen Energy, 2018. 43(31): p. 14742-14750.

141. Skafte, T.L., et al., Reactivating the Ni-YSZ electrode in solid oxide cells and stacks by infiltration. Journal of Power Sources, 2018. 378: p. 685-690.

142. Song, Y., et al., Rational Design of a Water-Storable Hierarchical Architecture Decorated with Amorphous Barium Oxide and Nickel Nanoparticles as a Solid Oxide Fuel Cell Anode with Excellent Sulfur Tolerance. Adv Sci (Weinh), 2017. 4(11): p. 1700337.

143. Tomov, R.I., et al., Inkjet Printing and Inkjet Infiltration of Functional Coatings for SOFCs Fabrication. 2017: p. 161-165.

144. Tomov, R.I., et al., Performance optimization of $\mathrm{LSCF} / \mathrm{Gd}: \mathrm{CeO}_{2}$ composite cathodes via single-step inkjet printing infiltration. Journal of Applied Electrochemistry, 2017. 47(5): p. 641-651.

145. Troskialina, L. and R. Steinberger-Wilckens, The effects of Sn infiltration on dry reforming of biogas at solid oxide fuel cell operating conditions over Ni-YSZ catalysts. IOP Conference Series: Materials Science and Engineering, 2019. 509: p. 012064.

146. Venâncio, S.A. and P.E.V. de Miranda, Direct utilization of carbonaceous fuels in multifunctional SOFC anodes for the electrosynthesis of chemicals or the generation of electricity. International Journal of Hydrogen Energy, 2017. 42(19): p. 13927-13938.

147. Wang, C., et al., Inkjet printing infiltration of $\mathrm{Ni}-\mathrm{Gd}: \mathrm{CeO}_{2}$ anodes for low temperature solid oxide fuel cells. Journal of Applied Electrochemistry, 2017. 47(11): p. 1227-1238.

148. Welander, M.M., et al., Mitigating Carbon Formation with $\mathrm{Al}_{2} \mathrm{TiO}_{5}$-Enhanced Solid Oxide Fuel Cell Anodes. The Journal of Physical Chemistry C, 2019. 123(18): p. 11406-11413.

149. Yu, A.S., et al., Modification of SOFC Cathodes by Atomic Layer Deposition. Journal of The Electrochemical Society, 2013. 160(11): p. F1225-F1231.

150. Zeng, Y., et al., Powering Solid Oxide Fuel Cells with Syngas Using $\mathrm{La}_{0.4} \mathrm{Sr}_{0.5} \mathrm{Ba}_{0.1} \mathrm{TiO}_{3}$ Anode Infitrated with Nano-composite. Fuel Cells, 2019. 19(2): p. 141-146.

151. Zhang, Y., et al., $\mathrm{La}_{0.6} \mathrm{Sr}_{0.4} \mathrm{Co}_{0.2} \mathrm{Fe}_{0.8} \mathrm{O}_{3-\delta}$ nanoparticles modified $\mathrm{Ni}$-based anode for direct methane-fueled SOFCs. Energy Procedia, 2019. 158: p. 2250-2255.

152. Zhu, C., et al., Perovskite $\mathrm{SrFeO}_{3-\delta}$ decorated with Ni nanoparticles for high temperature carbon dioxide electrolysis. International Journal of Hydrogen Energy, 2018. 43(36): p. 17040-17047. 
153. Gorte, R., Recent developments on anodes for direct fuel utilization in SOFC. Solid State Ionics, 2004. 175(1-4): p. 1-6.

154. Lu, X.C., et al., Pd-impregnated SYT/LDC composite as sulfur-tolerant anode for solid oxide fuel cells. Journal of Power Sources, 2009. 192(2): p. 381-384.

155. Jiang, S.P., Nanoscale and nano-structured electrodes of solid oxide fuel cells by infiltration: Advances and challenges. International Journal of Hydrogen Energy, 2012. 37(1): p. 449-470.

156. Shearing, P.R., et al., Exploring microstructural changes associated with oxidation in NiYSZ SOFC electrodes using high resolution X-ray computed tomography. Solid State Ionics, 2012. 216: p. 69-72.

157. Corre, G., et al., Activation and Ripening of Impregnated Manganese Containing Perovskite SOFC Electrodes under Redox Cycling. Chemistry of Materials, 2009. 21(6): p. 1077-1084.

158. EG\&G Technical Services, I., Fuel Cell Hand Book. 2004.

159. Huijsmans, J.P.P., Ceramics in solid oxide fuel cells. Curr Opin Solid St M, 2001. 5(4): p. 317-323.

160. Wang, Z., et al., Catalytic modification of Ni-Sm-doped ceria anodes with copper for direct utilization of dry methane in low-temperature solid oxide fuel cells. Journal of Power Sources, 2008. 179(2): p. 541-546.

161. You, H.-X., et al., Reactions of low concentration dry methane at Ni-YSZ anode in the SOFCs. Journal of Fuel Chemistry and Technology, 2011. 39(1): p. 69-74.

162. Cimenti, M. and J.M. Hill, Direct utilization of methanol and ethanol in solid oxide fuel cells using $\mathrm{Cu}-\mathrm{Co}(\mathrm{Ru}) / \mathrm{Zr}_{0.35} \mathrm{Ce}_{0.65} \mathrm{O}_{2-\delta}$ anodes. Journal of Power Sources, 2010. 195(13): p. 3996-4001.

163. Wang, W., et al., Enhanced electrochemical performance, water storage capability and coking resistance of a $\mathrm{Ni}+\mathrm{BaZr}_{0.1} \mathrm{Ce}_{0.7} \mathrm{Y}_{0.1} \mathrm{Yb}_{0.1} \mathrm{O}_{3-\delta}$ anode for solid oxide fuel cells operating on ethanol. Chemical Engineering Science, 2015. 126: p. 22-31.

164. Ramos, I.A.C., et al., Hydrogen production from ethanol steam reforming on $\mathrm{M} / \mathrm{CeO}_{2} / Y S Z$ $(M=R u, P d, A g)$ nanocomposites. Catalysis Today, 2012. 180(1): p. 96-104.

165. Galenda, A., M.M. Natile, and A. Glisenti, LSCF and $\mathrm{Fe}_{2} \mathrm{O}_{3} / L S C F$ powders: Interaction with methanol. Journal of Molecular Catalysis A: Chemical, 2008. 282(1-2): p. 52-61.

166. Resini, C., et al., Yttria-stabilized zirconia (YSZ) supported Ni-Co alloys (precursor of SOFC anodes) as catalysts for the steam reforming of ethanol. International Journal of Hydrogen Energy, 2008. 33(14): p. 3728-3735.

167. Lou, X., et al., Controlling the morphology and uniformity of a catalyst-infiltrated cathode for solid oxide fuel cells by tuning wetting property. Journal of Power Sources, 2010. 195(2): p. 419-424.

168. Huang, Y., J.M. Vohs, and R.J. Gorte, SOFC Cathodes Prepared by Infiltration with Various LSM Precursors. Electrochemical and Solid-State Letters, 2006. 9(5): p. A237.

169. Jiang, Z., C. Xia, and F. Chen, Nano-structured composite cathodes for intermediatetemperature solid oxide fuel cells via an infiltration/impregnation technique. Electrochimica Acta, 2010. 55(11): p. 3595-3605.

170. Yao, S.-Y. and Z.-H. Xie, Deagglomeration treatment in the synthesis of doped-ceria nanoparticles via coprecipitation route. Journal of Materials Processing Technology, 2007. 186(1-3): p. 54-59. 
171. Li, W., et al., Effect of adding urea on performance of $\mathrm{Cu} / \mathrm{Ce} \mathrm{O}_{2} /$ yttria-stabilized zirconia anodes for solid oxide fuel cells prepared by impregnation method. Electrochimica Acta, 2011. 56(5): p. 2230-2236.

172. Li, X., et al., Performance of a commercial cathode-supported solid oxide fuel cells prepared by single-step infiltration of an ion-conducting electrocatalyst. Journal of Power Sources, 2012. 199: p. 132-137.

173. Shah, M. and S. Barnett, Solid oxide fuel cell cathodes by infiltration of La0.6Sr0.4Co0.2Fe0.8O3- $\delta$ into Gd-Doped Ceria. Solid State Ionics, 2008. 179(35-36): p. 2059-2064.

174. Tucker, M.C., et al., Performance of metal-supported SOFCs with infiltrated electrodes. Journal of Power Sources, 2007. 171(2): p. 477-482.

175. Nicholas, J.D. and S.A. Barnett, Measurements and Modeling of $\mathrm{Sm}_{0.5} \mathrm{Sr}_{0.5} \mathrm{CoO}_{3}-x-$ $\mathrm{Ce}_{0.9} \mathrm{Gd}_{0.1} \mathrm{O}_{1.95} \mathrm{SOFC}$ Cathodes Produced Using Infiltrate Solution Additives. Journal of The Electrochemical Society, 2010. 157(4): p. B536.

176. Jiang, Z., et al., Electrochemical characteristics of solid oxide fuel cell cathodes prepared by infiltrating ( $\mathrm{La}, \mathrm{Sr}) \mathrm{MnO}_{3}$ nanoparticles into yttria-stabilized bismuth oxide backbones. International Journal of Hydrogen Energy, 2010. 35(15): p. 8322-8330.

177. Dudek, M., et al., Feasibility of direct carbon solid oxide fuels cell (DC-SOFC) fabrication by inkjet printing technology. Electrochimica Acta, 2013. 105: p. 412-418.

178. Tomov, R.I., et al., Direct Ceramic Inkjet Printing and Infiltration of Functional Coatings for Metal Supported SOFC. ECS Transactions, 2015. 68(1): p. 2491-2501.

179. Ruiz-Trejo, E., A. Atkinson, and N.P. Brandon, Metallizing porous scaffolds as an alternative fabrication method for solid oxide fuel cell anodes. Journal of Power Sources, 2015. 280: p. 81-89.

180. Buyukaksoy, A., V. Petrovsky, and F. Dogan, Efficient Cathodes for Solid Oxide Fuel Cells Prepared by Polymeric Precursor Infiltration. Journal of The Electrochemical Society, 2012. 159(1): p. B68. 


\section{Chapter 3 : pDA Bio-Surfactant Assisted Nano-Catalyst Infiltration of Solid-Oxide Fuel Cell (SOFC) Electrodes}

\subsection{Introduction}

The introduction of nano-catalysts into the porous electrode microstructure of Solid Oxide Fuel Cells (SOFC) was previously achieved through solution or suspension impregnation methods. These impregnation processes typically showed an increase in cell power density over short operation times reported by Jiang et al. [1]. According to the review, various aspects of fuel, oxidant adsorption, and diffusion can be distinctly engineered by incorporating a small volume fraction of nano-catalyst into the electrodes. This can even be accomplished after the final sintering process of the SOFC membrane-electrode assembly (MEA) is completed. One attractive aspect of this method is that the performance of the SOFCs may be increased without any extensive alterations to the anode or cathode microstructure after initial cell fabrication. Typical nanocatalyst impregnated compositions for SOFC electrodes include doped- $\mathrm{CeO}_{2}, \mathrm{Cu}, \mathrm{Co}, \mathrm{Pt}$, and $\mathrm{Ni}$ for the anode [2-6], and $\mathrm{Pd}$, doped- $\mathrm{CeO}_{2},(\mathrm{La}, \mathrm{Sr}) \mathrm{MnO}_{3}$ and $(\mathrm{La}, \mathrm{Sr}) \mathrm{CoO}_{3}$ [7-10] for the cathode. Most papers in the literature describe one major processing restriction for wet infiltration/impregnation strategies; the process usually requires multiple infiltrations and drying steps in order to achieve the desired nano-catalyst loading and to insure the proper increase in performance [11]. Numerous steps are necessary since preferential drying at the surface of the porous structure results in precipitate segregation and agglomeration, eliminating the ability to further incorporate more salt solution deeper into the microstructure.

To control the dispersion and wetting of porous structures with metal salt solutions, some dispersant and surfactant additives, such as Triton $\mathrm{X}-1$, glycol, urea and citric acid $[9,12]$ were introduced in the previous studies. The surfactants utilized for these works were specifically 
associated with the composition of the substrate and/or nano-catalyst; therefore, the surfactant system needed to be re-engineered for any change in the SOFC electrode or nano-catalyst composition. One potential solution to this issue is to use a versatile substrate modifying surfactant, such as poly-dopamine (pDA). pDA is a biochemical that is commonly found in nature, for example, in the foot protein of a mussel. Owing to the multi-functional $\mathrm{OH}^{-}$and amine groups, the molecule was shown to adsorb or react with various organic and inorganic materials [13] (Figure 3.1).
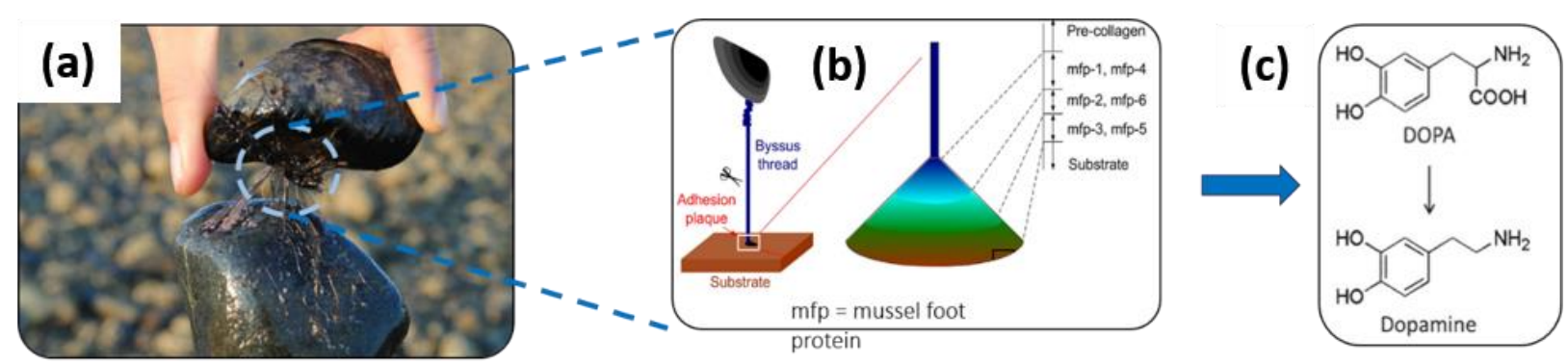

Figure 3.1. (a) A mussel sticks to the rocks by the polymerized dopamine [14]. (b) DOPA is synthesized at the mussel legs in various molarities (mfp) [15] (c) the molecular structure of DOPA and dopamine.

Recent research showed that the deposition of nanoscale, two-dimensional films of metals, oxides, and polymers onto planar substrates with various chemistries could be achieved by surface modification of those surfaces with pDA. Specifically, the $\mathrm{OH}^{-}$groups in the polymer chain of pDA locally attract metal cations and chelate into the metal hydroxide form. The mechanism can be articulated as a deposition process that is not altered by the fast drying or cation migration towards the edges. Hence, the prime advantage of using pDA as a surfactant is the ability to grow a thin film that allows for distinct control of the nucleation and growth rate of a broad spectrum of compositions through the simple tuning of the pDA solution concentration and immersion time 
[16]. In addition, being independent of the substrate and the coating material, the catechol templating has great potential in assembling nanoparticles on to the planar substrate and also potentially through the 3-D porous backbones.

The objective of this work is to develop a facile two-step dip-coating process to incorporate a controlled amount of nano-catalyst into the both porous SOFC electodes (the anode and cathode). At first, the pDA surfactant was introduced into the porous electrode structure through an initial dip-coating procedure to control the heterogeneous nucleation mechanism (bio-coating) for this process. The second step included the dip-coating of the SOFC membrane with a catalyst precursor to deposit nano-catalyst on to the pDA layer. In this study, ceria $\left(\mathrm{CeO}_{2}\right)$ was used as the baseline catalyst composition to demonstrate the process. Cerium oxide has a cubic fluorite-type structure that has been one of the major non-noble constituents in catalytic systems due to its +4 to +3 valence switching character. Hereafter, nanostructured ceria catalysts can be used in both reducing and oxidizing environments. As shown in Figure 2.13, cerium based catalyst systems are one of the most utilized nano-catalyst systems for promoting the half-reaction kinetics on both the cathode and the anode in the literature. Off-the-shelf SOFCs were infiltrated with pDA-treated cerium nitrate protocol to demonstrate the applicability of the process to commercial cells, where the electrode microstructures did not need to be further modified in order to increase process efficiency, which is typically required for nano-infiltration/impregnation methods.

\subsection{Experimental}

Thermal gravimetric analysis (TGA) was performed on as-received dopamine hydrochloride (99\%, Alfa-Aesar) and polymerized dopamine (pDA). For Poly-dopamine, $2 \mathrm{mg} / \mathrm{ml}$ of dopamine hydrochloride (99\%, Alfa-Aesar) is polymerized in water with 0.05M TRIS (tris(hydroxymethyl) aminomethane, 99\%, Alfa-Aesar) buffer at $\mathrm{pH} 8.5$ for 16 hours. Then the 
solution is dried in the oven overnight to precipitate the pDA. All the samples were heated to $850^{\circ} \mathrm{C}$ with $2^{\circ} \mathrm{C} / \mathrm{min}$ rate in the air during the TGA testing.

Anode-supported button SOFCs (ASC-2.7, NexTech Materials, Ltd.) were used for this study. These cells were $27 \mathrm{~mm}$ in diameter and consist of a $240 \mu \mathrm{m}$ thick NiO/yttrium-stabilized zirconia (YSZ) anode, a dense $8 \mu \mathrm{m}$ thick YSZ electrolyte (27 mm in diameter), and a ( $\mathrm{La}, \mathrm{Sr}) \mathrm{MnO}_{3}$ (LSM)/LSM-GDC cathode, which was $12.5 \mathrm{~mm}$ in diameter and $50 \mu \mathrm{m}$ thick.

Contact angle measurements were performed to characterize the wettability of pDA and cerium nitrate solutions in various water/ethanol ratios. $\mathrm{NiO} / \mathrm{YSZ}$ pellets were prepared and sintered at $1450^{\circ} \mathrm{C}$ as substrates to mimic a conventional anode surface. Droplet images were taken with a Dino-lite digital microscope (AnMo Electronics Corp, Taiwan). The contact angle was measured by a drop analysis plugin in Image-J software.

The modification of the electrodes was initially completed by incorporating the pDA into the porous electrode microstructures through a well-known dip-coating (DC) process. The pDA solution was prepared by dissolving $1 \mathrm{mg} / \mathrm{ml}$ dopamine hydrochloride (99\%, Alfa-Aesar) into a 0.05 M TRIS (tris(hydroxymethyl) aminomethane, 99\%, Alfa-Aesar) and 1:1 vol \% water-ethanol mixture at $\mathrm{pH}$ 8.5. The TRIS buffer stabilized the $\mathrm{pH}$ during the polymerization reaction [13]. Polymerization was confirmed visually by the transition of solution color from transparent to brown. Two pDA assisted dip-coating techniques were used in these experiments: 1) ex-situ polymerization (ex-situ $\mathrm{DC} \mathrm{pDA}$ ), in which the bio-coating solution was polymerized in a separate beaker before submersion of the SOFC membrane into the solution; and 2) in-situ polymerization (in-situ $\mathrm{DC} \mathrm{pDA}$ ), in which the bio-coating solution polymerization reaction was initiated after the SOFC was submerged into the solution. For the ex-situ polymerization process, a Nalgene ${ }^{\circledR}$ polyethersulfone $0.2 \mu \mathrm{m}$ syringe filter (Thermo Scientific) was used to filter the polymerized bio- 
coating solution to eliminate micron-sized pDA aggregates from the solution. These aggregates could potentially block pores and restrict the infiltration of the salt solution during the second step of the process.

The pDA bio-coating step was applied to both electrodes simultaneously by submerging the entire SOFC into a beaker containing the pDA solution. The beaker was placed in a vacuum chamber under $30 \mathrm{~mm} \mathrm{Hg}$ vacuum for $5 \mathrm{~min}$. The beaker was removed from the vacuum chamber and transferred to a rocker table for $3 \mathrm{~h}$ in ambient conditions. The cell was then rinsed two times with a $50 \%$ ethanol-water mixture before immersing into the cerium solution. The cerium solution had a concentration of $0.4 \mathrm{M}$ within a $1: 1$ vol \% water-ethanol solvent and cerium (III) nitrate hexahydrate (REacton ${ }^{\circledR}, 99.5 \%$, Alfa Aesar) the salt to form the solution. The SOFCs remained submerged within the cerium solution on the rocking table for a $24 \mathrm{~h}$ period before removal. The surfaces of both electrodes were rinsed with a 1:1 vol \% water-ethanol solution, and permitted to dry in ambient conditions. After drying, all impregnated cells were fired at $750^{\circ} \mathrm{C}$ to obtain pure ceria nanoparticles. The impregnated cells were weighed before and after firing to measure the degree of nano-catalyst incorporation.

To compare the effectiveness of the bio-coating procedures, the cells were dipped inside the cerium solution for $24 \mathrm{~h}$ without pretreatment of the pDA surfactant. One SOFC sample was also impregnated using the dripping method which is the conventional method demonstrated throughout literature. The experiment included dripping $1 \mathrm{ml}$ of $0.4 \mathrm{M}$ cerium (III) nitrate solution from the 1:1 vol \% water-ethanol mixture onto the anode side. The solution was dripped onto the top surface of the anode using a $3 \mathrm{ml}$ plastic pipette, before placing the cell under $30 \mathrm{~mm} \mathrm{Hg}$ vacuum. It should be noted that only the anode was impregnated with the cerium nano-catalyst for this baseline experiment. The sample was then dried in a vacuum oven at $50^{\circ} \mathrm{C}$. Fuel cell testing 
(current-voltage-power and impedance spectroscopy measurements) was performed at $750^{\circ} \mathrm{C}$ with humid $\mathrm{H}_{2}$ fuel, using the same procedure described in a previous paper [17].

\subsection{Results and Discussion}

Prioir to the SOFC electrode infiltration, preliminary tests were performed to determine that the pDA layer enters the system only as a sacrifice layer that does not stay in the system after the thermal treatment and does not alter the fuel cell performance itself. Figure 3.2 shows thermogravimetric analysis (TGA) dopamine hydrochloride and polymerized (poly) dopamine (pDA). From the TGA results, $20 \mathrm{wt} \%$ residue of dopamine hydrochloride was observed while pDA completely burns away totally around $600{ }^{\circ} \mathrm{C}$. The left-over residue probably consists of the hydrochloride group which closely corresponds to $19.2 \%$ of the molecular weight of dopamine hydrochloride. However, the loosely bonded hydrochloride group is released to the solvent during the polymerization stage. Hence, the rest of the carbonaceous moieties burned out from the system below the operating temperature of a fuel cell. 


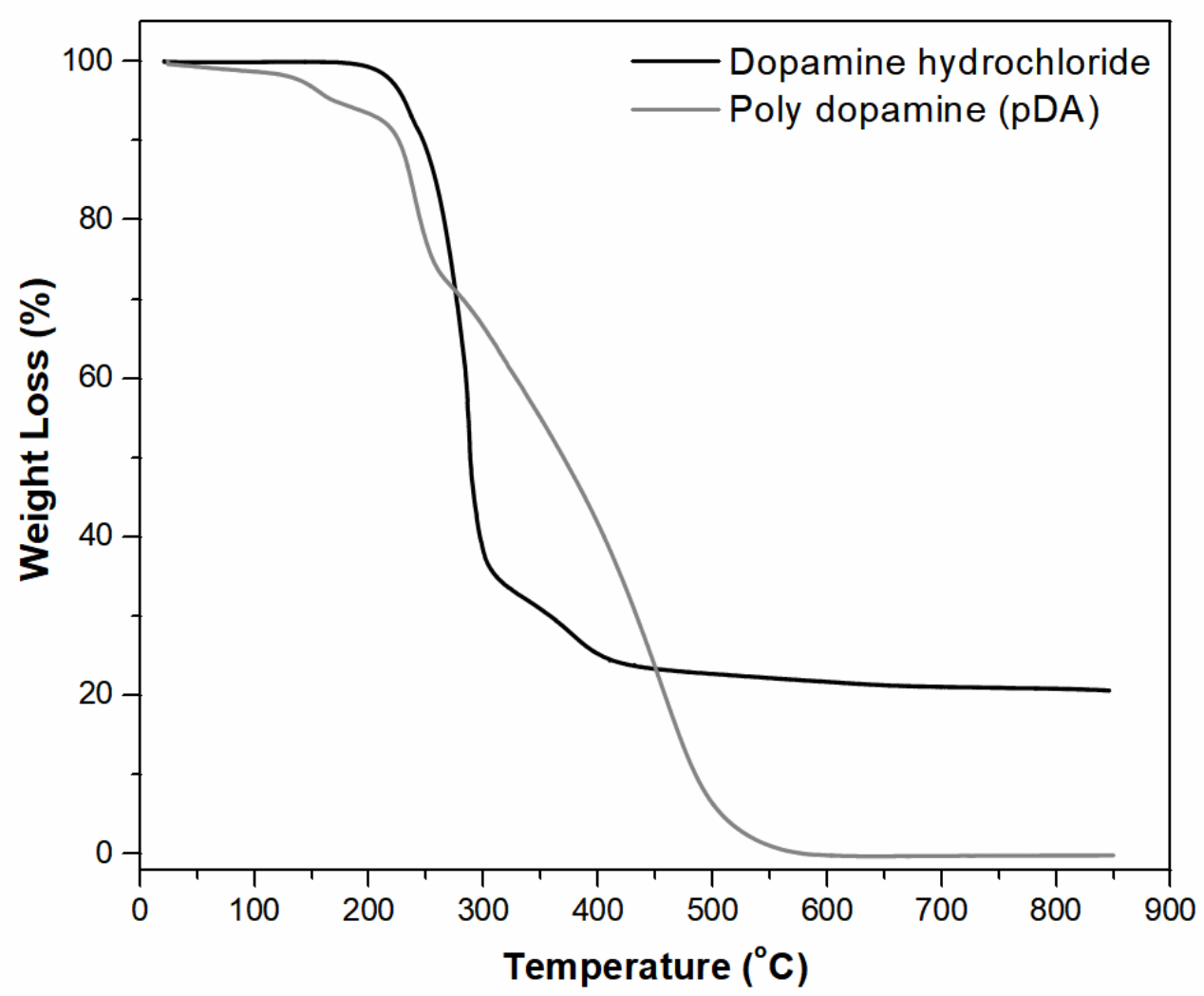

Figure 3.2. TGA of dopamine hydrochloride and poly dopamine (pDA).

In the next stage, the electrochemical characterization was performed only on pDA coated fuel cell with no infiltrated catalyst. Figure 3.3 displays the current-voltage-power (I-V-P) curve of the baseline and the dopamine treated cells. The cells were tested at $750^{\circ} \mathrm{C}$, which is above the burn-out temperature, as shown in Figure 3.3. First, open-circuit voltage (OCV) of both cells was around $1.075 \mathrm{~V}$, which is close to the $1.1 \mathrm{~V}$ Nernst potential for the fuel-oxidant combination. This indicates the consistency of the testing set-up and conditions. Moreover, the peak power densities of both cells were very similar, around $400 \mathrm{~mW} / \mathrm{cm}^{2}$. The performance data that these cells have shown nearly identical performance meaning that the dopamine surfactant treatment altered the performance neither negatively nor positively by itself. 


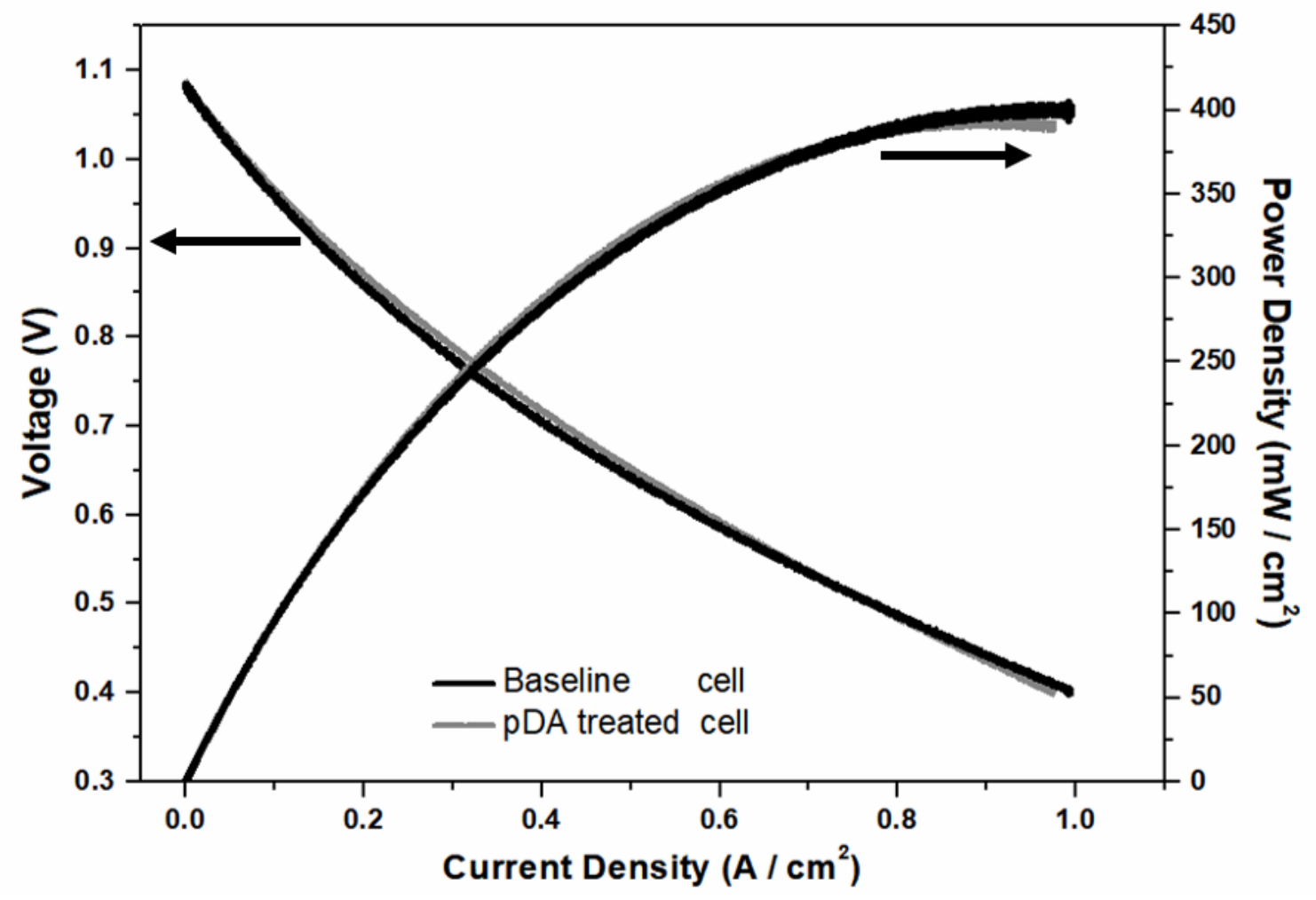

Figure 3.3. I-V-P curve of baseline and pDA treated anode supported cell tested with 300 sccm air and $300 \mathrm{sccm} \mathrm{H}_{2}\left(3 \%\right.$ humidified) at $750^{\circ} \mathrm{C}$.

In the literature, both the dip-coating steps, the pDA surfactant and secondary coating precursor solution (nano-catalyst) solvents have usually been aqueous solutions. However, the use of water/alcohol co-solvent may enhance the wettability and penetrability through the porous electrode. Lou et al., previously reported that the addition of ethanol into the aqueous precursor solutions dramatically reduces the contact angle of the droplet onto the LSCF, LSM, YSZ, and GDC surfaces [18]. Hence, solvent modification experiments were performed on $\mathrm{NiO} / \mathrm{YSZ}$ pellets. Figure 3.4 shows the contact angle change of the $2 \mathrm{mg} / \mathrm{ml} \mathrm{pDA}$ and $0.4 \mathrm{M}$ cerium nitrate droplets with various water / ethanol ratios. Droplets of $100 \%$ DI water solution showed partial wetting, where the contact angle $(\theta, \mathrm{CA})$ of $\mathrm{pDA}$ and cerium nitrate solutions were $79 \pm 7.3^{\circ}$ and $68.1 \pm 0.7^{\circ}$, respectively (Figure 3.5.a and b). The CA's dropped gradually until $50 \%$ vol ethanol 


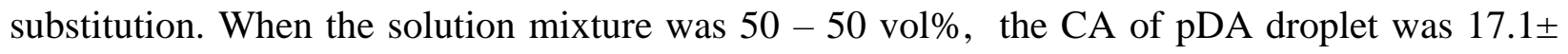
$1.06^{\circ}$ (Figure 3.5.c.) while the CA of the cerium nitrate solution droplet was measured $28.8 \pm 4.3^{\circ}$ (Figure 3.5.d.). It was observed that further additions did not produce a noticeable change in the wettability. Furthermore, less water content slowed down the polymerization of the pDA. To keep the solution mixture consistency and avoiding any precipitation, both cerium nitrate and pDA solvent mixtures were kept the same (1:1 vol \% water-ethanol mixture).

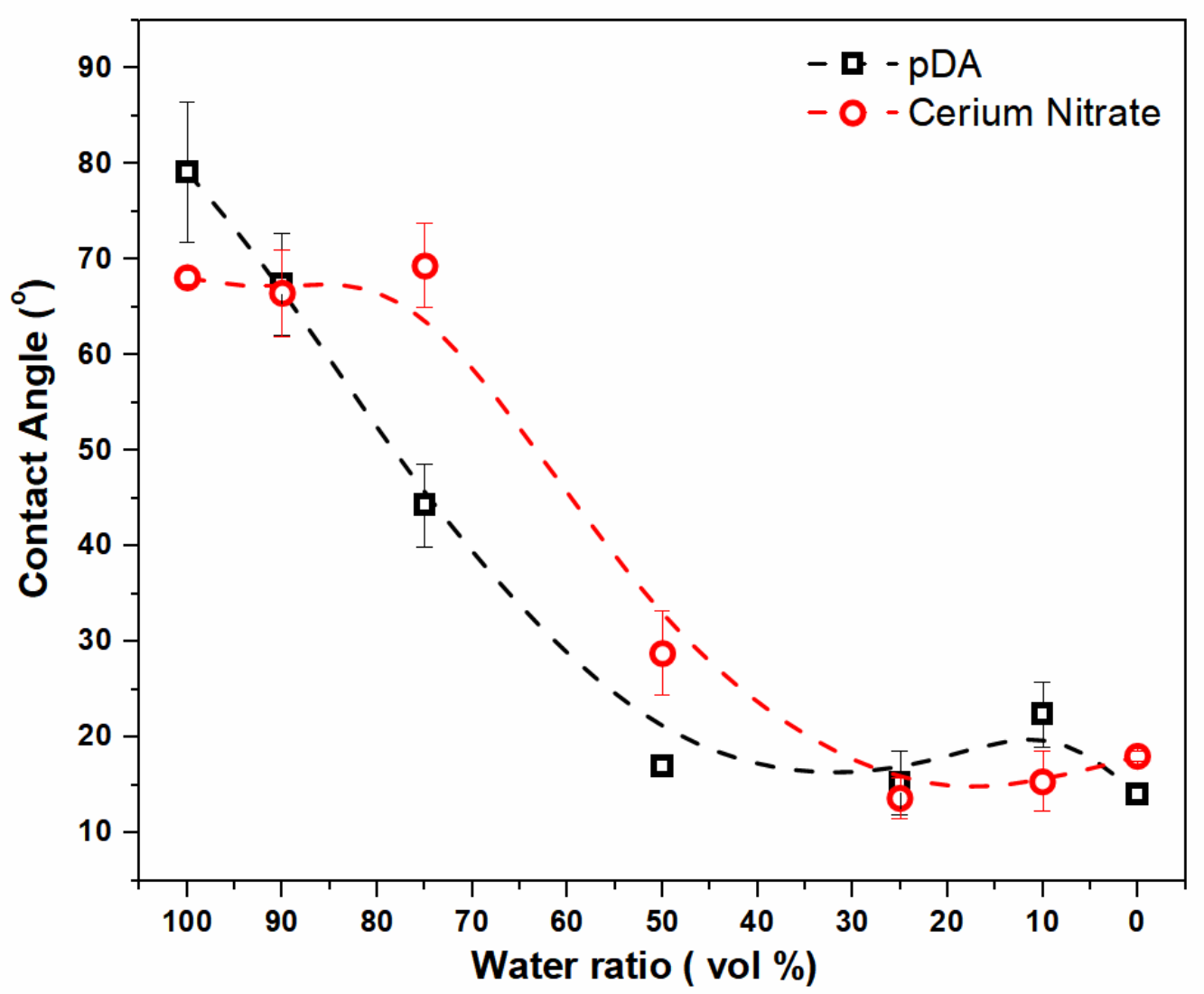

Figure 3.4. Contact angle drift of droplets of $\mathrm{pDA}$ and cerium nitrate DI water solutions as a function of ethanol substitute. 

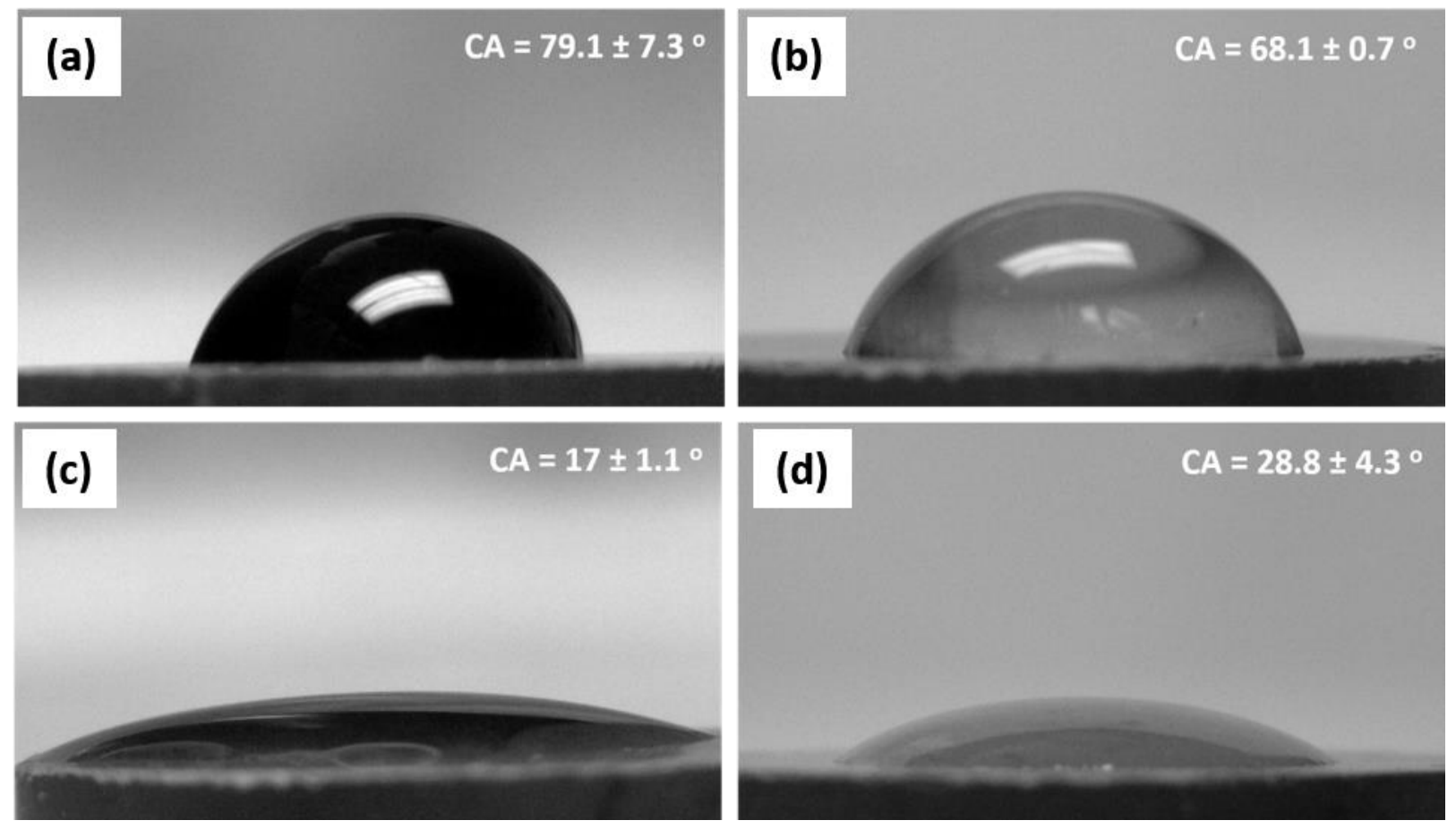

Figure 3.5. Droplet images of (a) pDA and (b) cerium nitrate of 100 vol \% DI water solution and (c) pDA and (d) cerium nitrate of 1:1 vol \% water-ethanol mixture on to the NiO/YSZ pellets.

The one-step conventional dripping method deposited approximately $0.4 \mathrm{mg}(0.33$ $\left.\mathrm{mg} / \mathrm{cm}^{2}\right) \mathrm{CeO}_{2}$. The dip-coated cell without pDA treatment gained $0.5 \mathrm{mg}$ of nano-catalyst within the electrodes. Note that the dip-coating method (using no pDA) was slightly more effective than the dripping method. The ex-situ polymerized pDA-assisted the dip-coating deposition by depositing $\sim 1.1 \mathrm{mg}$ of $\mathrm{CeO}_{2}$ nano-catalyst in a single step. The in-situ polymerized pDA-assisted dip-coating protocol deposited $1.4 \mathrm{mg}$ of nano-catalyst in a single step. These results show that the addition of the bio-coating pretreatment allowed for 3.5 times more catalyst deposition amount in a single step over the conventional dripping method. 
Figure 3.6. (a-d) are SEM cross-sectional images of the in-situ DC pDA dip-coated cell after testing over $300 \mathrm{~h}$. The SEM micrograph shows the ceria nanoparticles located within the bulk thickness and near the active layer of both the anode and cathode microstructure. The level of nano-catalyst deposition into the active anode layer was shown to be lower due to the thickness ( 240 microns thick), and the density of the un-reduced anode support structures. This result highlights the limitation of infiltrating commercial anode-supported cells, where the unreduced microstructure usually possesses $<30$ vol\% porosity, and hence restricts efficient infiltration to the active layer. The deposition within the cathode is extensive, where the single catalyst infiltration step resulted in a filled cathode porosity. The enhanced nano- $\mathrm{CeO}_{2}$ deposition on the cathode side can be attributed to the high porosity level (35-45\%) and relative thinness $(\sim 50 \mu \mathrm{m})$ of the cathode layer. The particle size of the infiltrated nano-catalyst was approximately 20-50 nm after $300 \mathrm{~h}$ testing. 


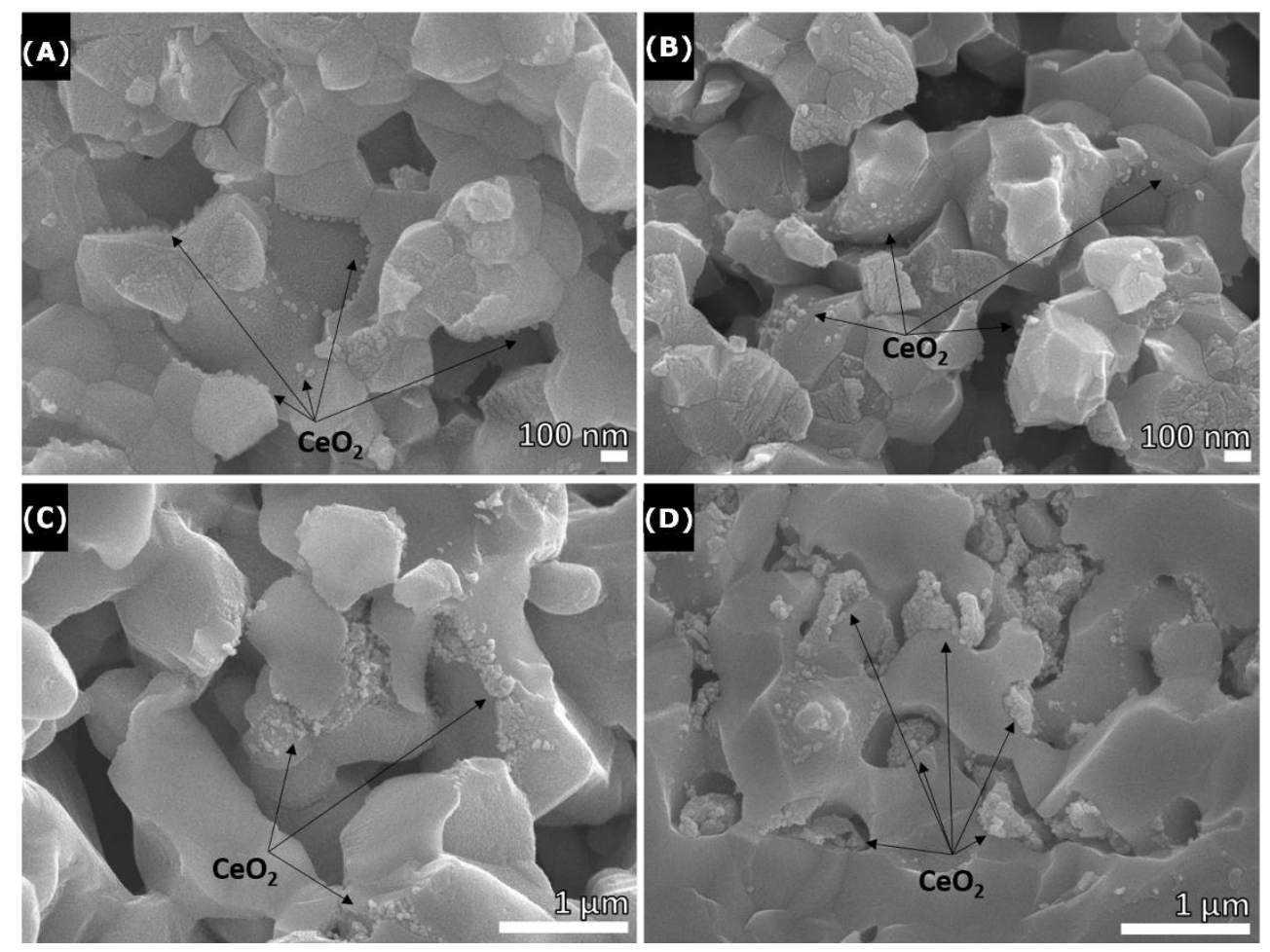

Figure 3.6. Cross section SEM images of in-situ DC pDA dip coated cell, which were taken from the anode (A) middle layer, (B) active layer, and cathode (C) middle layer, (D) active layer of the anode-supported cell after testing at $750^{\circ} \mathrm{C}$ for 300 hours.

The SOFCs that utilized the two-step bio-coating process (where only one thermal treatment was used) were characterized using both I-V-P measurements and electrochemical impedance spectroscopy (EIS). The SOFCs were tested under constant current conditions $(0.33$ $\mathrm{A} / \mathrm{cm}^{2}$ ) using humid $\mathrm{H}_{2}$ fuel at $750^{\circ} \mathrm{C}$ for approximately $300 \mathrm{~h}$. Again, the nano-ceria was incorporated into both the anode and cathode microstructure simultaneously. Figure 3.7 displays I-V-P curves for the SOFCs pre-treated with pDA (both through an in-situ and ex-situ polymerization process) and a baseline SOFC with no nano-catalyst incorporation. The I-V-P curves were taken before constant current loading at $0 \mathrm{~h}$, and after $300 \mathrm{~h}$ of constant current loading. The data indicated an appreciable initial enhancement in power density by $20.7 \%$ and 
$17.9 \%$ for the ex-situ DC pDA and in-situ DC pDA samples, respectively. After approximately $300 \mathrm{~h}$ of fuel cell testing, the power density of the impregnated cells was $1.5 \%$ and $5.8 \%$ higher than the baseline performance, respectively. The results depict a greater gap in power density change for the ex-situ polymerized pDA dip-coated cells, which exhibited an $11.5 \%$ degradation. In the in-situ polymerized pDA, the degradation was around $5.6 \%$.

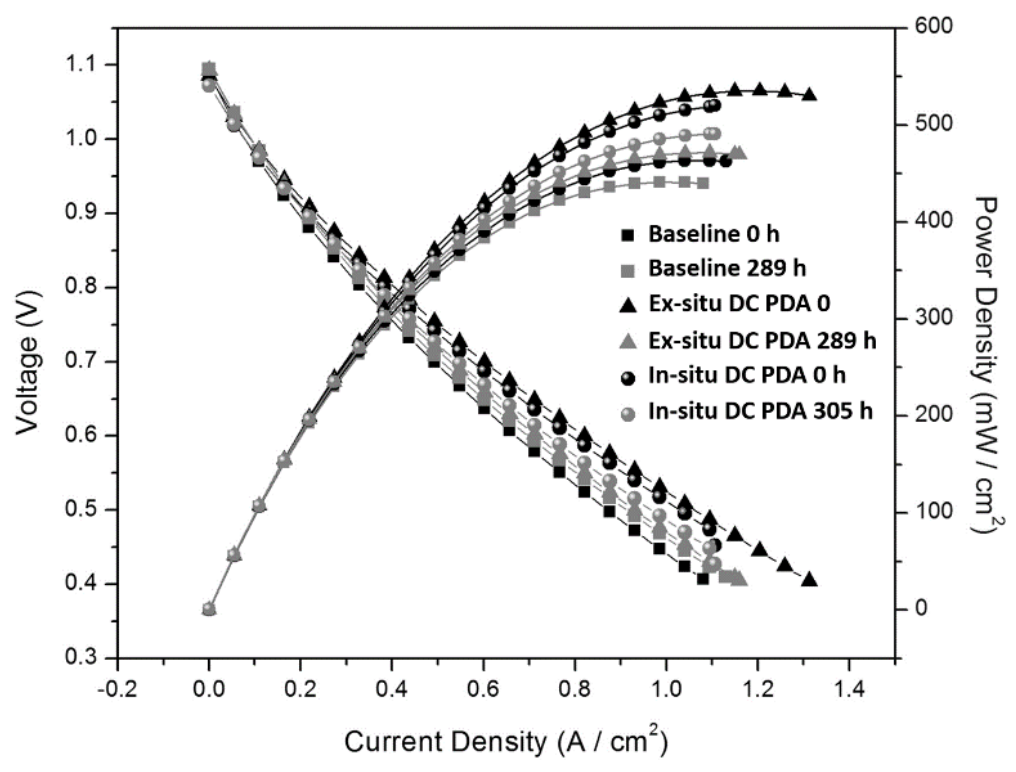

Figure 3.7. I-V-P curves of baseline and impregnated SOFCs using the in-situ and ex-situ polymerized pDA surfactant before nano-ceria impregnation.

The degradation in power density was due to the sintering of the impregnated nano-catalyst over time at the operating temperature. In literature, it has been demonstrated that metallic $(\mathrm{Ni}$, Pd, Pt) nanoparticles (with low thermal stability) and non-metallic (NiO, SDC, $\mathrm{CeO}_{2}, \mathrm{GDC}, \mathrm{LSM}$ ) nanoparticles tend to coarsen over time leading to reduced surface area, activity, and triple-phase boundary area which all affect the performance of the cell [19-23]. As noted above, after testing in $\mathrm{H}_{2}$ for $300 \mathrm{~h}$, the particle size of the catalyst increased to 20 to $50 \mathrm{~nm}$. In this way, an in-situ bio-coating process encouraged better penetration of the pDA to the electrode active zone before 
polymerization. This resulted in better homogeneity throughout the porous 3-D structure and hence improved the catalyst island distribution.

EIS Nyquist plots, shown in Figure 3.8.a., display a total electrode polarization resistance $\left(\mathrm{R}_{\mathrm{p}}\right)$ of $0.31 \mathrm{ohm} \cdot \mathrm{cm}^{2}$ for the ex-situ DC pDA cell and $0.32 \mathrm{ohm} \cdot \mathrm{cm}^{2}$ for the in-situ DC pDA cell. The $\mathrm{R}_{\mathrm{p}}$ for the baseline cell was measured as $0.41 \mathrm{ohm} \cdot \mathrm{cm}^{2}$. These values correspond to a $23.4 \%$ and $21.7 \%$ decrease in $\mathrm{R}_{\mathrm{p}}$ for the ex-situ and in-situ DC pDA samples, respectively. However, as time proceeded to $300 \mathrm{~h}$, the $\mathrm{R}_{\mathrm{p}}$ of the cells was observed to increase. Bode plots depicted in Figure 3.8.b were generated to understand the electrochemical mechanisms and associated frequency regions. It has been established that Region 1 is associated with the anode charge transfer reaction [10, 24]; Region 2 is associated with the cathode polarization [10, 25]; and Region 3 is related to gas diffusion limitations $[10,26]$. As shown in Figure 3.8.b, the infiltrated cells displayed a significant decrease in Region 1 and a slight reduction in Regions 2 and 3. This means that the nano- $\mathrm{CeO}_{2}$ activated both the anode and cathode sides due to the dual infiltration. Nanoceria particles migh also add additional oxygen pathway by its MIEC nature. Moreover, an increase in resistance over time in Regions 1 and 2 was observed, suggesting that the anode and cathode showed deactivation due to the catalyst sintering/growth. The growth of the catalyst particles and the backbone structure may be responsible for the decrease in Region 3, which indicates a relaxation of the cathode gas path through the active area. 


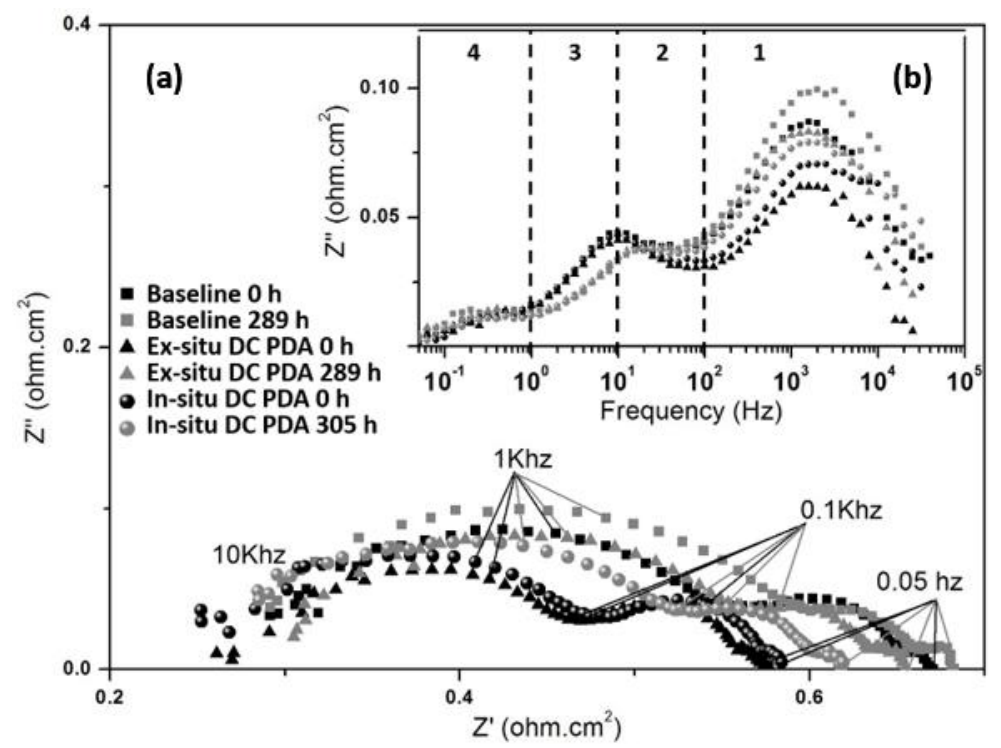

Figure 3.8. (a) Nyquist and (b) Bode plots of the baseline and bio-coating assisted dipcoat infiltrated cells under $0.4 \mathrm{~A}\left(0.325 \mathrm{~A} / \mathrm{cm}^{2}\right)$ at $750{ }^{\circ} \mathrm{C}$.

\subsection{Conclusion}

In this study, polydopamine (pDA), a bio-inspired surfactant, was coated throughout the porosity of both SOFC electrodes (cathode and anode) to enhance and control the deposition of nano- $\mathrm{CeO}_{2}$ catalyst throughout the microstructure. The entire infiltration process consisted of two dip-coating steps. The process included the initial submersion of the entire SOFC into a pDA solution, followed by the dip-coating of the cell into a cerium salt solution. The process was completed by a drying and high-temperature thermal treatment. The simple dip-coating protocol showed enhanced penetration and distribution of the nanocatalyst in both electrodes. The work demonstrated the process using existing commercial cell architectures (with the typical low porosity in the unreduced anode state), where most infiltration studies require the redesign of the SOFC electrode microstructure in order to facilitate liquid penetration. As indicated, ceria was 
used to demonstrate the efficacy of the protocol, but the method permits the deposition of other catalyst compositions targeted for single or dual-electrode performance enhancement.

Although the use of both the pDA surfactant and the dip-coating process showed an overall enhanced deposition efficiency, the work also highlighted the need for better control of the deposition rate when the electrodes display a different level porosity (such as the anode and cathode in this work) for dual infiltration. Although dual infiltration was focused upon in this work, a single electrode can also be infiltrated with a promising catalyst(s) by masking the other electrode. In the end, the simple and efficient process resulted in a significant decrease $(0.41$ $\left.0.32 \mathrm{ohm} \cdot \mathrm{cm}^{2}\right)$ in the polarization resistances of both electrodes. Unfortunately, as in most nanocatalyst infiltration studies described in the literature (and also shown in this work), nano-catalyst sintering and grain growth decreased the enhanced performance achieved through the infiltration process, and further work is needed to stabilize the microstructure for sustained performance enhancement.

\subsection{References}

1. Jiang, S.P., A review of wet impregnation-An alternative method for the fabrication of high performance and nano-structured electrodes of solid oxide fuel cells. Materials Science and Engineering: A, 2006. 418(1-2): p. 199-210.

2. $\quad$ Sholklapper, T.Z., et al., Synthesis of Dispersed and Contiguous Nanoparticles in Solid Oxide Fuel Cell Electrodes. Fuel Cells, 2008. 8(5): p. 303-312.

3. Kurokawa, H., et al., Ceria Nanocoating for Sulfur Tolerant Ni-Based Anodes of Solid Oxide Fuel Cells. Electrochemical and Solid-State Letters, 2007. 10(9): p. B135.

4. Lee, S.-I., J.M. Vohs, and R.J. Gorte, A Study of SOFC Anodes Based on $\mathrm{Cu}$-Ni and $\mathrm{Cu}$ Co Bimetallics in $\mathrm{CeO}_{2}$-YSZ. Journal of The Electrochemical Society, 2004. 151(9): p. A1319.

5. McIntosh, S., J.M. Vohs, and R.J. Gorte, Effect of Precious-Metal Dopants on SOFC Anodes for Direct Utilization of Hydrocarbons. Electrochemical and Solid-State Letters, 2003. 6(11): p. A240.

6. Qiao, J., et al., $\mathrm{Ni} / \mathrm{YSZ}$ and $\mathrm{Ni}-\mathrm{CeO}_{2} / \mathrm{YSZ}$ anodes prepared by impregnation for solid oxide fuel cells. Journal of Power Sources, 2007. 169(2): p. 253-258.

7. Jiang, S.P. and W. Wang, Fabrication and Performance of GDC-Impregnated ( La,Sr)MnO ${ }_{3}$ Cathodes for Intermediate Temperature Solid Oxide Fuel Cells. Journal of The Electrochemical Society, 2005. 152(7): p. A1398. 
8. Liang, F., et al., Development of Nanostructured and Palladium Promoted ( $\mathrm{La}, \mathrm{Sr}) \mathrm{MnO}_{3}-$ Based Cathodes for Intermediate-Temperature SOFCs. Electrochemical and Solid-State Letters, 2008. 11(12): p. B213.

9. Jiang, Z., et al., Electrochemical characteristics of solid oxide fuel cell cathodes prepared by infiltrating $(\mathrm{La}, \mathrm{Sr}) \mathrm{MnO}_{3}$ nanoparticles into yttria-stabilized bismuth oxide backbones. International Journal of Hydrogen Energy, 2010. 35(15): p. 8322-8330.

10. Lee, S., N. Miller, and K. Gerdes, Long-Term Stability of SOFC Composite Cathode Activated by Electrocatalyst Infiltration. Journal of the Electrochemical Society, 2012. 159(7): p. F301-F308.

11. Jiang, S.P., Nanoscale and nano-structured electrodes of solid oxide fuel cells by infiltration: Advances and challenges. International Journal of Hydrogen Energy, 2012. 37(1): p. 449-470.

12. Nicholas, J.D. and S.A. Barnett, Measurements and Modeling of $\mathrm{Sm}_{0.5} \mathrm{Sr}_{0.5} \mathrm{CoO}_{3}-x-$ $\mathrm{Ce}_{0.9} \mathrm{Gd}_{0.1} \mathrm{O}_{1.95} \mathrm{SOFC}$ Cathodes Produced Using Infiltrate Solution Additives. Journal of The Electrochemical Society, 2010. 157(4): p. B536.

13. Lee, H., et al., Mussel-inspired surface chemistry for multifunctional coatings. Science, 2007. 318(5849): p. 426-30.

14. Qin, Z. and M.J. Buehler, Impact tolerance in mussel thread networks by heterogeneous material distribution. Nat Commun, 2013. 4: p. 2187.

15. Qin, Z. and M.J. Buehler, Molecular mechanics of mussel adhesion proteins. Journal of the Mechanics and Physics of Solids, 2014. 62: p. 19-30.

16. Liu, Y., K. Ai, and L. Lu, Polydopamine and its derivative materials: synthesis and promising applications in energy, environmental, and biomedical fields. Chem Rev, 2014. 114(9): p. 5057-115.

17. Gandavarapu, S.R., et al., Direct foamed and nano-catalyst impregnated solid-oxide fuel cell (SOFC) cathodes. Materials Letters, 2013. 95: p. 131-134.

18. Lou, X., et al., Controlling the morphology and uniformity of a catalyst-infiltrated cathode for solid oxide fuel cells by tuning wetting property. Journal of Power Sources, 2010. 195(2): p. 419-424.

19. Tucker, M.C., et al., Stability and robustness of metal-supported SOFCs. Journal of Power Sources, 2008. 175(1): p. 447-451.

20. Simner, S.P., et al., Development of lanthanum ferrite SOFC cathodes. Journal of Power Sources, 2003. 113(1): p. 1-10.

21. Okawa, Y., et al., Thermal stability of nanometer-sized NiO and Sm-doped ceria powders. Journal of Materials Research, 2011. 17(09): p. 2266-2274.

22. Rupp, J.L.M., A. Infortuna, and L.J. Gauckler, Microstrain and self-limited grain growth in nanocrystalline ceria ceramics. Acta Materialia, 2006. 54(7): p. 1721-1730.

23. Shah, M., et al., Stability and Performance of LSCF-Infiltrated SOFC Cathodes: Effect of Nano-Particle Coarsening. 2011: p. 2045-2053.

24. Leonide, A., et al., Evaluation and Modeling of the Cell Resistance in Anode-Supported Solid Oxide Fuel Cells. Journal of The Electrochemical Society, 2008. 155(1): p. B36.

25. Chen, X.J., K.A. Khor, and S.H. Chan, Identification of $\mathrm{O}_{2}$ reduction processes at yttria stabilized zirconia|doped lanthanum manganite interface. Journal of Power Sources, 2003. 123(1): p. 17-25. 
26. Endler, C., et al., Time-Dependent Electrode Performance Changes in Intermediate Temperature Solid Oxide Fuel Cells. Journal of The Electrochemical Society, 2010. 157(2): p. B292. 


\section{Chapter 4 : pNE Bio-Surfactant Assisted Nano-Catalyst Infiltration of Solid-Oxide Fuel Cell (SOFC) Electrodes}

\subsection{Introduction}

The wet infiltration method (also termed the impregnation method) is a practical and wellutilized technique to incorporate nanoparticles within the porous electrode microstructure of solid oxide fuel cells (SOFC). Many reports showed that the infiltration of catalytically active nanoparticles reduces the polarization resistance of the cell [1]. The decrease in electrode polarization (or the overpotential) is dependent on the catalytic nature of the metal or oxide nanoparticles, and its synergistic activity with other components within the existing electrode to enhance the oxygen reduction reaction (in the cathode) or the oxidation kinetics of the fuel (in the anode). Early studies began with incorporating precious or semi-precious metals, such as $\mathrm{Au}, \mathrm{Pd}$, $\mathrm{Pt}$, Rh, etc., into both SOFC cathodes and anodes [2-5]. Those nano-particles exhibit high catalytic nature in both oxidation and reduction half-reactions. Although there are still some efforts studying precious metal infiltration, research on the use of cost-effective metal/metal oxide alternative systems has attracted increased interest recently. A review by Sholklapper et al. addresses a general perspective for the infiltrant materials and strategies [6]. Critical factors that impact the reduction of the electrode polarization using the nano-catalyst infiltration strategy include: i) catalyst loading, ii) catalyst composition and particle size, iii) surface decoration of the electrode grains with the catalyst, and iv) distribution of the catalyst throughout the volume of the porous microstructure. It should be noted that those factors are all interrelated and may or may not be achieved altogether during processing. 
The nano-catalyst loading within the electrode microstructure can be tuned by performing repetitive infiltration cycles. The infiltration protocol can be completed using methods such as dripping [7], spin coating [8], electrodeposition [9], spraying [10], inkjet printing [11], and dip coating [12]. In general, a co-firing step is followed after each infiltration cycle to transform the solution precipitates (typically hydroxides and nitrates) to binary or more complex oxide compositions. The process is repeated until the desired nano-catalyst loading is achieved. The second way is to infiltrate oxide particulate suspensions or concentrated precursor solutions into the electrode microstructure. In this route, the number of infiltration cycles can be reduced dramatically, but inter-particle interactions, pore-clogging, and inhomogeneous deposition are the major potential risks in this strategy, which may result in reduced gas diffusion in the electrode architecture during the cell operation $[13,14]$.

The nano-catalyst deposition location through the thickness of the electrode layer after infiltration is another parameter that affects the performance of a SOFC. To be able to improve the triple- and/or double-phase boundary length, the infiltrant materials must be located in the active area, deep within the porous electrode layer near to the electrolyte interface. When the targeted electrode is the mechanical support for the SOFC, the microstructure is typically engineered with a relatively higher density, and the electrode layer is usually thick $(>500 \mu \mathrm{m})$ to provide mechanical strength to the cell. In this case, the infiltration process becomes more challenging and inefficient. To overcome this issue, researchers often include surfactants to the precursor solution to enhance the wetting and the penetrability of the catalyst precursor solution. Also, various engineering methods, such as vacuum-assisted infiltration, can be used to remove entrapped gas within the fine porosity and help to force the solution through electrode layer porosity $[15,16]$. If the salt solution precipitates the nano-catalyst preferentially at locations far from the active area 
(such as a location near the surface or middle thickness of the electrode), then the electrode performance will show minimal improvement, and in some instances the performance will decrease due to gas diffusion limitations (due to porosity blockage by the nano-catalyst buildup).

The final major factor that impacts the reduction of the electrode polarization is the distribution of nano-catalyst particles over the granular microstructure of the electrode. As is common knowledge, the high surface area of the nano-particles promotes the electrocatalytic activity dramatically [17]. Since these nano-catalysts possess such a high surface area, the driving force for coarsening and sintering mechanisms are also enhanced. At elevated temperatures, the particles tend to reduce the surface area (and, therefore, associated surface energy) by driving these mechanisms. Since SOFCs are relatively high-temperature systems, nano-particle stability during operation is a major challenge. The loss of active surface area during coarsening/sintering adversely affects the long-term stability of the fuel cell $[18,19]$. For this reason, the degradation rate of the infiltrated cells is as important a parameter to monitor over time as the relative performance improvement achieved with the infiltration process. To be able to maintain the stability of the cell during operation, the infiltrant particles should be decorated uniformly and discretely, with little contact with adjacent nano-catalyst particles, to limit the coarsening/sintering processes. To conclude, the goal of infiltration of SOFCs is to minimize infiltration/co-firing step(s) with the optimum concentration of the catalytically-active nano-particles within the active electrode area in a manner that enhances and stabilizes the performance.

Various additives can be added to the precursor solution such as ethanol [20] and various surfactants such as Triton-X [21] as wetting agents, glycine and citric acid as a complexation agent $[22,23]$, urea as a precipitation agent [24], etc. The study by Nicholas et al. noted that citric acid addition reduces the impurity content for $\mathrm{Sm}_{0.5} \mathrm{Sr}_{0.5} \mathrm{CoO}_{3-\mathrm{x}}$ (SSC) phase in comparison to Triton- 
$\mathrm{X}$ additions [23]. This work showed the efficacy of those additives may vary depending on the nature of catalyst precursor. According to the author's knowledge, the influence of those precursor surfactants on the control of the precipitation has not been proved.

Alternatively, internal electrode surfaces can also be treated with the surfactants, which promote deposition of the nano-catalyst. For example, the catechol chemical family, which consists of a benzene ring with a 1,2-hydroxyl (benzene diol), group configuration, has been used as a material-independent surfactant to modify substrates in order to deposit uniform metal and metal oxide thin films. This family allows for material-independent controllable coating and/or adhesion properties [25], as well as other physicochemical properties including enhanced surface wettability [26]. Poly-dopamine is one catechol surfactant used in many fields over the past decade to deposit metals, metal oxides, and polymers onto various substrate compositions [27].

Figure 4.1 is provided to assist in briefly describing how a catechol surfactant, such as pDA, assists in the direct and controlled deposition of metal oxide/hydroxide structures. The process consists of two main steps. The first step consists of the oxidative cross-linking of catechol in a basic medium at $\mathrm{pH} 8.5$, and the deposition of this polymerized porous layer onto the electrode internal surface (Figure 4.1.a-b). In the second step, the coated substrate is immersed into a metal salt solution where local chelation of the metal-organic complex occurs by binding between the cerium ion and the organic layer by deprotonation (Figure 4.1.c). Previous studies assessed that the surface morphology and thickness of both the pDA layer can be engineered by the pDA solution immersion time [28, 29], $\mathrm{pH}[30]$, temperature [28], and pDA concentration [30, 31]. Moreover, the material coating over the pDA can be controlled by modifying the precursor solution immersion time [32,33] and concentration [34]. Typically, the formation kinetics of catechol starts with small islands at the beginning (Figure 4.1.c). Later, the island coverage expands (Figure 4.1.d) 
and a complete layer film is formed (Figure 4.1.e). For example, a study by Ryu et al. showed that a hydroxyapatite deposition begins with nuclei (island) formation in the initial immersion times onto the pDA coated substrate. Subsequently, the hydroxyapatite islands become agglomerates and then these agglomerate cover the surface after further immersion [35]. In addition, Wang et al. reported that a similar trend of silver coating on the pDA treated microspheres can be seen as a function of precursor molarity by fixing the immersion time [34].

(a)

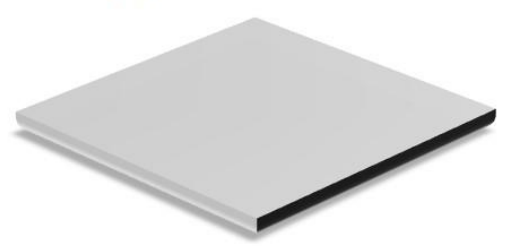

(d)

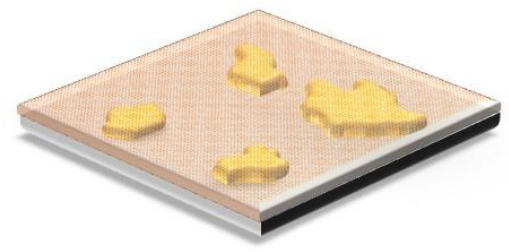

(b)

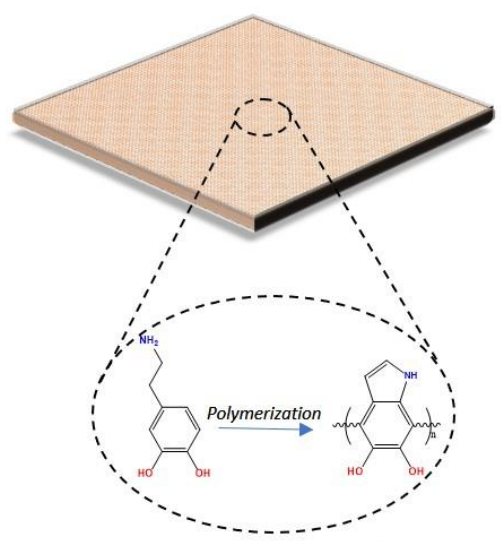

(e) (c)

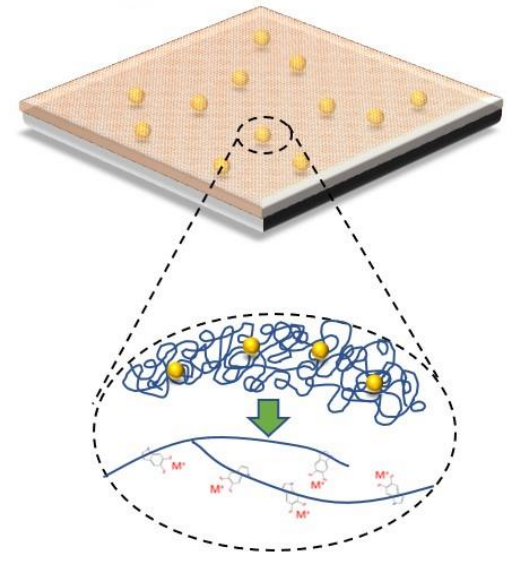

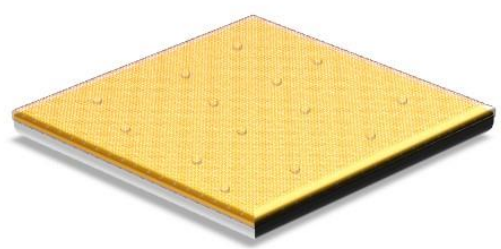

Figure 4.1 Schematic representation of (a) untreated surface (b) pDA coated surface, (c), (d), and (e) progressive incubation of metal ion chelation with pDA layers

In the previous chapter, a poly-dopamine (pDA) assisted two-step infiltration protocol was developed for modifying the internal surfaces of three-dimensional anode and cathode electrode network to deposit catalytic cerium oxide nanoparticles [36]. In that study, a performance increase was shown at the beginning of the electrochemical test, but then a noticeable degradation over 
$\sim 300 \mathrm{~h}$ was observed potentially due to the inter-particle interaction and coarsening at elevated temperatures. Ding et al. reported that the pDA concentration higher than $1 \mathrm{mg} / \mathrm{ml}$ inevitably promotes micron-sized aggregation [37], which is why pDA could potentially clog microporous SOFC electrode architecture and prevent homogenous coating distribution. Hence, there is a substantial need to reduce the inevitable thick micron-sized layer surfactant layer development, so that a thin, homogenous surface modification can be developed within the SOFC electrodes.

As an alternative to pDA, Lee et al. demonstrated the use of another catecholamine called poly nor-epinephrine ( $\mathrm{pNE}$ ) for the deposition of a thin layer onto a planar substrate. The pNE chemistry offered a smoother coating and a lower degree of aggregate formation due to the intermediate formation of 3,4-dihydroxybenzaldehyde - DHBA [38], which lessened agglomeration kinetics. Owing to the promising deposition properties, pNE was used to modify the substrates/particles in a few applications, including over various dense substrates [39], metal oxide particles [40], and microporous sponges [41]. Our earlier work also showed that pNE can be used as a surface modification template for porous architectures and can yield higher material depositions per coating step [42].

In the current work, poly-norepinephrine (pNE) was used as the surfactant for controlled nano- $\mathrm{CeO}_{2}$ deposition to avoid the potential limitations of pDA stated above during the polymerization stage. The work first demonstrated metal oxide deposition improvement by pNE treatment onto the conventional SOFC anode and cathode backbone surfaces, NiO, YSZ, and LSM pellets. The protocol was applied to commercial button anode-supported fuel cells and evaluated the effect of the surfactant coating on the nanoparticle deposition rate and morphology with a change in precursor solution concentration. Moreover, the reduction of polarization resistance of the infiltrated cells as a function of pNE-assisted ceria deposition amount was characterized. 
Finally, the stability of the infiltrated cell was assessed using impedance spectroscopy over $300 \mathrm{~h}$ of operation. The motivation of this work was to develop an efficient infiltration protocol that enables specific control of the deposition kinetics and morphology of nano-catalyst loading for commercial SOFC cells, which will retain the desired enhanced electrochemical performance achieved with the infiltration procedure over the extended high-temperature operation.

\subsection{Experimental}

To confirm the efficacy of the pNE coatings over the sub-constituents of the SOFC electrodes, commercial nickel oxide -NiO- (Novamet Specialty Products Corp., TN, USA), yttria-stabilized zirconia - YSZ- (TZ-8Y, Tosoh Corporation, Tokyo, Japan), and in-house fabricated lanthanum strontium manganite -LSM-, powders were pressed into pellets, fired at $1350^{\circ} \mathrm{C}, 1450^{\circ} \mathrm{C}$ and $1150^{\circ} \mathrm{C}$, respectively. The pellets were then polished prior to the deposition protocol. A $1 \mathrm{mg} / \mathrm{ml}$ DL-norepinephrine hydrochloride ( $\geq 97 \%$ (TLC), Aldrich, USA) was first dissolved in a $0.05 \mathrm{M}$ TRIS (tris(hydroxymethyl) aminomethane, 99\%, Alfa-Aesar, USA) and 1:1 vol \% water-ethanol mixture at $\mathrm{pH}$ 8.5. A dip-coating infiltration protocol was used to ensure uniform exposure in all the experiments. The setup was placed within a vacuum desiccator under $30 \mathrm{~mm} \mathrm{Hg}$ vacuum for $5 \mathrm{~min}$ and then transferred to a rocker table for $12 \mathrm{~h}$ that permitted the surfactant to polymerize homogeneously. Meanwhile, this time-dependent oxidative polymerization step had a transition from transparent to brown color as a function of time as observed in the previous studies [38, 39].

After the polymerization of the norepinephrine (pNE) step, the pellets were rinsed with 1:1 vol \% water-ethanol solution. The pNE-coated pellets were then immersed into 0.4 cerium (III) nitrate hexahydrate (REacton ${ }^{\circledR}, 99.5 \%$, Alfa Aesar, USA) solution of 1:1 vol\% water-ethanol solvent for $24 \mathrm{~h}$. After the rinsing and drying step under ambient conditions, the pellets were finally 
fired at $750^{\circ} \mathrm{C}$ for $1 \mathrm{~h}$ for nitrate decomposition, forming the ceria $\left(\mathrm{CeO}_{2}\right)$ phase. The protocol developed from this initial work was then applied in the rest of the work to actual SOFCs.

For the deposition of the nano-catalyst into actual SOFCs, commercial anode-supported button cells (cell type ASC-2.7) were purchased from Nexceris, LLC (Lewis Center, OH, USA). These cells were $27 \mathrm{~mm}$ in diameter and consisted of a $250 \mu \mathrm{m}$ thick nickel oxide (NiO) /yttriastabilized zirconia (YSZ) anode with a dense $8 \mu \mathrm{m}$ thick YSZ electrolyte (27 $\mathrm{mm}$ in diameter) and lanthanum strontium manganite (LSM) / gadolinium doped ceria (GDC) cathode, which was 12.5 $\mathrm{mm}$ in diameter in $50 \mu \mathrm{m}$ thick. The same dip-coating protocol was applied to the cells but the concentration of the cerium salt solution was varied in order to achieve a range of infiltrated catalyst amount. The cells were weighed after the thermal process in order to calculate the infiltrated ceria content. In this study, four infiltrated ceria loadings were investigated: $\sim 1.3 \mathrm{mg}$ ceria infiltrated cell in $0.4 \mathrm{M}$ precursor solution (denoted as IC-1), $\sim 3.5 \mathrm{mg}$ ceria infiltrated cell in $0.7 \mathrm{M}$ precursor solution (denoted as IC-2), $\sim 5 \mathrm{mg}$ infiltrated cell in $1 \mathrm{M}$ precursor solution (denoted as IC-3), and finally, $\sim 8.5 \mathrm{mg}$ ceria infiltrated cell in $2 \mathrm{M}$ precursor solution (denoted as IC-4). To be able to estimate the catalyst amount per electrode, the protocol of IC-1 was applied only to the anode electrode by masking the cathode side which resulted in a $0.8 \mathrm{mg}$ weight change. From this experiment, it was deduced that $\sim 60 \%$ of the infiltrated catalysts was impregnated into the larger area anode support electrode $\left(\sim 0.16 \mathrm{mg} / \mathrm{cm}^{2}\right)$ while the remaining $\sim 40 \%$ was located into the small area cathode electrode $\left(\sim 0.41 \mathrm{mg} / \mathrm{cm}^{2}\right)$.

\subsubsection{Testing and Characterization}

The morphology of the cerium thin films deposited onto YSZ, LSM, and NiO pellet planar surfaces were characterized by atomic force microscopy (Agilent 5500 SPM, USA) in the tapping mode. The mapping area of all the samples was $2 \mu \mathrm{m} \times 2 \mu \mathrm{m}$. 
The current-voltage-power (I-V-P) and electrochemical impedance spectroscopy (EIS) of the impregnated SOFC button cells were completed at $750^{\circ} \mathrm{C}$ for $\sim 300 \mathrm{~h}$ using $300 \mathrm{sccm}$ humidified (3\%) hydrogen fuel and $300 \mathrm{sccm}$ air. During the electrochemical testing, the cells were sandwiched between alumina flanges, and the button cells were sealed using mica washers placed on both sides of the cells. For the I-V-P measurements, the connections were wired to Pt mesh using minimal Pt paste for the cathode side and Pt mesh with Ni paste for the anode side. An electronic load of (Agilent N3301A, USA) was used to apply constant current $\left(0.325 \mathrm{~A} / \mathrm{cm}^{2}\right)$ to the cell during the tests. The electrode polarization measured using EIS with a frequency response analyzer (Solartron 1455A, England) and a potentiostat (Solartron 1470E, England) over a frequency range of $0.01-100 \mathrm{kHz}$ under operating current load. The first data points were taken after the cathode activation within the first $48 \mathrm{~h}$ and then at $150 \mathrm{~h}$ and $300 \mathrm{~h}$. The electrode microstructure of the tested ceria impregnated cells was examined by scanning electron microscopy (JEOL 7600F, Japan).

\subsection{Results and Discussion}

Prior to the SOFC button cell infiltration, the efficacy of the pNE treatment on the $\mathrm{CeO}_{2}$ deposition was first demonstrated on the planar YSZ, NiO, and LSM pellets separately. The surface morphology of the untreated surfaces, and the surfaces coated using the cerium nitrate dip-coated (with and without pNE treatment) were characterized using atomic force microscopy (AFM) after the calcination step at $750^{\circ} \mathrm{C}$. To deliver the particle height comparison, $1.5 \mu \mathrm{m}$ length line profiles were drawn over areas where the particles populated in all the images. Figure 4.2.a-c show the AFM images of the finely polished NiO, YSZ, and LSM surfaces. The topography images of all polished, untreated baseline surfaces display a few pores, but overall, appear to be smooth with 0.9, 0.7, and 0.5 nm line RMS values for NiO, YSZ and LSM surfaces respectively. Figure 4.2.d- 
f display the AFM images of the cerium nitrate treated surfaces that did not receive a pNE pretreatment. The purpose of completing this round of samples was to better compare the deposition morphology when the pNE treatment was later used before the cerium nitrate step. These NiO, YSZ, and LSM samples were dip-coated into the $0.4 \mathrm{M}$ cerium nitrate solution for 24 $\mathrm{h}$, and then the samples were removed and dried within ambient atmosphere. The images show that the deposition of the nano- $\mathrm{CeO}_{2}$ onto the $\mathrm{NiO}, \mathrm{YSZ}$, and LSM substrates was similar showing larger particles (Figure 4.2.e) and randomly distributed islands (Figure 4.2.d and f) over the surfaces, but overall, the line scans revealed that the particles were around $15-60 \mathrm{~nm}$. The islands on $\mathrm{NiO}$ and LSM surfaces, for example, were gathered near grain boundaries of the substrate material. The volume of nano- $\mathrm{CeO}_{2}$ contained within these clusters distributed non-homogenously across the entire surface. In addition, the LSM surface looked noticeably deformed after the cerium nitrate treatment in Figure 4.2.f. This deformation could motive from the low chemical stability of the perovskite LSM structure under the acidic cerium nitrate medium $(\mathrm{pH} 4)$. However, when the surfaces were treated with the $1 \mathrm{mg} / \mathrm{ml} \mathrm{pNE}$ treatment for $12 \mathrm{~h}$ prior to the cerium nitrate dipcoating, the resulting calcined particles were much finer $(<\sim 20 \mathrm{~nm})$ across the line-scan as shown in Figure 4.2.g-i. The deposited nano-ceria population was also found to be higher when the surface was treated with pNE. The RMS of the line scans across particles showed an improvement from $10.4 \mathrm{~nm}$ to $13.3 \mathrm{~nm}$ in $\mathrm{NiO}$ and $3.0 \mathrm{~nm}$ to $4.6 \mathrm{~nm}$ for $\mathrm{YSZ}$ surfaces between with and without $\mathrm{pNE}$ treatment indicating enhanced discrete particle population. Although, a fine and even coating of ceria particles were observed on the LSM surface with the pNE treatment (line scan (LS) RMS 8.4 $\mathrm{nm}$ ), the trend could not be applicable as leaching of LSM surface (by cerium nitrate) disturbed the roughness vastly (LS RMS $28.1 \mathrm{~nm}$ ). The topographic analysis of the surfaces clearly showed 
the efficacy of pNE treatment on the various surfaces, on finer particle deposition, and higher decoration by anchoring the cerium cations.

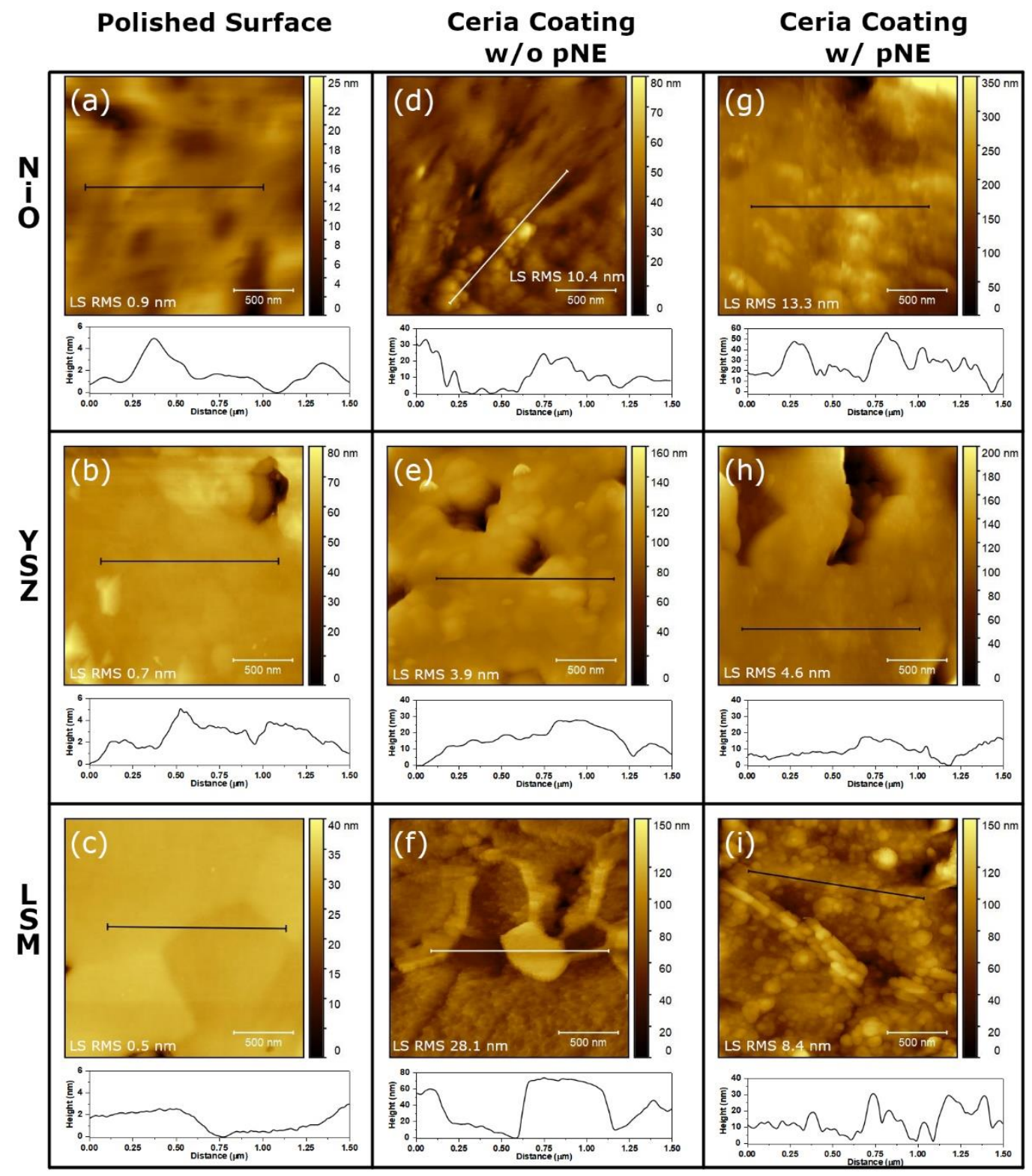

Figure 4.2 AFM images, $1.5 \mu \mathrm{m}$ line scans and line scan RMS values of (a-c) untreated and polished, and ceria coating without (d-f) and with pNE treatment (g-i) of $\mathrm{NiO}$, YSZ and LSM surfaces. 
After the validation of the deposition enhancement of the pNE coated surfaces, the same protocol was applied to infiltrate the cerium nitrate with various molarities into both electrodes simultaneously. After the calcination, the electrochemical impedance spectroscopy (EIS) and current-voltage (I-V) test were performed on each cell during the $\sim 300 \mathrm{~h}$ operation. Figure 4.3.a presents the electrode overpotential as a function of the current density of the infiltrated cells with various infiltrated ceria amounts. The total electrode overpotential was calculated by subtracting the ohmic resistance of the cell, taken from the Nyquist plot, from the total resistance found by the $\mathrm{I}-\mathrm{V}$ data at the $300^{\text {th }}$ operating hour (stated as $300 \mathrm{~h}$ throughout the rest of the paper). Based on calculations, the baseline cell exhibited a total electrode overpotential of $\sim 173 \mathrm{mV}$, where the dashed line is drawn at the operating current density of $0.325 \mathrm{~A} / \mathrm{cm}^{2}$. First, a substantial decrease in electrode overpotential was confirmed in the overall infiltrated cells. The electrode overpotentials of IC-1, IC-2, and IC-3 infiltrated cells at the operating current load were shown to decrease gradually, as a function of increased infiltrant concentration. The lowest electrode overpotential $(\sim 112 \mathrm{mV})$ was measured for the cell containing $5 \mathrm{mg}$ ceria (IC-3 cell). With an increase of ceria loading from $5 \mathrm{mg}$ to $8.5 \mathrm{mg}$, the electrode overpotential of the IC- 4 cell increased back towards the value of the baseline cell. Figure 4.3.b summarizes the electrode overpotential reduction by percent of each infiltrated cell at the operating current density. The change of the IC1, IC-2, and IC-3 cells reduced the polarization resistance by $17 \%, 21 \%$, and $35 \%$ over the baseline, respectively, while the IC-4 cell increased back towards the value of the baseline cell ( 11\% decrease in overpotential). 


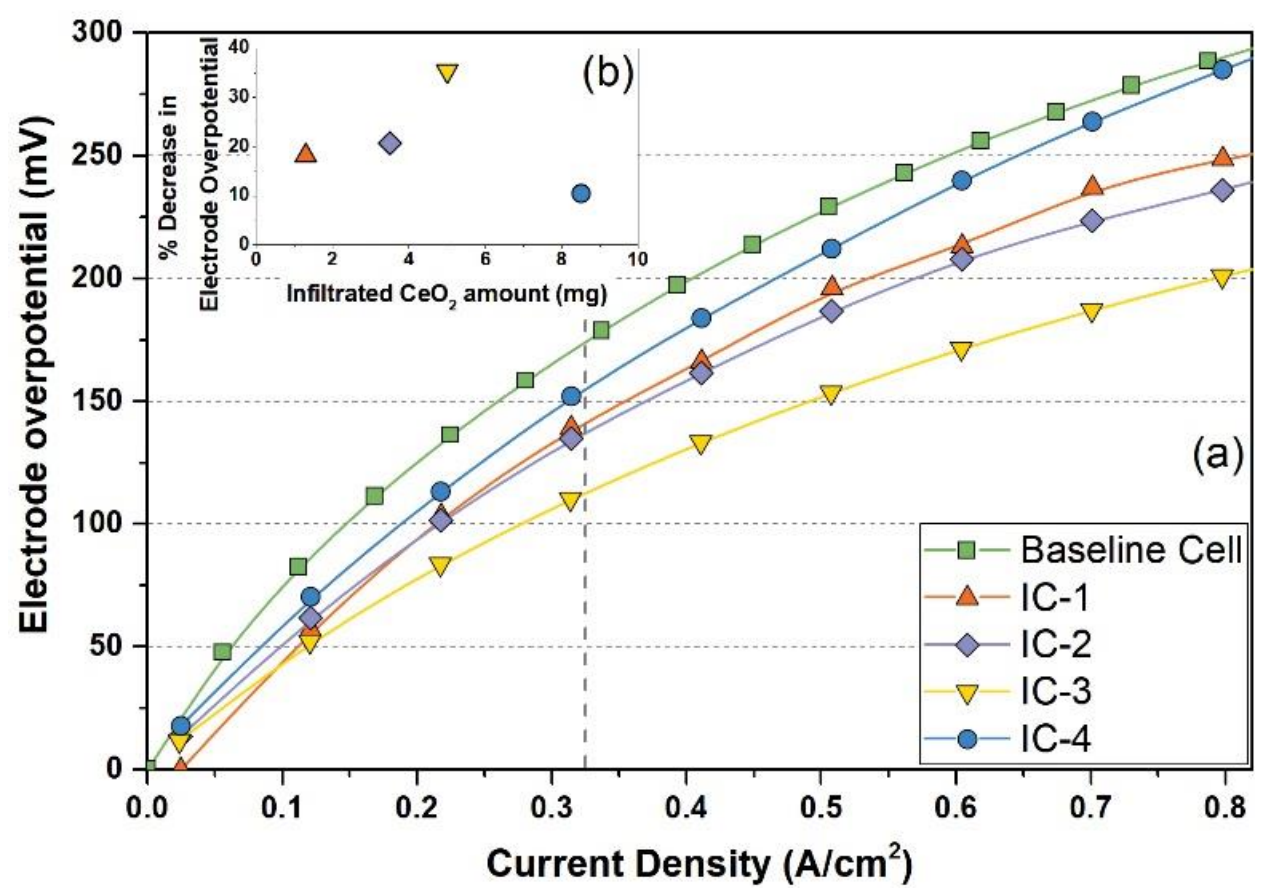

Figure 4.3 (a) Current density vs. Electrode Overpotential at 300 h (b) Percentage decrease in over potential vs. infiltrated $\mathrm{CeO}_{2}$ amount at $300 \mathrm{~h}, 0.325 \mathrm{~A} / \mathrm{cm}^{2}$.

To tabulate the relative effect of the various infiltration amounts on the fuel cell performance, Figure 4.4 displays time-varying electrode polarization resistance $\left(R_{p}\right)$ of the infiltrated cells calculated from the Nyquist EIS data at 48, 150 and $300 \mathrm{~h}$ under $0.325 \mathrm{~A} / \mathrm{cm}^{2}$ load. The $\mathrm{R}_{\mathrm{p}}$ of the cells was calculated from the difference between high frequency and low-frequency intercepts at the $\mathrm{x}$-axis (real part of the impedance) in the Nyquist EIS plots. In the plot, three separate timedependent $\mathrm{R}_{\mathrm{p}}$ change behaviors were observed, as labeled Zone I, Zone II and Zone III. In the Zone I, both the baseline cell and the IC-1 cell showed an initial increase in $\mathrm{R}_{\mathrm{p}}$ as a function of operation time. The baseline cell showed a gradual $R_{p}$ increase from 0.317 to $0.405 \mathrm{ohm} \cdot \mathrm{m}^{2}$ over the $300 \mathrm{~h}$ of operation. The IC- 1 cell also showed a slight $\mathrm{R}_{\mathrm{p}}$ increase from 0.359 to $0.381 \mathrm{ohm} \cdot \mathrm{cm}^{2}$ in 48 and $150 \mathrm{~h}$, but then later, decreased to a value of $0.369 \mathrm{ohm} \cdot \mathrm{cm}^{2}$ at the $300 \mathrm{~h}$. Although the IC-1 cell displayed $13.2 \%$ higher $\mathrm{R}_{\mathrm{p}}$ than the baseline cell in the $50 \mathrm{~h}$, the $150 \mathrm{~h}$, and $300 \mathrm{~h} \mathrm{R}_{\mathrm{p}}$ 
values decreased by $\sim 4.5 \%$ and $\sim 8.9 \%$, respectively. Based on the initial increase in $\mathrm{R}_{\mathrm{p}}$, it can be concluded that the IC-1 cell displayed the baseline-like behavior in Zone I.

In the Zone II, the infiltrated cells with the moderate catalyst loadings, 3.5, 5.0 mg (labeled as IC-2, IC-3), started with higher $\mathrm{R}_{\mathrm{p}}$ values than the baseline cell at $48 \mathrm{~h}$, but then all displayed a progressive decrease as a function of time. To begin with, IC-2 cell $\mathrm{R}_{\mathrm{p}}$ decreased by $5.5 \%$ over the $250 \mathrm{~h}$ period. Interestingly, the IC-3 cell showed a lower decrease in polarization $(\sim 1.8 \%)$ from 0.335 to $0.329 \mathrm{ohm} \cdot \mathrm{cm}^{2}$ at $48 \mathrm{~h}$ to $150 \mathrm{~h}$, respectively. Then a substantial decrease in electrode polarization was observed over the next $150 \mathrm{~h}$ of operation which resulted in an overall $18 \%$ reduction. By comparing the baseline, IC-1, IC-2, and IC-3 cells in Figure 4.4, it can be seen that there is a parallel trend in the reduction in the $\mathrm{R}_{\mathrm{p}}$ with the increase in the impregnated nano-CeO 2 content up to the $5.0 \mathrm{mg}$ concentration. However, when the nano- $\mathrm{CeO}_{2}$ content increased beyond the $5.0 \mathrm{mg}$ concentration, the $\mathrm{R}_{\mathrm{p}}$ increased significantly towards values shown for the baseline cell performance as monitored for IC-4 cell $\left(8.5 \mathrm{mg} \mathrm{CeO}_{2}\right.$ infiltrated cell) in the Zone III. The cell showed $R_{p}$ values of $0.411,0.4$, and $0.393 \mathrm{ohm} \cdot \mathrm{cm}^{2}$ at the 48,150 and $300 \mathrm{~h}$, respectively. This finding indicates that IC-4 cell in the Zone III may contain large a volume of nano-catalyst (overimpregnated), which may affect the performance negatively due to the potential decrease in the active surfaces, triple-phase boundary (TPB) length and porosity [43, 44]. 


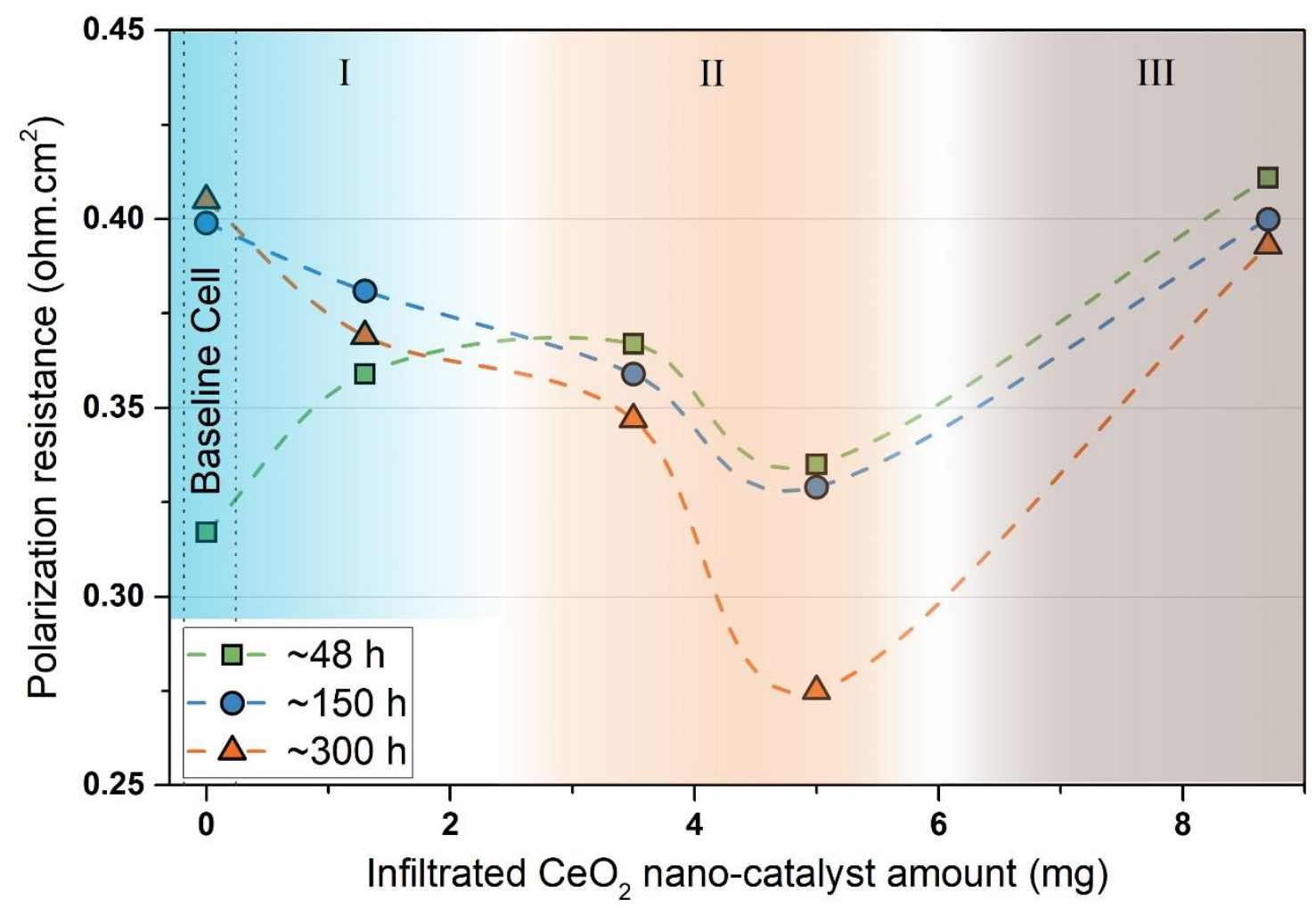

Figure 4.4 Infiltrated catalyst amount vs. polarization resistance.

Interestingly, even though the IC-4 cell showed $\mathrm{R}_{\mathrm{p}}$ levels near that of the original baseline cell, the $\mathrm{R}_{\mathrm{p}}$ of this cell continued to decrease over the $300 \mathrm{~h}$ operation, similar to the infiltrated cells in the Zone III. These results indicate that the oxygen reduction reaction and/or the fuel oxidation reaction were still altered due to a time-dependent process during operation. This timedependent process is enhanced by the incorporation of the nano-ceria inside both electrodes. This alteration could be the result of a surface reaction with the electrode composition (which is kinetically limited), or slight alterations in the catalyst microstructure over time. Unfortunately, it is difficult to distinguish in this work which of the electrodes is being most affected, since both electrodes were impregnated by the soaking process. 
As stated above, the polarization resistance of the low catalyst infiltrated cell IC-1 in Zone I fluctuated (increased between 48-150 hour and then decreased at $300 \mathrm{~h}$ ) and the infiltrated cells in the Zone II and III showed a continuous decrease over duration of operation. We would interpret this time-dependent activation is due to mainly particle coarsening and sintering of nano ceria particles. Infiltrated nano particles tend to coarsen over time at elevated temperatures. In a discrete and sparse distrubution, this could result in deactivation due to the surface area and TPB loss as observed in the first stages of IC-1 cell. With the increase of nanoparticle population, the nanoparticle sintering promotes interparticle connection, which forms a continuous pathway for ionic conduction and extending TPB. Therefore, the electrochemical activation over time could achieve by interconnected particles as experienced in the infiltrated cells in the Zone II and III. There are a few other possible concurring mechanisms that may relate specifically to the presence of nanoceria particles at the anode electrode which may cause a consistent improvement of the electrode over time. It has been known that cerium undergoes chemical-state shifting under reducing environment from $\mathrm{Ce}^{+4}$ to $\mathrm{Ce}^{+3}$ [45]. Jiang et al. proposed that the reducing environment may create active sites for $\mathrm{H}_{2}$ oxidation at the catalyst surface within the anode electrode [46]. Therefore, even though nano-catalyst coarsening/sintering occurs over time, the increased presence of the reduced nano-ceria may overcome the effect as the activation of IC-1 cell (Zone I) was monitored at the $300 \mathrm{~h}$ after a major deactivation at $150 \mathrm{~h}$ in Figure 4.4. A second reason for the stabilization of nano-ceria particles in the anode electrode may be related to volumetric expansion which occurs during the valence change of $\mathrm{CeO}_{2}$, since $\mathrm{Ce}^{+3}$ ions are approximately $17.5 \%$ larger in diameter than $\mathrm{Ce}^{+4}$ ions [47], which equates to a $60 \%$ lattice expansion $[48,49]$. According to Zhang et al., the $\mathrm{Ce}^{+3}$ concentration in the bulk ceria can go up to $5.6 \%$ when the particle size is around $10 \mathrm{~nm}$ [49]. This chemical-state shift relates to a volumetric change and 
creates a lattice strain at the catalyst oxide - backbone metallic interface as Farmer et al. stated. It was reported that the localized strain created by ceria on Ag nanoparticles mitigated the particle growth [50]. In conclusion, a series of complex mechanisms could play a role in the timedependent activation phenomena.

To better analyze the effect of pNE-assisted nano- $\mathrm{CeO}_{2}$ infiltration on the cells (and their electrochemical processes), the EIS Bode plots for the baseline and infiltrated cells after operation for 48, 150 and $300 \mathrm{~h}$ are shown in Figure 4.5. According to the past studies, it was proven that the change in reactance at the high frequency $(>100 \mathrm{~Hz}$, denoted as Region $I$ ) is associated with the anode charge-transfer reaction $[51,52]$. Similar studies indicate that the middle-frequency changes (10-100 Hz, denoted as Region II) are associated with the cathode polarization [51, 53]. Also, it was observed that the low-frequency changes $(1-10 \mathrm{~Hz}$, denoted as Region III) are generally related to gas diffusion steps and the associated polarization [51, 54]. As presented in Figure 4.5.a, all of the infiltrated cells showed higher reactance over the baseline cell in Region I and $I I$ within the first $48 \mathrm{~h}$. This observation shows that the nano- $\mathrm{CeO}_{2}$ catalyst activation did not dominate the performance of the electrode activity within the first $48 \mathrm{~h}$, as was also shown by the electrode polarization data in Figure 4.5.a. However, after 150 and $300 \mathrm{~h}$ of operation, the infiltrated cells displayed a lower reactance in both Region I (associated with the anode reactions) and Region II (associated with the cathode charge-transfer reactions), as displayed in Figure 4.5.bc. Furthermore, Region III did not show a significant decrease between the 48 to 300 h operation time in all the cells. This could be related to possible particle coarsening / activation mechanisms stated above. 

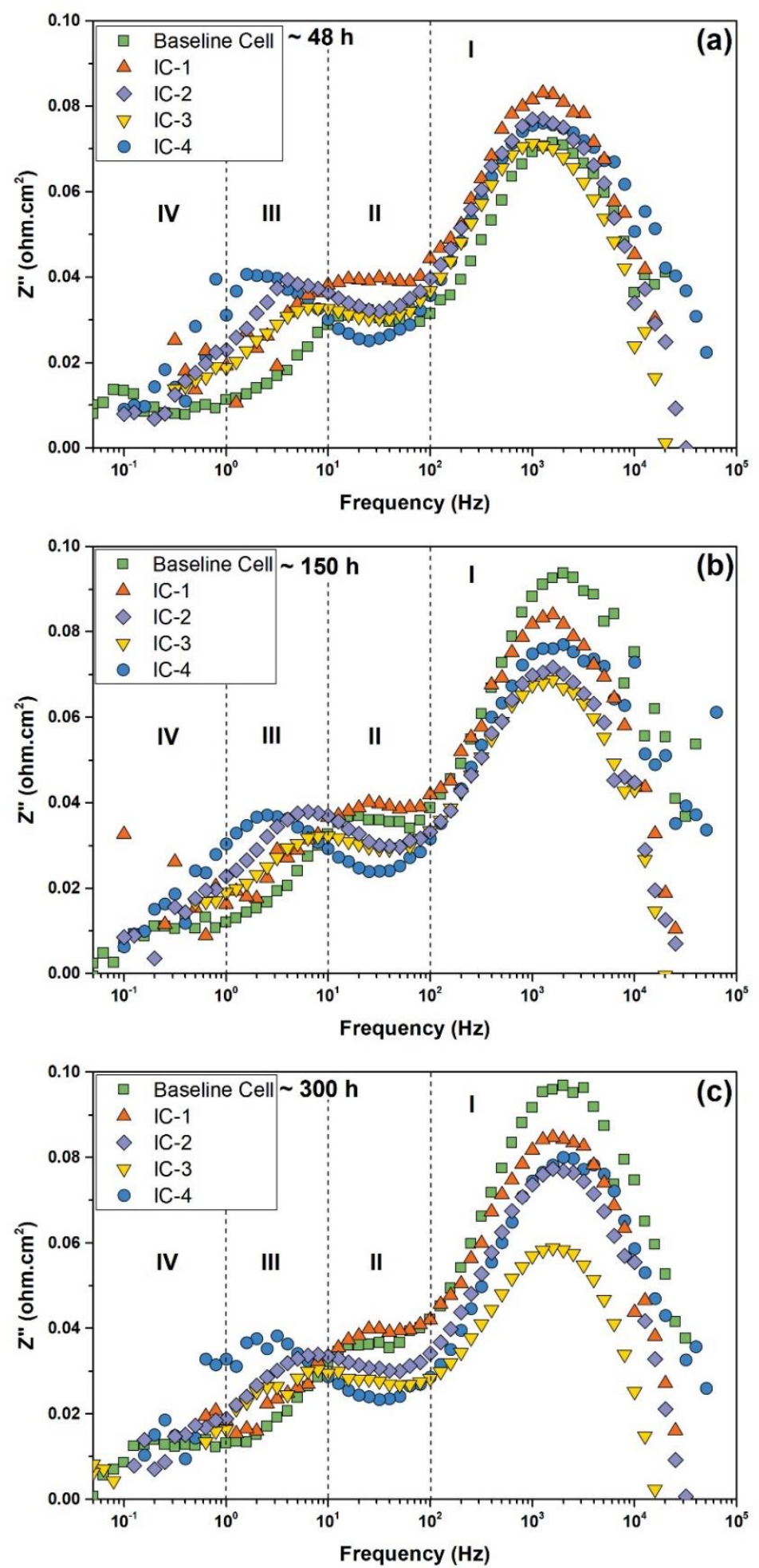

Figure 4.5 EIS bode plot of the cells in (a) $48 \mathrm{~h}$ (b) $150 \mathrm{~h}$ and (c) $300 \mathrm{~h}$ operation at 750 ${ }^{\circ} \mathrm{C}$ under $0.325 \mathrm{~A} / \mathrm{cm}^{2}$. 
Figure 4.6.a-d compares the cross-sectional SEM images of the post-operated anode functional layer micrographs of the IC-1, 2, 3 and 4 cells, respectively. In Figure 4.6.a, a uniform coating with discrete particulate islands with sizes $<15 \mathrm{~nm}$ was observed. The island size likely corresponds to the structures shown in Figure 4.1, as the same treatment and precursor molarity (0.4 M) was applied. Also, the catalyst decoration was retained in all of the micrographs. The cross-section of the coating in Figure 4.6.b depicted that the thickness of the coating in the IC-2 anode functional layer micrograph was around $30-35 \mathrm{~nm}$. The increase in the precursor molarity resulted in an increase in the infiltrated particle size. The average catalyst island of IC-3 was around 35-40 nm when $1 \mathrm{M}$ precursor was used (Figure 4.6.c), whereas the size of the islands went up to $>60 \mathrm{~nm}$ when the precursor solution was the $2 \mathrm{M}$ precursor solution (Figure 4.6.d). 

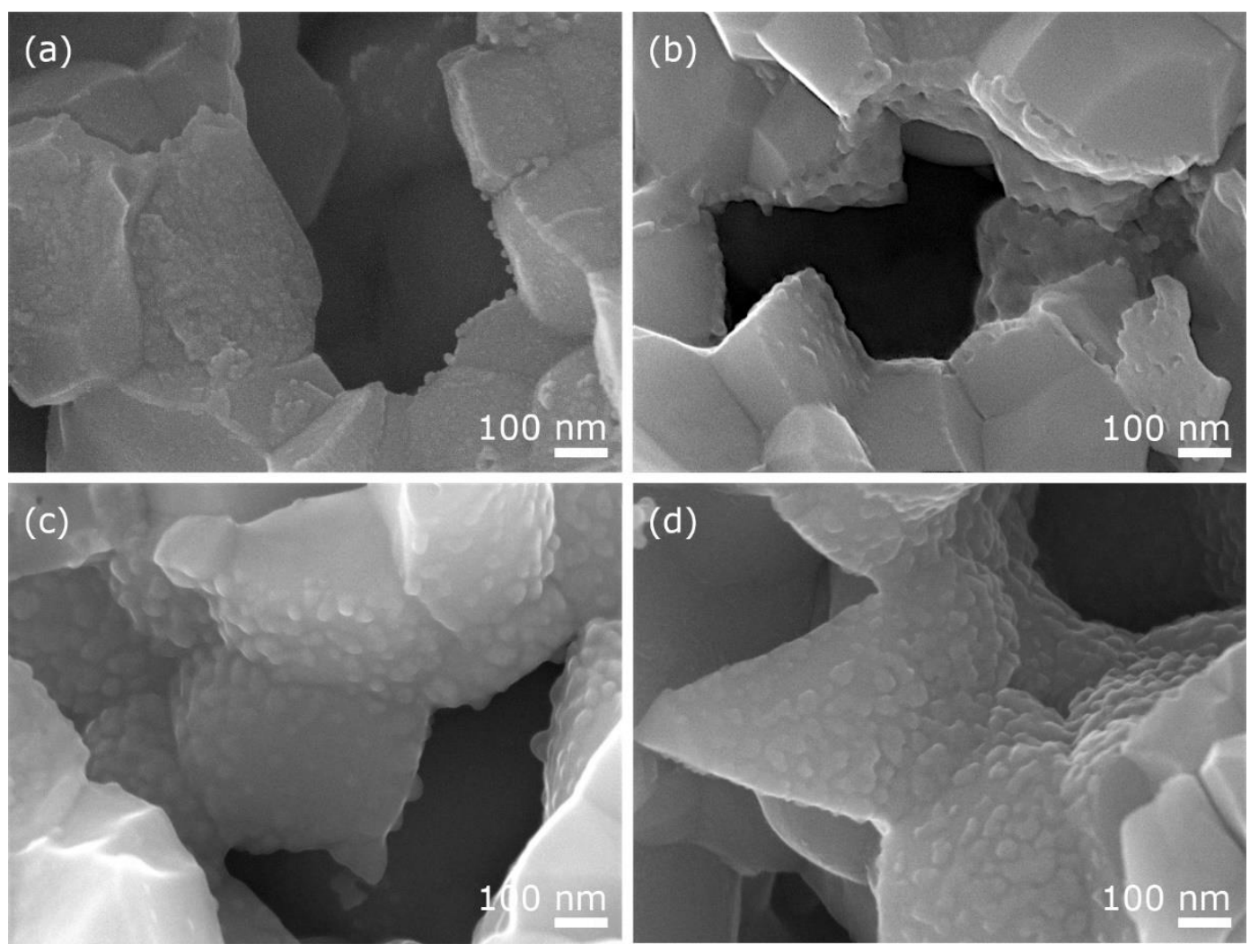

Figure 4.6 Anode active region SEM images of (a) IC-1, (b) IC-2, (c) IC-3 and (d) IC-4, for $300 \mathrm{~h}$ of testing at $750^{\circ} \mathrm{C}$ and $0.325 \mathrm{~A} / \mathrm{cm}^{2}$.

Likewise, Figure 4.7.a-d represents the crossectional SEM images of the post-operated cathode functional layer of the IC-1-4 cell. Particles in the cathode active layer in Figure 4.7.a-d maintained a thin film but were composed of smaller particle sizes in comparison to the anode functional layer decoration. In Figure 4.7.a., it can be seen that the nano-catalyst coverage resulted in a discontinuous decoration inside the pore which is probably due to the low catalyst loading by the $0.4 \mathrm{M}$ precursor. As the molarity increased to $0.7 \mathrm{M}$ and $1 \mathrm{M}$, there was continuous particle coverage at the non-fractured surfaces, which can be observed in Figure 4.7.b-c respectively. In. Figure 4.7.d. the particles were relatively larger with a higher population inside the pores. The oversaturated coverage could induce a beneficial higher contact area in terms of enhanced oxygen 
ion transport and TPB, but at the same time, the case might be prone to gas mass-transport limitation.
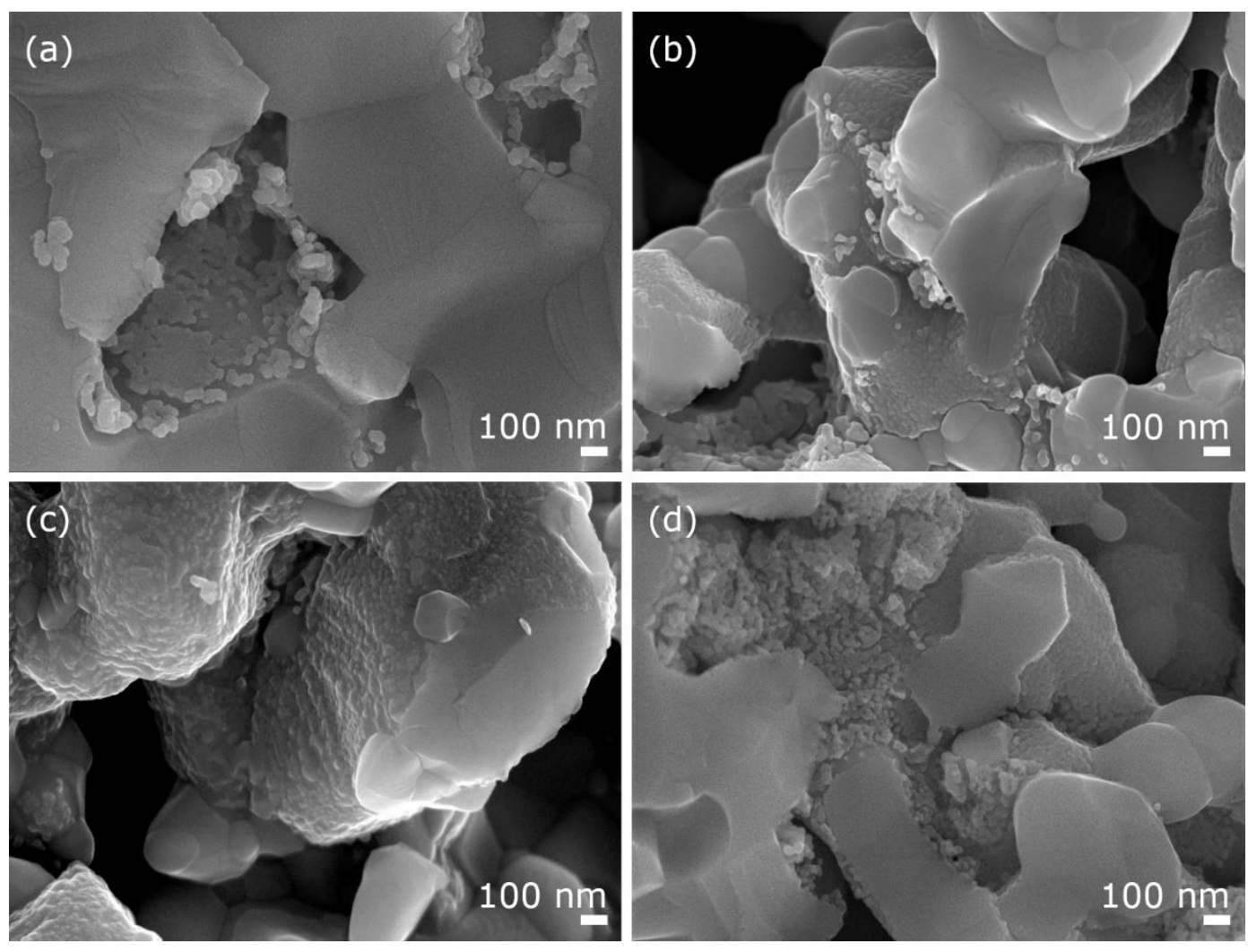

Figure 4.7 Cathode active region SEM images of (a) IC-1, (b) IC-2, (c) IC-3 and (d) IC4, after $300 \mathrm{~h}$ of testing at $750^{\circ} \mathrm{C}$ and $0.325 \mathrm{~A} / \mathrm{cm}^{2}$.

From all the SEM pictures, it can be deduced that the pNE protocol enabled the infiltration of the nano-catalyst into the active area, near the electrolyte region. Connor et al. reported that thin and even coatings are an indication of the positive surface interactions and good wetting [55], which confirms the use of catechol surfactants as excellent wetting agents [26] for low porosity architectures such as anode-supported electrodes. The electrochemical performance results also showed that the film formation of the nano-catalysts was beneficial for cell stability. The study by Wang et al. on silver coatings on silica microspheres using pDA mentions that the molarity of the 
silver nitrate precursor influences the coating morphology continuity, thickness, and compactness [34]. In their study, the coating layer morphology shifted from a sparse and discrete island to a continuous film as the metal nitrate concentration was increased. The difference in the particle size and the decoration morphology is most likely due to the accelerated deposition/chelation kinetics in the high precursor molarity in the dipping process. Hence, the precursor molarity not only adjusted the deposition amount but also the catalyst morphology. The study by Lund et al. confirms the direct relationship of the mean grain size on the polarization resistance change and overinfiltration [56]. The finding was directly reflected in the electrochemical performance. The EIS data showed the lowest polarization resistance in the IC-3 cell $\left(5 \mathrm{mg} \mathrm{CeO}, \sim 0.52 \mathrm{mg} / \mathrm{cm}^{2}\right.$ at the anode electrode and $\sim 1.63 \mathrm{mg} / \mathrm{cm}^{2}$ at the cathode electrode). Then, the IC-4 cell with $8.3 \mathrm{mg}$ ceria shifted back in performance and displayed the same performance as the baseline cell.

\subsection{Conclusion}

A poly-norepinephrine (pNE), a bio-inspired surfactant, assisted solution infiltration method was developed for SOFC electrodes. The experiments show that the pNE treatment enhances the catalyst deposition on the electrodes sub-constituents' surfaces such as YSZ, NiO, and LSM. With the single-step infiltration of ceria, the polarization resistance of the comparison cells revealed three different trends (Zones) as a function of the amount of infiltrated ceria. In the Zone I, the baseline cell and lesser ceria infiltrated cell (IC-1) monitored a similar trend in terms of activation and deactivation during the operation period. Beyond that point, the activation improves over time, and the $5 \mathrm{mg}$ ceria infiltrated cell showed the lowest $\mathrm{R}_{\mathrm{p}}$ in the Zone II. Beyond this point the nano-catalyst activation was suppressed possibly due to the gas starvation and inhomogeneous, local nano-catalyst settlement but still activating over time (Zone III). A change in decoration and island size on the top of the film formation was observed as the precursor 
molarity increased. Over $\sim 300 \mathrm{~h}$ of testing, the infiltrated cells demonstrated initial performance boost and continuous time-dependent activation. Further measurements and performance evaluation of catechol assisted infiltration in only one-electrode may be needed to understand the driving mechanism(s) better. This systematic approach proves that not only the material chemistry but the nano-catalyst amount and decoration is also critical to maintaining stability.

\subsection{References}

1. Jiang, S.P., A review of wet impregnation-An alternative method for the fabrication of high performance and nano-structured electrodes of solid oxide fuel cells. Materials Science and Engineering: A, 2006. 418(1-2): p. 199-210.

2. Babaei, A., et al., $\mathrm{Pd}$-promoted $(\mathrm{La}, \mathrm{Ca})(\mathrm{Cr}, \mathrm{Mn}) \mathrm{O}_{3} / \mathrm{GDC}$ anode for hydrogen and methane oxidation reactions of solid oxide fuel cells. Solid State Ionics, 2010. 181(25-26): p. 12211228.

3. Gavrielatos, I., V. Drakopoulos, and S. Neophytides, Carbon tolerant Ni-Au SOFC electrodes operating under internal steam reforming conditions. Journal of Catalysis, 2008. 259(1): p. 75-84.

4. McIntosh, S., J.M. Vohs, and R.J. Gorte, Effect of Precious-Metal Dopants on SOFC Anodes for Direct Utilization of Hydrocarbons. Electrochemical and Solid-State Letters, 2003. 6(11): p. A240.

5. Babaei, A., et al., Performance and stability of $\mathrm{La}_{0.8} \mathrm{Sr}_{0.2 \mathrm{MnO}}$ cathode promoted with palladium based catalysts in solid oxide fuel cells. Journal of Alloys and Compounds, 2011. 509(14): p. 4781-4787.

6. $\quad$ Sholklapper, T.Z., et al., Synthesis of Dispersed and Contiguous Nanoparticles in Solid Oxide Fuel Cell Electrodes. Fuel Cells, 2008. 8(5): p. 303-312.

7. Afshar, M.R., et al., Impregnation of $\mathrm{La}_{0.4} \mathrm{Ce}_{0.6} \mathrm{O}_{1.8}-\mathrm{La}_{0.4 \mathrm{Sr}} \mathrm{Sr}_{6.6 \mathrm{TO}}$ as solid oxide fuel cell anode in $\mathrm{H}_{2}$ S-containing fuels. Journal of Power Sources, 2015. 274: p. 211-218.

8. Klemens $\varnothing$, T., et al., High performance metal-supported solid oxide fuel cells with $G d$ doped ceria barrier layers. Journal of Power Sources, 2011. 196(22): p. 9459-9466.

9. Jung, S.W., J.M. Vohs, and R.J. Gorte, Preparation of SOFC Anodes by Electrodeposition. Journal of The Electrochemical Society, 2007. 154(12): p. B1270.

10. Dowd, R.P., et al., Engineering the solid oxide fuel cell electrocatalyst infiltration technique for industrial use. International Journal of Hydrogen Energy, 2016. 41(33): p. 14971-14981.

11. Dudek, M., et al., Feasibility of direct carbon solid oxide fuels cell (DC-SOFC) fabrication by inkjet printing technology. Electrochimica Acta, 2013. 105: p. 412-418.

12. Kiebach, R., et al., Infiltration of SOFC Stacks: Evaluation of the Electrochemical Performance Enhancement and the Underlying Changes in the Microstructure. Fuel Cells, 2016. 16(1): p. 80-88.

13. Timurkutluk, B., et al., Anode-supported solid oxide fuel cells with ion conductor infiltration. International Journal of Energy Research, 2011. 35(12): p. 1048-1055. 
14. Qiao, J., et al., $\mathrm{Ni} / \mathrm{YSZ}$ and $\mathrm{Ni}-\mathrm{CeO}_{2} / \mathrm{YSZ}$ anodes prepared by impregnation for solid oxide fuel cells. Journal of Power Sources, 2007. 169(2): p. 253-258.

15. Zhu, X., et al., A rapid preparation of acicular Ni impregnated anode with enhanced conductivity and operational stability. Journal of Power Sources, 2014. 256: p. 424-429.

16. Cimenti, M. and J.M. Hill, Direct utilization of ethanol on ceria-based anodes for solid oxide fuel cells. Asia-Pacific Journal of Chemical Engineering, 2009. 4(1): p. 45-54.

17. Li, X., et al., Performance of a commercial cathode-supported solid oxide fuel cells prepared by single-step infiltration of an ion-conducting electrocatalyst. Journal of Power Sources, 2012. 199: p. 132-137.

18. Miller, E.C., et al., Stability of Nickel-Infiltrated Anodes in Intermediate Temperature SOFCs. ECS Transactions, 2015. 68(1): p. 1245-1254.

19. Mason, J., et al., Performance Degradation Predictions Based on Microstructural Evolution Due to Grain Coarsening Effects in Solid Oxide Fuel Cell Electrodes. Journal of The Electrochemical Society, 2018. 165(2): p. F64-F74.

20. Lou, X., et al., Controlling the morphology and uniformity of a catalyst-infiltrated cathode for solid oxide fuel cells by tuning wetting property. Journal of Power Sources, 2010. 195(2): p. 419-424.

21. Tucker, M.C., et al., Performance of metal-supported SOFCs with infiltrated electrodes. Journal of Power Sources, 2007. 171(2): p. 477-482.

22. Jiang, Z., et al., Electrochemical characteristics of solid oxide fuel cell cathodes prepared by infiltrating ( $\mathrm{La}, \mathrm{Sr}) \mathrm{MnO}_{3}$ nanoparticles into yttria-stabilized bismuth oxide backbones. International Journal of Hydrogen Energy, 2010. 35(15): p. 8322-8330.

23. Nicholas, J.D. and S.A. Barnett, Measurements and Modeling of $\mathrm{Sm}_{0.5} \mathrm{Sr}_{0.5} \mathrm{CoO}_{3}-x-$ Ce ${ }_{0.9} \mathrm{Gd}_{0.1} \mathrm{O}_{1.95} \mathrm{SOFC}$ Cathodes Produced Using Infiltrate Solution Additives. Journal of The Electrochemical Society, 2010. 157(4): p. B536.

24. $\mathrm{Li}, \mathrm{W}$., et al., Effect of adding urea on performance of $\mathrm{Cu} / \mathrm{CeO}_{2} /$ yttria-stabilized zirconia anodes for solid oxide fuel cells prepared by impregnation method. Electrochimica Acta, 2011. 56(5): p. 2230-2236.

25. Waite, J.H., Mussel power. Nat Mater, 2008. 7(1): p. 8-9.

26. Kang, S.M., et al., One-step modification of superhydrophobic surfaces by a musselinspired polymer coating. Angew Chem Int Ed Engl, 2010. 49(49): p. 9401-4.

27. Liu, Y., K. Ai, and L. Lu, Polydopamine and its derivative materials: synthesis and promising applications in energy, environmental, and biomedical fields. Chem Rev, 2014. 114(9): p. 5057-115.

28. Jiang, J., et al., Surface characteristics of a self-polymerized dopamine coating deposited on hydrophobic polymer films. Langmuir, 2011. 27(23): p. 14180-7.

29. Nirasay, S., et al., Polydopamine-Supported Lipid Bilayers. Materials, 2012. 5(12): p. 2621-2636.

30. Ball, V., et al., Kinetics of polydopamine film deposition as a function of $p H$ and dopamine concentration: insights in the polydopamine deposition mechanism. J Colloid Interface Sci, 2012. 386(1): p. 366-72.

31. Wang, W., et al., Preparation of PET/Ag hybrid fibers via a biomimetic surface functionalization method. Electrochimica Acta, 2012. 79: p. 37-45.

32. Park, J.Y., et al., Cell-repellant dextran coatings of porous titania using mussel adhesion chemistry. Macromol Biosci, 2013. 13(11): p. 1511-9. 
33. Zlotnikov, I., I. Gotman, and E.Y. Gutmanas, Characterization and nanoindentation testing of thin ZrO2 films synthesized using layer-by-layer (LbL) deposited organic templates. Applied Surface Science, 2008. 255(5): p. 3447-3453.

34. Wang, W., et al., Fabrication of silver-coated silica microspheres through mussel-inspired surface functionalization. J Colloid Interface Sci, 2011. 358(2): p. 567-74.

35. Ryu, J., et al., Mussel-Inspired Polydopamine Coating as a Universal Route to Hydroxyapatite Crystallization. Advanced Functional Materials, 2010. 20(13): p. 21322139.

36. Ozmen, O., et al., Bio-inspired surfactant assisted nano-catalyst impregnation of SolidOxide Fuel Cell (SOFC) electrodes. Materials Letters, 2016. 164: p. 524-527.

37. Ding, Y., et al., Insights into the aggregation/deposition and structure of a polydopamine film. Langmuir, 2014. 30(41): p. 12258-69.

38. Hong, S., et al., Poly(norepinephrine): ultrasmooth material-independent surface chemistry and nanodepot for nitric oxide. Angew Chem Int Ed Engl, 2013. 52(35): p. 918791.

39. Kang, S.M., et al., Norepinephrine: material-independent, multifunctional surface modification reagent. J Am Chem Soc, 2009. 131(37): p. 13224-5.

40. Chen, J., et al., A norepinephrine coated magnetic molecularly imprinted polymer for simultaneous multiple chiral recognition. J Chromatogr A, 2015. 1409: p. 268-76.

41. Hong, J.-Y., et al., Bio-inspired functionalization and redox charge transfer of graphene oxide sponges for pseudocapacitive electrodes. Carbon, 2015. 83: p. 71-78.

42. Ozmen, O., et al., Porous SOFC Electrode Infiltration Methods By Bio-Adhesive Templating. Meeting Abstracts, 2015. MA2015-01(1): p. 212.

43. Ding, X., et al., Enhanced SOFC cathode performance by infiltrating Ba0.5Sr0.5Co0.8Fe0.2O3- $\delta$ nanoparticles for intermediate temperature solid oxide fuel cells. Fuel Processing Technology, 2015. 135: p. 14-19.

44. Huang, B., et al., High-performance $\mathrm{Gd}_{0.2} \mathrm{Ce}_{0.8} \mathrm{O}_{2}$-impregnated $\mathrm{LaNi}_{0.6} \mathrm{Fe}_{0.4} \mathrm{O}_{3-\delta}$ cathodes for intermediate temperature solid oxide fuel cell. Journal of Power Sources, 2012. 209: p. 209-219.

45. Badwal, S.P.S., et al., Structural and microstructural stability of ceria - gadolinia electrolyte exposed to reducing environments of high temperature fuel cells. Journal of Materials Chemistry A, 2013. 1(36): p. 10768.

46. Jiang, S.P., et al., Performance of GDC-Impregnated Ni Anodes of SOFCs. Electrochemical and Solid-State Letters, 2004. 7(9): p. A282.

47. Karimaghaloo, A., et al., Nanoscale Surface and Interface Engineering of Solid Oxide Fuel Cells by Atomic Layer Deposition. International Journal of Precision Engineering and Manufacturing-Green Technology, 2019. 6(3): p. 611-628.

48. Perebeinos, V., S.-W. Chan, and F. Zhang, 'Madelung model' prediction for dependence of lattice parameter on nanocrystal size. Solid State Communications, 2002. 123(6-7): p. 295-297.

49. Zhang, F., et al., Cerium oxidation state in ceria nanoparticles studied with X-ray photoelectron spectroscopy and absorption near edge spectroscopy. Surface Science, 2004. 563(1-3): p. 74-82.

50. Farmer, J.A. and C.T. Campbell, Ceria maintains smaller metal catalyst particles by strong metal-support bonding. Science, 2010. 329(5994): p. 933-6. 
51. Lee, S., N. Miller, and K. Gerdes, Long-Term Stability of SOFC Composite Cathode Activated by Electrocatalyst Infiltration. Journal of the Electrochemical Society, 2012. 159(7): p. F301-F308.

52. Leonide, A., et al., Evaluation and Modeling of the Cell Resistance in Anode-Supported Solid Oxide Fuel Cells. Journal of The Electrochemical Society, 2008. 155(1): p. B36.

53. Chen, X.J., K.A. Khor, and S.H. Chan, Identification of $\mathrm{O}_{2}$ reduction processes at yttria stabilized zirconia|doped lanthanum manganite interface. Journal of Power Sources, 2003. 123(1): p. 17-25.

54. Endler, C., et al., Time-Dependent Electrode Performance Changes in Intermediate Temperature Solid Oxide Fuel Cells. Journal of The Electrochemical Society, 2010. 157(2): p. B292.

55. Connor, P.A., et al., Tailoring SOFC Electrode Microstructures for Improved Performance. Advanced Energy Materials, 2018. 8(23): p. 1800120.

56. Lund, A., et al., The effect of loading and particle size on the oxygen reaction in CGO impregnated Pt electrodes. Journal of Solid State Electrochemistry, 2011. 16(3): p. 11611168. 


\section{Chapter 5 : Kinetics of Growth Study of Catechol Surfactant and Ceria Nano particles onto the Planar Substrates}

\subsection{Introduction}

Catechol-based molecules, such as dopamine and other benzene diaol-like derivatives that have multi-functional end-groups are a specific type of bio-monomer found in nature. Apart from the neurotransmitter functions, these end-groups are capable of strong adhesion when biomonomers are linked and polymerized, as can be found in mussel foot protein (MFP) [1-3]. Marine mussels can naturally produce various amounts of DOPA (3,4-dihydroxyphenylalanine) as a moiety of mussel food proteins, Mefp-3, Mefp-5, and Mefp-6, in the byssus plaque to attach to solid surfaces in the marine medium [3-5]. The mechanism is virtually a spontaneous and $\mathrm{pH}-$ induced oxidative polymerization occurring in alkaline medium that has multiple complex intermediate species/steps [5-10]. Owing to the amine and hydroxyl groups, polydopamine (pDA) gains adhesion property where the functionalized molecules are able to adhere and polymerize over both the organic and inorganic surfaces, such as polar and non-polar polymer surfaces, and metal and metal oxide surfaces $[1,11]$.

The research on poly-dopamine (pDA) and related catechol thin film coatings have shown a steady increase over the past decade [6]. Many of these studies used a similar solution concentration and polymerization for deposition, which included a $24 \mathrm{~h}$ polymerization reaction for a $2 \mathrm{mg} / \mathrm{ml}$ aqueous catechol solution at a $\mathrm{pH}$ 8.5. One major drawback shown in these works for using $\mathrm{pDA}$ as a surfactant for a coating process is that the polymerization step is not controllable and leads to the formation of dopamine aggregates within the solution over the deposition period [12]. It was reported that non-covalent forces such as $\pi$ - $\pi$ bonding and Van der 
Walls forces, and the insoluble nature of the melanin species, trigger the aggregation process [11, 13-15]. However, the main potential problem is that the aggregation then limits the formation of a smooth and homogenous coating with low roughness. In some works, various solutions and deposition variables such as deposition method [16], solid loading [12, 17], polymerization $\mathrm{pH}$ [18], time [19] and temperature [20] were tested to mitigate the agglomeration. To overcome this issue, the preparation of a fresh solution after every few hours of immersion time was also an option $[12,16]$. However, in the case of a microporous interconnected 3-D network, such as found in fuel cell electrodes or membranes, pore-clogging during the coating step is an additional terminal downside of pDA aggregation. In early studies within this work, a concentration of 1 $\mathrm{mg} / \mathrm{ml} \mathrm{pDA}$ solution with 1:1 vol \% water-ethanol mixture at $\mathrm{pH} 8.5$ was passed every $12 \mathrm{~h}$ through a 0.2-micron filter to eliminate the initial aggregates [21]. However, by the nature of spontaneous aggregation, new aggregates might form inside the 3-D solid oxide fuel cell (SOFC) electrodes during the dip-coating stage, and this would restrict the catalyst precursor infiltration/penetration through an electrode structure (especially electrodes with $<\sim 25 \%$ porosity). The bloggage of these pores with the surfactant, and later the adsorbed nano-catalyst, would result in performance loss due to the gas diffusion limitations during operation. In the previous chapter, the problem was overcome by switching the poly-dopamine catechol to nor-epinephrine which gave a homogenous catalyst decoration throughout of the 3-D electrode architecture.

Nor-epinephrine, an alternative catecholamine that offers a material-independent coating feature, was reported by Lee et al. [22]. In their later study, they showed a low degree of aggregation as the main advantage of polymerized nor-epinephrine (pNE) over pDA, which potentially allows a higher decoration control of the secondary coating in terms of morphology and thickness [23]. Yang et al. reported that the pNE morphology on planar quartz contains fewer 
protuberances and more than half of the surface roughness (measured as RMS-root mean square) compared to pDA coating under the same conditions (2 $\mathrm{mg} / \mathrm{ml}, 24 \mathrm{~h}$ incubation) [24].

Once the catechol layer is deposited over the substrate, a variety of organic and inorganic secondary functional coatings can be designed [6]. One group formed metal/metal oxide layers by immersing the pNE catechol layer into a metal salt solution. The metal ion binds to the hydroxyl groups on the catechol graft through a chelation reaction [25]. After the secondary coating, the catechol coating can be thermally treated, which combusts the catechol layer and allows the functional secondary coating to calcine and bond to the substrate or template. The study of $\mathrm{ZrO}_{2} / \mathrm{pDA}$ multilayer films by $\mathrm{Ou}$ et al. reported that as the deposition proceeds, the first deposited $\mathrm{ZrO}_{2}$ layer acted as a seed layer to boost the population of $\mathrm{ZrO}_{2}$ particles over the initially deposited oxide layer [26]. The secondary layer morphology and thickness can be modified by varying the metal ion solution concentration [27] and/or the substrate immersion time [28]. To date, there are only a few reported works focussing on the chelation of metal ions using pNE. For example, a study by Doherty et al. assessed the ability of "a gut-signaling hormone," norepinephrine, to chelate iron [29]. Another study by Kang et al. reported the formation of silver nanoparticles by an overnight reaction of silver nitrate immersion of the pNE coated graphene oxide surfaces[30]. A previous study showed that the use of $\mathrm{pNE}$ as a surface modifier for the porous, multi-phase, and 3-D SOFC electrode architecture could yield secondary coating of the cerium nitrate solution by the chelating effect [31].

Cerium oxide (also known as ceria) has a cubic fluorite-type structure that has been one of the major non-noble constituents in catalytic systems due to its +4 to +3 valence switching character. Nanostructured ceria catalysts can be used in both reducing and oxidizing environments, such as a three-way catalyst (TWCs) [32], a diesel soot combustion catalyst [33] in the automotive 
industry, steam reforming catalysts (SMR)[34], water-gas-shift (WGS) reaction catalyst [35], photo-catalyst for degradation of dyes [36], and half-reaction catalysts in the fuel cell electrodes including polymer exchange membrane fuel cells (PEMFCs) [37] and solid oxide fuel cells (SOFCs) [21].

Nanostructured materials show enhanced material properties due to their higher surface area to volume ratio. However, structural stability at elevated temperatures is a well-known challenge due to their high surface energy. Particle coarsening is the transformation of smaller particles into larger particles, driven by capillary (Oswald ripening) and/or diffusional effects [38] to reduce the overall surface energy. This evolution can be controlled by tuning the initial particle size/distribution [39, 40], grain boundary composition [41], designing sintering-resistant core-shell nanocomposite morphology [42] or sintering-resistant advance support topology with nano compartments [43]. Hence, with these efforts, the activity of nanoparticles can be stabilized over longer operating times at elevated temperatures.

In this study, pNE polymerization as a function of the time and solid loading is monitored. Then a correlation of the degree of polymerization (dp) with the adhered pNE surfactant film thickness and morphology which were deposited on yttria-stabilized zirconia, YSZ, single crystal surfaces, is constructed as a function of immersion time and solid loading. In the second part, cerium nitrate solution and palladium nitrate solutions were chosen as a secondary treatment solution for pNE coated YSZ single crystals. The chemical state of the adhered pNE layer and the secondary treatment deposits have been analyzed in detail by X-ray photoelectron spectroscopy (XPS). Finally, the surface morphology of cerium oxide formation of the fired samples as a function of pNE and cerium nitrate immersion times was assessed. The results were correlated with the ceria nucleation and growth mechanisms as a function of pNE morphology and cerium 
nitrate immersion time. To analyze cerium oxide morphology, the YSZ surfaces were patterned with stripe lines as a marker by photolithography prior to the pNE coating.

\subsection{Experimental}

Catechol-based surfactant, DL-Norepinephrine hydrochloride ( $\geq 97 \%$ (TLC), Aldrich), was dissolved into a 0.05 M TRIS (tris(hydroxymethyl) aminomethane, 99\%, Alfa-Aesar) and 1:1 vol $\%$ water-ethanol mixture at $\mathrm{pH}$ 8.5. The polymerization of the monomer was confirmed visually by the transition of the solution from transparent to a brown color. UV-Vis absorption analysis of the surfactants was carried out by means of a double beam spectrophotometer (Shimadzu 2600), at room temperature. The polymerized catechol solutions were analyzed using a diluted 1:19 vol\% ratio from the stock solution for the UV-Vis spectroscopic analysis.

In the first part of the study, one-side polished $1 \mathrm{~mm} \times 1 \mathrm{~mm}(100)$ yttria-stabilized zirconia (YSZ) single crystals (MTI Corporation, USA) were used as substrates. First, the substrates were cleaned by sonicating in acetone, ethanol and then in a water bath for 5 minutes each. The substrates were then dried at $150^{\circ} \mathrm{C}$ for 5 minutes. The substrates were submersed into the pNE solution for the surface coating for $1,3,6,12$ and $24 \mathrm{~h}$. The substrates were rinsed in a 1:1 vol \% water-ethanol mixture after the coating to remove loosely bonded species, then the samples were dried in air at $50{ }^{\circ} \mathrm{C}$. The coatings were gently inscribed by a fine needle tip and areas were analyzed by atomic force microscopy (Agilent 5500 Atomic Force Microscope, AFM) using the tapping mode. As can be seen from a representative pNE AFM image in Figure 5.1.a, the needle mark created pNE piles at the edges. Also, the adhered pNE showed rough surface characteristics. The average pNE thickness was measured by combining the Rv (maximum valley depth) parameters after the pile and the $\mathrm{R}_{\mathrm{q}}(\mathrm{RMS}$, root mean square) of the pNE surfaces as shown in 
Figure 5.1.b. The average of three line scan measurements were taken for film thickness, using an open software, Gwyddion (Version 2.48).
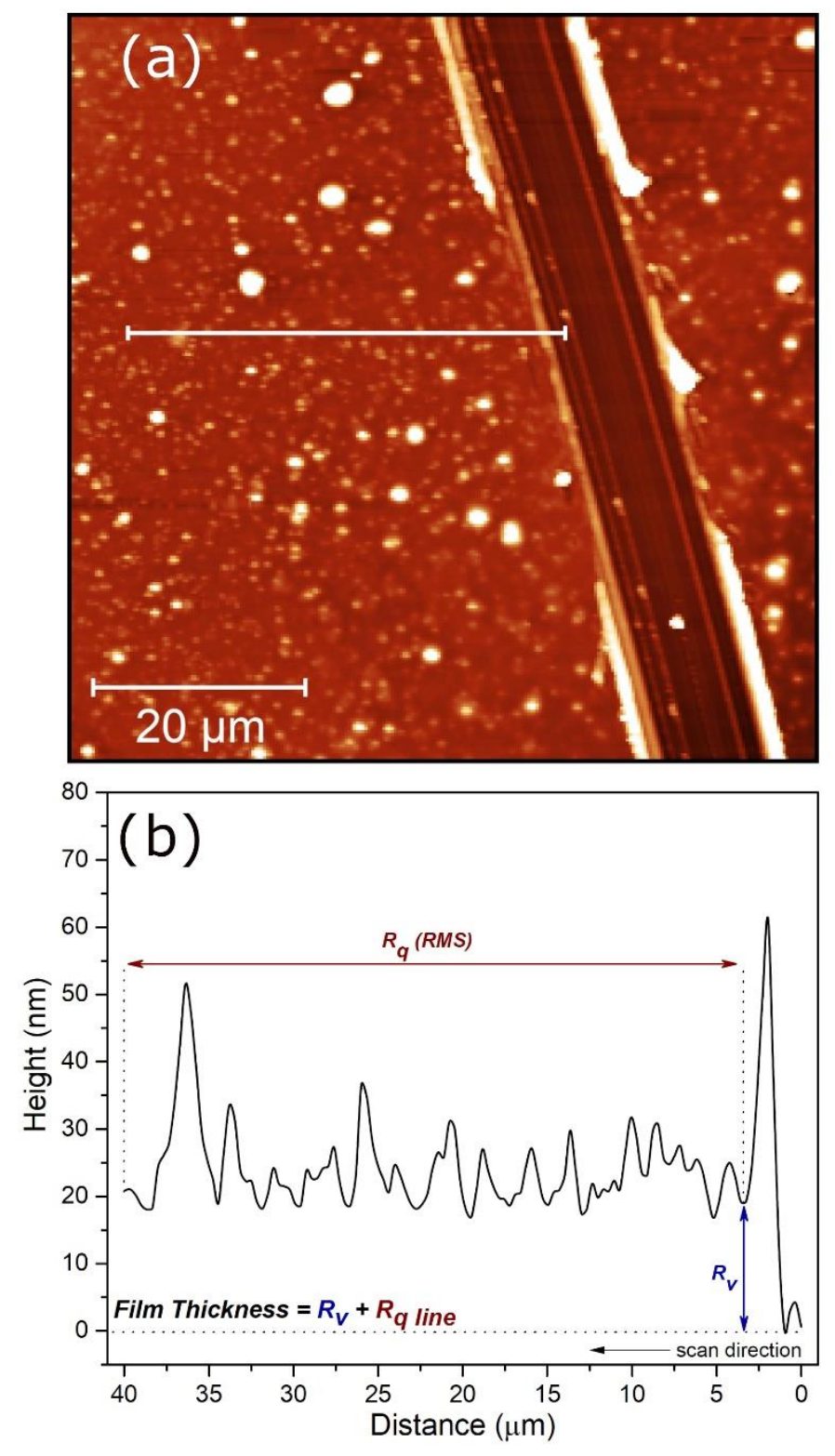

Figure 5.1 (a) A representative AFM image of pNE coated YSZ surface inscribed by fine needle tip (b) A line scan profile along the needle mark and the pNE coating that shows the method of pNE layer thickness measurement. $R_{v}$ denotes the maximum valley depth and the $\mathrm{R}_{\mathrm{q}}$ (RMS) denotes root mean square parameters. 
In the second part of the study, the surface-chemical state of the elements present on the bare and unfired $\mathrm{pNE}+0.15 \mathrm{M}$ cerium (III) nitrate (REacton ${ }^{\circledR}, 99.5 \%$, Alfa Aesar, USA) solution treated and pNE + 0.2 M palladium (II) nitrate dihydrate (99.8\%, Alfa Aesar, USA) solution treated YSZ single crystals were characterized using monochromatized Al Ka radiation (1486.6 eV) X-ray photoelectron spectroscopy (XPS, Physical Electronics PHI 5000 VersaProbe, MN, USA). The concentration of the pNE coating $2 \mathrm{mg} / \mathrm{ml}$ and substrates were coated for 24 hours for all the samples. In addition, the metal precursor immersion time was set to 3 hours. Prior to analysis, the surfaces were gently sputtered to remove contamination without changing the chemical state of elements by an $\mathrm{Ar}^{+}$gun at $0.5 \mathrm{kV}$ rastered over $2 \times 2 \mathrm{~mm}^{2}$ area for $6 \mathrm{sec}$. The adventitious C1s (284.8 eV) peak was taken as a reference for the carbonaceous surfaces.

In the third part of the study, a photolithography technique was applied to the YSZ substrates in a class 1000 cleanroom before the coating treatments. The schematic of the fabrication process is shown in Figure 5.2. First, the substrates were sonicated in acetone, isopropanol and DI water each for 5 minutes. SU-8-2 photoresist (Microchem, MA, USA) was spin-coated on the cleaned substrates using a Laurel Technologies 400 spinner (North Wales, PA, USA). The substrates were soft-baked for $1 \mathrm{~min}$ each at $65^{\circ} \mathrm{C}$ and $95^{\circ} \mathrm{C}$. A $15 \mu \mathrm{m}$ striped pattern was transferred to the SU-8 coated substrate using a photomask (UTZ Technologies, Little Falls, NJ, USA) and cured under UV Flood Exposure (OAI, CA, USA). The substrates were then postbaked on a hot plate for $10 \mathrm{sec}$ each at $65^{\circ} \mathrm{C}$ and $95^{\circ} \mathrm{C}$. Finally, the pattern was developed with the SU-8 developer solution (Microchem, MA, USA) for $30 \mathrm{sec,} \mathrm{rinsed} \mathrm{several} \mathrm{times} \mathrm{with} \mathrm{isopropanol}$ and dried by blowing dry $\mathrm{N}_{2}$. The patterned substrates were immersed into the $1 \mathrm{mg} / \mathrm{ml} \mathrm{pNE}$ solution for $3 \mathrm{~h}, 12 \mathrm{~h}$ and $24 \mathrm{~h}$ as described above. The SU-8 patterns were lifted-off by immersing the substrates into MS-111 epoxy stripping agent (Miller-Stephenson Co., Danbury, CT) for $4 \mathrm{~min}$ 
and then rinsed with ethanol. At the final stage, the samples were moved into a $0.15 \mathrm{M}$ cerium (III) nitrate hexahydrate (REacton ${ }^{\circledR}, 99.5 \%$, Alfa Aesar, USA) and 1:1 vol\% water-ethanol solvent for $24 \mathrm{~h}$. After the precipitation step, samples were rinsed again and dried under ambient conditions. Finally, the coated substrates were fired at $750^{\circ} \mathrm{C}$ for $1 \mathrm{~h}$ for nitrate solution decomposition, forming the ceria $\left(\mathrm{CeO}_{2}\right)$ phase. The topography of the ceria layers was then analyzed using AFM.

1. Clean the Substrate

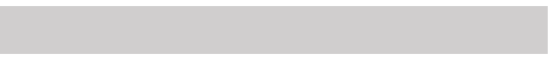

2. Apply Photoresist \& Prebake

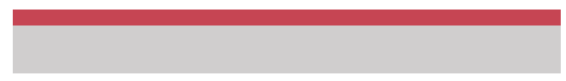

3. Align the Mask \& Expose Light

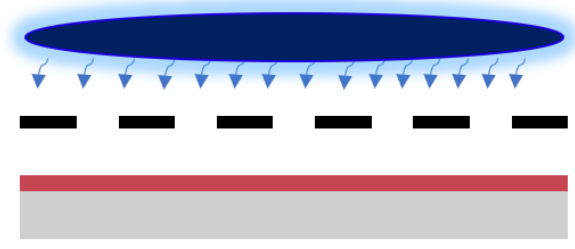

4. Develop \& Postbake

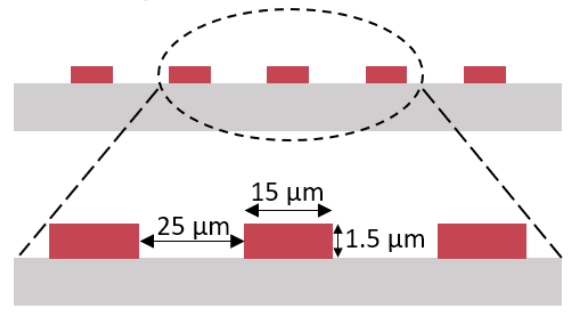

5. Dip into pNE Sol

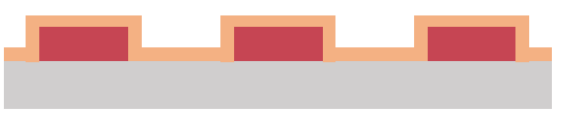

6. Pattern Lift-out

7. Dip into Cerium Nitrate Sol

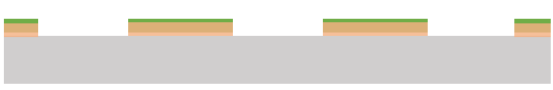

8. Calcine

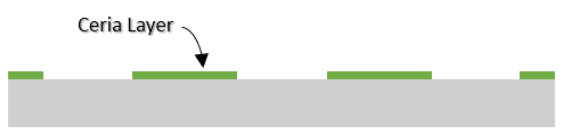

Figure 5.2 Schematic of SU-8 patterning and pNE+ceria decoration on YSZ single crystals. 


\subsection{Results and Discussion}

\subsection{1. pNE Characterization}

Figure 5.3 shows images of clear nor-epinephrine precursor and the polymerized pNE solultion after $12 \mathrm{~h}$ of oxidation. When the $\mathrm{pH}$ of the freshly received nor-epinephrine solution is shifted to alkaline conditions, the time-dependent oxidative polymerization is initiated. One visual indication of catechol polymerization is the solution color which shifts from transparent to brownish color as the time proceeds. This phenomenon occurs due to catecholamine monomer grafting into larger chains [23] and can be seen in other known catechol systems such as pDA [20].

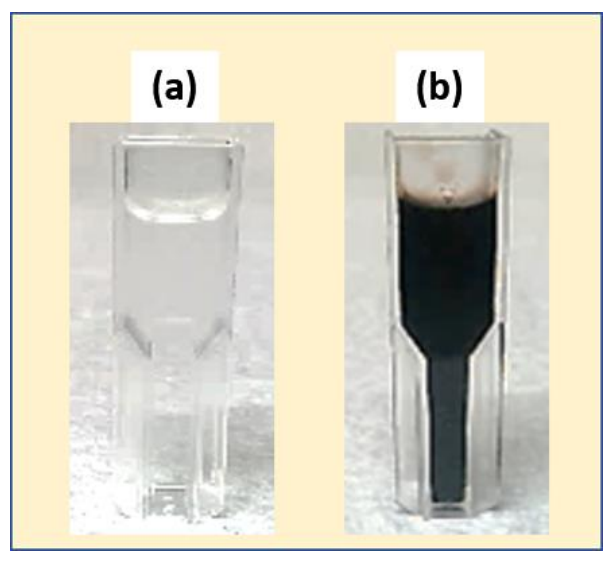

Figure 5.3 Representative images of (a) clear nor-epinephrine (b) polymerized pNE solution.

To monitor this time-dependent oxidative polymerization, UV-Vis spectroscopic analysis was performed. Figure 5.4.a, $\mathrm{b}$, and $\mathrm{c}$ show the UV-Vis data for $\mathrm{pNE}$ in varying polymerization time and solid loading of $1,3,6,12$, and $24 \mathrm{~h}$ of $0.5 \mathrm{mg} / \mathrm{ml}, 1 \mathrm{mg} / \mathrm{ml}$ and $2 \mathrm{mg} / \mathrm{ml} \mathrm{pNE}$, respectively. As a general trend, a gradual upshift at $350 \mathrm{~nm}$ was observed both as a function of time and solid loading. The solid loading produced a negligible difference in the first hour. However, as time proceeded, the absorption variance at $350 \mathrm{~nm}$ became more significant and 
reached $0.46,0.69$, and 0.94 at $24 \mathrm{~h}$ incubation of the $0.5 \mathrm{mg} / \mathrm{ml}, 1 \mathrm{mg} / \mathrm{ml}$ and $2 \mathrm{mg} / \mathrm{ml} \mathrm{pNE}$ respectively. The change in absorption in the pDA was attributed to the quinone formation by Cheng et al. [19]. Kang et al. also noted that quinone undergoes pNE formation [22].

To visualize the relative degree of polymerization [dp], each absorption peak at $350 \mathrm{~nm}$ was proportioned with the value of $550 \mathrm{~nm}$ which is out of the peak area. Figure 5.4.d displays a normalized absorption peak difference $[350 \mathrm{~nm}-550 \mathrm{~nm}]$ as a function of solids loading and time. For this purpose, the $\Delta$ absorption value $[350 \mathrm{~nm}-550 \mathrm{~nm}]$ of $2 \mathrm{mg} / \mathrm{ml} \mathrm{pNE}$ solution after the 24 $\mathrm{h}$ deposition (in the darkest brown color) was taken as 1 . The figure shows that the $\mathrm{pNE}$ was driven close to a logarithmic behavior of catechol adhesion as a function of immersion time. It can be seen that the effect of solid loading on the rate of polymerization had more impact after $3 \mathrm{~h}$ of polymerization. This plot gives a preliminary mapping of the rate of the pNE oxidation.
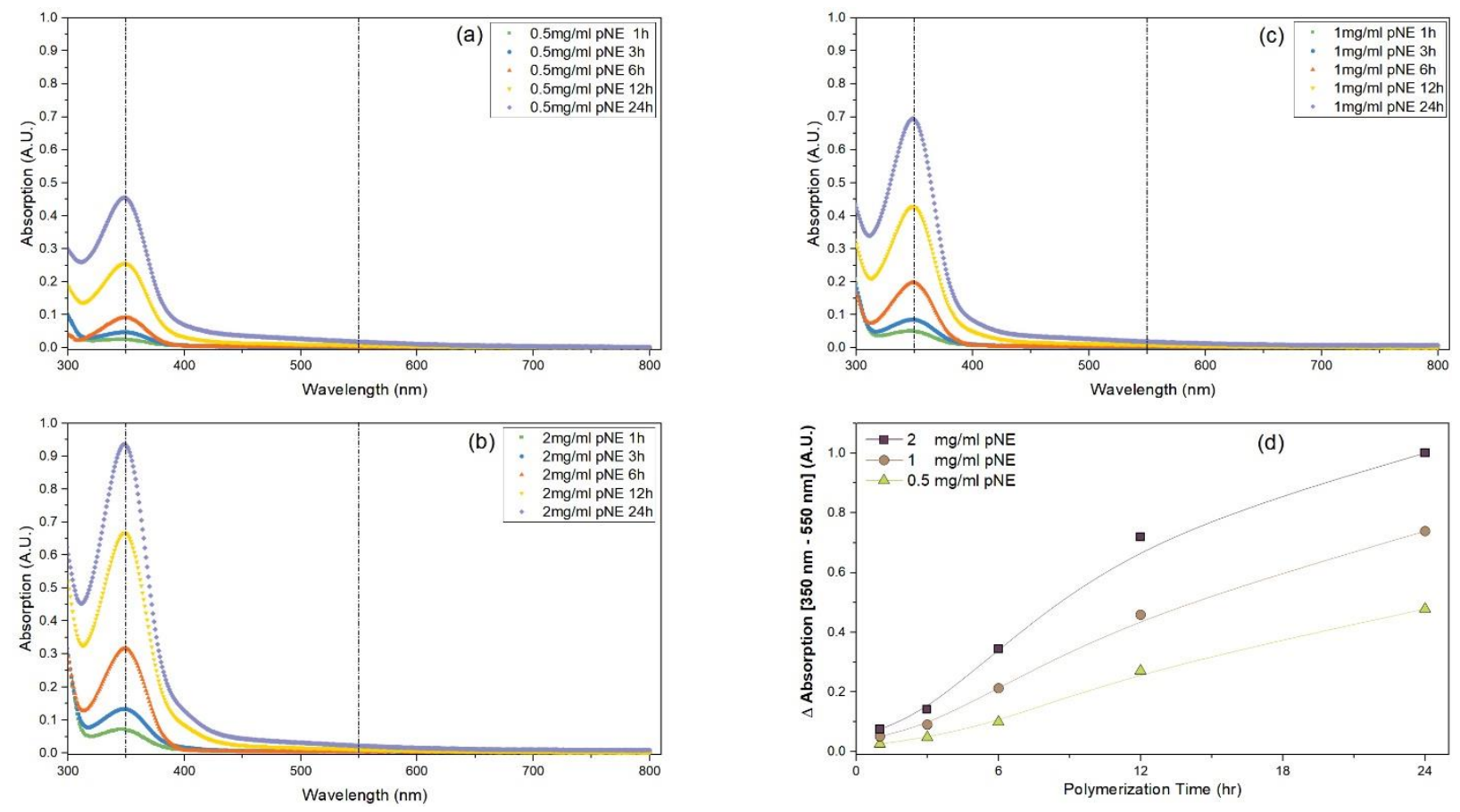

Figure 5.4 UV-Vis spectroscopy of diluted (a) $0.5 \mathrm{mg} / \mathrm{ml}$, (b) $1 \mathrm{mg} / \mathrm{ml}$, (c) $2 \mathrm{mg} / \mathrm{ml} \mathrm{pNE}$ and (d) $\Delta$ absorption values $[350 \mathrm{~nm}-550 \mathrm{~nm}]$ of pNE solutions as a function of time. 
The pNE film thicknesses on the YSZ single crystal surfaces were analyzed by atomic force microscopy. Figure 5.5 displays the film thickness of the pNE coating layer on a YSZ single crystal as a function of solid loading $(0.5,1$, and $2 \mathrm{mg} / \mathrm{ml})$ and immersion time $(1,3,6,12$, and $24 \mathrm{~h})$. Also, the data attained from Figure 5.4.d were inserted into the plot as contour lines showing the relative degree of polymerization (dp), the $\Delta$ absorption value between $350 \mathrm{~nm}$ and $550 \mathrm{~nm}$. It can be seen that as the pNE incubation time increases, the film thickness increases in all solid loadings. It was found that increasing the immersion time reflected minimal development when the concentration was $0.5 \mathrm{mg} / \mathrm{ml}$. The film thickness was $<2 \mathrm{~nm}$ at the beginning, and the growth of the pNE was almost linear within the first $12 \mathrm{~h}$ where the thickness reached $8.4 \mathrm{~nm}$. Then, a steeper rate to $21.7 \mathrm{~nm}$ film at $24 \mathrm{~h}$ was observed. The pNE with $1 \mathrm{mg} / \mathrm{ml}$ solid loading started with a < $2.5 \mathrm{~nm}$ layer in $1 \mathrm{~h}$ and showed slower growth within $6 \mathrm{~h}$. Then the slope of growth increased between the $6 \mathrm{~h}$ and $24 \mathrm{~h}$ of immersion, reaching $39 \mathrm{~nm}$ in thickness. The slow growth rate of pNE $0.5 \mathrm{mg} / \mathrm{ml}$ and $1 \mathrm{mg} / \mathrm{ml}$ solid loadings can be attributed to lower concentrations which retarded the growth kinetics. Finally, the trend of pNE adhesion with $2 \mathrm{mg} / \mathrm{ml}$ solid loading was observed distinctly different. The thickness of the pNE layer started around $5 \mathrm{~nm}$ and grew rapidly within the initial $12 \mathrm{~h}$. The slope reduced in the $24 \mathrm{~h}$ and the pNE layer thickness measured $48 \mathrm{~nm}$. Postma et al. reported that the so-called plateauing trending of pDA could be due to the depletion of dissolved oxygen in the water or reactive catechol in the solution [44]. A similar case could be possible for the $2 \mathrm{mg} / \mathrm{ml} \mathrm{pNE}$ concentration. The thickness data obtained in this study are also considerably closer to the study by Kang et al., where they found pNE thickness values can vary around 30-40 $\mathrm{nm}$ with the $18 \mathrm{~h}$ polymerization of $2 \mathrm{mg} / \mathrm{ml}$ solution [22]. For further investigation, Taskin et al. reported that the pNE layer reached $117.5 \pm 24.63 \mathrm{~nm}$ thickness after $16 \mathrm{~h}$ polymerization of $2 \mathrm{mg} / \mathrm{ml} \mathrm{NE}$ solution at $\mathrm{pH} 8.5$ [45]. Also, Chen et al. measured the pNE 
thickness as $6 \mathrm{~nm}$ after $24 \mathrm{~h}$ polymerization of $3 \mathrm{mg} / \mathrm{ml} \mathrm{pNE}$ solution [46]. The reason for the variation could be due to the substrate chemistry, morphology or slight temperature difference during the polymerization.

The deposition kinetics of the $2 \mathrm{mg} / \mathrm{ml} \mathrm{pNE}$ could be fitted the exponential decay trend (Eq. 5.1) as a function of time that corresponds with previous literature for pDA kinetics [12] [47].

$d(t)=d o+d_{\max }\left(1-e^{(-k t)}\right)$

The $\mathrm{d}_{\max }$ and $\mathrm{k}$ denote the maximal thickness and kinetic constant respectively. Hence, the exponential decay function trend is fitted to the $2 \mathrm{mg} / \mathrm{ml} \mathrm{pNE}$ growth rate, with a satisfactory reduced chi-sqr value of 3.11. The kinetic rate constant value, $\mathrm{k}$, was $0.075 \mathrm{~h}^{-1}$ which was fairly close to the $\mathrm{k}$ value of $2 \mathrm{mg} / \mathrm{ml} \mathrm{pDA}$ growth rate at $\mathrm{pH} 8.5\left(0.072 \mathrm{~h}^{-1}\right)$ [12]. Unfortunately for the concentrations below $2 \mathrm{mg} / \mathrm{ml}$, the exponential decay function could not be fitted. As discussed above, the linearity in the $\mathrm{pNE}$ thickness of $0.5 \mathrm{mg} / \mathrm{ml}$ and $1 \mathrm{mg} / \mathrm{ml}$ solid loadings in the first $12 \mathrm{~h}$ occurred, which could probably be due to being far from the oxygen and catechol depletion times. Hence, the exponential decaying function trends were not seen. 


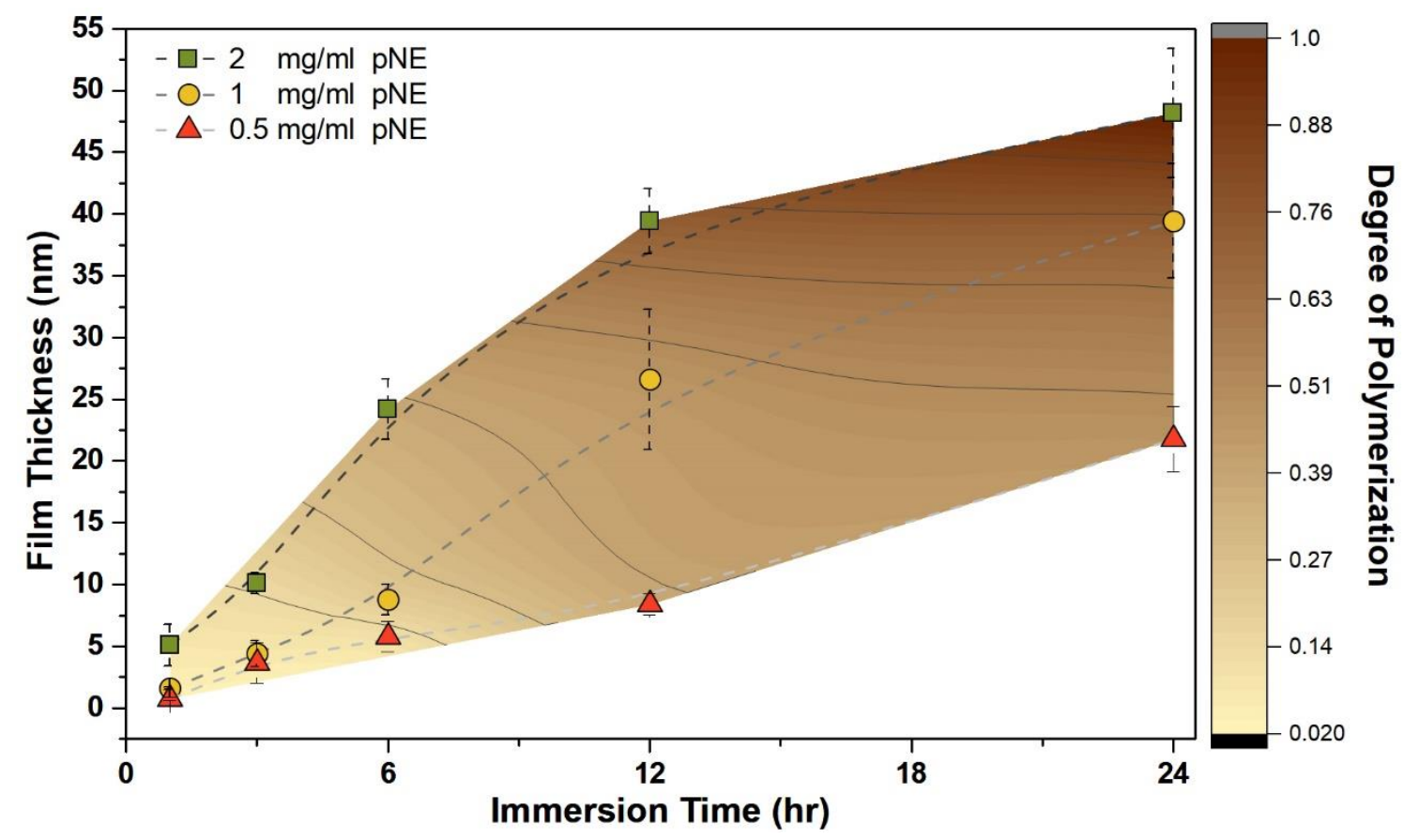

Figure 5.5 pNE film thickness and the relative degree of polymerization contour plot as a function of immersion time.

Further surface characterization was carried out by X-ray photoelectron spectroscopy (XPS) as an indicator of chemical composition change after pNE treatment on the YSZ single crystal substrates. In order to insure the homogenous coating, a sample was coated with $2 \mathrm{mg} / \mathrm{ml}$ pNE for 48 h. Figure 5.6 compares the wide scan (a-b), C1s core-level before (c-d) and after (e-f) the soft sputtering and O1s core level region $(\mathrm{g}-\mathrm{h})$ of the untreated and pNE coated YSZ surface, respectively. The wide-range XPS analysis in Figure 5.6.a shows the untreated YSZ surface spectrum that only includes strong O KLL (974.3 eV), O 1s (530.1 eV), Zr 3s (433.9 eV), Zr 3p (346.5 and 333.1 eV), Y 3p (312.3 and $300.5 \mathrm{eV})$ and $\mathrm{C} 1 \mathrm{~s}(284.5 \mathrm{eV})$ peaks. After the pNE coating, the XPS profile only shows $\mathrm{O}, \mathrm{N}$, and $\mathrm{C}$ peaks corresponding to a void-free homogenous coating. For further analysis, Figure 5.6.c-d compare C 1s spectra of the untreated and pNE coated surface in detail. The deconvoluted C1s spectrum of the untreated surface-displayed peaks 
corresponding to $\mathrm{C}-\mathrm{O} / \mathrm{C}-\mathrm{N}$ and $\mathrm{C}-\mathrm{C}$ bonds with the low signal-to-noise ratio. The pNE coated surface, however, displayed an increased $\mathrm{C} 1 \mathrm{~s}$ intensity that was fitted with three components: CO/C-N (at 296.2 eV), C-C (at 284.8 eV), and possibly C-Zr (at 283.3 eV), indicating pNE-substrate bonding. To confirm the carbon content, $0.5 \mathrm{kV}$ Ar+ ion sputtering was performed for $6 \mathrm{~s}$ to remove any potential carbonaceous contamination without damaging the pNE layer and then the post-sputter $\mathrm{C} 1 \mathrm{~s}$ regions were taken at that spot. As can be seen, the carbon signal vanished on the untreated substrate after the post-sputtering (Figure 5.6.e). However, the $\mathrm{C} 1 \mathrm{~s}$ region intensity of the pNE-coated substrate remained unchanged in Figure 5.6.f after the sputtering. Furthermore, the post-sputtered O1s region of the untreated substrate showed a strong peak that can be fitted with one peak at $\sim 529.1 \mathrm{eV}$, indicating predominantly $\mathrm{O}=\mathrm{Zr}$ bonding of substrate as shown in Figure 5.6.g. The same peak appeared in the post-sputter O1s core-level of the pNE coated sample at the shoulder of the $\mathrm{O}=\mathrm{C}$ peak of the $\mathrm{pNE}$ layer fitted as the more contributing peak at $531.3 \mathrm{eV}$ in Figure 5.6.h. 

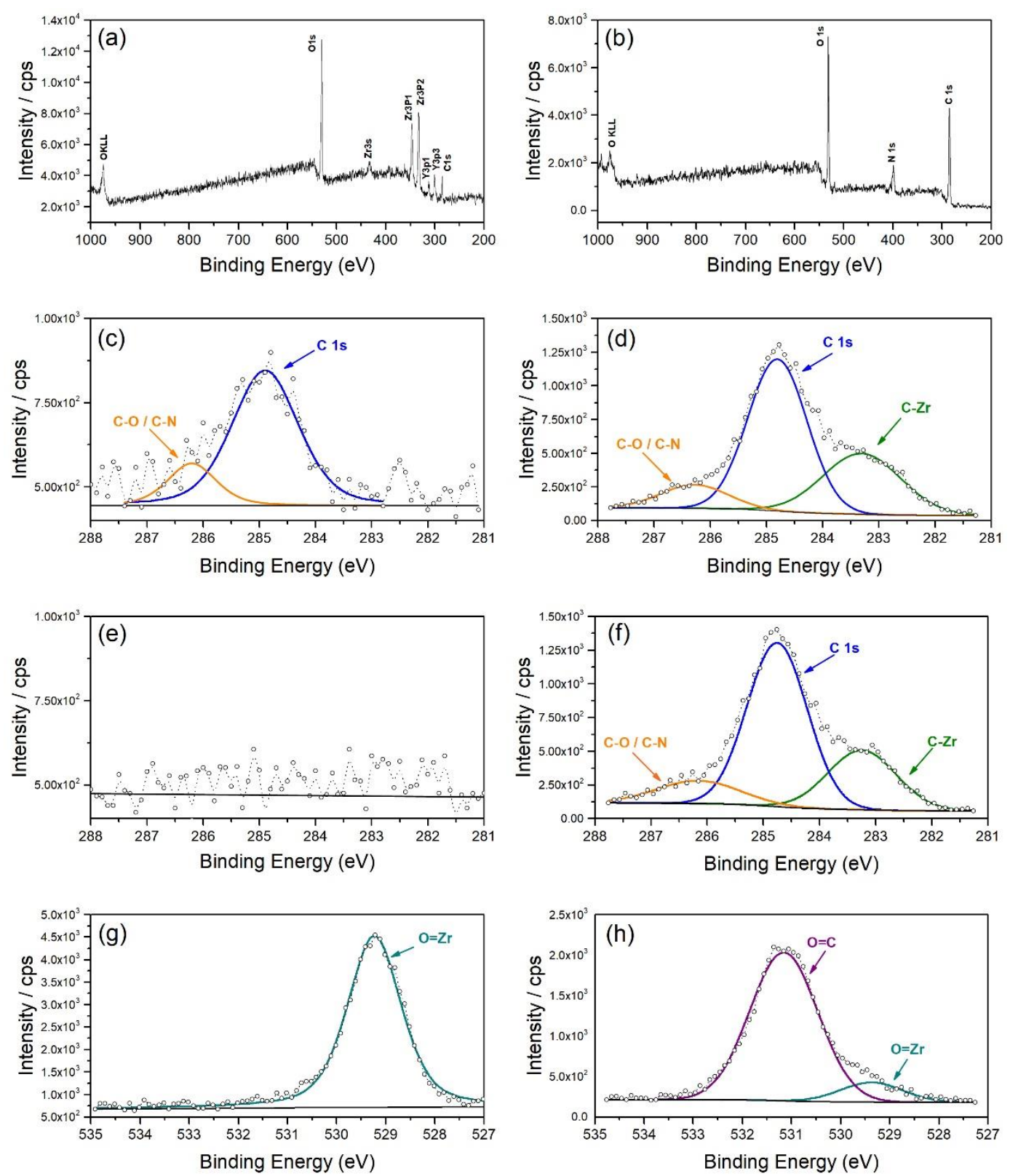

Figure 5.6 XPS survey spectra (a), (b); C1s core level spectra before (c),(d) and after (e),(f) Ar+ sputtering; and O1s core level spectra (g), (h) of untreated and pNE coated YSZ single crystal respectively. 


\subsubsection{Wet-deposited Ion Characterization}

At the next stage, metal-ion and pNE layer interactions were assessed by XPS. As a first candidate, cerium (III) nitrate hexahydrate solution was used as a source of cerium. Uncoated and pNE coated substrates were dip-coated into cerium nitrate solution for $12 \mathrm{~h}$ and rinsed. The samples were directly analyzed with XPS without firing. Figure 5.7.a shows the post-sputtered (6 s) wide-range spectra of the cerium nitrate treated YSZ (red) and pNE+YSZ (black) substrates. The spectral analysis showed no traces of a cerium signal on the YSZ surface after the treatment as the wide range spectrum is identical to the untreated YSZ surface, as in Figure 5.7.a. However, a noticeable intensity upshift was observed in the Ce $3 \mathrm{~d}$ region after the cerium salt immersion of pNE+YSZ surface. It can be noted that $\mathrm{C} 1 \mathrm{~s}$ peak was still retained after the treatment. For a detailed analysis, the $\mathrm{C} 1 \mathrm{~s}$ spectra of this sample were fitted with three peaks similar to $\mathrm{C} 1 \mathrm{~s}$ region of pNE+ substrate plot in Figure 5.7.d. The last fitted peak at the lowest binding energy was shifted from 283.3 to $282.7 \mathrm{eV}$ which is possibly assigned to $\mathrm{C}-\mathrm{Ce}$ interaction after the chelation. After confirming the presence of chelated cerium on the surface, the Ce $3 \mathrm{~d}$ core-level spectrum was analyzed in detail in Figure 5.7.c. The deconvolution of the Ce $3 \mathrm{~d}$ core-level spectrum revealed the complex presence of peaks that originate with the $\mathrm{Ce}^{+4}$ and $\mathrm{Ce}^{+3}$ states $[48,49]$. The $\mathrm{Ce}^{3+}$ state consists of four peaks: $\mathrm{v}_{0}(881.69 \mathrm{eV}), \mathrm{v}^{`}(886.36 \mathrm{eV}), \mathrm{u}_{0}(900.29 \mathrm{eV})$ and $\mathrm{u}^{`}(905.09 \mathrm{eV}) . \mathrm{In}$

addition, there are 6 peaks that correspond to $\mathrm{Ce}^{4+}$ state: $\mathrm{v}(883.25 \mathrm{eV}), \mathrm{v}^{\prime \prime}(889.90 \mathrm{eV}), \mathrm{v}^{\prime \prime}(899.20$ $\mathrm{eV}), \mathrm{u}(901.85 \mathrm{eV}), \mathrm{u}^{\prime \prime}(908.58 \mathrm{eV})$ and $\mathrm{u}^{\prime \prime}(917.71 \mathrm{eV})$. The quantification of cerium ions can be calculated by proportioning peak areas (Eq. 5.1 and 5.2).

$$
\begin{aligned}
& {\left[C e^{3+}\right]=\frac{A_{C e^{3+}}}{A_{C e^{3+}+A_{C e^{4+}}}}} \\
& {\left[C e^{3+}\right]=\frac{A_{v_{0}}+A_{v}+A_{u_{0}}+A_{u^{\prime}}}{\left(A_{v_{0}}+A_{v^{+}}+A_{u_{0}}+A_{u^{\prime}}\right)+\left(A_{v}+A_{v^{\prime \prime}}+A_{v^{\prime \prime}}+A_{u}+A_{u^{\prime \prime}}+A_{u^{\prime \prime \prime}}\right.}}
\end{aligned}
$$


According to the equations, the $\mathrm{Ce}^{4+}$ content percent in the chelated cerium complex was calculated to be $61 \%$ (and $39 \%$ for $\mathrm{Ce}^{+3}$ ). To further determine the concentrations of the chelated cerium with different valence states, the $\mathrm{O} 1 \mathrm{~s}$ core-level spectrum was fitted with three components. O-C at $533.5 \mathrm{eV}$ designates the carbon in the pNE layer. The other two components at $532.1 \mathrm{eV}$ and $530.2 \mathrm{eV}$ were associated with cerium valence bands, $\mathrm{Ce}^{3+}$ and $\mathrm{Ce}^{4+}$, respectively. According to the study by Zhang et al., the peak positions could most likely be attributed to the cerium with -OH groups [50]. The peak area ratio of $\mathrm{OH}-\mathrm{Ce}^{4+}$ to $\mathrm{OH}-\mathrm{Ce}^{3+}$ was calculated 1.54. Thus, the $\mathrm{Ce}^{4+}$ ratio was also confirmed with $\mathrm{O} 1 \mathrm{~s}$ region as well. Though the area calculations confirmed the presence of $\mathrm{Ce}^{4+}$ twice, the existence of $\mathrm{Ce}^{4+}$ was somewhat surprising. As commercial cerium (III) nitrate hexahydrate was used as the cerium source, the chemical state of the cerium should predominantly be $\mathrm{Ce}^{3+}$. The reason for high $\mathrm{Ce}^{4+}$ in the precipitated Ce complex in the pNE can be explained in two ways. The first hypothesis is that the cerium had $3+$ state initially as in the precursor solution, but the pNE layer shifted the valence state to 4+ during chelation. The second hypothesis is that the cerium (III) nitrate hexahydrate already contained the 4+ species, so the pNE layer did not alter the chemical state of cerium. 

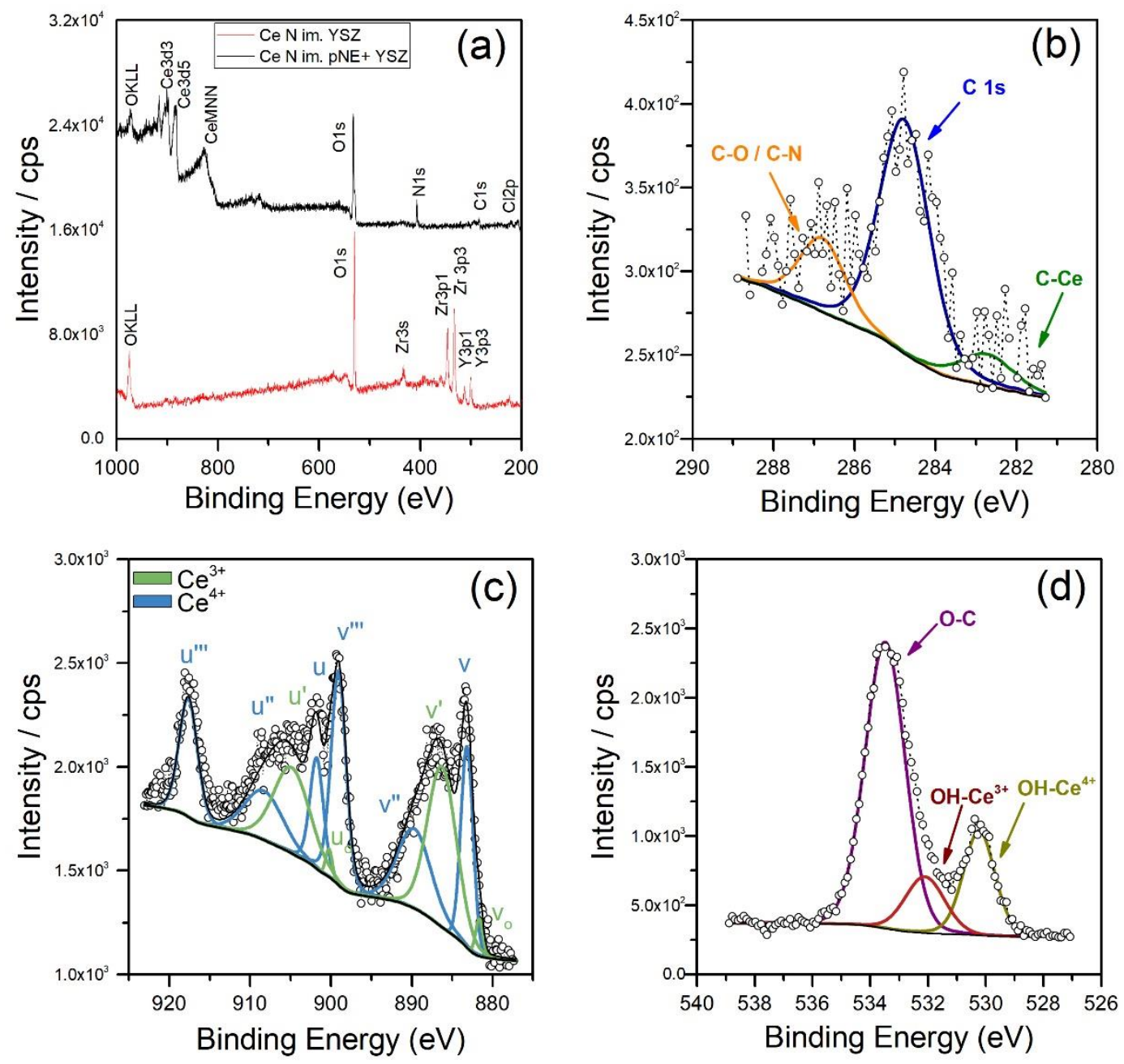

Figure 5.7 (a) XPS survey spectra of cerium nitrate immersed YSZ and pNE coated YSZ single crystal; (b) C1s, (c) Ce 3d, and (d) O1s core level spectra of cerium (III) nitrate solution immersed pNE coated YSZ single crystal.

For the validation, the $\mathrm{Ce} 3 \mathrm{~d}$ band of the cerium nitrate hexahydrate crystal which was purchased and first opened approximately a year before analysis was compared with the Ce3d band of the chelated cerium by pNE layer in Figure 5.8.a. The plot is normalized to avoid any intensity differences. It can be seen that the peak positions and the complexity of the Ce $3 \mathrm{~d}$ bands were almost identical and contained predominantly $\mathrm{Ce}^{4+}$. The comparison supports the second hypothesis that $\mathrm{pNE}$ does not change the valence state of cerium during the chelation. Figure 5.8.b 
shows the Ce $3 \mathrm{~d}$ band of cerium (III) nitrate hexahydrate crystals from the freshly opened container. In this case, the analysis of freshly opened crystals displayed predominantly $3+$ as Figure 5.8.c which compares the Ce $3 \mathrm{~d}$ difference between pure $\mathrm{Ce}^{3+}$ and $\mathrm{Ce}^{4+}$ spectra as a reference [51]. The results deduce that cerium (III) nitrate hexahydrate is not stable since $\mathrm{Ce}^{3+}$ crystals undergo the valence change (to $\mathrm{Ce}^{4+}$ ) over the shelf-life. 

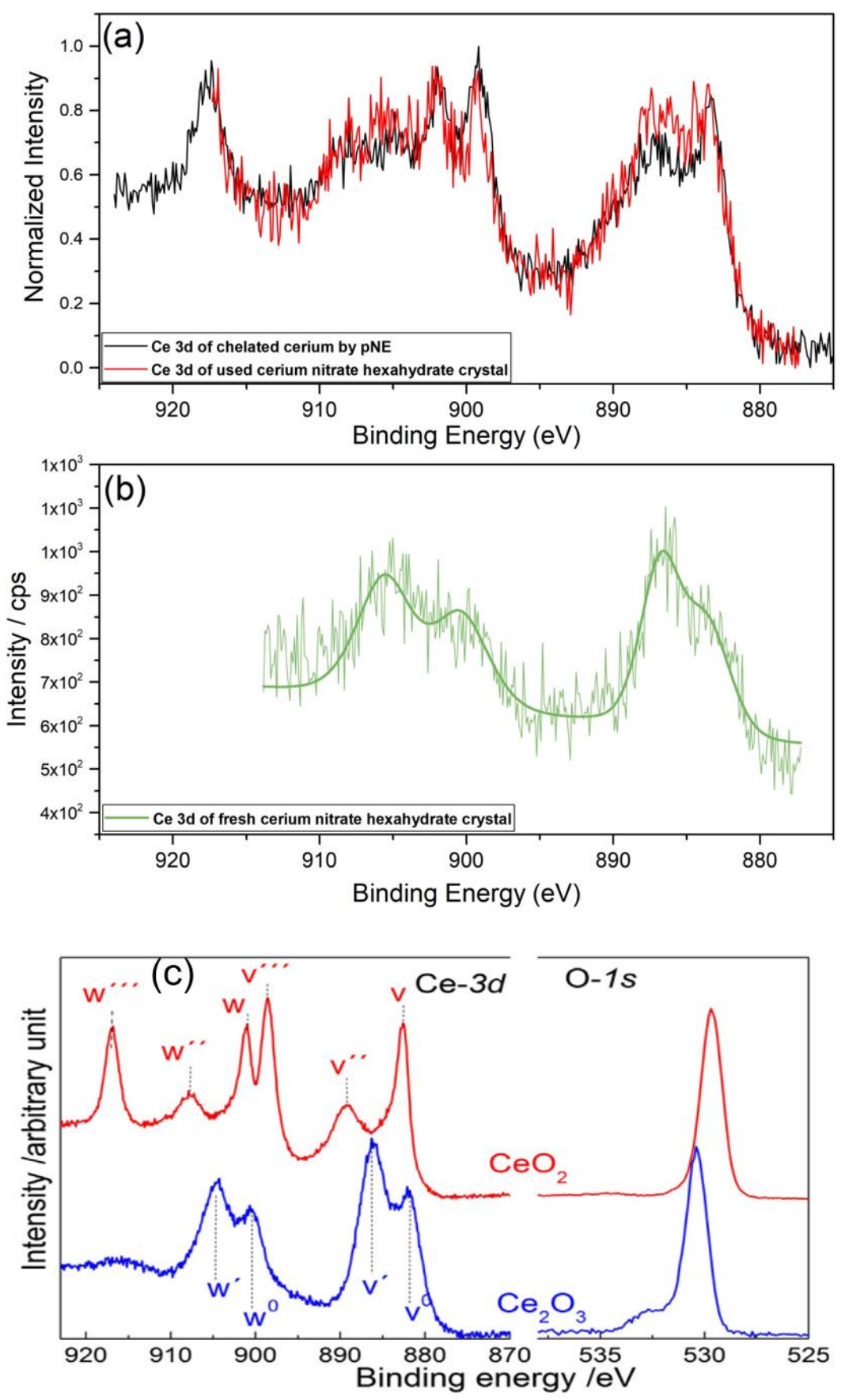

Figure 5.8. Post-sputtered $(0.5 \mathrm{kV}, 6 \mathrm{~s})$ XPS Ce $3 \mathrm{~d}$ core level spectra of a) chelated cerium complex and used cerium (III) nitrate hexahydrate crystals, in normalized intensity b) freshly opened cerium nitrate (III) hexahydrate crystals. Both are supplied from the same vendor (Alfa Aesar) and in \%99.5 purity. c) XPS Ce-3d and O-1s core level spectra of $\mathrm{CeO}_{2}$ (red) and $\mathrm{Ce}_{2} \mathrm{O}_{3}$ films as a reference [51]. 
As the second example, the interaction of pNE layer and palladium ions (a noble metal) was also observed. Figure 5.9.a provides the Pd 3d spectra of Pd nitrate-treated pNE coated YSZ single crystal surface. As noted in the graph, the $\mathrm{Pd} 3 \mathrm{~d}_{5 / 2}$ peak is positioned at $335.8 \mathrm{eV}$. Brun et al. reported that the binding energies of $\mathrm{Pd}$ and $\mathrm{PdO}$ are $335.4 \mathrm{eV}$ and $336.8 \mathrm{eV}$ respectively [52]. Also, Khudorozhkov et al. stated that the binding energies of $\mathrm{Pd}, \mathrm{PdO}$ and $\mathrm{Pd}(\mathrm{OH})_{2}$ are $335.1 \mathrm{eV}$, $336.7 \mathrm{eV}$ and $337.4 \mathrm{eV}$, respectively [53]. These studies confirm that the experimental data obtained from $\mathrm{Pd}+\mathrm{pNE}$ layer represents the metallic $\mathrm{Pd}$ phase. It was also found that the $\mathrm{C} 1 \mathrm{~s}$ peak still existed while forming the Pd metallic phase (inset of Figure 5.9.a). The O1s region in Figure 5.9.b contained $\mathrm{O}=\mathrm{C}$ bonds only at $531.2 \mathrm{eV}$. The other peak found at $533.1 \mathrm{eV}$ was confirmed to be $\operatorname{Pd} 3 p$ peak. 

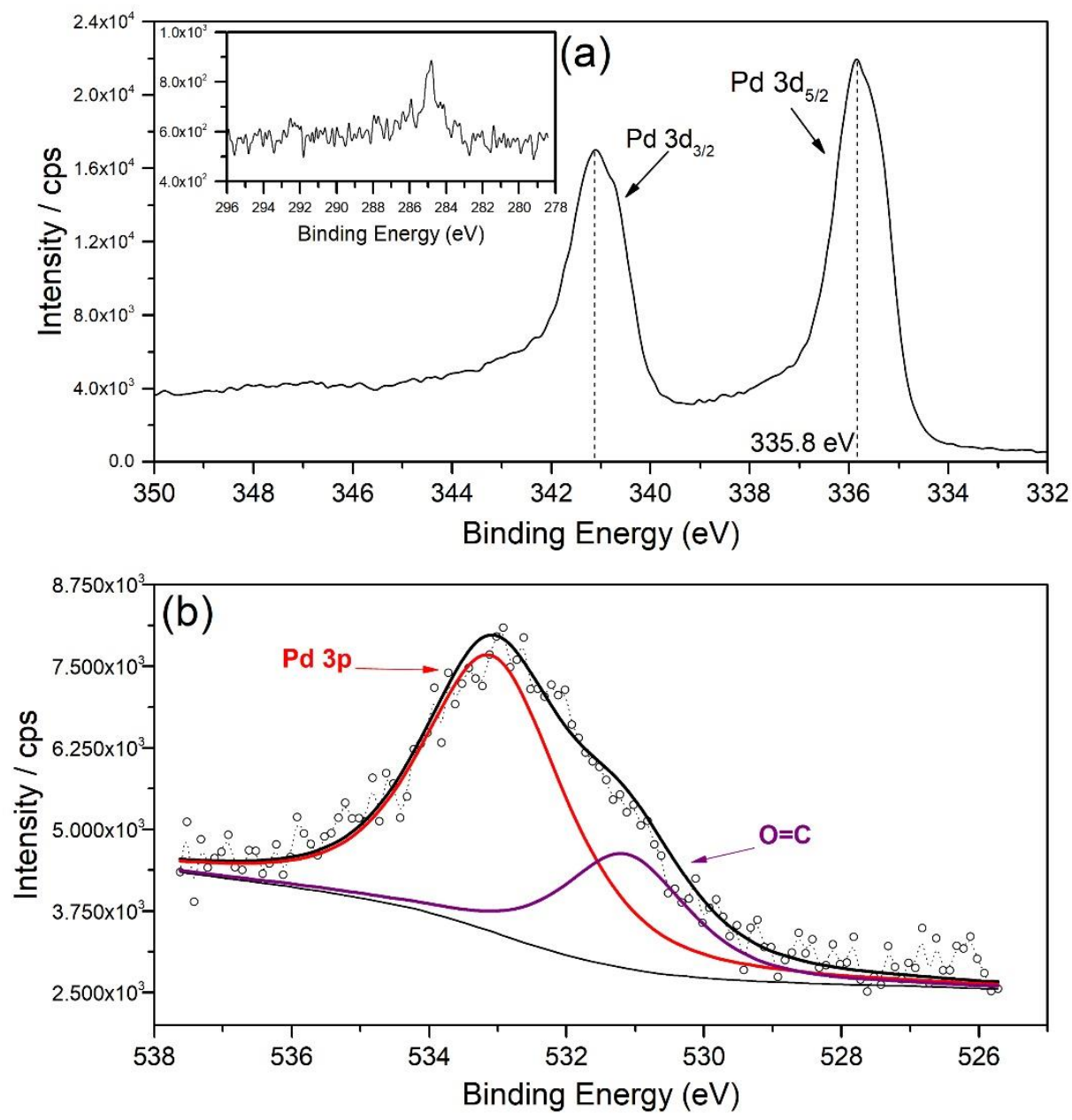

Figure 5.9 Post sputtered XPS (a) Pd 3d core level spectra (b) O1s core level spectra of Pd (II) nitrate solution immersed pNE coated YSZ single crystal.

Apparently, the results confirm that there are two different deposition mechanisms occurring between the Ce ions + pNE layer and the Pd ions + pNE layer. The schematics in Figure 5.10 summarize the difference in the mechanism that were discussed. The experiments revealed that Ce ions deposit as a form of cerium hydroxide complex precipitates inside the pNE layer as shown in Figure 5.10.a. Whereas, the Pd ions are reduced by the pNE layer and deposit as a metallic phase inside the pNE layer as shown in Figure 5.10.b. The difference precipitation mechanisms dependent on the reduction capability of the quinone form of the pNE. As it was known, catecholamine oxidation forms quinone by releasing two electrons and two protons. 
According to Lee et al., this catechol to quinone transformation creates a high reducing potential (e.g., $E_{o}$ of a benzene-1.2-diol = $\left.-795 \mathrm{mV}\right)$ [54]. Since catechols have a higher $E_{o}$ than Pd (Eo of $\mathrm{Pd}=+0.915 \mathrm{mV}[55])$, the reaction spontaneously supplies electrons to the Pd ions to form metallic (reduced) nano-particle phase. Since $\mathrm{Ce}^{3+}$ ions have very low reducing potential $\left(\mathrm{E}_{\mathrm{o}}=\right.$ $-2.336 \mathrm{eV})$, catechol to quinone transformation can not reduce the Ce ions into the metallic phase spontaneously.

The surface AFM images of these samples after immersion and rinsing indicated that the precipitated Ce hydroxide complex + pNE framework (RMS: $3 \mathrm{~nm}$ ) was much smoother than the $\mathrm{Pd}^{0}+$ pNE framework (RMS: $12.4 \mathrm{~nm}$ ) as shown in Figure 5.10.c and d respectively.

(a)
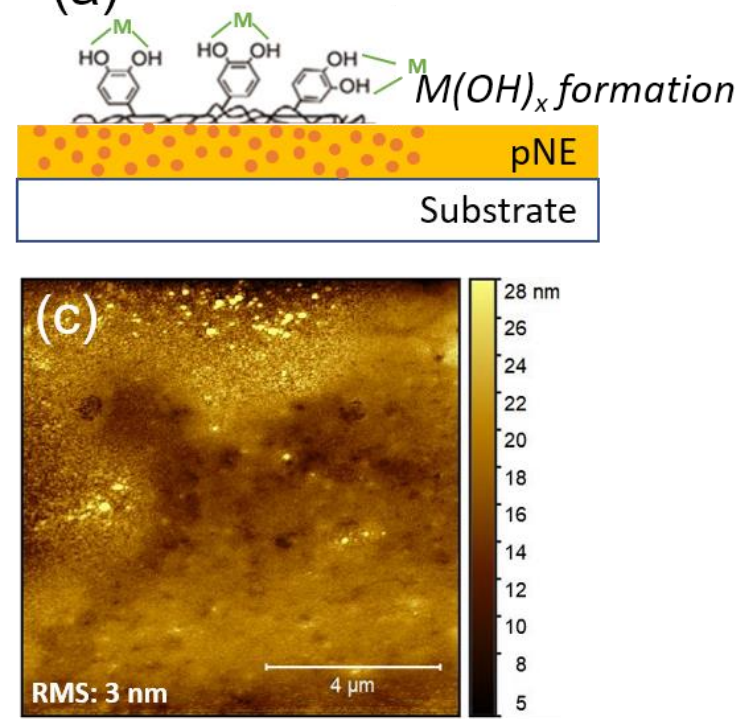
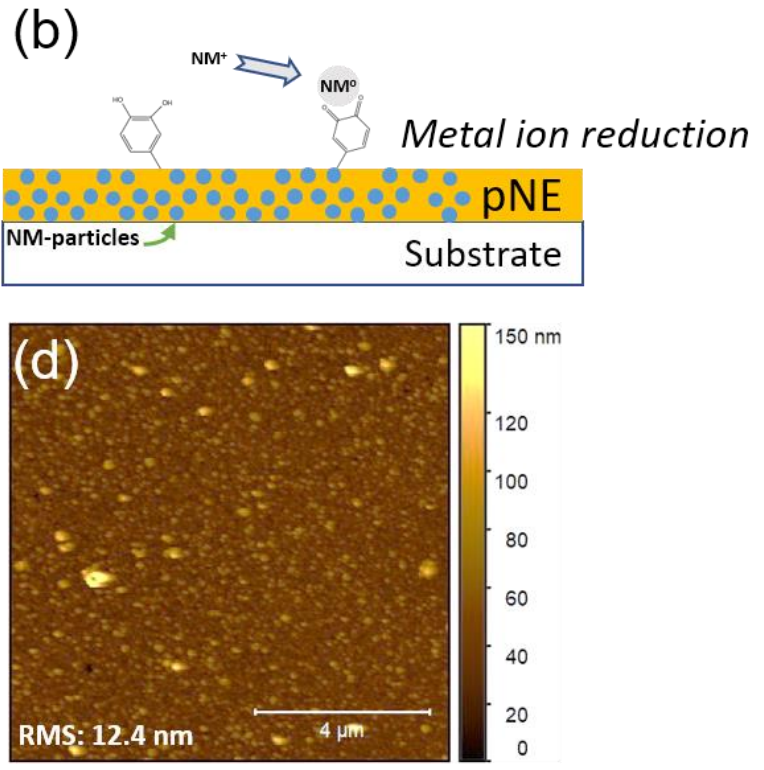

Figure 5.10 Schematics of (a) Ce-complex formation and (b) reduced Pd particle formation inside the pNE layer. AFM images of (c) deposited Ce-complex $+\mathrm{pNE}$ framework and (d) deposited Pd particles + PNE framework. 


\subsubsection{Deposited Cerium Oxide Characterization}

The aim of this work was to observe the morphological difference of nano-catalyst formation as a function of precursor immersion time and pNE morphology. To begin with, the bare single crystals were patterned with $20 \mu \mathrm{m}$ wide SU-8-2 photoresist mask in a class 1000 cleanroom as a marker, as shown in Figure 5.11.a. The clean gaps between the masked layers were designed with $25 \mu \mathrm{m}$ width (Figure 5.11.b) and $1.5 \mu \mathrm{m}$ height (Figure 5.11.c). A lift-off process was used to de-pattern the SU-8 lines and leave only the pNE coated areas which then are exposed to the cerium nitrate solution. Finally, cerium nitrate + pNE dip-coated samples were fired at $750^{\circ} \mathrm{C}$. Figure 5.11.d. shows a representative AFM image of the ceria layer after the depatterning and coating protocols were applied. It can be seen in the image that the de-patterning and firing steps left some photoresist residue behind with a height of $75 \mathrm{~nm}$ at the edges.
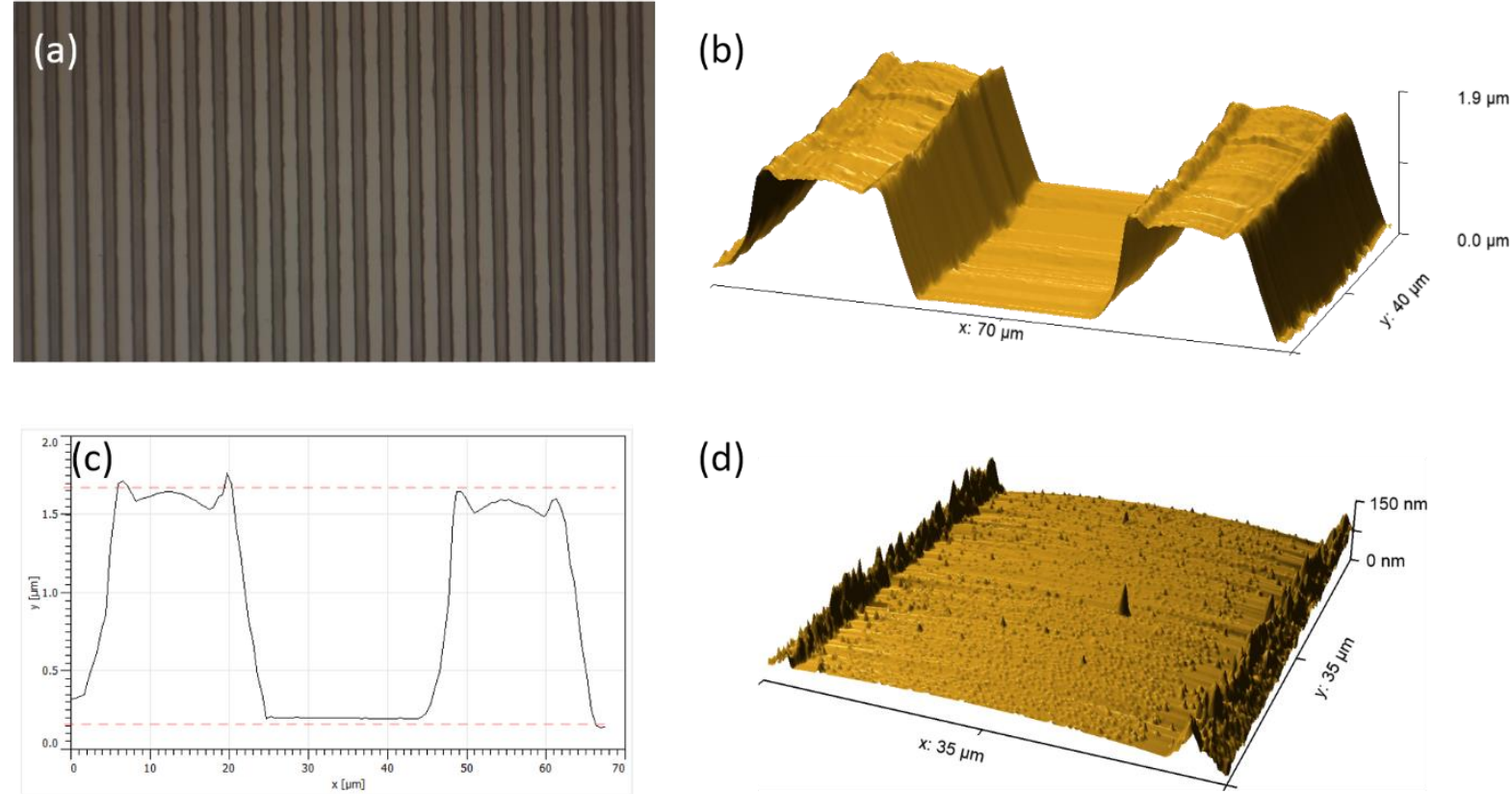

(d)

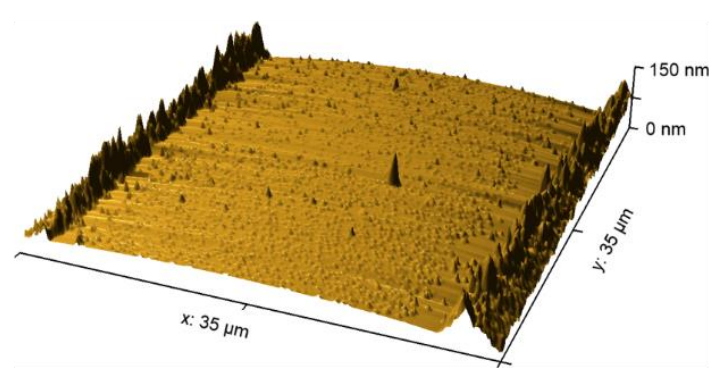

Figure 5.11 (a) Optical micrograph and (b) AFM image and the (c) AFM line scans of SU82 patterns on YSZ single crystals. The pattern design is $\sim 20 \mu \mathrm{m}$ wide, $1.5 \mu \mathrm{m}$ height and 
$25 \mu \mathrm{m}$ gap on each photoresist stripe. (d) A representative final AFM image of ceria formation on the clean area after the pattering and coating protocols.

To begin with, three pNE morphologies with $1 \mathrm{mg} / \mathrm{ml}$ solid loading were included in the ceria coating studies: $6 \mathrm{~h}, 12 \mathrm{~h}$ and $24 \mathrm{~h}$ adhered pNE layers on YSZ single crystals. The RMS values of the coated substrates were found to be gradually increasing from $1.8 \mathrm{~nm}$ in the $6 \mathrm{~h}$ Figure 5.12 to $12.5 \mathrm{~nm}$ and $16.5 \mathrm{~nm}$ in the $12 \mathrm{~h}$ and $24 \mathrm{~h}$ (Figure 5.12.b and c), respectively.

(a)

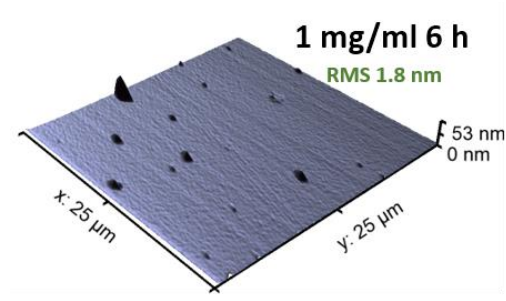

(b)

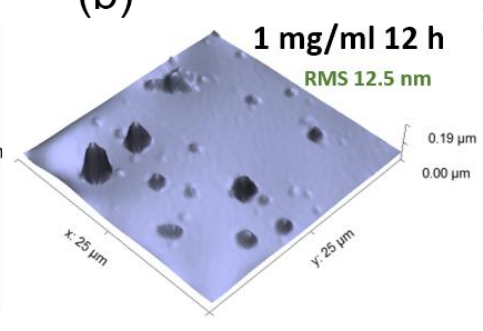

(c)

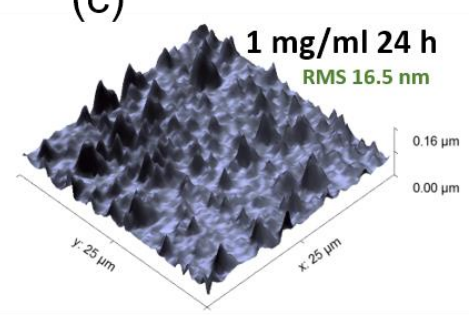

Figure 5.12 The AFM images of $1 \mathrm{mg} / \mathrm{ml} \mathrm{pNE}$ coated YSZ single crystals for (a) $6 \mathrm{~h}$, (b) $12 \mathrm{~h}$, and (c) $24 \mathrm{~h}$. All the AFM scans are in $25 \times 25 \mu \mathrm{m}$ mapping area.

Initially, the $6 \mathrm{~h}$ pNE coated on patterned YSZ single crystals were prepared for cerium nitrate immersion and then fired at $750^{\circ} \mathrm{C}$ shortly after the rinsing step. Figure 5.13.a-c show the histogram plots of ceria particles imaged on the un-patterned areas that were dip-coated with 0.4 M cerium nitrate solution for $6 \mathrm{~h}, 12 \mathrm{~h}$, and $24 \mathrm{~h}$, respectively. The histogram analysis shows that the ceria particle distribution was right-skewed (positive-skewed) and was mostly populated $<5$ $\mathrm{nm}$ with the low immersion times $(6 \mathrm{~h})$ as shown in Figure 5.13.a. When the immersion time was increased to $12 \mathrm{~h}$, a slightly symmetrical particle distribution was observed with a drop in population density from 9.8 particles (prt) $/ \mu \mathrm{m}^{2}$ to $8.5 \mathrm{prt} / \mu \mathrm{m}^{2}$ (Figure 5.13.b). The symmetric distribution brought a drop in the particle count at the $<5 \mathrm{~nm}$ range, but an increase at the $>5 \mathrm{~nm}$ 
range but not higher than $8 \mathrm{~nm}$, predominantly. As the cerium nitrate immersion time was set to 24 h, a similar right-skewed distribution was formed, but a broader range of particles was observed where the highest particle populations were between 2-4 $\mathrm{nm}$. In addition, a considerable number of particles between 5-10 nm particles were observed as well (Figure 5.13.c). Here, the highest population density, $12.3 \mathrm{prt} / \mu \mathrm{m}^{2}$ was observed within the same mapping area. Figure 5.13.d summarizes that the number of particles and the projected total particle area versus as a function of cerium nitrate immersion time. According to the plot, for a lower particle size at $6 \mathrm{~h}$ immersion time, the projected particle area was $0.6 \%$ of the $10 \times 10 \mu \mathrm{m}$ mapping area. In addition, even though the particle number dropped, the particle distribution shifted to the right which reflected a $1.1 \%$ projected total particle area. At the last stage of the experiment ( $24 \mathrm{~h}$ immersion $)$, the particle population reached the maximum by forming $<4 \mathrm{~nm}$ and $>7 \mathrm{~nm}$ particles. Thus, the projected particle area also reached the highest point, $1.25 \%$ of the total area.

The results showed that the chelated cerium ion growth is a continuous process inside the pNE layer and occurs in two ways. As the first nuclei grow on the surface, these particles can grow over time to bigger particles. In addition, new nuclei also continue to form as it was observed from the histogram data. 

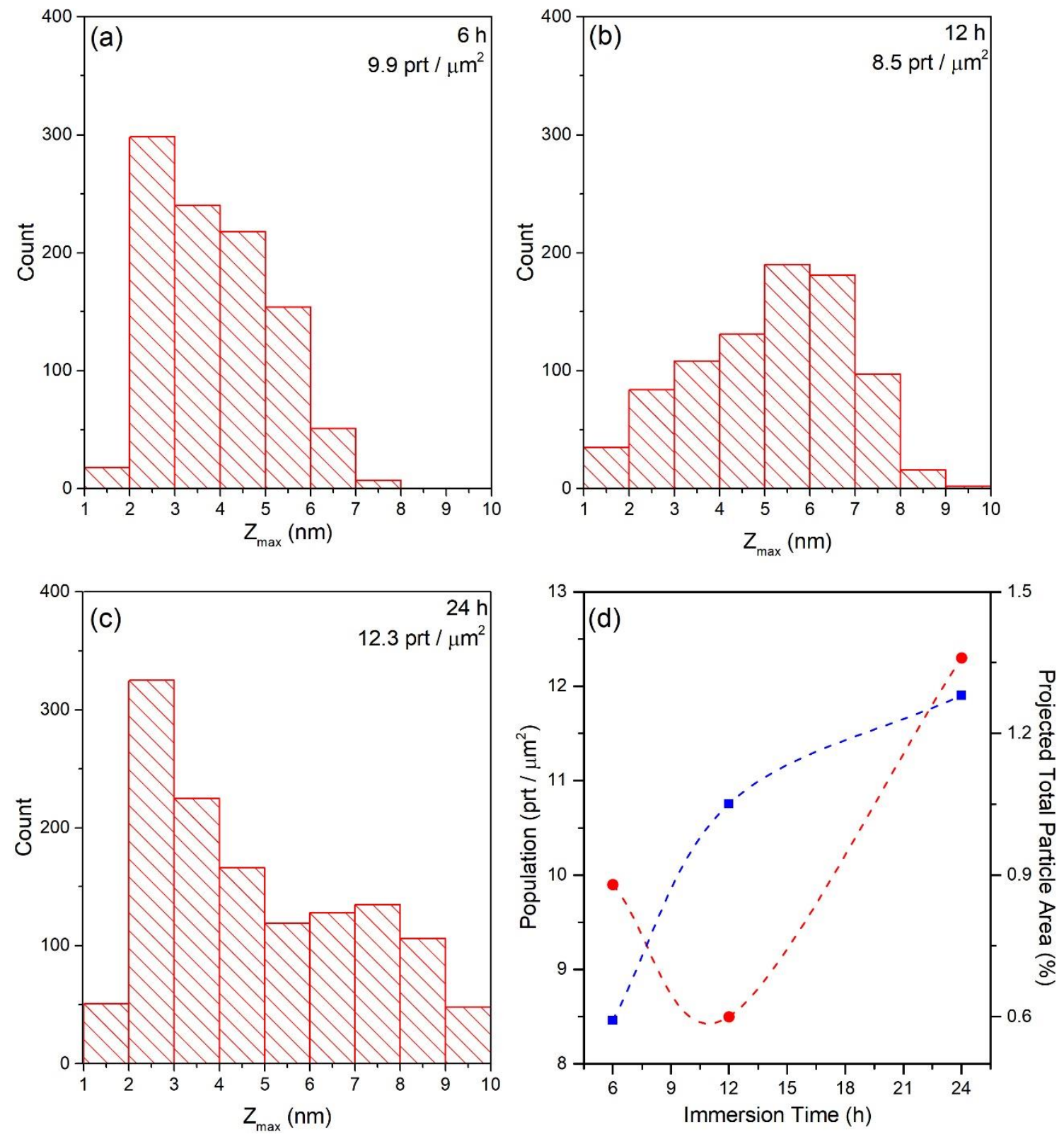

Figure 5.13 Deposited ceria particle histogram plots of (a) $6 \mathrm{~h}$, (b) $12 \mathrm{~h}$, and (c) $24 \mathrm{~h}$ cerium nitrate dip-coated samples over the $1 \mathrm{mg} / \mathrm{ml} \mathrm{pNE}$ coated patterned YSZ single crystals for 6 hours. (d) Particle number and projected total particle area (\%) comparison of the ceria particles on the unpatterned areas. The mapping area for all the samples is $10 \times 10 \mu \mathrm{m}$. 
To observe the effect of pNE decoration on the final ceria deposition, $6 \mathrm{~h}, 12 \mathrm{~h}$ and $24 \mathrm{~h}$ (as described in Figure 5.12) $1 \mathrm{mg} / \mathrm{ml}$ pNE-coated YSZ substrates for were de-patterned and then immersed in $0.4 \mathrm{M}$ cerium nitrate solution for 24 hours. As the last step, the samples were rinsed and fired $750^{\circ} \mathrm{C}$. When the pNE is coated only for 6 hours, the RMS of the final ceria layer was measured at $2.15 \mathrm{~nm}$ (Figure 5.12.a). As the pNE coating time increased, a significant enhancement in particle growth and population occurred (Figure 5.14.b-c). As depicted in Figure 5.14.b, circular islands developed and became distinctive as the RMS of the coated area increased to $2.45 \mathrm{~nm}$. When the pNE immersion time was set to 24 hours, cerium complex formation was accelerated due to the thick adhered pNE layer which resulted in highly developed ceria particles (20 to $100 \mathrm{~mm}$ in size) with the 8.91 RMS (Figure 5.14.c). In addition to the particulate formation, the film formation was also observed in Figure 5.14.b-c. The highlighted area in Figure 5.14.c was magnified in Figure 5.14.d to show the film formation. The line scan along the direction of the arrow showed that the film formation includes small particles that were around 2-6 nm. Hence the AFM images revealed that a very thin ceria film can be developed when the pNE layer was deposited over 6 h. However, as the pNE layer reached above a certain thickness (RMS $12.5 \mathrm{~nm}$, polymerized and immersed for $12 \mathrm{~h}$ ), ceria film + island formation developed. 

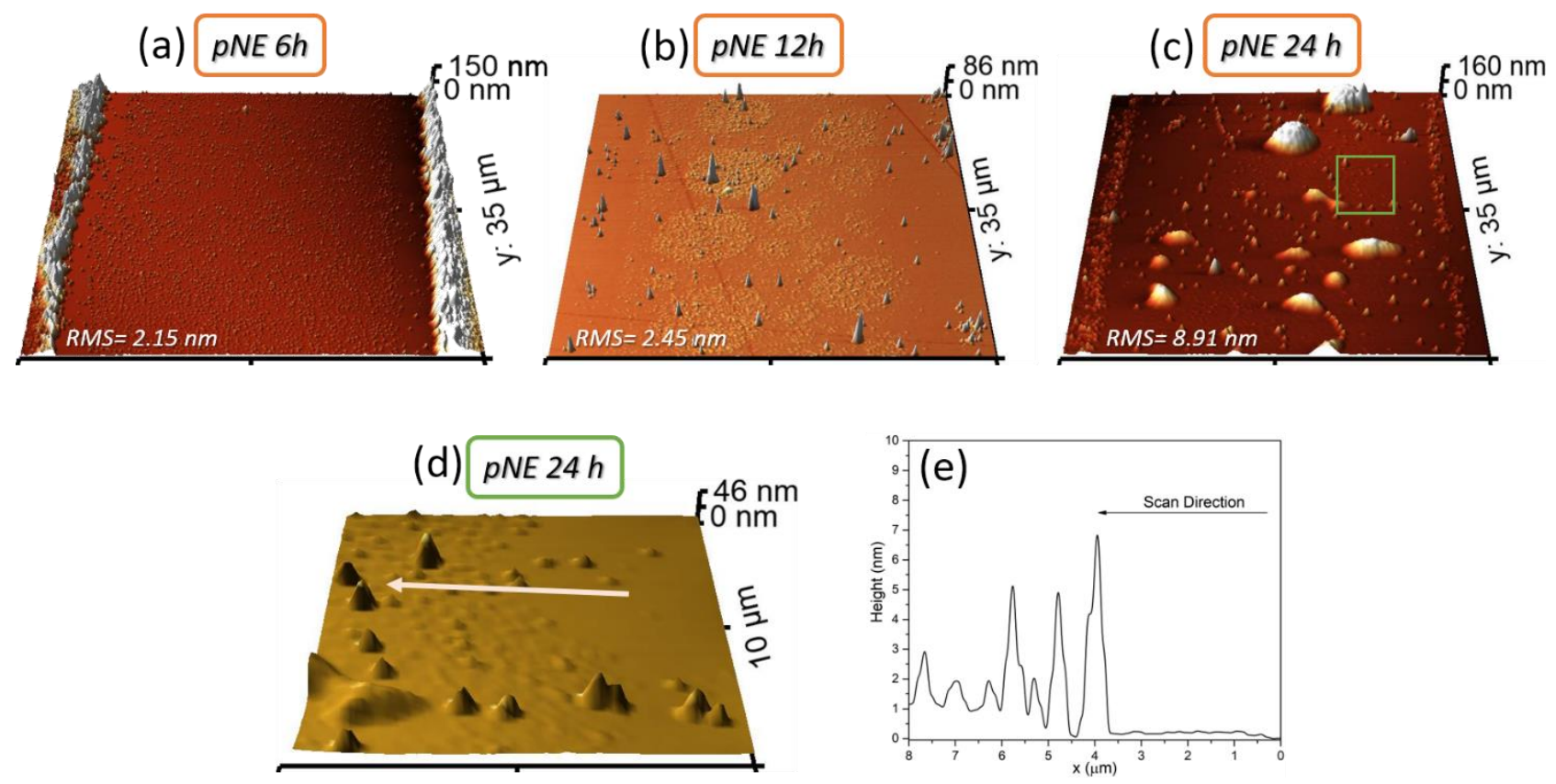

Figure 5.14 The AFM images 0.4 M cerium nitrate immersed $(24 \mathrm{~h})$ samples over various mg/ml pNE immersion times: (a) $6 \mathrm{~h}$ immersed (b) $12 \mathrm{~h}$ immersed, and (c) $24 \mathrm{~h}$ immersed to pNE. (d)The highlighted area of pNE $24 \mathrm{~h}$ (c). Mapping area for (a-c) are $35 \times 35 \mu \mathrm{m}$ and for is $10 \times 10$ $\mu \mathrm{m}$. (e) The line scan height profile in the direction of the arrow in (d).

Basic thin film growth modes are classified and schematically shown in Figure 5.15. According to our experiments, it can be deduced that cerium oxide was grown by the layer + island Stranski-Krastanov) mode. Typically, the few monolayers of the wetting layer grow on the substrate to fit the interface energy. As the layer thickens, the system, the system tends to form islands to relief the stress by creating dislocations, toreduce the strain energy $[56,57]$. 
Frank - van der Merwe

Layer-by-layer
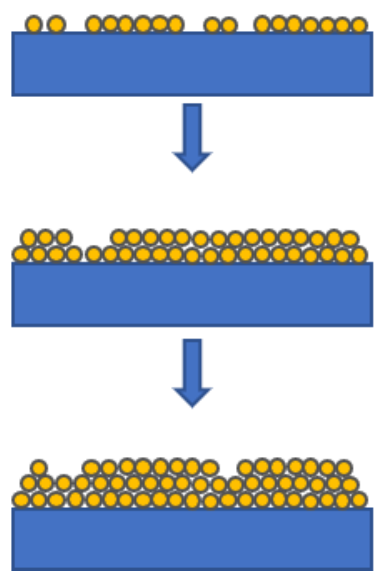

Vollmer - Weber

Island
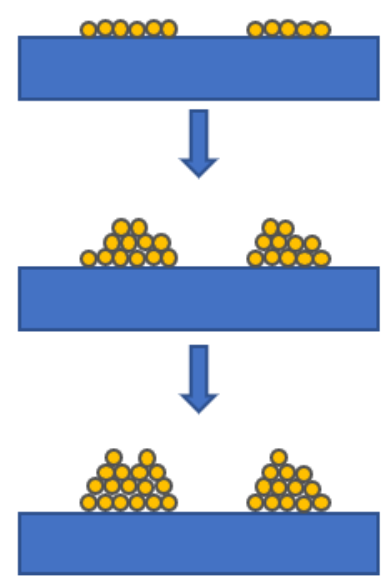

Stranski - Krastanov

Layer + Island
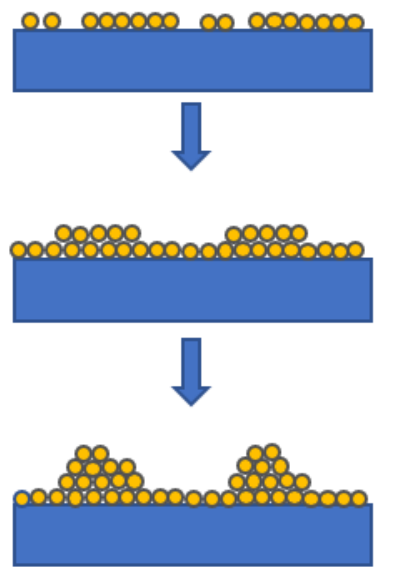

Figure 5.15 Basic thin film growth modes

\subsection{Conclusion}

In this study, the primary motivation was to observe the effects of controllable parameters on the morphology of the pNE surfactant layer. To correlate with SOFCs, the study was performed on pristine YSZ single crystals. First, the correlation between the degree of polymerization versus immersion time and the film thickness/aggregate size of $\mathrm{pNE}$ in various solid loadings was investigated. This mapping showed the flexibility of the protocol in that the pNE primary aggregate size, coating thickness, and the polymerization rate can easily be re-engineered for dense or porous microstructures. In addition, the growth kinetics of pNE at high concentration $(2 \mathrm{mg} / \mathrm{ml})$ was fitted with exponential decay function. Secondly, the chemical state of the pNE layer and the efficacy of the pNE layer on metal ion deposition (cerium) as the chelation complex were studied. The experiments showed a high cerium complex on the substrate when the pNE coating was applied. In addition, the cerium complex and the carbon pNE layer were found at the same time, indicating the formation of an organo-metallic framework. The study also revealed that the chelated cerium 
complex was composed of $61 \% \mathrm{Ce}^{+4}$ and $39 \% \mathrm{Ce}^{+3}$. Finally, the growth of the fired ceria particles with thin pNE coatings showed that the growth of ceria particles can occur by forming new nuclei or growing over the existing nuclei. As the pNE layer thickens, islands of ceria particles formed over a few monolayer of thin film (2-6 nm). Hence, the ceria deposits grows by the layer + island mode (Stranski - Krastanov).

The work could be helpful investigating most optimum ceria or other metal-oxide layers and decoration that is aimed to mitigate the particle coarsening seen at longer firing regimes. This kinetic understanding could help to construct more stable ceria nano-catalyst decoration by engineering the infiltration protocol parameters.

\subsection{References}

1. Waite, J.H., Mussel power. Nat Mater, 2008. 7(1): p. 8-9.

2. Zhao, F.K.Y.a.B., Adhesion Properties of Self-Polymerized Dopamine Thin film. The Open Surface Science Journal, 2011. 3: p. 115-122.

3. Lee, H., et al., Mussel-inspired surface chemistry for multifunctional coatings. Science, 2007. 318(5849): p. 426-30.

4. Silverman, H.G. and F.F. Roberto, Understanding marine mussel adhesion. Mar Biotechnol (NY), 2007. 9(6): p. 661-81.

5. Bandara, N., H. Zeng, and J. Wu, Marine mussel adhesion: biochemistry, mechanisms, and biomimetics. Journal of Adhesion Science and Technology, 2013. 27(18-19): p. 21392162.

6. Ryu, J.H., P.B. Messersmith, and H. Lee, Polydopamine Surface Chemistry: A Decade of Discovery. ACS Appl Mater Interfaces, 2018. 10(9): p. 7523-7540.

7. Mian, S.A., et al., A fundamental understanding of catechol and water adsorption on a hydrophilic silica surface: exploring the underwater adhesion mechanism of mussels on an atomic scale. Langmuir, 2014. 30(23): p. 6906-14.

8. Dreyer, D.R., et al., Elucidating the structure of poly(dopamine). Langmuir, 2012. 28(15): p. 6428-35.

9. Zangmeister, R.A., T.A. Morris, and M.J. Tarlov, Characterization of polydopamine thin films deposited at short times by autoxidation of dopamine. Langmuir, 2013. 29(27): p. 8619-28.

10. Son, E.J., et al., Quinone and its derivatives for energy harvesting and storage materials. Journal of Materials Chemistry A, 2016. 4(29): p. 11179-11202.

11. Liu, Y., K. Ai, and L. Lu, Polydopamine and its derivative materials: synthesis and promising applications in energy, environmental, and biomedical fields. Chem Rev, 2014. 114(9): p. 5057-115. 
12. Ball, V., et al., Kinetics of polydopamine film deposition as a function of $p H$ and dopamine concentration: insights in the polydopamine deposition mechanism. J Colloid Interface Sci, 2012. 386(1): p. 366-72.

13. d'Ischia, M., et al., Chemical and structural diversity in eumelanins: unexplored biooptoelectronic materials. Angew Chem Int Ed Engl, 2009. 48(22): p. 3914-21.

14. $\mathrm{Ju}, \mathrm{K} . \mathrm{Y}$,, et al., Bioinspired polymerization of dopamine to generate melanin-like nanoparticles having an excellent free-radical-scavenging property. Biomacromolecules, 2011. 12(3): p. 625-32.

15. Arzillo, M., et al., Eumelanin buildup on the nanoscale: aggregate growth/assembly and visible absorption development in biomimetic 5,6-dihydroxyindole polymerization. Biomacromolecules, 2012. 13(8): p. 2379-90.

16. Bernsmann, F., et al., Melanin-containing films: growth from dopamine solutions versus layer-by-layer deposition. Chemphyschem, 2010. 11(15): p. 3299-305.

17. Ding, Y., et al., Insights into the aggregation/deposition and structure of a polydopamine film. Langmuir, 2014. 30(41): p. 12258-69.

18. Bridelli, M.G., Self-assembly of melanin studied by laser light scattering. Biophysical Chemistry, 1998. 73(3): p. 227-239.

19. Cheng, C., et al., The hydrodynamic permeability and surface property of polyethersulfone ultrafiltration membranes with mussel-inspired polydopamine coatings. Journal of Membrane Science, 2012. 417-418: p. 228-236.

20. Jiang, J., et al., Surface characteristics of a self-polymerized dopamine coating deposited on hydrophobic polymer films. Langmuir, 2011. 27(23): p. 14180-7.

21. Ozmen, O., et al., Bio-inspired surfactant assisted nano-catalyst impregnation of SolidOxide Fuel Cell (SOFC) electrodes. Materials Letters, 2016. 164: p. 524-527.

22. Kang, S.M., et al., Norepinephrine: material-independent, multifunctional surface modification reagent. J Am Chem Soc, 2009. 131(37): p. 13224-5.

23. Hong, S., et al., Poly(norepinephrine): ultrasmooth material-independent surface chemistry and nanodepot for nitric oxide. Angew Chem Int Ed Engl, 2013. 52(35): p. 918791.

24. Yang, D., et al., Performance comparison of immobilized enzyme on the titanate nanotube surfaces modified by poly(dopamine) and poly(norepinephrine). RSC Advances, 2015. 5(53): p. 42461-42467.

25. Sever, M.J., et al., Metal-mediated cross-linking in the generation of a marine-mussel adhesive. Angew Chem Int Ed Engl, 2004. 43(4): p. 448-50.

26. Ou, J., et al., Mechanical property and corrosion resistance of zirconia/polydopamine nanocomposite multilayer films fabricated via a novel non-electrostatic layer-by-layer assembly technique. Surface and Interface Analysis, 2011. 43(4): p. 803-808.

27. Wang, W., et al., Fabrication of silver-coated silica microspheres through mussel-inspired surface functionalization. J Colloid Interface Sci, 2011. 358(2): p. 567-74.

28. Park, J.Y., et al., Cell-repellant dextran coatings of porous titania using mussel adhesion chemistry. Macromol Biosci, 2013. 13(11): p. 1511-9.

29. Doherty, N.C., et al., The effect of the human gut-signalling hormone, norepinephrine, on the growth of the gastric pathogen Helicobacter pylori. Helicobacter, 2009. 14(3): p. 22330. 
30. Kang, S.M., et al., Simultaneous Reduction and Surface Functionalization of Graphene Oxide by Mussel-Inspired Chemistry. Advanced Functional Materials, 2011. 21(1): p. 108112.

31. Ozmen, O., et al., Porous SOFC Electrode Infiltration Methods By Bio-Adhesive Templating. Meeting Abstracts, 2015. MA2015-01(1): p. 212.

32. Shelef, M. and R.W. McCabe, Twenty-five years after introduction of automotive catalysts: what next? Catalysis Today, 2000. 62(1): p. 35-50.

33. Bueno-López, A., Diesel soot combustion ceria catalysts. Applied Catalysis B: Environmental, 2014. 146: p. 1-11.

34. Kusakabe, K., et al., Methane steam reforming over Ce-ZrO ${ }_{2}$-supported noble metal catalysts at low temperature. Fuel Processing Technology, 2004. 86(3): p. 319-326.

35. Vecchietti, J., et al., Understanding the Role of Oxygen Vacancies in the Water Gas Shift Reaction on Ceria-Supported Platinum Catalysts. ACS Catalysis, 2014. 4(6): p. 20882096.

36. Khan, S.B., et al., Exploration of $\mathrm{CeO}_{2}$ nanoparticles as a chemi-sensor and photo-catalyst for environmental applications. Sci Total Environ, 2011. 409(15): p. 2987-92.

37. Lei, M., et al., Self-assembled mesoporous carbon sensitized with ceria nanoparticles as durable catalyst support for PEM fuel cell. International Journal of Hydrogen Energy, 2013. 38(1): p. 205-211.

38. Behafarid, F. and B. Roldan Cuenya, Coarsening phenomena of metal nanoparticles and the influence of the support pre-treatment: Pt/TiO 2 (110). Surface Science, 2012. 606(1112): p. 908-918.

39. Castro, R.H.R., On the thermodynamic stability of nanocrystalline ceramics. Materials Letters, 2013. 96: p. 45-56.

40. Fang, Z.Z., H. Wang, and V. Kumar, Coarsening, densification, and grain growth during sintering of nano-sized powders-A perspective. International Journal of Refractory Metals and Hard Materials, 2017. 62: p. 110-117.

41. Aidhy, D.S., Y. Zhang, and W.J. Weber, Stabilizing nanocrystalline grains in ceramicoxides. Phys Chem Chem Phys, 2013. 15(43): p. 18915-20.

42. Adijanto, L., et al., Synthesis and Stability of Pd@CeO $\mathrm{O}_{2}$ Core-Shell Catalyst Films in Solid Oxide Fuel Cell Anodes. ACS Catalysis, 2013. 3(8): p. 1801-1809.

43. Liu, J., et al., Sintering-Resistant Nanoparticles in Wide-Mouthed Compartments for Sustained Catalytic Performance. Sci Rep, 2017. 7: p. 41773.

44. $\quad \mathrm{Li}, \mathrm{B}$., et al., Ultrathin and stable active layer of dense composite membrane enabled by poly(dopamine). Langmuir, 2009. 25(13): p. 7368-74.

45. Taskin, M.B., et al., Poly(norepinephrine) as a functional bio-interface for neuronal differentiation on electrospun fibers. Phys Chem Chem Phys, 2015. 17(14): p. 9446-53.

46. Chen, J., et al., A norepinephrine coated magnetic molecularly imprinted polymer for simultaneous multiple chiral recognition. J Chromatogr A, 2015. 1409: p. 268-76.

47. Zheng, L., et al., Controlled preparation of titania nanofilm by a template of polydopamine film and its reversible wettability. Thin Solid Films, 2012. 520(7): p. 2776-2780.

48. Meng, F., et al., Morphology-Controlled Synthesis of $\mathrm{CeO}_{2}$ Microstructures and Their Room Temperature Ferromagnetism. Journal of Materials Science \& Technology, 2017. 33(5): p. 444-451. 
49. Zhang, F., et al., Cerium oxidation state in ceria nanoparticles studied with X-ray photoelectron spectroscopy and absorption near edge spectroscopy. Surface Science, 2004. 563(1-3): p. 74-82.

50. Gao, L., C. Zhang, and M. Zhang, Cerium chemical conversion coating on a novel Mg-Li alloy. Journal of Wuhan University of Technology-Mater. Sci. Ed., 2010. 25(1): p. 112117.

51. Eloirdi, R., et al., X-ray photoelectron spectroscopy study of the reduction and oxidation of uranium and cerium single oxide compared to $(U-C e)$ mixed oxide films. Applied Surface Science, 2018. 457: p. 566-571.

52. Brun, M., A. Berthet, and J.C. Bertolini, XPS, AES and Auger parameter of Pd and PdO. Journal of Electron Spectroscopy and Related Phenomena, 1999. 104(1-3): p. 55-60.

53. Khudorozhkov, A.K., et al., Propane Oxidation Over Pd/Al2O3: Kinetic and In Situ XPS Study. Topics in Catalysis, 2017. 60(1-2): p. 190-197.

54. Lee, Y. and T.G. Park, Facile fabrication of branched gold nanoparticles by reductive hydroxyphenol derivatives. Langmuir, 2011. 27(6): p. 2965-71.

55. Nadagouda, M.N., V. Polshettiwar, and R.S. Varma, Self-assembly of palladium nanoparticles: synthesis of nanobelts, nanoplates and nanotrees using vitamin B1, and their application in carbon-carbon coupling reactions. Journal of Materials Chemistry, 2009. 19(14): p. 2026.

56. Kaiser, N., Review of the fundamentals of thin-film growth. Appl Opt, 2002. 41(16): p. 3053-60.

57. Prieto, J.E. and I. Markov, Stranski-Krastanov mechanism of growth and the effect of misfit sign on quantum dots nucleation. Surface Science, 2017. 664: p. 172-184. 


\section{Chapter 6 : Investigation of Alternative Catecholamine Surfactant Assisted Nano-Ceria Infiltration Anode of Electrolyte-Supported Solid Oxide Fuel Cells (SOFCs)}

\subsection{Introduction}

The incorporation of nanomaterials within the porous electrodes of solid oxide fuel cell (SOFC) through infiltration/impregnation is a well-used method to increase the performance and/or enhance stability. Owing to the facile and low-cost process, tailoring off-the-shelf SOFCs by infiltration becomes a favorable protocol without electrode re-engineering. To increase the effectiveness of the infiltration protocol, there are two main strategies: i) precursor modification ii) electrode backbone modification. In the first route, precursor additives such as Triton-X [1], glycine [2], citric acid [3], and urea [4] were reported to facilitate the formation of nanostructures with specific morphologies, phase stabilities, and performance criteria. The second route utilized a pretreat to the electrode scaffold, especially to the relatively thick and dense unreduced anode electrode, to open up the porosity. For example, Jiang et al. reduced $\mathrm{NiO}$ to $\mathrm{Ni}$ by purging $\mathrm{H}_{2}$ prior to the infiltration to enhance porosity and pore network connectivity [5]. In addition, Ye et al. applied an alternative route of leaching nickel from the conventional NiO/YSZ anode matrix through the use of concentrated $\mathrm{HNO}_{3}$ treatment [6]. These pretreatment methods enhanced the infiltration efficiency; however, the inevitable trade-offs need to be addressed, such as the loss of the nickel, mechanical weakness, and the labor cost.

Another scaffold pretreatment was performed by S.-W. Jung et al. where an additional conductive carbon layer was coated on to a porous YSZ scaffold by n-butane pyrolysis. The purpose of this conductive layer was to assist $\mathrm{Co}$ and Ni chloride electrodeposition to the YSZ 
scaffold. After the decarbonatization step, a Ni and Co thick film on the SOFC anode was achieved $[7]$.

Over the past decades, poly-catecholamines were used as surface modifiers (wetting agents) [8-10] for metal, metal oxide and organic coatings, as well as, adhesive agents for various coating studies [9]. These works focused on the deposition of the catechol and targeted material onto planar substrates[11, 12] and highly porous polymeric membranes [13, 14]. Poly-dopamine (pDA) was the most utilized of this chemical group over the past decade $[12,15]$. When monomer dopamine (DA) oxidizes, the DA monomer will polymerize and provide a film with a range of local reaction sites due to the functional amine and 1,2-hydroxyl end-groups attached to the benzene ring (Figure 6.1). This characteristic allows the film to attach to various substrates and permits the polymerized film to adsorb various metal and metal oxide species from the surrounding solution. Over continuous exposure to a dispersion or salt solution, a significant build-up of these attracted dispersed species may result in the polymerized catechol layer. The metal chelation mechanism from a salt solution precursor onto a pDA coating was used to efficiently coat the porous electrodes of a commercial anode-supported SOFC with redox nano-catalyst, as discussed in Chapter 3 [16].

In this early work, a cerium nitrate precursor solution was chosen to infiltrate both electrodes to prove the efficacy of the protocol, after the pDA treatment. The treatment assisted in the deposition of nearly 3.5 times more ceria nano-catalyst after a single firing step. As a result, a $20 \%$ increase in power density was achieved with dual-electrode infiltration with the ceria nanocatalysts. However, the power density of the infiltrated cells dropped and resulted in only $5 \%$ higher performance over the baseline cell in $300 \mathrm{~h}$ of testing. This could be attributed to the one drawback of the pDA surfactant, which is the continuous aggregation during the polymerization 
step $[17,18]$. Hence, the use of the pDA surfactant would potentially clog the open pores inside the electrodes, preventing effective liquid penetration and final homogenous catalyst precipitation. These issues later resulted in the nano-catalyst coarsening and deactivating during SOFC operation. To overcome this issue, the implementation of poly-norepinephrine (pNE), another alternative to pDA which has a less-aggregate formation and a smoother coating owing to the 3,4dihydroxybenzaldehyde (DHBA) formation during polymerization was studied [19]. The new surfactant resulted in the formation of a uniform nano-catalyst thin film within the active area both at the anode and the cathode electrodes with up to $35 \%$ improved catalytic activity. Moreover, this nano-ceria morphology achieved a gradual reduction in polarization resistance over the $300 \mathrm{~h}$ of operation.

Apart from $\mathrm{pDA}$ and $\mathrm{pNE}$, there are a variety of catecholamine or phenolic structured surfactants with similar chemistry. Another common point of these surfactants is their strong affinity for metal / metal oxide surfaces. Thus, there has been a growing interest in those molecules owing to their remarkable interfacial adhesion properties in colloidal chemistry. A broad review of these molecules in colloid and surface chemistry was completed by Ata et al. [20].

In this study, a combined approach is presented to introduce alternative catechol surfactants and their usage in SOFC anode pretreatment to modify internal surfaces, in order to build metalorganic-frameworks (MOFs). From the variety of catecholamine family, poly-gallic acid (pGA), poly-dihydroxyhydrocinnamic acid (pDHC) and poly-caffeic acid (pCA) were chosen due to their similar chemical structure and properties compared with poly-epinephrine (pNE) as the catecholbased surfactant for strong adsorption nature. These molecules are phenolic compounds found in nature similar to the DA and NE. In addition, the molecules have similar functional OH groups, 
and also, carboxylic and/or amino groups bonded to an aromatic ring with slight variations as shown in Figure 6.1.<smiles>NC(=O)C(O)Cc1ccc(O)c(O)c1</smiles>

Nor-epinephrine<smiles>O=C(O)c1cc(O)c(O)c(O)c1</smiles>

Gallic Acid

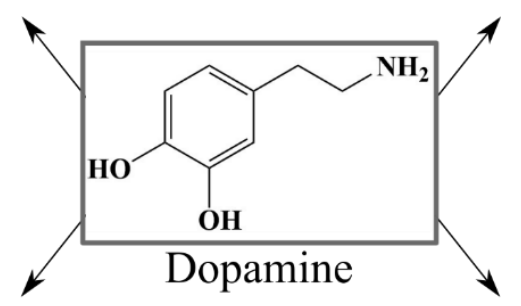<smiles>O=C(O)CCc1ccc(O)c(O)c1</smiles>

3,4-Dihydroxyhydrocinnamic Acid<smiles>O=C(O)/C=C/c1ccc(O)c(O)c1</smiles>

Caffeic Acid

Figure 6.1 Molecular structures of selected monomers in catechol family.

The work initially characterizes the polymerization of these catechol surfactant by UVVisible spectroscopy and then the surfactant coatings were analyzed by AFM. After this characterization, a two-step anode dip-coating infiltration protocol was used to impregnate the SOFCs with a similar ceria nano-catalyst. Throughout this study, the cerium nitrate precursor was only infiltrated into the anode electrode as a demonstration to compare the catalyst loading efficacy, nano-catalyst morphology, and electrochemical performance. SOFC current-voltage testing was performed at $750^{\circ} \mathrm{C}$ using pure $\mathrm{H}_{2}$ fuel for these cells up to $\sim 75 \mathrm{~h}$. SEM and TEM characterization was performed at the last step to investigate the decoration properties of the ceria nanoparticles at the post-operated anode electrode structures. 


\subsection{Experimental}

\subsubsection{Catechol surfactant characterization}

The characterization of catechol-based surfactants was investigated at a constant concentration, $1 \mathrm{mg} / \mathrm{ml}$, and constant $\mathrm{pH}$ at 8.5 . Catechol-based surfactants, dopamine hydrochloride (99\%, Alfa-Aesar), DL-Norepinephrine hydrochloride ( $\geq 97 \%$ (TLC), Aldrich), caffeic acid (Min 98\%, TCI America), 3,4-Dihydroxyhydrocinnamic acid (DHC, 98\%, Aldrich) and gallic acid (3,4,5-Trihydroxybenzoic acid, 99\%, Alfa-Aesar) were dissolved into a $0.05 \mathrm{M}$ TRIS (tris(hydroxymethyl) aminomethane, 99\%, Alfa-Aesar) and a 1:1 by volume ratio waterethanol mixture. Samples were collected at the 1,6 and $12 \mathrm{~h}$ of polymerization and were diluted $1: 19$ vol\% ratio prior to the UV-Vis absorbance (300-900 $\mathrm{nm}$ ) spectroscopy using a double beam spectrophotometer (Shimadzu 2600).

For adhered catechol topography analysis, one side polished $1 \mathrm{~mm} \times 1 \mathrm{~mm}$ sized, (100) yttria-stabilized zirconia (YSZ) single crystals (MTI Corporation, USA) were used as a substrate. The crystals were first cleaned by soaking in an acetone bath for 5 min then rinsed with 1:1 vol \% water-ethanol solution. Then the clean substrates were submerged for coating into catechol surfactant solutions for $12 \mathrm{~h}$. After coating, the substrate is immersed into the clean 1:1 vol \% water-ethanol solution to remove loosely bonded moieties from the samples. The samples were dried in the oven at $75^{\circ} \mathrm{C}$. The surface microstructure was imaged using an atomic force microscopy (Agilent 5500 Atomic Force Microscope, AFM) in over random 50 x $50 \mu \mathrm{m}^{2}$ areas. The AFM image was processed using open source software, Gwyddion (Version 2.48).

\subsubsection{Anode Electrode Infiltration}

Commercial electrolyte-supported button SOFC's (NexctCell-HP-2.5, Nexceris, LLC, OH, USA) were used for this study. These cells consisted of a $12.5 \mathrm{~mm}$ diameter anode with $\sim 15 \mu \mathrm{m}$ 
thick nickel oxide (NiO) /yttria-stabilized zirconia (YSZ), a $\sim 10 \mu \mathrm{m},(\mathrm{Ni}, \mathrm{Co})$ Samaria-doped ceria (SDC) composite and a $\sim 5 \mu \mathrm{m}$ SDC barrier layer anode structure. The electrolyte was $25 \mathrm{~mm}$ diameter $(\sim 150 \mu \mathrm{m}$ thick) of dense scandium stabilized zirconia (ScSZ). Finally, the cathode consisted of a $12.5 \mathrm{~mm}$ diameter ( $30 \mu \mathrm{m}$ thick) lanthanum strontium manganese (LSM)gadolinium-doped ceria (GDC) / LSM electrode.

In this study, the anode electrode was only infiltrated by exposing the infiltration solutions only to the anode layer using a hollow cylinder which was sealed around the outer edge of the anode layer. Hollow cylinders (50 $\mathrm{mm}$ tall, $25 \mathrm{~mm}$ in diameter) were printed using chemicallyresistant $\mathrm{CPE}+$ filament. The cells were placed under the hollow cylinders facing anode-side up, and the outer rim was sealed with a hot adhesive (Crystalbond 509, Aremco Products, Inc., NY, USA) to protect the cathode electrode from the precursor solutions. In the first step, $1 \mathrm{mg} / \mathrm{ml}$ catechol-surfactants were first dissolved in a 0.05 M TRIS (tris(hydroxymethyl) aminomethane, 99\%, Alfa-Aesar, USA) and 1:1 vol \% water-ethanol mixture at $\mathrm{pH} 8.5$. The surfactant precursors were then filled into the infiltration cup. To remove the air bubbles, the set-up was placed in a vacuum desiccator under $15 \mathrm{~mm} \mathrm{Hg}$ vacuum for $5 \mathrm{~min}$, and then transferred to a rocker table for $12 \mathrm{~h}$, which allowed the surfactant to polymerize homogeneously within the internal surfaces of the anode electrode. After the in-situ catechol polymerization, the solutions were emptied, and the anode area was rinsed with 1:1 vol \% water-ethanol solution. In the second step, the cup was immediately filled with $0.15 \mathrm{M}$, the cerium (III) nitrate hexahydrate (REacton ${ }^{\circ}, 99.5 \%$, Alfa Aesar, USA) solution of 1:1 vol\% water-ethanol mixture. The vacuum and immersion parameters were repeated in the second step. After the cerium nitrate immersion, the cells were rinsed again and dried under ambient conditions. The epoxy around the outer rim was cleaned carefully with acetone dipped cotton sticks. Finally, the infiltrated cells were removed from the infiltration cup 
and fired at $750^{\circ} \mathrm{C}$ for $1 \mathrm{~h}$. This method is called cup-infiltration throughout this chapter. The infiltrated catalyst amounts were measured by weight difference before and the after the infiltration protocol.

All the cells were operated at $750^{\circ} \mathrm{C}$ for $\sim 75 \mathrm{~h}$ using $300 \mathrm{sccm}$ humidified (3\%) hydrogen fuel and $300 \mathrm{sccm}$ air. During the electrochemical testing, the cells were sandwiched between alumina flanges, and mica gaskets were placed on both electrode sides as the sealant. For current collection and voltage readings, the connections were wired to Pt mesh with Pt paste for the cathode side and Pt mesh with Ni paste for the anode side. An electronic load of (Agilent N3301A, USA) was used to apply constant current $\left(0.35 \mathrm{~A} / \mathrm{cm}^{2}\right)$ to the cell during the tests. The performance of the cells was evaluated by electrochemical impedance spectroscopy (EIS) using a frequency response analyzer (Solartron 1455A, England) and a potentiostat (Solartron 1470E, England) with the frequency range of $100 \mathrm{kHz}-0.01 \mathrm{~Hz}$ under operating current load. The electrode microstructure of tested ceria impregnated cells was examined by scanning electron microscopy (JEOL 7600F, Japan). The samples were denoted as: p“surfactant” as. inf. to imply polymerized surfactant assisted infiltration, such as $\mathrm{pNE}$ as. inf for polymerized norepinephrine assisted infiltration.

\subsection{Results and Discussion}

Prior to the SOFC anode-electrode infiltration, a comparative study of polymerization and adhesion characterization of the selected alternative catecholamine surfactants were performed. Time-varied UV-Vis spectroscopic analysis was completed in the 1,12 and $24 \mathrm{~h}$ after initiating the pH-induced oxidative polymerization. Figure 6.2.a-d show the UV-Vis spectral data in the $300 \mathrm{~nm}$ to $800 \mathrm{~nm}$ range for $\mathrm{pNE}$, PGA, pDHC and $\mathrm{pCA}$, respectively. At the beginning of the 
polymerization step, all of the solutions were transparent (images not shown). The progression of the oxidative polymerization of each solution was visually confirmed by indicative color transitions. The solution color after the $12 \mathrm{~h}$ polymerization was brown for the polymerized norepinephrine (pNE), yellow-green for polymerized gallic acid (pGA), orange for polymerized 3,4-Dihydroxhydrocinnamic acid (pDHC), and red for polymerized caffeic acid, (pCA), as shown within the inset pictures in Figure 6.2.a-d. The spectroscopic data show the absorption bands for each solution, where certain wavelengths appeared with a time-dependent rise. For pNE and pGA, the rise in the absorption peak was observed at $350 \mathrm{~nm}$ (Figure 6.2.a, b). This band was also found during the polymerization of $\mathrm{pDA}$, where it is often correlated with the quinone formation and the development of higher molecular weight species throughout the polymerization [21]. Tóth et al. also reported that the irreversible GA oxidation to quinone-hydroquinone species produces a color change under ambient conditions [22]. The pGA spectra also revealed minor absorbance bands at the visible range, $495 \mathrm{~nm}$ and $700 \mathrm{~nm}$, which are indicators of the orange-green pGA solution color. During the pDHC solution analysis, the observed visible band was at $415 \mathrm{~nm}$, which links to the high blue light absorption for yellow solutions (Figure 6.2.c). Also, the shoulder at $350 \mathrm{~nm}$ got narrowed with higher intensity as the polymerization time proceeded. Unlike the other surfactants, the UV-Vis of pDHC during polymerization did not show any noticeable peak. Small increments of upshift were observed at $450 \mathrm{~nm}$ during the polymerization step, which is responsible for blue/indigo light absorption of red colored solutions. Behboodi-Sadabad et al. also reported the same trend in their time-dependent kinetic study for caffeic acid [21]. They assumed that the absorbance curve is convoluted and the absorbance value at $380 \mathrm{~nm}$ is an indicator of oxidation (polymerization) similar to other catechol surfactants. In Figure 6.2 all the surfactants experienced a rising trend of absorbance intensity at lower wavelengths but only the time- 
dependent reduction of the band at $312 \mathrm{~nm}$ in pCA could be measured under the testing spectrum (300-800 nm) in Figure 6.2.d. According to Tóth et al., this trend could potentially happen due to the deprotonation of the carboxyl groups which indicates the consumption of carboxylic groups through polymerization [22].
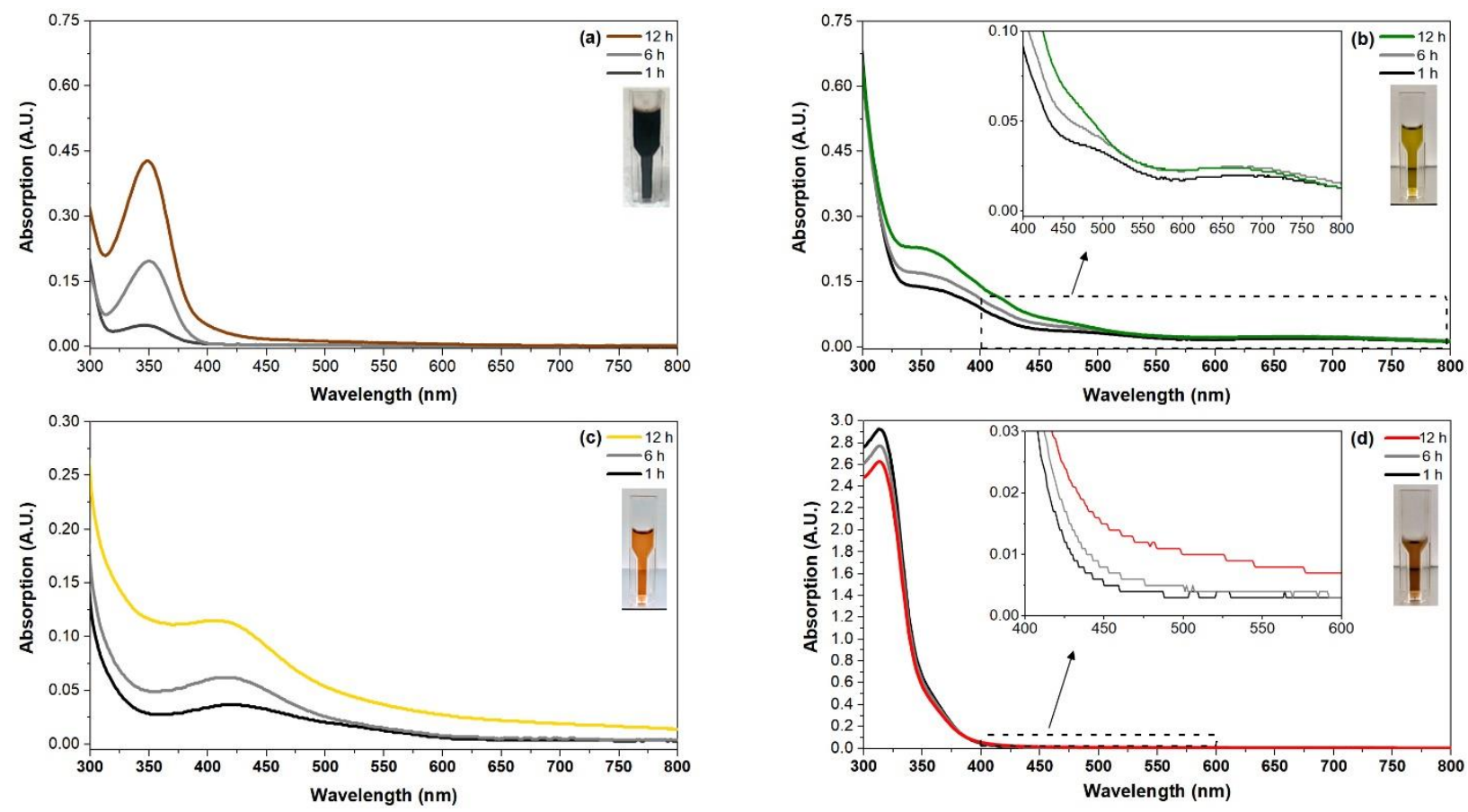

Figure 6.2 UV-Vis spectra of $1 \mathrm{mg} / \mathrm{ml}$ (a) $\mathrm{pNE}$, (b) pGA, (c) pDHC, (d) pCA polymerized for 1,6 and $12 \mathrm{~h}$.

The self-adhered coatings of these catechol solutions were tested by the dip-coating method in $1 \mathrm{mg} / \mathrm{ml}$ solid loading for $12 \mathrm{~h}$ at $\mathrm{pH} 8.5$. The morphology of the adhered layer onto the ultraflat YSZ single crystal surfaces was characterized by AFM in the tapping mode, using a $40 \mu \mathrm{m}$ line scans on a $50 \times 50 \mu \mathrm{m}^{2}$ mapping area. The surface profiles of $\mathrm{pNE}, \mathrm{pGA}, \mathrm{pDHC}$ and $\mathrm{pCA}$ are shown in Figure 6.3, respectively. Firstly, the reference sample, pNE, morphology included a homogenous blend of medium-sized $(\sim 40 \mathrm{~nm})$ and predominantly fine particles $(<20 \mathrm{~nm})$ as shown in Figure 6.3.a. In addition, the measured RMS of the pNE surface was $8.1 \mathrm{~nm}$. The adhered pGA 
surface shown in Figure 6.3.b consisted of large and anisotropic aggregates (60-80 nm) with smaller particles underneath. Hence, the RMS of the pGA surface increased to $19.9 \mathrm{~nm}$. Similarly, the pDHC treated surface also included some aggregates, but showed a lower population of islands in comparison to the pGA treated surface, as shown in Figure 6.3.c. Sparse and discrete aggregate morphology aided in the reduction of the RMS to $17.4 \mathrm{~nm}$.

The pCA morphology, shown in Figure 6.3.d, contained the mostly homogenously distributed equiaxed, spherical particles which were less than $10 \mathrm{~nm}$ in size. The RMS was measured to $4.9 \mathrm{~nm}$, the lowest among the other candidates, including the reference surfactant, pNE. The aggregate free, smooth coating of the caffeic acid showed the most promising coating morphology under these experimental conditions ( $1 \mathrm{mg} / \mathrm{ml}$ solution at $\mathrm{pH} 8.5$ and $12 \mathrm{~h}$ immersion). 

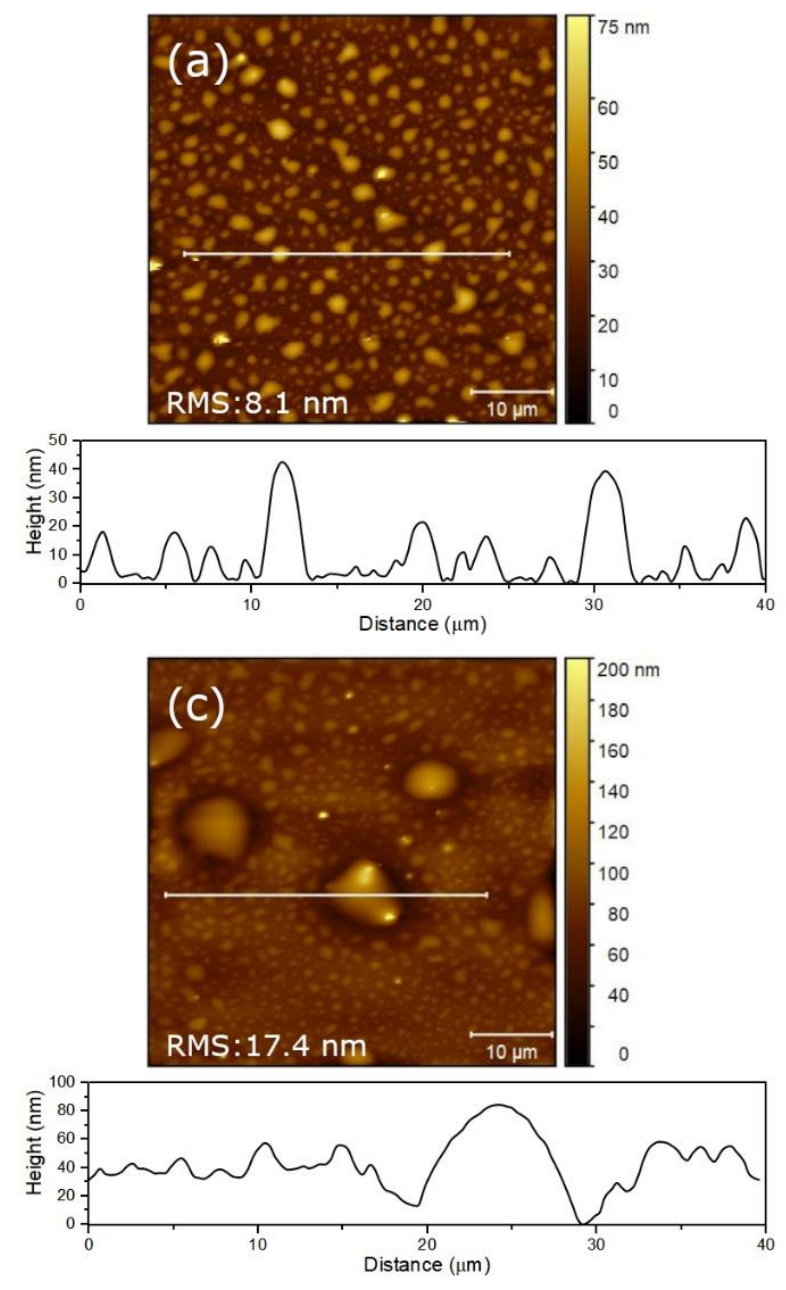
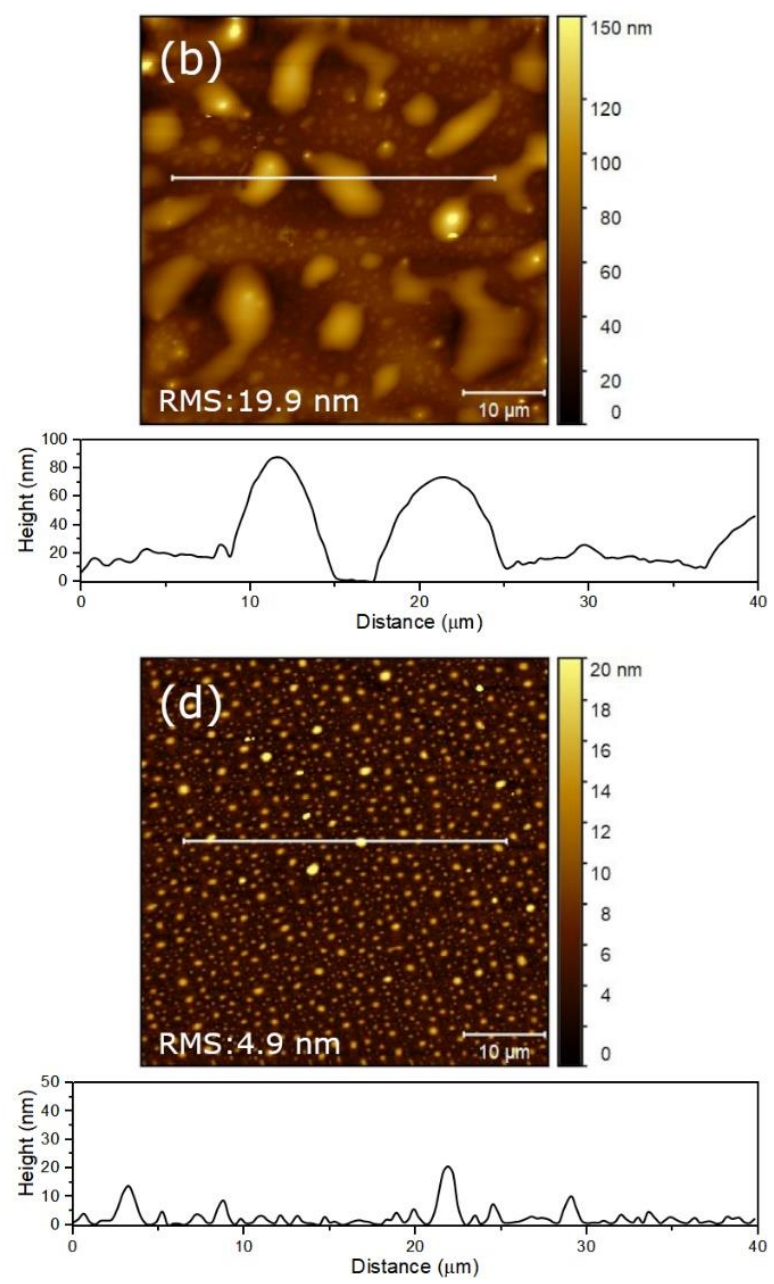

Figure 6.3 AFM images of $1 \mathrm{mg} / \mathrm{ml}$ (a) $\mathrm{pNE}$ (b) pGA, (c) pDHC and (d) pCA polymerized for $12 \mathrm{~h}$. Mapping area is $50 \times 50 \mu \mathrm{m}^{2}$, line scan length is $40 \mu \mathrm{m}$.

After the catechol polymerization and the adhesion validation, polymerization procedures were applied to the anode electrode with a so-called cup infiltration method. The cup prevented any leakages during the anode infiltration and protected the cathode electrode. After the infiltration and calcination step was completed, the entire cell weight was measured and compared against the initial weight. This gave an estimate of the total ceria infiltration within the anode electrode. The infiltrated ceria amounts were approximately $0.2 \mathrm{mg}\left(\sim 0.16 \mathrm{mg} / \mathrm{cm}^{2}\right)$ for all cells, except for the pDHC assisted infiltration which showed $\sim 0.3 \mathrm{mg}\left(\sim 0.25 \mathrm{mg} / \mathrm{cm}^{2}\right)$ deposition. As a reference, a 
non-surfactant infiltration protocol, denoted as only Ce N., was performed, and the infiltrated ceria amount for this sample was $0.06 \mathrm{mg}\left(\sim 0.05 \mathrm{mg} / \mathrm{cm}^{2}\right)$. 


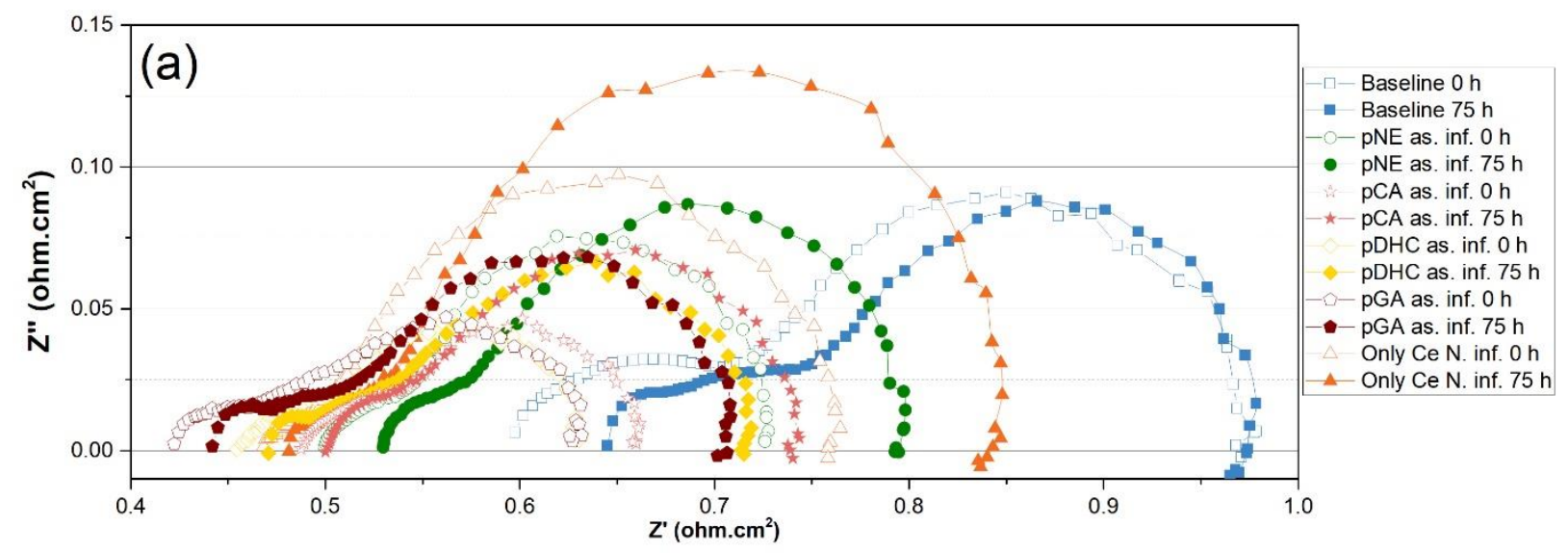

(b)

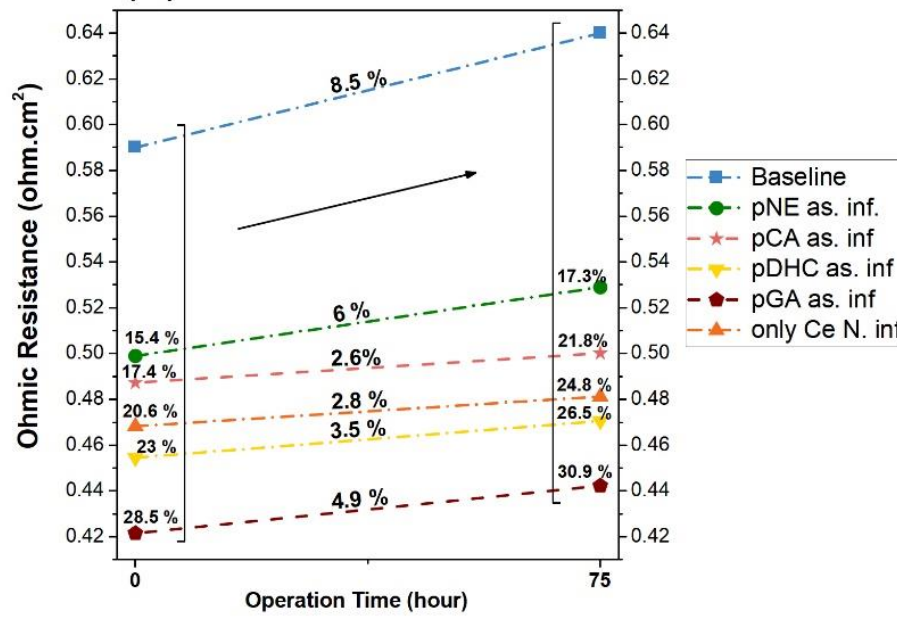

(c)
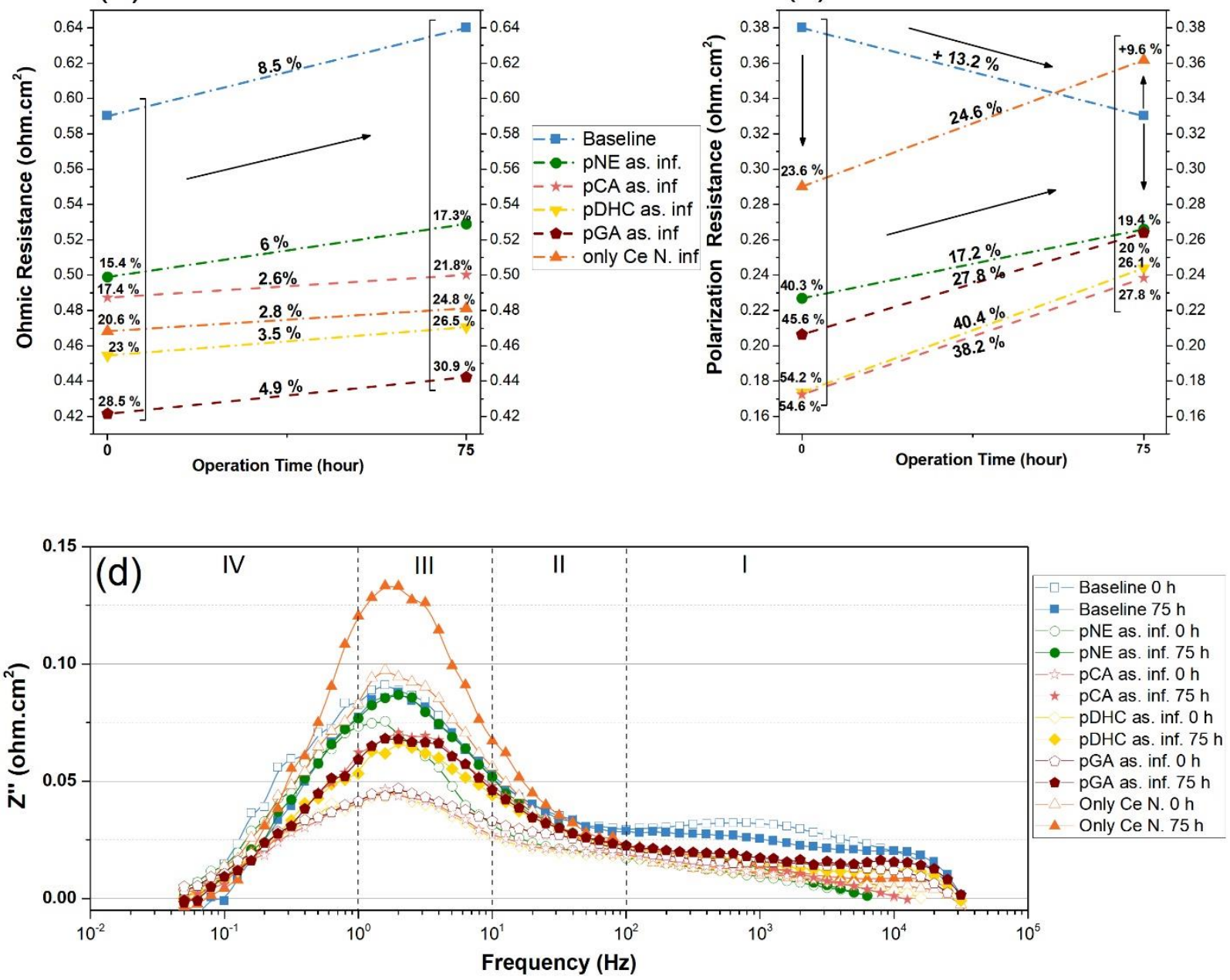

Figure 6.4 (a) Nyquist (b) Ohmic resistance (c) Polarization resistance and (d) Bode plots of baseline and only cerium nitrate and $\mathrm{pNE}, \mathrm{pCA}, \mathrm{pDHC}, \mathrm{pGA}$ assisted cerium nitrate infiltrated cells operated at $750^{\circ} \mathrm{C}, 0.35 \mathrm{~A} / \mathrm{cm}^{2}$ for $75 \mathrm{~h}$. 
The time-dependent EIS Nyquist plots of the baseline and the infiltrated cells are shown in Figure 6.4.a. Surprisingly, the ohmic resistances at the $0 \mathrm{~h}$ varied up to $28.5 \%$ from cell to cell in the same batch. At first glance, this makes the spectra more complicated for the analysis of the influence of ceria infiltration. For further analysis, the impedance spectra were extracted and the ohmic resistance and the non-ohmic resistance changes are plotted in Figure 6.4.b and Figure 6.4.c, respectively. The beginning point (first leg) of the impedance near abscissa was taken as the ohmic resistance in Figure 6.4.b. As stated above, the cell to cell variance in the ohmic resistance can be seen at the $0^{\text {th }}$ hour. The ohmic resistance of the baseline cell was measured as $0.59 \mathrm{ohm} \cdot \mathrm{cm}^{2}$, where the rest of the infiltrated cells showed values that were $15.4 \%$ (pNE assisted infiltrated cell) to $28.5 \%$ (pGA assisted infiltrated cell) lower $\mathrm{R}_{\mathrm{o}}$ than the baseline cell. The reduction of $\mathrm{R}_{\mathrm{o}}$ may be related to additional ceria phase at the SDC barrier layer which potentially increased the density of ionic conducting phases. At the end of the run, the ohmic resistances of all the cells were higher than that of the beginning of the test for all samples. The increase in ohmic resistance was $8.5 \%$ for the baseline cell and ranged from 2.6-6\% increase in ohmic resistance for the infiltrated cells. In Figure 6.4.c, the non-ohmic parts (also referred as polarization resistance, $\mathrm{R}_{\mathrm{p}}$ ) were represented by taking the net resistance between the two legs of the impedance curve where they intercept to the abscissa. First, it can be observed that the baseline cell had the highest $R_{p}$ of $0.38 \mathrm{ohm} \cdot \mathrm{cm}^{2}$ at the beginning of the test, and it is followed by the infiltrated cell without the surfactant step. The $\mathrm{R}_{\mathrm{p}}$ non-surfactant assisted infiltrated sample was $\sim 23.6 \%$ below the baseline cell $(-23.6 \%)$. Further initial enhancements were seen in the surfactant-treated infiltrated cells where the $R_{p}$ are $0.227(-40.3 \%), 0.206(-45.6 \%), 0.173(-54.2 \%)$ and $0.172(-54.6 \%) \mathrm{ohm} \cdot \mathrm{cm}^{2}$ for pNE, pGA, pDHC and pCA assisted infiltrated cells, respectively. At the end of the operation $(\sim 75 \mathrm{~h})$, it was shown that the non-ohmic part of the baseline cell dropped about $13.2 \%$ to $0.33 \mathrm{ohm} \cdot \mathrm{cm}^{2}$. On the 
other hand, all the infiltrated cells were deactivated over time. The $R_{p}$ at $75 \mathrm{~h}$ of the non-surfactant infiltrated cell was $9.6 \%$ higher than the baseline cell which indicates particle-particle interactions and coarsening related deactivation. The $\mathrm{R}_{\mathrm{p}}$ 's of surfactant-assisted protocols at $75 \mathrm{~h}$ were also found to be higher than the initial Rp's, but they at least remained below the baseline cell. In addition, a correlation of initial performance versus percent deactivation can be deduced from the plot. The slope of the line is found to be steeper as the initial enhancement was better. For example, pNE assisted infiltrated cell (green line) had the lowest enhancement at the beginning and also showed the lowest deactivation rate, $17.2 \%$ increase in $R_{p}$ between 0 to $75 \mathrm{~h}$. The trend was similar with the pGA assisted infiltrated cell with $27.8 \%$ and finally, the pDHC and pCA assisted infiltrated cells $\sim 39 \%$. To better analyze the electrochemical effect of surfactant assisted ceria infiltrated anodes, the EIS Bode plots for the baseline and infiltrated cells for $0 \mathrm{~h}$ and $75 \mathrm{~h}$ are shown in Figure 6.4.d. Previous studies showed that the change in reactance at the high frequency (> $10^{2} \mathrm{~Hz}$, denoted as Region I) is associated with the anode charge-transfer reaction [23, 24]. Correspondingly, the middle-frequency changes $\left(10-10^{2} \mathrm{~Hz}\right.$, denoted as Region II) denote the change in cathodic polarization $[23,25]$. In addition, it was observed that the low-frequency changes (1-10 Hz, denoted as Region III) are generally related to anodic gas diffusion polarization $[23,26]$. Region $I V$ is not considered in the analysis and negligible due to the lower inductance. As can be found Figure 6.4.d, all the infiltrated cells displayed lower reactance in Region I which indicates overall activation of ceria at the anode electrode. The slight upshifts in pDHC, pCA and only Ce assisted infiltrated cells were relatively noticeable than the other cell. These cells showed also showed higher Rp change over time as shown in Figure 6.4.c. except for pCA as. inf. cell. Along with the pNE as. inf. cell (the lowest recorded time dependent Rp degradation), pCA as. inf. cell did not show any shift in reactance in the Region I between $0 \mathrm{~h}$ and $75 \mathrm{~h}$. At the low 
frequency range (Region III), the ceria infiltrated cell without surfactant (only Ce N.) positioned at a remarkably high arc and the baseline cell with a time dependent upshift which can be evidence of inhomogeneous deposition and agglomeration of ceria nano-particles. Even though the infiltrated ceria amount resulted in only one-third of the surfactant assisted ceria infiltrated cells, the high reactance at the Region III showed that gas diffusion issues due to poor infiltration. The general trend for the surfactant-assisted ceria infiltrated cells, on the other hand, the initial $(0 \mathrm{~h})$ and the final $\operatorname{arcs}(75 \mathrm{~h})$ were lower than the baseline cell, although the final arcs were always higher than the $0 \mathrm{~h}$ which can also be a sign of coarsening.

To be able to compare the actual time-dependent electrode performance, the electrode overpotential versus time is plotted in Figure 6.5. The electrode overpotential calculation was formulated in Eq. 6.1. The total overpotential $\left(\eta_{\text {total }}\right)$ was assumed to be the combination of the ohmic ( $\left.\eta_{\text {ohmic }}\right)$ and electrode overpotential $\left(\eta_{\text {electrode }}\right)$. Thus, the electrode overpotential was calculated by subtracting the ohmic overpotential from the total overpotential. The total overpotential $\left(\eta_{\text {total }}\right)$ is the difference between open circuit voltage $(\mathrm{OCV})$ and operating cell voltage $\left(\mathrm{V}_{\text {cell }}\right)$ under operating current $\left(0.43 \mathrm{~A}\right.$ or $\left.0.35 \mathrm{~A} / \mathrm{cm}^{2}\right)$ (Eq. 6.2). The ohmic overpotential ( $\eta_{\text {ohmic }}$ ) is obtained by the ohmic resistance multiplied by the operating current (Eq. 6.3).

$$
\begin{aligned}
& \eta_{\text {electrode }}=\eta_{\text {total }}-\eta_{\text {ohmic }} \\
& \eta_{\text {total }}=O C V-V_{\text {cell }} \\
& \eta_{\text {ohmic }}=R_{O} * I
\end{aligned}
$$




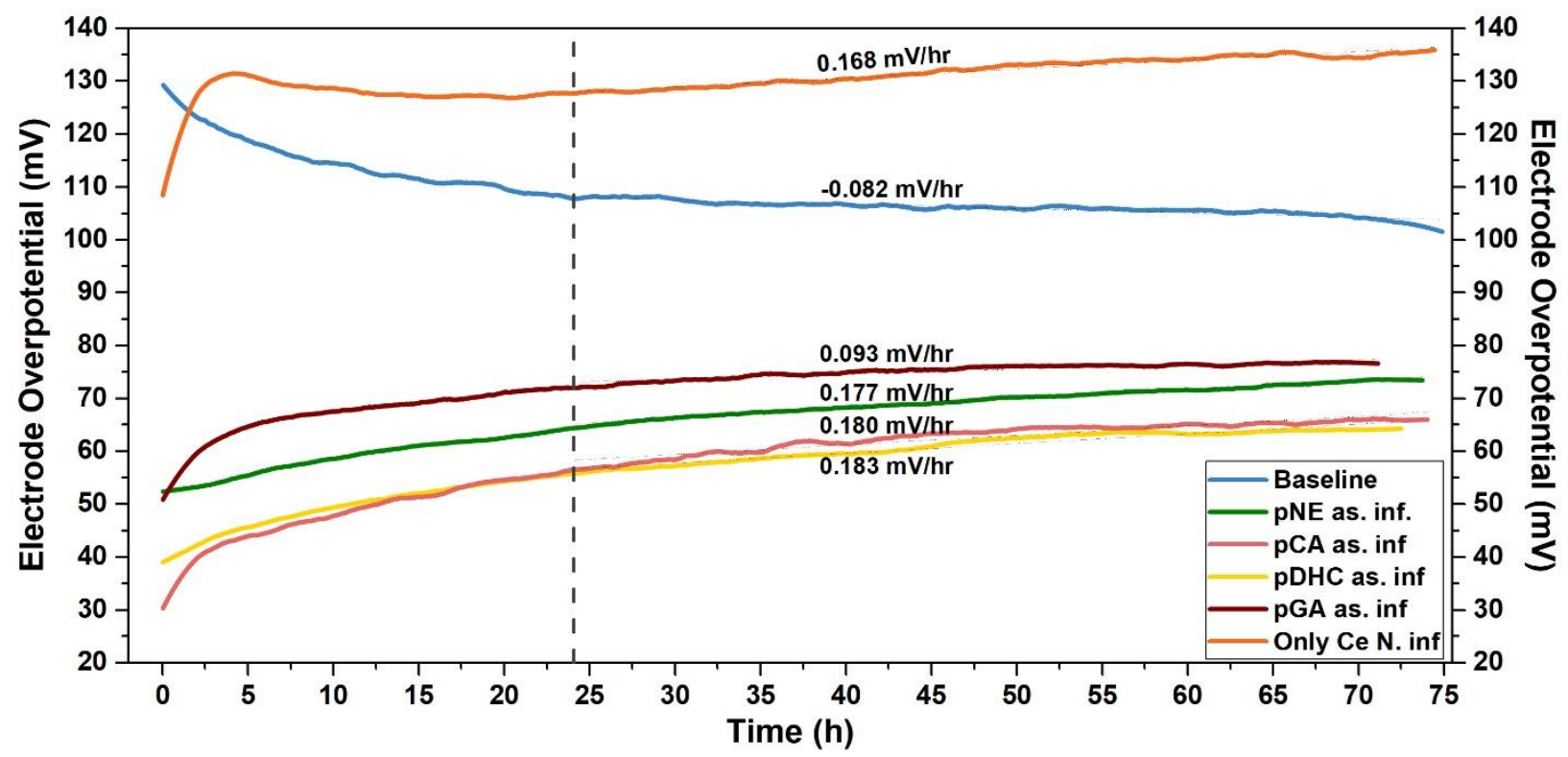

Figure 6.5 Time-dependent electrode overpotential change plot of baseline, only cerium nitrate, and pNE, pCA, pDHC, pGA assisted cerium nitrate infiltrated cells operated at $750^{\circ} \mathrm{C}, 0.35 \mathrm{~A} / \mathrm{cm}^{2}$ for $75 \mathrm{~h}$.

As shown in Figure 6.4.b, the ohmic resistance of the cells was only measured at the beginning $(0 \mathrm{~h})$ and at the end of the test $(\sim 75 \mathrm{~h})$. The rate of the time-dependent changes of the ohmic part was relatively 3 to 5 -fold lower than the non-ohmic part. Hence, the difference in the ohmic resistance was assumed to be linear and the change was obtained by linear interpolation. Since the ohmic overpotential was excluded from the total overpotential, and the cathode electrode was untouched, any change in the electrode overpotential must be due to the anode electrode contribution (and as such, due to the effect of the anode infiltration). In the plot, the electrode overpotential of the baseline cell initially was $130 \mathrm{mV}$. Then after a gradual decrease over the first $24 \mathrm{~h}$ of operation, the cell showed a stable performance where the overpotential change between the $24 \mathrm{~h}$ to the end of the run was $-0.082 \mathrm{mV} / \mathrm{hr}$. This gradual drop can be attributed to the typical burn-in period of the cell with LSM cathodes. Hence, a vertical reference line at $24 \mathrm{~h}$ was set to 
separate the burn-in and post burn-in stages. In Figure 6.4.b, the ceria infiltrated cell without the application of the surfactant showed a lower initial Rp but higher Rp than the baseline at $\sim 75 \mathrm{~h}$. In Figure 6.5, it is clearly depicted that the deactivation took place in the first hours of the run in the burn-in stage. In addition, the deactivation continued at the post burn-in stage at the rate of $0.168 \mathrm{mV} / \mathrm{hr}$. Concerning the infiltrated cells, it can be observed that the initial overpotential reduction ranking (from lowest to highest reduction) followed as $\mathrm{pGA}, \mathrm{pNE}, \mathrm{pDHC}$ and $\mathrm{pCA}$ assisted infiltrated cells respectively. At the pre burn-in stage, all the cells exhibited an increase in electrode overpotential. The pGA and pCA assisted infiltrated cells showed a sharp increase in the first $3 \mathrm{~h}$ in this stage, whereas the pNE and $\mathrm{pDHC}$ assisted cell had a moderate increase in electrode overpotential. After the burn-in stage, the trend continued as the deactivation rates during the post burn-in stage were measured as $0.093,0.177,0.180$ and $0.183 \mathrm{mV} / \mathrm{hr}$ in $\mathrm{pGA}, \mathrm{pNE}, \mathrm{pCA}$ and pDHC respectively.

The electrochemical test for the pCA and pDHC assisted infiltration showed the most promise over $75 \mathrm{~h}$ of operation. However, the pCA assisted infiltration protocol showed lower initial electrode overpotential compared to $\mathrm{pDHC}$ with having less catalyst deposition. Since the infiltrated cell stability is as important as the performance boost, the pCA assisted protocol was chosen for further testing. Hence the pCA protocol was modified by raising the cerium nitrate immersion time from $12 \mathrm{~h}$ to $24 \mathrm{~h}$. The infiltration resulted in the doubling of the infiltrated ceria amount to $0.4 \mathrm{mg}\left(0.32 \mathrm{mg} / \mathrm{cm}^{2}\right)$ (denoted as pCA 2).

Figure 6.6 shows the electrode overpotential comparison of pCA-2 with the pCA and the baseline cell. The long immersion time resulted in almost a two-fold increase in the initial electrode overpotential over that of the IC-1 sample. However, the cell was stable in both burn-in and post burn-in stage. During the burn-in stage, the overpotential rose to only $5 \mathrm{mV}$. The post burn-in 
stage resulted in an additional $2 \mathrm{mV}$ change with a change rate of $0.042 \mathrm{mV} / \mathrm{hr}$ which was fourfold less than the original pCA assisted protocol. Despite the pCA assisted infiltrated cell having a $4.5 \mathrm{mV}$ lower overpotential at $\sim 75 \mathrm{~h}$, the low deactivation rate of pCA-2 seemed further promising for longer operation.

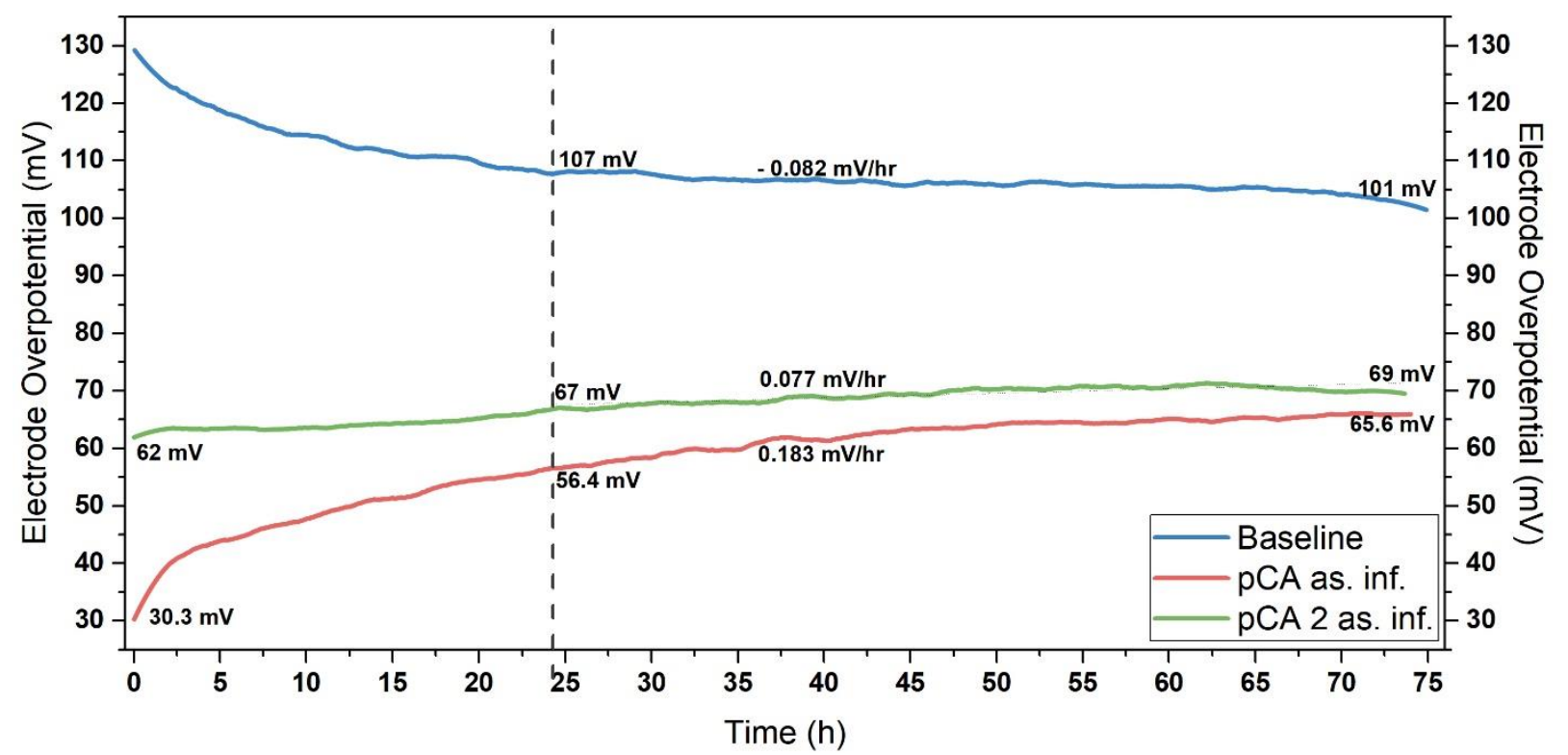

Figure 6.6 Time dependent electrode overpotential change plot of baseline, pCA and pCA 2 assisted infiltered cells operated at $750^{\circ} \mathrm{C}, 0.35 \mathrm{~A} / \mathrm{cm}^{2}$ for $75 \mathrm{~h}$.

The Bode plot shown in Figure 6.7 corresponds to the deactivation behavior identified in the overpotential analysis. The initial pCA 2 reactance values at the high-frequency zone (Region I) and low-frequency zone (Region III) were higher than the pCA assisted infiltrated cell, which could indicate the drawback of more catalyst loading causing deactivation and gas starvation. On the other hand, a slight drop of pCA 2 in Region I indicates a slight degree of activation due to achieving a more interconnected catalyst network after particle coarsening. 


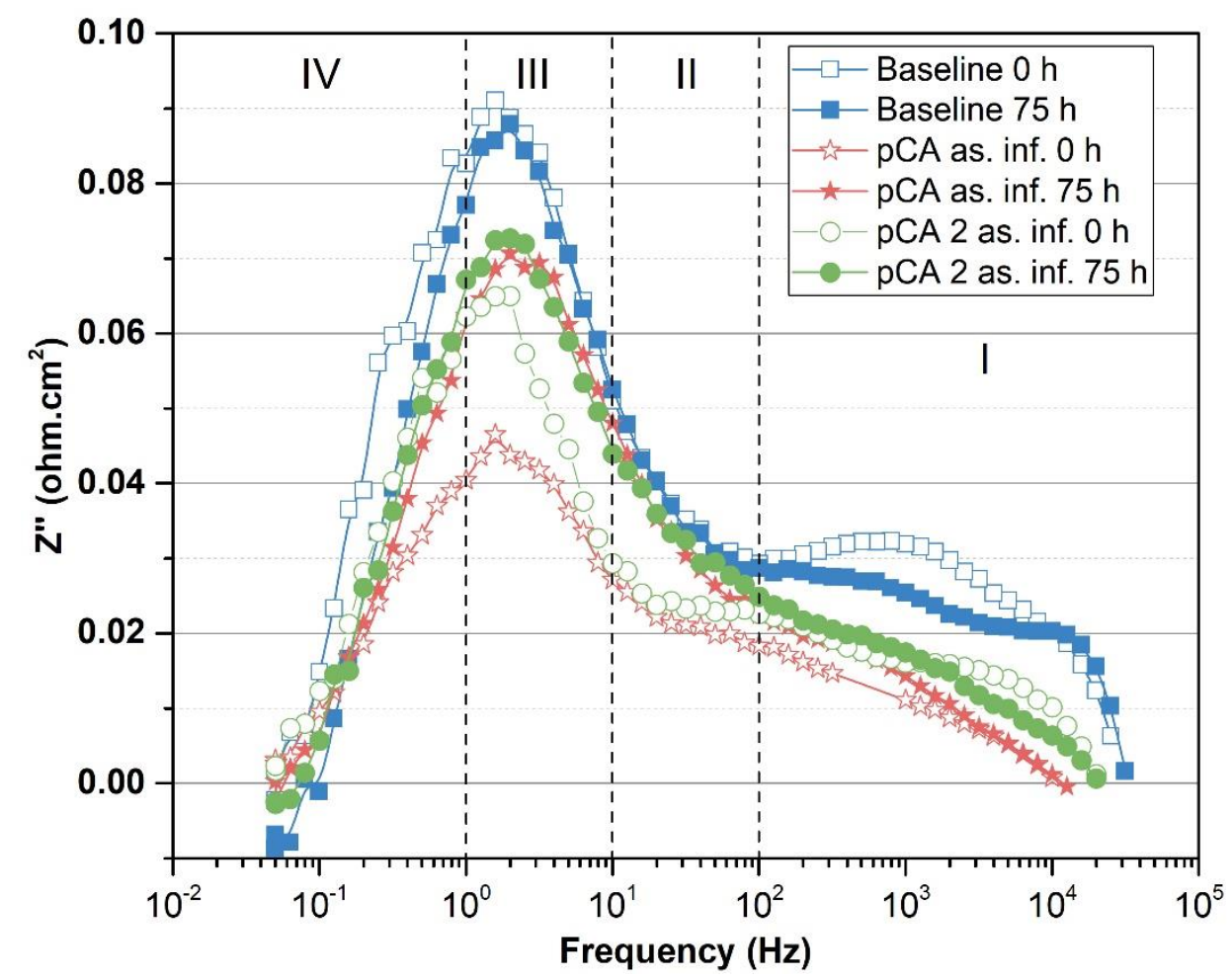

Figure 6.7 Bode plot of baseline, pCA and pCA -2 assisted infiltered cells operated at $750^{\circ} \mathrm{C}, 0.35 \mathrm{~A} / \mathrm{cm}^{2}$ for $75 \mathrm{~h}$.

To analyze the particle size, location, and population of post-operated pCA and pCA 2 as. inf. cell and the baseline cell anode regions were analyzed by Scanning Transmission Electron Microscope (STEM) in annular dark-field (HAADF) imaging and energy-dispersive X-ray Spectroscopy (EDS) modes. Figure 6.8 depicts the barrier layer region images of baseline cell, pCA and pCA 2 as. inf. cells in HAADF and EDS modes (Sm and Ce mapping). As shown in Figure 6.8.a, a barrier layer pore of baseline cell observed particle-free and in the SDC phase. On the contrast, Figure 6.8 , a and b revealed infiltrated particle population difference between pCA and pCA 2 as. inf. cell. According to the EDS elemental mapping, the nanoparticles found inside the pores did not show any Sm signals which confirms that composition of the particles was pure ceria, hence the infiltrated nanoparticles. This high catalyst load at the barrier layer in both pCA 
and pCA 2 could contribute to explain the reason of low ohmic resistance of the all infiltrated cells compared the baseline cell. Interconnected ceria nano-particles may have created additional ionic pathway that reduced the ohmic resistance of the cell. Since pCA 2 assisted infiltrated cell deposited two-folds more catalyst, it can be observed that the nano-particle population in the pores of pCA 2 as. inf. cell (Figure 6.8.b) was more than in pCA as. inf. cell (Figure 6.8.c). The decrease in $\mathrm{R}_{\mathrm{o}}$ from $0.487 \mathrm{ohm} \cdot \mathrm{cm}^{2}$ (pCA) to $0.472 \mathrm{ohm} \cdot \mathrm{cm}^{2}$ (pCA 2) also supported the trend. These ohmic resistance values of the $\mathrm{pCA}$ and $\mathrm{pCA} 2$ as. inf. cells were $17.4 \%$ and $18.2 \%$ lower than the baseline cells, respectively. Interestingly, the pCA 2 as. inf. cell's $\mathrm{R}_{\mathrm{o}}$ degraded $4.5 \%$ over $75 \mathrm{~h}$ operation while pCA as. inf. cell's ohmic resistance increase was only $2.6 \%$. Under the same operating conditions, the ohmic resistance increase of the baseline cells was recorded $8.5 \%$. 
(a)Baseline
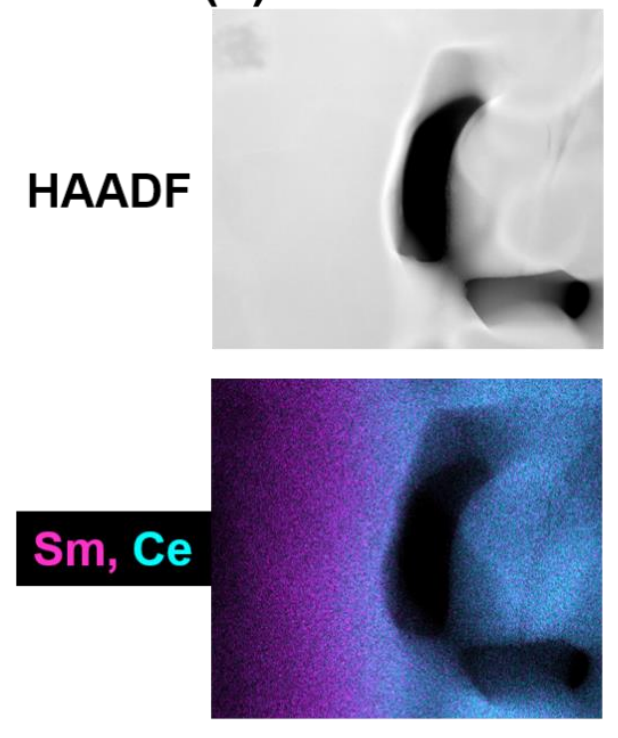

(b)pCA as. inf.

(c)pCA 2 as. inf.
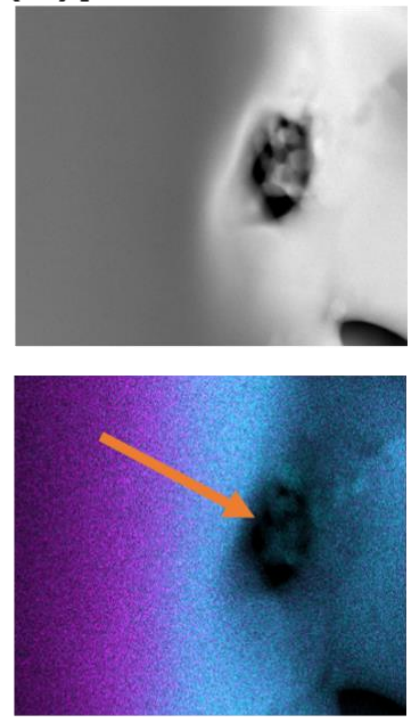

$500 \mathrm{~nm}$

Figure 6.8 HAADF and EDS mapping of (a) Baseline (b) pCA as. inf. cell, (c) pCA 2 as. inf. cell.

The EDS mapping of pCA 2 as. inf. cell also revealed cerium signals at the pore edges of the nickel phase in the anode active area as depicted in Figure 6.9.a-b. The observation provides thin film formation of over the nickel phase which attributed to the catalytic activity of the anode. 

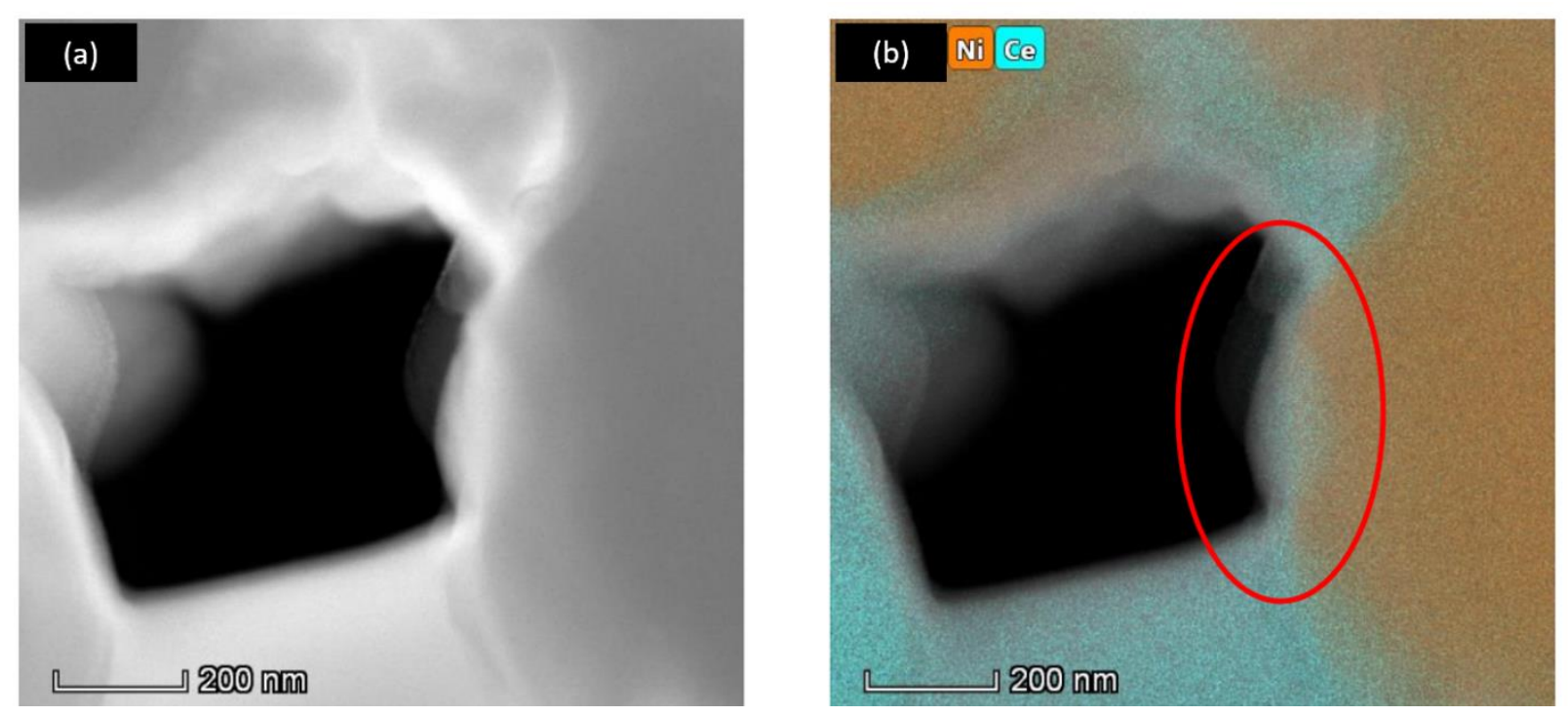

Figure 6.9 (a) HAADF mode and (b) EDS mode images of the cerium film phase over the nickel backbone at the active area of pCA 2. inf. cell.

The semi-quantitative confirmation of higher ceria content inside the Ni / YSZ current collection regions was also performed in long dwell time $(5000 \mathrm{~ms})$. Figure 6.10 shows the Ce L-alpha line comparison of baseline, pCA and pCA 2 cells. The results showed that ceria content was also found to be the highest pCA 2 than the pCA and the baseline cell at the current collection region which is $\sim 10 \mu \mathrm{m}$ down to the electrode surface. The TEM studies at the barrier layer, active layer, and the current collection layer suggest that ceria nanoparticles exist in every region of the anode. Moreover, semi-quantitative results confirm the higher ceria content in PCA 2 assisted infiltrated cells which showed: 1) higher particle population at the barrier region, 3) higher Ce L alpha line at the current collection region. 


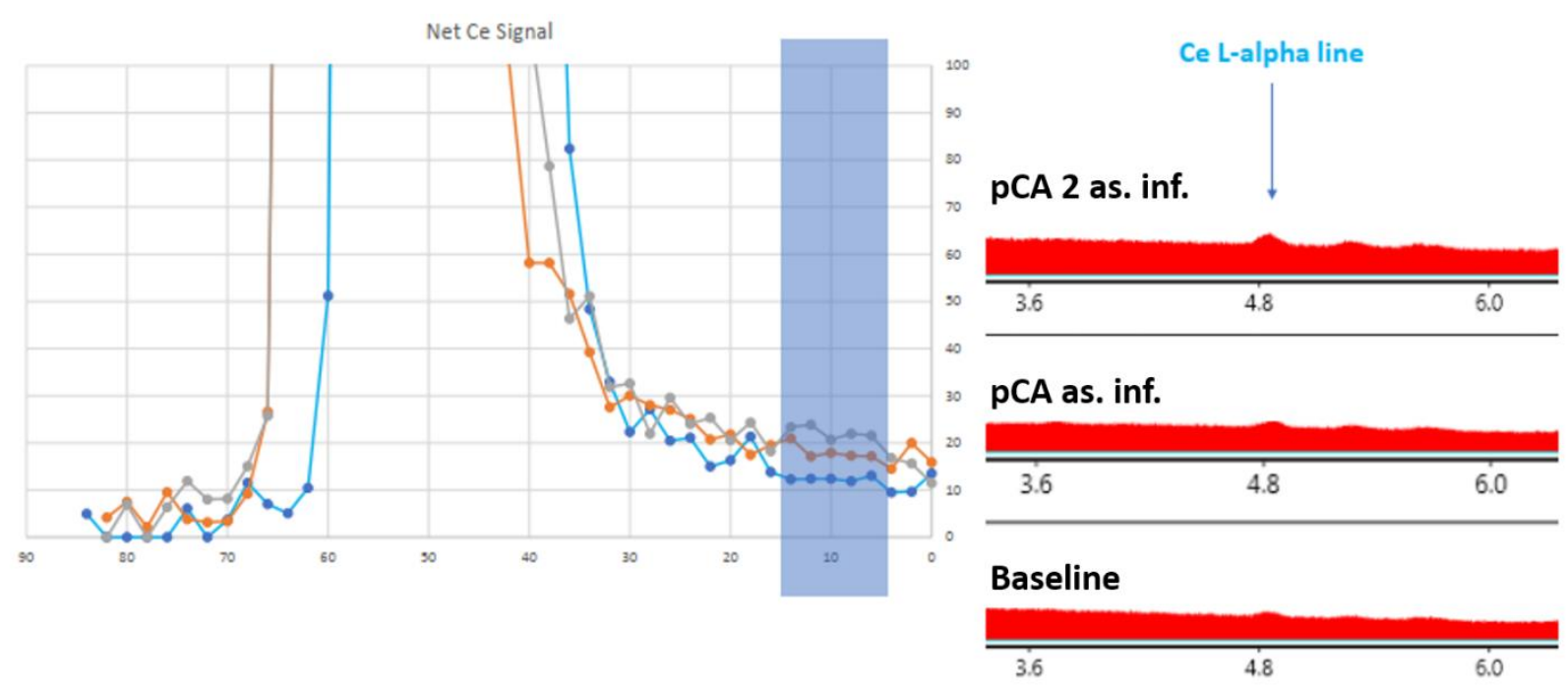

Figure 6.10 Cross-section of Ce L-alpha shell signal comparison of baseline, pCA and pCA 2 as. inf. cells.

\subsection{Conclusion}

In this study, selected catecholamine group surfactants, polymerized gallic acid (pGA), polymerized 3,4-Dihydroxhydrocinnamic acid (pDHC), polymerized caffeic acid, (pCA), were introduced to enhance and control the nano-catalyst infiltration throughout the anode of a SOFC. These materials were used in order to compare with previous work, where similar catechol surfactants were studied (pNE and pDA). The monomer forms share similar functional OH groups, carboxylic and/or amino groups bonded to an aromatic ring with slight variations. As for $\mathrm{pDA}$, the most utilized catechol surfactant discussed in the literature, these surfactants can also be functionalized by oxidative polymerization within an alkaline solution. This was verified by UVVis spectra analysis in this work. The adhered particle morphology also revealed the adhered particulate sizes can vary between $80 \mathrm{~nm}$ (pGA and pDHC) and $15 \mathrm{~nm}$ (pCA). Nevertheless, the nanocatalyst infiltration experiments showed that these polymerized surfactants could promote up 
to 4 times more catalyst deposition compared to non-surfactant infiltration with enhanced infiltrated particle morphology. The two-step pCA+cerium nitrate infiltration enhanced infiltration protocol resulted in up to $37 \%$ reduction in electrode overpotential. The TEM studies for pCA and pCA 2 as. inf. cells showed the nanoparticulate existance at the barrier layer. Hence, nano-ceria infiltration may also be responsible for the decrease in the ohmic resistance by creating additional ionic pathways at the barrier layer region. Also, the ceria thin film formation bonded to the $\mathrm{Ni}$ phase was observed at the active area. The crossectional line scans depicted the semiquaantitaive comparison of pCA 2, pCA and the baseline cells, showing that pCA 2 as. inf. cell had higher ceria content at the current collection zone $(\sim 10 \mu \mathrm{m}$ near the surface).

\subsection{References}

1. Tucker, M.C., et al., Performance of metal-supported SOFCs with infiltrated electrodes. Journal of Power Sources, 2007. 171(2): p. 477-482.

2. Jiang, Z., et al., Electrochemical characteristics of solid oxide fuel cell cathodes prepared by infiltrating ( $\mathrm{La}, \mathrm{Sr}) \mathrm{MnO}_{3}$ nanoparticles into yttria-stabilized bismuth oxide backbones. International Journal of Hydrogen Energy, 2010. 35(15): p. 8322-8330.

3. Nicholas, J.D. and S.A. Barnett, Measurements and Modeling of $\mathrm{Sm}_{0.5} \mathrm{Sr}_{0.5} \mathrm{CoO}_{3}-x-$ $\mathrm{Ce}_{0.9} \mathrm{Gd}_{0.1} \mathrm{O}_{1.95} \mathrm{SOFC}$ Cathodes Produced Using Infiltrate Solution Additives. Journal of The Electrochemical Society, 2010. 157(4): p. B536.

4. $\mathrm{Li}, \mathrm{W}$., et al., Effect of adding urea on performance of $\mathrm{Cu} / \mathrm{CeO}_{2} /$ yttria-stabilized zirconia anodes for solid oxide fuel cells prepared by impregnation method. Electrochimica Acta, 2011. 56(5): p. 2230-2236.

5. Jiang, S.P., et al., Fabrication and Performance of Impregnated Ni Anodes of Solid Oxide Fuel Cells. Journal of the American Ceramic Society, 2005. 88(7): p. 1779-1785.

6. Ye, X.-F., et al., Improvement of $\mathrm{Cu}-\mathrm{CeO}_{2}$ anodes for SOFCs running on ethanol fuels. Solid State Ionics, 2009. 180(2-3): p. 276-281.

7. Jung, S.W., J.M. Vohs, and R.J. Gorte, Preparation of SOFC Anodes by Electrodeposition. Journal of The Electrochemical Society, 2007. 154(12): p. B1270.

8. Kang, S.M., et al., One-step modification of superhydrophobic surfaces by a musselinspired polymer coating. Angew Chem Int Ed Engl, 2010. 49(49): p. 9401-4.

9. Zhao, F.K.Y.a.B., Adhesion Properties of Self-Polymerized Dopamine Thin film. The Open Surface Science Journal, 2011. 3: p. 115-122.

10. Hong, J.-Y., et al., Bio-inspired functionalization and redox charge transfer of graphene oxide sponges for pseudocapacitive electrodes. Carbon, 2015. 83: p. 71-78.

11. Jiang, J., et al., Surface characteristics of a self-polymerized dopamine coating deposited on hydrophobic polymer films. Langmuir, 2011. 27(23): p. 14180-7. 
12. Ryu, J.H., P.B. Messersmith, and H. Lee, Polydopamine Surface Chemistry: A Decade of Discovery. ACS Appl Mater Interfaces, 2018. 10(9): p. 7523-7540.

13. Cheng, C., et al., The hydrodynamic permeability and surface property of polyethersulfone ultrafiltration membranes with mussel-inspired polydopamine coatings. Journal of Membrane Science, 2012. 417-418: p. 228-236.

14. Arena, J.T., et al., Surface modification of thin film composite membrane support layers with polydopamine: Enabling use of reverse osmosis membranes in pressure retarded osmosis. Journal of Membrane Science, 2011. 375(1-2): p. 55-62.

15. Moulay, S., Recent Trends in Mussel-Inspired Catechol-Containing Polymers (A Review). Oriental Journal of Chemistry, 2018. 34(3): p. 1153-1197.

16. Ozmen, O., et al., Bio-inspired surfactant assisted nano-catalyst impregnation of SolidOxide Fuel Cell (SOFC) electrodes. Materials Letters, 2016. 164: p. 524-527.

17. Ball, V., et al., Kinetics of polydopamine film deposition as a function of $p H$ and dopamine concentration: insights in the polydopamine deposition mechanism. J Colloid Interface Sci, 2012. 386(1): p. 366-72.

18. Zhang, C., et al., Polydopamine Coatings with Nanopores for Versatile Molecular Separation. ACS Appl Mater Interfaces, 2017. 9(16): p. 14437-14444.

19. Hong, S., et al., Poly(norepinephrine): ultrasmooth material-independent surface chemistry and nanodepot for nitric oxide. Angew Chem Int Ed Engl, 2013. 52(35): p. 918791.

20. Ata, M.S., Y. Liu, and I. Zhitomirsky, A review of new methods of surface chemical modification, dispersion and electrophoretic deposition of metal oxide particles. RSC Advances, 2014. 4(43): p. 22716.

21. Behboodi-Sadabad, F., et al., UV-Triggered Polymerization, Deposition, and Patterning of Plant Phenolic Compounds. Advanced Functional Materials, 2017. 27(22): p. 1700127.

22. Toth, I.Y., et al., Mechanism of in situ surface polymerization of gallic acid in an environmental-inspired preparation of carboxylated core-shell magnetite nanoparticles. Langmuir, 2014. 30(51): p. 15451-61.

23. Lee, S., N. Miller, and K. Gerdes, Long-Term Stability of SOFC Composite Cathode Activated by Electrocatalyst Infiltration. Journal of the Electrochemical Society, 2012. 159(7): p. F301-F308.

24. Leonide, A., et al., Evaluation and Modeling of the Cell Resistance in Anode-Supported Solid Oxide Fuel Cells. Journal of The Electrochemical Society, 2008. 155(1): p. B36.

25. Chen, X.J., K.A. Khor, and S.H. Chan, Identification of $\mathrm{O}_{2}$ reduction processes at yttria stabilized zirconia|doped lanthanum manganite interface. Journal of Power Sources, 2003. 123(1): p. 17-25.

26. Endler, C., et al., Time-Dependent Electrode Performance Changes in Intermediate Temperature Solid Oxide Fuel Cells. Journal of The Electrochemical Society, 2010. 157(2): p. B292. 


\section{Chapter 7 : Conclusion}

\subsection{Thesis Summary}

This dissertation contains a systematic investigation of the use of catecholamine surfactants in Solid Oxide Fuel Cell (SOFC) electrode systems as chelators and wetting agents to control and improve the incorporating nano-catalysts. The review of the SOFC infiltration methods and materials in Chapter 2 revealed that there is a lack of research to pre-modify the internal porous surfaces to control the wetting precursor solutions throughout the porous SOFC electrode. There are very limited studies in the literature on the precipitation efforts of various oxide catalysts using these agents. This would potentially permit the controlled deposition and growth of these catalytic particles as well as the population.

The use of a mussel-inspired catechol, poly-dopamine, has been used for decades in coating planar and highly porous membranes. The monomers in the catechol solutions can be polymerized (or grafted) naturally and adhere to the internal electrode surfaces, owing to the multi hydroxyl bonds. When the treated electrodes are exposed to a catalyst precursor, the metal ions can be chelated by the grafted (polymerized) layer, forming a precipitated nano-catalyst population inside the carbonaceous framework, as well as, enhancing the wetting properties. In this set of studies, cerium nitrate precursor infiltration was used as an example to show the efficacy of the technology, but other metal precursors (and multiple compositions) can be utilized with the protocols demonstrated in this work.

The study first established the initial experiments on the most utilized catechol monomer,

dopamine (DA) in the literature in the Chapter 3. As discussed in the Chapter 2, the process of depositing secondary material systems onto substrates requires an initial soaking of a substrate 
within a monomer solution. This solution needs to be polymerized, mostly by natural oxidation, by shifting the $\mathrm{pH}$ to the basic condition ( $\mathrm{pH} 8.5$ ). The polymerization step is crucial to the deposition of the secondary material systems on to the substrate. Two methods of the polymerization route termed in-situ, and ex-situ polymerization were tested for dopamine as described in the second chapter. In-situ polymerization is defined by a dip-coating process where the SOFC was dipped into the DA solution, allowing the monomer infiltration inside the porous structure before the oxidative polymerization is started. In the ex-situ polymerization, the DA solution polymerization was first initiated in a beaker and the SOFC electrode was then immersed into the polymerized DA (pDA) solution. This allows the poly-dopamine to infiltrate into the porous structure. This work showed that both routes successfully deposited a proper surfactant layer required for the efficient deposition of the later nano-catalyst layer. Both methods resulted in almost a three-fold increase in the deposition amount over non-surfactant infiltration. The electrochemical cell performance data showed that ex-situ polymerization route brings higher degradation rates during the operation potentially due to clogging of pores by a known phenomenon of unstoppable pDA aggregation. The continuous pDA aggregation is driven by the oxidative polymerization that causes pDA polymers to keep growing and form micron-sized aggregates instead of adhering to the substrate walls. Hence these aggregates might clog the SOFC pores and/or limit further penetration of the polymer layer which also limits the catalyst precursor deposition. The in-situ polymerized pDA assisted ceria infiltration, and showed a better method to promote discrete particle formation homogenously. The best performing, in-situ pDA assisted infiltrated cell showed 5.8\% higher power density than the baseline cell after $300 \mathrm{~h}$ operation.

As seen in the initial work, a key issue is the clogging or blocking of the surface and/or near-surface electrode pores when the pDA becomes agglomerated during the initial step. This 
known phenomenon becomes problematic with commercial SOFC's which have $<35 \%$ porosity in the range of $<5 \mu \mathrm{m}$ pore size. The polydopamine showed initial promising results, but a catechol candidate that shows better size stability and allows agglomerate-free thin coatings was needed. Therefore, the next stage of the work focused upon alternative catechols that could provide the same wetting and cheating characteristics.

As a substitute, polymerized norepinephrine ( $\mathrm{pNE}$ ) assisted infiltration was introduced in Chapter 3. The substitution from the pDA resulted in a better penetration through the electrodes active area and achieved a uniform coating with particle + island ceria formation. This decoration type led to no degradation within $300 \mathrm{~h}$ of electrochemical testing where the polarization resistance was improving (activating). Also, the work demonstrated a systematic study on finding the optimum amount which could be achieved by simply changing the catalyst precursor molarity. For a commercial anode-supported $\mathrm{NiO} / \mathrm{YSZ} / \mathrm{LSM}$ button cells, $5 \mathrm{mg}$ ceria infiltration $\left(0.61 \mathrm{mg} / \mathrm{cm}^{2}\right.$ loading at the anode side, $1.63 \mathrm{mg} / \mathrm{cm}^{2}$ loading at the cathode electrode) showed the highest decrease in the polarization resistance, which means the highest activation in both electrodes.

The accomplishments of the Chapter 3 and 4 are:

1) Decreasing the number of infiltration step by developing catechol surfactant assisted infiltration protocol.

2) Controlling the liquid segregation and promote the material deposition.

3) Pinning the nanoparticles at the active area hence boosting the performance (up to 35\%)

4) Featuring continuously activated cells without degradation and discussing the possible mechanism(s). 
5) Performing electrochemical and material characterization to correlate performance versus microstructural changes, such as observing optimum infiltration amount and over infiltration.

In Chapter 5, the correlation of pNE polymerization kinetics versus solid loading and adhered film thickness on planar substrates was explored. UV-Vis spectra of the pNE solutions assisted to revealed absorbance upshift at $350 \mathrm{~nm}$ wavelength which denotes the quinone formation. Hence, this information was an indicator of, degree of surfactant polymerization. The atomic force microscopy (AFM) analysis on the pNE layer proved that both solid loading and polymerization time are important parameters on adhered catechol thickness. At early stages ( $3 \mathrm{~h}$ ), pNE adhesion was in $<10 \mathrm{~nm}$ size islands. The population and the coverage of these islands expanded as a function of time. Finally, at the higher immersion times $(24 \mathrm{~h})$, a film coating of $\sim 48 \mathrm{~nm}$ in thickness was achieved. In addition, the chemical states of the pNE film and chelated cerium nitrate deposit were investigated by XPS. The study revealed that both cerium complex and the carbon (pNE) were found at the same time, indicating an organo-metallic framework was formed. Finally, the study on the analysis of the ceria particles with different cerium nitrate precursor immersion times on pNE coated YSZ substrates showed that the ceria growth was driven by two mechanisms: 1) forming nuclei 2) growing over the existing islands. As the pNE layer thickens, the islands of ceria particles formed over a $2-5 \mathrm{~nm}$ thin film. The growth mode of ceria particles fit the layer + island mode (Stranski - Krastanov).

The accomplishments of Chapter 5 are:

1) Observing the growth of pNE layer up to $<50 \mathrm{~nm}$ in thickness with given parameters $(0.5$ 1- $2 \mathrm{mg} / \mathrm{ml}$ solid loading and 1-24 $\mathrm{h}$ immersion time). 
2) Fitting the pNE film thickness rate with exponential decay function at high solid loading (2 $\mathrm{mg} / \mathrm{ml})$.

3) Performing XPS for $\mathrm{pNE}$ and $\mathrm{pNE}+$ metal ion soft framework with gentle sputtering conditions.

4) Identifying different precipitation mechanisms of a lanthanide group metal ion (cerium) and a noble metal group metal ion (palladium) was observed by XPS.

5) Investigation of the growth of ceria nanoparticles was investigated with nanometer accuracy. The growth trend was associated with the possible film growth models and was likely matched with the Stranski-Krastanov (Layer + Island model).

In Chapter 6, the study concluded with the application of the method with alternative catechol systems with similar phenolic structures with small variations in their end-groups or configuration. Some potential alternative catechol surfactants such as poly-caffeic acid, polyhydroxyhydrocinnamic acid and poly-gallic acid were adapted to the SOFC infiltration. The UVvisible spectrum showed that all the alternative surfactants can be subjected to oxidative polymerization. In addition, the characterization of the adhered catechol morphology revealed that pCA showed the smallest features, predominantly in the $10 \mathrm{~nm}$ size range. Thus, the pCA assisted infiltration protocol showed the best initial performing cell over the $75 \mathrm{~h}$ of electrochemical testing.

The accomplishments of Chapter 6 are:

1) A new infiltration protocol is developed to infiltrate only anode electrode (with the same efficacy of dip-coating method ) 
2) Compared the aggregate size of pCA, pGA and pDHCA on planar substrates by taking pNE as a reference. pCA adhered with the fines coating among the other surfactants analyzed by AFM (4.9 nm RMS).

3) All the alternative surfactant treatments resulted $4 X$ more catalyst deposition as compared the non-treated electrode dip-coat infiltration.

4) Alt. Surfactant treatment also reduced the Rp of the cells 19.7 (pNE) to $27.8 \%$ (pCA) after 75 h operation.

5) PCA protocol was improved with $2 \mathrm{X}$ higher immersion time which resulted $2 \mathrm{X}$ more catalyst amount with better stability $(\Delta 25.3 \mathrm{mV}$ within $75 \mathrm{~h}(\mathrm{pCA})$ versus $\Delta 7 \mathrm{mV}$ within $75 \mathrm{~h}$ $(\mathrm{pCA}-2)$

6) TEM characterization identified nanoparticles at the anode barrier layer and Ce skin layer at the anode active area.

\subsection{Future Works}

Future works can focus the investigation of other catecholamine oxidation and/or polymerization mechanisms such as UV-light assisted or water oxidant catalyst (WOC) assisted oxidation. The WOC assisted oxidation not only reduces the oxidation time but also may control the aggregate size depending on how much oxidant is introduced to the system. The technology should be adapted for a rapid polymerization with the addition of a water oxidant catalyst (WOC) agent. The reaction of WOC can be formalized as in (Eq. 7.1);

$$
n \mathrm{O}_{\mathrm{x}}+2 \mathrm{H}_{2} \mathrm{O} \rightarrow n \mathrm{Red}+4 \mathrm{H}^{+}+\mathrm{O}_{2}
$$


where $\mathrm{O}_{\mathrm{x}}$ is the oxidant, $\mathrm{H}_{2} \mathrm{O}$ is water, Red is the reduced form of $\mathrm{O}_{\mathrm{x}}$, and $n$ is the number of equivalents necessary to consume $4 \mathrm{e}^{-}$from water (Mills et al., J. Mater. Chem., 2016). Therefore, non-aqueous solvent systems can be used to improve wetting properties.

Also, further studies on building layer by layer (LbL) approach (catechol + catalyst + catechol + catalyst ..... ) structure that allows the decoration/deposition of multi-functional catalyst systems inside internal pore might be performed. The composite catalyst infiltrated electrodes may run efficiently under various conditions/purposes such as SOEC / SOFC cycling. 3-D printing method can also be used for targeting this LbL approach to specific locations of the fuel cells

Apart from future studies, the current results from the kinetic investigation of catechol surfactant polymerization, growth and chelation properties, as well as, the successful adaptations of the SOFC infiltration protocols, should be ready to be driven towards to commercialization of this protocol. Preliminary experiments have already been performed with an industrial collaborator, Nexceris LLC. The modified pNE assisted dip-coat infiltration protocol was applied to a planar fuel cell with $77.5 \mathrm{~cm}^{2}$ active anode area. The reported performance enhancement is $4.6 \%$ at $650^{\circ} \mathrm{C}, 4.9 \%$ at $700^{\circ} \mathrm{C}$ and $9.4 \%$ at $650^{\circ} \mathrm{C}$ in comparison to the baseline cell after $\sim 100$ hours of operation. The collaboration showed that the technology is flexible to be scaled up and already shows enhanced performance on large-area cells with a $48 \mathrm{~h}$ of a process without compromising the existing manufacturing line. As the outcomes of this dissertation, three patent applications regarding the SOFC electrode infiltration methods have been submitted. The WVU Technology Transfer Office should bridge the potential partners and the inventors on licensing these technologies. 